\title{
Design and Development of a 100 MVA HTS Generator for Commercial Entry
}

\section{Final Technical Report}

Covers work done between September 27, 2001 and September 30, 2006

\section{Submitted To:}

US Department of Energy

National Renewable Energy Laboratory (NREL)

Golden, CO 80401-3305

\section{Submitted By:}

General Electric Company

Schenectady, NY 12345

December 30, 2006 


\section{DISCLAIMER}

This report was prepared as an account of work sponsored by an agency of the United States Government. Neither the United States Government nor any agency thereof, nor any of their employees, makes any warranty, express or implied, or assumes any legal liability or responsibility for the accuracy, completeness, or usefulness of any information, apparatus, product, or process disclosed, or represents that its use would not infringe privately owned rights. Reference herein to any specific commercial product, process, or service by trade name, trademark, manufacturer, or otherwise does not necessarily constitute or imply its endorsement, recommendation, or favoring by the United States Government or any agency thereof. The views and opinions of authors expressed herein do not necessarily state or reflect those of the United States Government or any agency thereof. 


\section{Acknowledgements}

A significant number of individuals and organizations contributed to the work covered by this report. The individuals listed here are contributors to this report but have drawn broadly on work from others in GE-Global Research, GE-Energy, American Electric Power Co., Los Alamos National Laboratory, and Oak Ridge National Laboratory.

Dr. James M. Fogarty, Editor

\section{GE-Global Research}

Dr. Robert S. Ackermann

James P. Alexander

Dr. James W. Bray

Dr. Aniruddha D. Gadre

Dr. Xianrui Huang

Dr. Liang Li

Dr. Kiruba Sivasubramaniam

Dr. John A. Urbahn

Los Alamos National Laboratory

Dr. Francesco Grilli

Dr. Eric N. Schmierer

\section{GE-Energy}

Siddharth N Ashar

Dr. Daniel H Baker

Richard N. Dawson

Dr. Wei Liu

Thomas Mancuso

Rebecca A. Nold

William R. Pearson

Paul S. Quail

Michael Reichert

Leon M. Richardson

Albert E. Steinbach

Blake W. Wilson

Mark Wotzak

\section{American Electric Power Co.}

Arthur G. DeGroff

Albert J. F. Keri

James R. Michalec 


\section{Table of Contents}

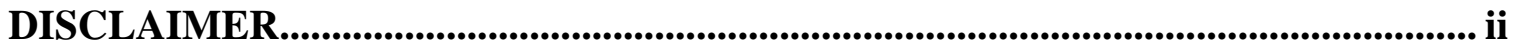

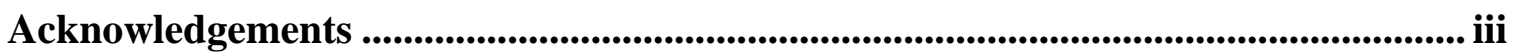

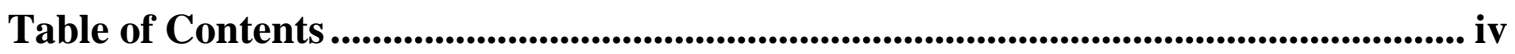

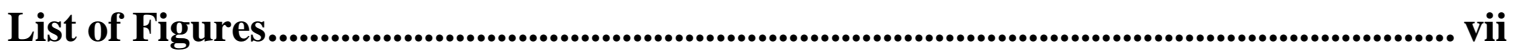

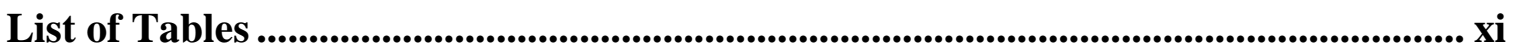

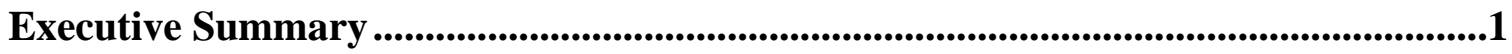

1 Introduction................................................................................................................ 1-1

$1.1 \quad$ Warm Iron Rotor HTS Generator Concept ............................................. 1-1

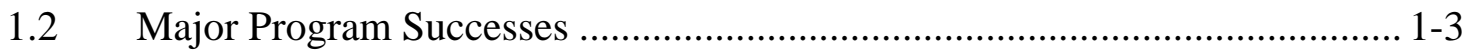

1.3 Remaining Challenges...................................................................... 1-3

2 Program Management................................................................................ 2-1

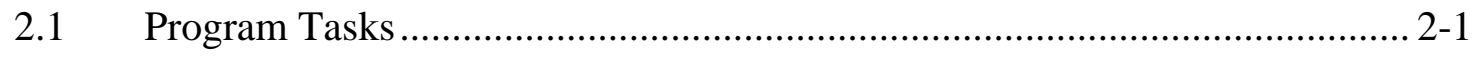

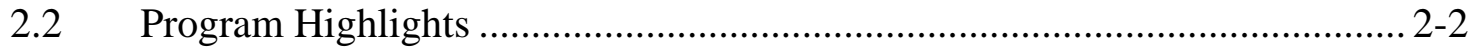

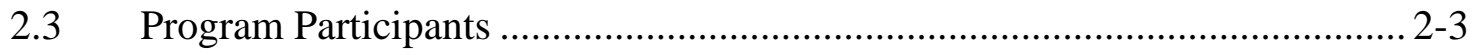

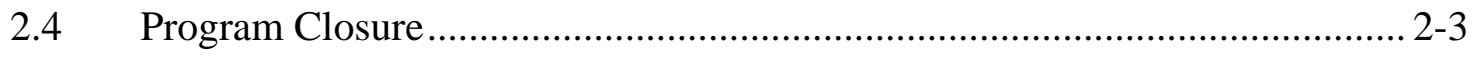

$3 \quad 1.5$ MW Demonstrator............................................................................... 3-1

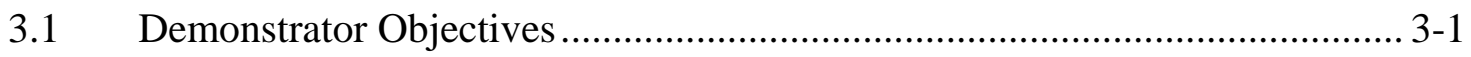

3.2 Demonstrator Test Set-up................................................................. 3-2

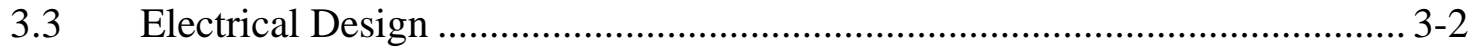

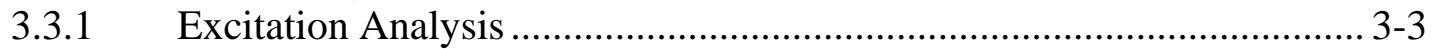

3.3.2 HTS Coil .................................................................................... 3-5

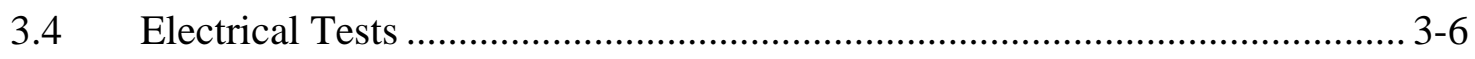

3.4.1 Steady State Short Circuit Tests ........................................................ 3-6

3.4.2 Steady State Open Circuit Tests ...................................................... 3-10

3.4.3 Sudden Short Circuit Tests ............................................................... 3-10

3.4.4 Operational Impedance Tests............................................................ 3-11

Coil I-V Tests......................................................................... 3-15

3.5 Demonstrator Mechanical Design ....................................................... 3-16

3.5.1 Thermal Design Considerations...................................................... 3-16

Coil Support Subsystem................................................................... 3-20

3.5.3 Demonstrator EM Shield .............................................................. 3-23 
3.5.4 Vacuum System Performance................................................................. 3-25

3.5.5 Rotor Structural Design ......................................................................... 3-29

3.6 Demonstrator Refrigeration System ....................................................... 3-36

3.7 Transfer Coupling.................................................................................. 3-39

$4 \quad$ Technology Development ............................................................................. 4-1

$4.1 \quad$ Refrigeration Development ..................................................................... 4-1

4.1.1 Gifford McMahon .............................................................................. 4-1

4.1.2 Tradeoff Analysis............................................................................. 4-2

4.1.3 Reverse Brayton System ............................................................................ 4-3

4.2 HTS Wire Development ....................................................................... 4-4

4.2.1 HTS Wire Specification.................................................................. 4-4

4.2.2 HTS Wire Characteristics …………………….................................... 4-6

4.2.3 Wire Splicing Methods ………………………................................... 4-13

4.2.4 AC Loss Characteristics of HTS Wire..................................................... 4-13

4.2.5 Wire Insulation.............................................................................. 4-14

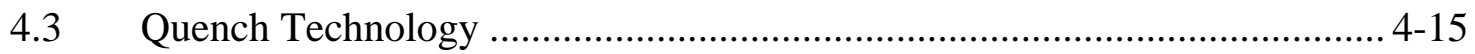

4.3.1 Introduction....................................................................................... 4-15

4.3.2 Coil Over-Current Analysis for an 18-Cycle Fault.................................. 4-16

4.3.3 Quench Detection \& Protection Strategies .............................................. 4-17

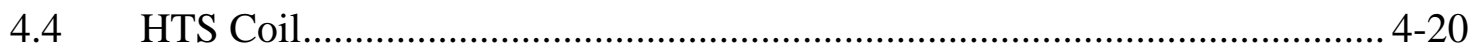

4.4.1 Coil Resonance .............................................................................. 4-20

4.4.2 AC Coil Loss............................................................................... 4-21

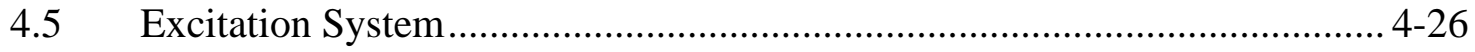

$5 \quad 100$ MVA Generator Design........................................................................................ 5-1

5.1 Product Requirements .......................................................................... 5-1

5.2 Electromagnetic Design ........................................................................ 5-3

5.2.1 Electrical Design .................................................................................. 5-3

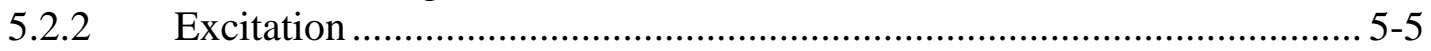

5.2.3 Short Circuit Pole Face Loss.................................................................... 5-9

5.2.4 Unbalanced Loads........................................................................ 5-9

5.2.5 Operational Impedances............................................................................ 5-9

5.2.6 Transient Stability and Maximum Field Current ..................................... 5-10

5.2.7 Generator Fault Duty …………………………................................ 5-13

5.3 Machine Ventilation Design................................................................ 5-15

5.3.1 Load Points ........................................................................................ 5-15

5.3.2 Stator Temperatures......................................................................... 5-16

5.4 Rotor Mechanical Design - Rotor Shaft …………................................. 5-17

5.4.1 Primary Design Requirements ....................................................... 5-18

5.4.2 Body Cross-Slot Arrangement.............................................................. 5-18

$5.5 \quad$ HTS Coil......................................................................................... 5-19 


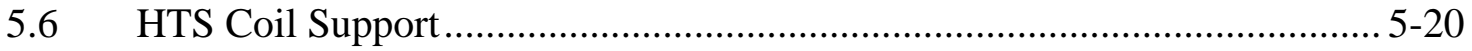

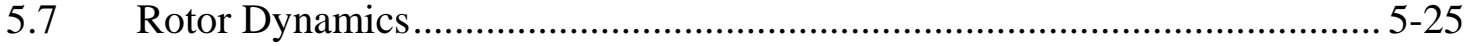

5.8 Electromagnetic Shield/Vacuum Enclosure …………………………......... 5-32

$5.9 \quad$ Bore Components ..................................................................................... 5-37

5.9.1 Support System, Vacuum Seal and Insulation System ........................... 5-37

5.9.2 Refrigeration Tubes ....................................................................... 5-38

5.9.3 Heat Station............................................................................... 5-39

5.9.4 Current Leads ................................................................................ 5-40

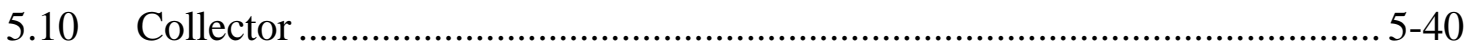

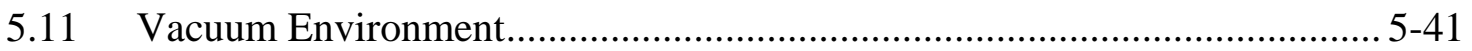

5.12 Emissivity Controls ................................................................................... 5-43

5.13 Transfer Coupling...................................................................................... 5-45

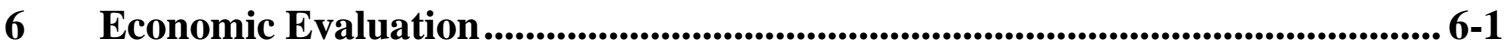

6.1 Possible HTS Generator Benefits ................................................................ 6-1

6.2 Costs of the HTS Generator …………………...................................... 6-2

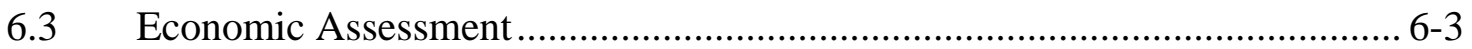

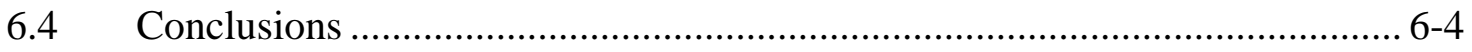

$7 \quad$ Plant Integration .................................................................................................... 7-1

7.1 Equipment Packaging ............................................................................... 7-1

7.1.1 Refrigeration System ...................................................................

7.1.2 Helium Transfer Coupling ................................................................. $7-1$

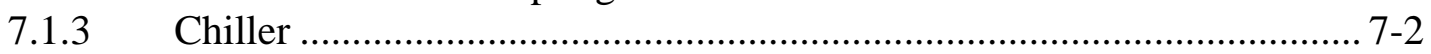

7.2 Operation and Maintenance........................................................................... 7-2

8 Power System Integration ....................................................................................... 8-1

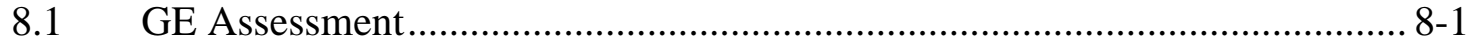

8.1.1 Grid Interaction Studies .................................................................. 8-1

8.1.2 Preliminary Protection Assessment ..................................................... 8-16

8.2 American Electric Power Studies............................................................... 8-17

8.2.1 Commercial Value of Reactive Power................................................... 8-17

8.2.2 HTS Generator Reactive Capability \& Voltage Control Performance Study .............................................................................. 8-17

8.2.3 HTS Generator System Stability Performance Study ............................ 8-20

$9 \quad$ Appendices..................................................................................................................... 9-1

9.1 Selected References............................................................................. 9-1

9.2 Nomenclature \& Abbreviations..................................................................... 9-3 


\section{List of Figures}

Figure 1-1 - Magnetic Pole and HTS Coil Assembly of the 1.5 MW Warm Iron

Rotor HTS Generator Demonstrator $1-2$

Figure 3-1 - Demonstrator Superconducting Field Coil And Support System................. 3-3

Figure 3-2 - Calculated Demonstrator Saturation Curve (2D Model) ............................... 3-5

Figure 3-3 - HTS Coil for the Demonstrator ………………….................................... 3-6

Figure 3-4 - Synchronous Impedance Curve For HTS Demonstrator - Test And

Prediction

Figure 3-5 - AC Loss in Coil and Coil Support During Synchronous Impedance

Test

Figure 3-6 - Air Gap Flux Density Profile and Harmonic Contents Under Short

Circuit Conditions

Figure 3-7 - HTS Demonstrator Test Saturation Curve.

$3-10$

Figure 3-8 - Field Current Trace for 0.54 pu SSC From No Load - Measured

(Left) and Simulation (Right)

Figure 3-9 - Armature Current Traces for 0.54 pu Voltage SSC - Measured

(Left) and Simulation (Right)

Figure 3-10 $-\mathrm{X}_{\mathrm{d}}(\mathrm{s})$ by Finite Element Analysis and SSFR Tests ................................. 3-12

Figure 3-11 $-\mathrm{X}_{\mathrm{q}}(\mathrm{s})$ by Finite Element Analysis and SSFR Tests .................................. 3-14

Figure 3-12 - Field Self-Reactance Comparison .......................................................... 3-14

Figure 3-13 - Compiled Coil I-V Test Results.............................................................. 3-15

Figure 3-14 - Time History of I-V Coil Lead Test Voltage at 45 A .............................. 3-15

Figure 3-15 - The Cold Coil Support System ............................................................. 3-17

Figure 3-16 - Refrigerator Cold Head Temperature and Heat Load vs. Time at

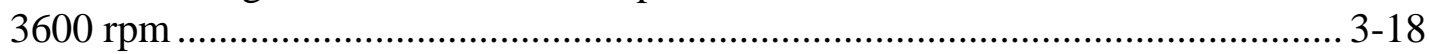

Figure 3-17 - Rotor Dynamic Heat Load vs. Time ........................................................ 3-20

Figure 3-18 - Demonstrator Coil Support Design .......................................................... 3-21

Figure 3-19 - Demonstrator Coil Support Finite Element Model .................................. 3-22

Figure 3-20 - Demonstrator Coil Strain at $4500 \mathrm{rpm}$................................................ 3-22

Figure 3-21 - Drawings of the Composite Aluminum and Steel Shield System ........... 3-24

Figure 3-22 - The Demonstrator EM Shield Assembly ................................................ 3-25

Figure 3-23 - Shield Forces (Per Unit Length) During a Three-Phase Sudden

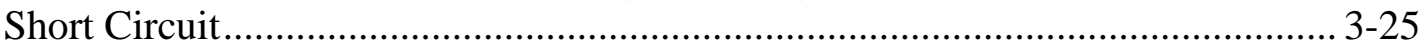

Figure 3-24 - Root Cause Analysis for Loss of Vacuum.............................................. 3-27

Figure 3-25 - Demonstrator Vacuum Integrity Tests ................................................. 3-27

Figure 3-26 - Heat Load History on Demonstrator ....................................................... 3-28

Figure 3-27 - SAES ST-172 getter unit ................................................................. 3-28

Figure 3-28 - The Getter Module Assembly for the Demonstrator ................................. 3-29

Figure 3-29 - Impact Modal Test on the Rotor Subassembly ......................................... 3-30

Figure 3-30 - Accelerometer Probe Locations.................................................................. 3-30

Figure 3-31 - Rotor Dynamic Model for the Rotor Assembly........................................ 3-32

Figure 3-32 - Damped Natural Frequency Map.............................................................. 3-32

Figure 3-33 - Torsional Analysis Using ANSYS ……………................................... 3-33

Figure 3-34a - Demonstrator Mode Shapes 1 - 4........................................................... 3-33

Figure 3-35 - Vibration Change at 3600 rpm............................................................... 3-36 
Figure 3-36 - Functional Diagram of the SHI Refrigeration System for the

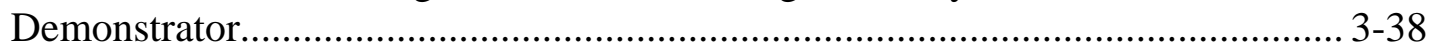

Figure 3-37 - SHI Refrigeration System for the Demonstrator ................................. 3-38

Figure 3-38 - Demonstrator Transfer Coupling ........................................................ 3-39

Figure 4-1 - SHI Refrigerator for 100 MVA Generator .............................................. 4-2

Figure 4-2 - Schematic of Air Liquide Reverse-Brayton Refrigerator ........................... 4-4

Figure 4-3 - The GE Four-Point Bending Apparatus................................................. 4-8

Figure 4-4 - Schematic of a Bending Spring ........................................................ 4-8

Figure 4-5 - Critical Current Retention Under Tensile and Compressive Cyclic

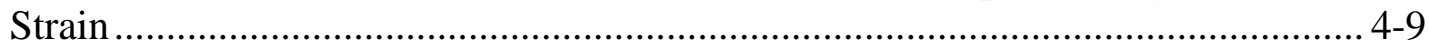

Figure 4-6 - Typical $I_{C}$ Degradation as a Function of Tensile Strain ........................... 4-10

Figure 4-7 - Statistical Analysis of the Critical Strain Under Tensile Strain

Cycles................................................................................................... 4-10

Figure 4-8 - Normalized $I_{c}$ as a Function of the Number of Cycles With a Cyclic

Compressive Strain of $0.207 \%$.................................................................... 4-12

Figure 4-9 - Photomicrograph of HTS Wire Lay-up ................................................ 4-15

Figure 4-10 - Superconducting Operating Region and a Thermal Run-Away

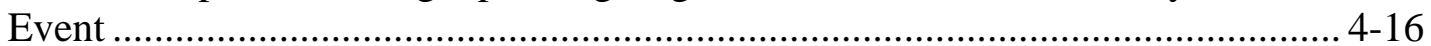

Figure 4-11 - System Model for Fault Current Analysis .......................................... 4-16

Figure 4-12 - Field Current and Coil Flux Density During Fault and Recovery........... 4-17

Figure 4-13 - Field Current and Minimum $\mathrm{I}_{\mathrm{c}}$ During an 18-Cycle Fault \&

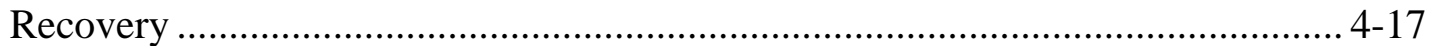

Figure 4-14 - Coil Temperature and Voltage During an 18-Cycle Fault \&

Recovery .......................................................................................... 4-17

Figure 4-15 - Repeated Faults Cause Thermal Run-Away ......................................... 4-18

Figure 4-16 - HTS Quench Protection Experimental Arrangement.............................. 4-19

Figure 4-17 - Coil Voltage, Current and RTD Signal During an Over-Current

Test with 2 Second Pulse Width and 5 Second Relaxation Time......................... 4-20

Figure 4-18 - Resonant Frequencies of the Demonstrator HTS Coil in Free Space ..... 4-21

Figure 4-19 - Full Coil Cross-Section Modeling Approach ....................................... 4-22

Figure 4-20 - Meshing of single conductor tape (red = superconductor, cyan =

Ag, gray = air) for FEA analysis............................................................. 4-22

Figure 4-21 - AC Losses for 0.05\%, 113A, 2040 Hz, 1.5T Field. - Solid Line is

Moving Average of Loss_SC ........................................................................ 4-23

Figure 4-22 - AC Losses for 10\% AC Current with 113A DC, 2040 Hz, 0T Field ...... 4-24

Figure 4-23 - Evolution of the AC Losses for the Three 50hz Cases - A Constant

Current Reached with a Ramp (Red); A Constant Current with AC

Oscillation Reached with a Ramp (Blue); A Pure AC Oscillation (Green).

The Frequency is $50 \mathrm{~Hz}, 113$ +/- 10\% DC A, 0T ............................................. 4-25

Figure 4-24 - Magnification of Figure 4-23............................................................ 4-25

Figure 5-1 - 3D Cut-Away View Of The HTS Field Rotor. - Field Coil Is In Red,

Helium Duct Is Pink, Magnetic Pole Is Green, Non-Magnetic Spacer Is

Dark Blue, U-Channel Is Brick Red, And Electromagnetic Shield Is Light

Blue

Figure 5-2 - Section Views of the HTS Rotor; Pole Cross-section Through

Support Hole (Left) And Assembly Of Coil And Coil Support (Right). 5-4 
Figure 5-3 - Rotor Model And Input Variables ........................................................ 5-6

Figure 5-4 - Coil/Support Model ............................................................................. 5-7

Figure 5-5 - 2D FE Excitation Solution for 2005 Design of the 100 MVA

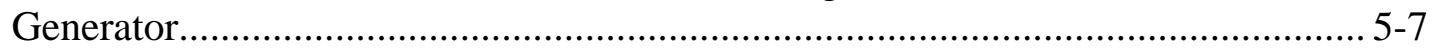

Figure 5-6 - 3D Model Used to Check MMF and Saturation ........................................ 5-8

Figure 5-7 - HTS Coil DC Steady State Flux Density Exposure In Tesla For

Rated Day And Cold Day Loads ....................................................................... 5-8

Figure 5-8 - Generator Cross-section at End of Full Load Run................................... 5-12

Figure 5-9 - Rotating Grid Field Circuit Current During Load, Sudden Short

Circuit and Recovery ................................................................................... 5-12

Figure 5-10 - Armature Circuit Current During Double Line-to-Ground Fault ............ 5-14

Figure 5-11 - Field Circuit Current During Three-Phase Fault at Terminal................. 5-14

Figure 5-12 - Field Circuit Current During Double Line-to-Ground Fault ................... 5-14

Figure 5-13 - Field Voltage During Three-Phase Fault ............................................. 5-15

Figure 5-14 - Total Shaft Torque for Terminal Faults............................................ 5-15

Figure 5-15 - RTD Temperatures for HTS and Conventional 7E Generators ............... 5-16

Figure 5-16 - HTS Rotor Structure Components .................................................. 5-17

Figure 5-17 - Rotor Body Cross-Slotting ….......................................................... 5-18

Figure 5-18 - Coil Construction Schematic. The Actual Coil Has 2740 Turns............. 5-20

Figure 5-19 - 100 MVA Rotor Body, Coil and Coil Support ...................................... 5-21

Figure 5-20 - Rotor Cross-section Through Coil Support Stud.................................... 5-21

Figure 5-21 - Coil Support Tolerances …............................................................... 5-23

Figure 5-22 - Coil Support Finite Element Model..................................................... 5-23

Figure 5-23 - Calculated Coil Strain for Typical Tolerance Condition ........................ 5-24

Figure 5-24 - Rotor Thermal Stress Model......................................................... 5-24

Figure 5-25 - Thermal Spacer Stress Range ........................................................... 5-25

Figure 5-26 - 100 MVA HTS Rotor Dynamics Model.............................................. 5-26

Figure 5-27 - Rotor Mode 1 - 1st Horizontal Rotor Mode .......................................... 5-27

Figure 5-28 - Rotor Mode 2 - 1st Vertical Rotor Mode.............................................. 5-27

Figure 5-29 - Rotor Mode 3 - 2nd Horizontal Rotor Mode ......................................... 5-28

Figure 5-30 - Rotor Mode 4 - 1st Axial Coil Mode..................................................... 5-28

Figure 5-31 - Torsional Rotor Dynamics Model 7E GT - Load Coupling - 100

MVA HTS Generator.................................................................................. 5-30

Figure 5-32 - Torsional Modes 1-3 ...................................................................... 5-30

Figure 5-33 - Torsional Modes 4-6 ...................................................................... 5-30

Figure 5-34 - Calculated Torque Due to 3 Phase Fault ............................................ 5-31

Figure 5-35 - Three-Phase Short Circuit Rotor Response Torque and Shear

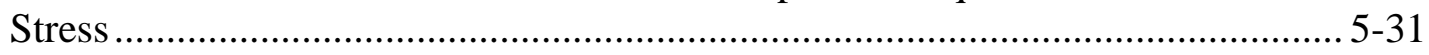

Figure 5-36 - Electromagnetic Shield/Vacuum Enclosure ....................................... 5-32

Figure 5-37 - Electromagnetic Shield/Vacuum Enclosure End Details........................ 5-33

Figure 5-38 - Electromagnetic Shield/Vacuum Enclosure Center Details ................... 5-33

Figure 5-39 - Rotor Cross-Section Showing EM Shield .......................................... 5-35

Figure 5-40 - EM Shield and Rotor Temperatures Rise Above 25 Deg C ................... 5-35

Figure 5-41 - Temperature Rise Versus Time at EM Shield Shrink Locations............. 5-36

Figure 5-42 - Interference Fit vs. Time for Thermal Transient .................................. 5-36

Figure 5-43 - Bore Component Configuration........................................................ 5-37 
Figure 5-44 - Bore Component Support Assembly ................................................... 5-38

Figure 5-45 - Refrigeration Tube Configuration ...................................................... 5-39

Figure 5-46 - Heat Transfer Station ......................................................................... 5-39

Figure 5-47 - Power Leads.................................................................................... 5-40

Figure 5-48 - Conductance Circuit .................................................................. 5-41

Figure 5-49 - Getter Assembly .......................................................................... 5-42

Figure 5-50 - Pump-out Port Location ..................................................................... 5-43

Figure 5-51 - Demonstrator Emissivity Components ................................................... 5-44

Figure 5-52 - Emissivity Degradation Study .......................................................... 5-44

Figure 5-53 - Schematic of Transfer Coupling ....................................................... 5-45

Figure 5-54 - Reliability Model for Transfer Coupling ............................................. 5-45

Figure 8-1 - Voltage Step Simulation Comparing HTS To Conventional

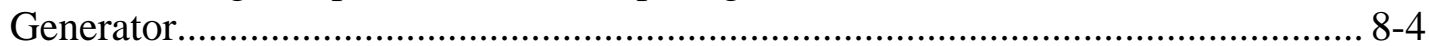

Figure 8-2 - Load Rejection Simulation On HTS Generator Design 3........................... 8-5

Figure 8-3 - Root Loci Versus System Strength - HTS Generator Design 3 In

Manual Control

Figure 8-4 - Time Response For Fault With And Without PSS - HTS Generator

Design \#3 - 6 Lead/Lag Parameters .................................................................. 8-8

Figure 8-5 - Critical Fault Clearing Time (Cycles) \& HTSG Design 3 Field

Current (Amps). Load P = 0.9, Q = 0.436, Vt(Initial) $=1.0$ pu............................ 8-9

Figure 8-6 - 18 Cycle Three-Phase Fault On High Side ............................................ 8-10

Figure 8-7 - Normally Cleared Low Side Double Line-To-Ground Fault.................... 8-11

Figure 8-8 - Normally Cleared Low Side Double Line-To-Ground Fault.................... 8-12

Figure 8-9 - Normally Cleared Low Side Double Line-To-Ground Fault.................... 8-12

Figure 8-10 - Low Voltage Generator Zone Three-Phase Fault - HTS Design 3

Generator (2.20 $\Omega$ Field Discharge Resistor) ................................................... 8-13

Figure 8-11 - Low Voltage Generator Zone Three Phase Fault - HTS Design 3

Generator (2.20 $\Omega$ Field Discharge Resistor) ................................................. 8-13

Figure 8-12 - Low Voltage Generator Zone Three Phase Fault - HTS Design 3

Generator (2.20 $\Omega$ Field Discharge Resistor) .................................................... 8-14

Figure 8-13 - Torques For 120 Degree Synchronization Out Of Phase ....................... 8-15

Figure 8-14 - Induced Field Voltage From Pole Slipping - HTS Generator

Design 3

Figure 8-15 - Reactive Capability Curve for Generator

Figure 8-16 - Rockport Simulation Showing Unacceptable Stability Performance Without PSS.

Figure 8-17 - Rockport Simulation Showing Acceptable Stability Performance with PSS. 


\section{List of Tables}

Table 2-1 - 100 MVA HTS Generator Program Tasks..................................................... 2-1

Table 2-2 - Key Milestones in the 100 MVA HTS Generator Program ........................... 2-2

Table 3-1 - Summary of Demonstrator Test Objectives .................................................. 3-2

Table 3-2 - Demonstrator Design Information............................................................... 3-4

Table 3-3 - Excitation Calculations to Understand Saturation and Modeling After the Test...................................................................................................... 3-5

Table 3-4 - Field Current Harmonics During Second Short Circuit Test ......................... 3-8

Table 3-5 - Short Circuit Shield Losses vs. Rotor Speed for $\mathrm{I}_{\mathrm{f}}=40 \mathrm{~A}$.............................. 3-9

Table 3-6 - Comparison of FE/SIMOFIT_FE Terminal Reactance to Test Results...... 3-13

Table 3-7 - Summary of Coil Support Stress \& Strain Levels....................................... 3-22

Table 3-8 - Vacuum Enclosure/EM Shield Functions ...................................................... 3-23

Table 3-9 - Summary of Predicted and Measured Modal Frequencies for Components and Subassemblies ........................................................................ 3-31

Table 4-1 - HTS Wire Tensile and Compressive Strain Requirements ........................... 4-5

Table 4-2 - Characteristics of AMSC BSCCO-2223 Tape Used for Strain Measurements ............................................................................................... 4-7

Table 4-3 - Batch-to-Batch Variation of Critical Strains in the Tensile Test ................. 4-11

Table 4-4 - Comparison of the Measurements at Different Sites ................................... 4-11

Table 4-5 - The Predicted Compressive Strand for 95\% $\mathrm{I}_{\mathrm{c}}$ Retention ............................ 4-12

Table 4-6 - Comparison of Measured and Calculated Resonant Frequencies for the Demonstrator Coil.................................................................................... 4-21

Table 5-1 - Highlights of the Product Specification for the 100 MVA HTS

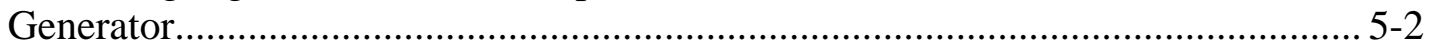

Table 5-2 - Change in Losses for the HTS Generator Compared to the Conventional Generator .................................................................................... 5-5

Table 5-3 - Rotor Dimensions - 2005 Design ................................................................. 5-6

Table 5-4 - Summary of Excitation Results ............................................................... 5-8

Table 5-5 - Results Of Frequency Response Analysis for the 2005 PDR Design

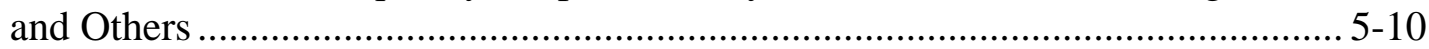

Table 5-6 - Comparison of Transient Stability Run by Various Methods ....................... 5-11

Table 5-7 - Comparison of Peak Duties for Terminal Faults......................................... 5-13

Table 5-8 - Load Points for 7E HTS Generator Stator Ventilation Validation .............. 5-16

Table 5-9 - Average Air Gap Temperature for HTS and Conventional Generators...... 5-17

Table 5-10 - Coil Support Design Requirements...................................................... 5-22

Table 5-11 - 100 MVA HTS Rotor 3 Step Balance Plan................................................ 5-29

Table 5-12 - Mechanical Functional and Design Requirements of the Electromagnetic Shield and Vacuum Enclosure.................................................... 5-34

Table 5-13 - Performance of Getter System.................................................................. 5-42

Table 6-1 - Cost of 100 MVA HTS Generator Compared to Conventional

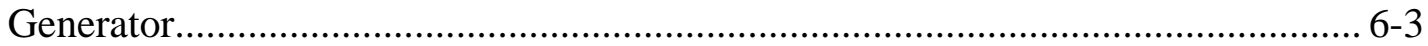

Table 6-2 - Benefits of Efficiency Savings on a 100 MVA Generator.............................. 6-4

Table 6-3 - Benefits of Efficiency Savings on a 575 MVA Generator.............................. 6-4

Table 8-1 - Comparison of Generator Parameters ....................................................... 8-2

Table 8-2 - Qualitative Comparison of Alternative VAR Solutions................................ 8-18 


\section{Design and Development of a 100 MVA HTS Generator for Commercial Entry}

\section{Executive Summary}

In 2002, General Electric and the US Department of Energy (DOE) entered into a cooperative agreement for the development of a commercialized 100 MVA generator using high temperature superconductors (HTS) in the field winding. The intent of the program was to

- Identify and develop technologies that would be needed for such a generator.

- Develop conceptual designs for generators with ratings of 100 MVA and higher using HTS technology.

- Perform proof of concept tests at the 1.5 MW level for GE's proprietary warm iron rotor HTS generator concept.

- Design, build, and test a prototype of a commercially viable 100 MVA generator that could be placed on the power grid.

This report summarizes work performed during the program and is provided as one of the final program deliverables.

The design for the HTS generator was based on GE's warm iron rotor concept in which a cold HTS coil is wound around a warm magnetic iron pole. This approach for rotating HTS electrical machinery provides the efficiency benefits of the HTS technology while addressing the two most important considerations for power generators in utility applications: cost and reliability. The warm iron rotor concept uses the least amount of expensive HTS wire compared to competing concepts and builds on the very high reliability of conventional iron core stators and armature windings.

\section{Program Management}

The 100 MVA Generator program started in 2002 and continued through late 2005. Engineering work was halted at that time by mutual agreement of GE and DOE based on the continuing uncertainty of the economic viability of such a machine.

The program was divided into six major tasks

- Task 1 - Conceptual design of the 100 MVA generator, power plant integration, and economic assessment

- $\quad$ Task 2 - Development of key technologies

- Task 3 - Development and testing of a 1.5 MW Demonstrator HTS generator

- Task 4 - Detailed design of the 100 MVA generator

- Task 5 - Manufacture of the prototype 100 MVA generator 
- $\quad$ Task 6 - Full load testing of the prototype generator

Tasks 1 and 3 were completed, Task 2 was largely complete, and Task 4 was complete through a Preliminary Design Review. Work on Tasks 5 and 6 was started but not completed at the time the program was shut down.

GE's program partners included GE's Global Research Center and its Energy business, Oak Ridge National Laboratory (ORNL), Los Alamos National Laboratory (LANL), and American Electric Power Company (AEP). American Superconductor (AMSC) supplied the HTS wire, and Sumitomo Heavy Industries (SHI) and Air Liquide supplied refrigeration systems.

GE also had technical discussions with other vendors of HTS technology, most notably IGC-Superpower and Sumitomo Electric Incorporated, in order to fully understand the progress being made in areas such as second-generation HTS wire and refrigeration systems.

\subsection{MW HTS Demonstrator Generator}

A 1.5 MW HTS Demonstrator generator was designed, built and successfully tested as part of Task 3 of the program. The Demonstrator tests provided "proof of concept" for the warm iron rotor as well as performance data for the HTS coil, the refrigeration system, and the helium transfer coupling. It also verified the accuracy of tools needed to design the 100 MVA generator.

\section{Technology Development}

Task 2 focused on developing technology that would be needed for a commercial HTS generator. For instance, it was not sufficient to consider just a simple refrigeration system suitable for the 100 MVA generator test. Instead, the refrigeration system had to be designed to meet operating conditions in a power plant and the high expectations for reliability and maintainability.

A reverse-Brayton cycle refrigeration system was designed and manufactured by Air Liquide. It had the cooling capacity as well as the reliability needed for the 100 MVA generator and its technology could be easily extended to refrigeration systems for larger generators.

Significant work was done to understand the performance of BSCCO-2223 HTS wire under various types of mechanical strain. The ability of that wire to withstand strain is insufficient for use in high-speed generators at ratings of $250 \mathrm{MVA}$ and higher. The strain capability also imposed significant design constraints and manufacturing costs on how the HTS coil was to be supported within the spinning rotor. 
The characteristics of the HTS wire and the wound HTS coil were investigated using analytical models and bench tests of coils similar that in the Demonstrator. Teams from ORNL and LANL contributed significantly in this area. In particular, the susceptibility of the wire and coil to AC losses and the quench characteristics of the coil were two areas of interest.

Supporting work in cryogenic design was performed by GE and LANL to understand how to achieve and maintain low thermal emissivities in large structures in a manufacturing environment. Tests were performed to the out-gassing characteristics of various materials

\section{MVA HTS Generator}

Tasks 1 and Task 4 considered the conceptual and detailed design of the 100 MVA generator. The intent was to replace the conventional rotor in a generator for the GE Frame 7E gas turbine with a warm iron HTS rotor. The scope of the tasks included the overall generator design, the mechanical, electrical and thermal design of the rotor, procurement of the generator auxiliary equipment (refrigeration system, helium transfer coupling, and excitation system), and assessments of how the generator would be integrated into a power plant and then operate on the grid.

A significant portion of the work in Task 4 focused on how to provide mechanical support of the HTS coil throughout all of the operating conditions. Support of the HTS coil has become one of the most significant cost-drivers for the HTS generator and is linked directly to the low strain capacity of the wire.

Task 1 was completed with a Conceptual Design Review in March 2003. Task 4 continued through a successful Preliminary Design Review in November 2005.

\section{Economic Assessment of HTS Generators}

GE's cost models showed that the 100 MVA HTS generator was significantly more expensive than a conventional generator. The HTS wire cost, the coil support cost, and the refrigeration cost were significant factors. The efficiency benefit of a 100 MVA HTS generator is not sufficient to offset those costs. In the present power generation industry, those generators are cyclically loaded and do not operate sufficiently often to recoup the added capital cost of the generator.

GE believes that generators rated higher than 500 MW may be suitable candidates for HTS technology because their efficiency benefit would be greater, they would more likely be fully dispatched and are large enough to offset some "fixed" costs. However, significant progress must first be made to reduce the wire cost to $\$ 5 / \mathrm{kA}-\mathrm{m}$ and increase the wire strain capability to at least $0.4 \%$. In addition, it is desirable to increase the wire 
performance to allow operation at 125A, $50-77 \mathrm{~K}$, and $2 \mathrm{~T}$ fields, and to reduce the cost of refrigeration systems.

\section{Power Plant Integration}

GE and AEP investigated how a generator with HTS technology would be integrated into a power plant. No significant issues were uncovered. Because the HTS rotor would undergo relatively few thermal cycles, it was expected that the reliability of an HTS rotor might be higher than the conventional rotor.

\section{Power System Integration}

Task 1 also included studies of how the HTS generator would perform on a power system. Numerous scenarios of transient events, faults, and misoperation were considered. In each instance, the behavior of the HTS generator was essentially equivalent to the conventional generator. 


\section{Design and Development of a 100 MVA HTS Generator for Commercial Entry}

\section{Introduction}

In 2002 General Electric, in conjunction with the US Department of Energy, began a program to develop a 100 MVA synchronous power generator that employed high temperature superconductors (HTS) for the field winding on the rotor. The intent of the program was to

- Identify and develop technologies that would be needed for such a generator.

- Develop conceptual designs for generators with ratings of 100 MVA and higher using HTS technology.

- Perform proof of concept tests at the 1.5 MW level for GE's proprietary warm iron rotor HTS generator concept.

- Design, build, and test a prototype of a commercially viable 100 MVA generator that could be placed on the power grid.

This report presents results in each of these areas of the program. It highlights successes and key challenges that were overcome and discusses the obstacles, both technical and economic, that must be overcome to develop a practical, economic, commercialized generator.

\subsection{Warm Iron Rotor HTS Generator Concept}

The warm iron rotor concept for an HTS generator was developed by GE to achieve three primary goals:

- Minimize the amount of expensive HTS wire needed for the excitation (field) winding within the generator

- Minimize the forces imposed directly on the HTS coil during machine operation

- Minimize or eliminate the risks and development effort needed for the stator of an HTS generator.

The active magnetic portions of such a rotor are shown in Figure 1-1.

Many HTS generator and motor concepts now being proposed or developed emphasize the high power density possible by driving the specific magnetic loading $(\mathrm{A} / \mathrm{m})$ in the air gap quite high. These machines, using air-gap armature windings, can achieve magnetic shear stresses of more than $500 \mathrm{kPa}$. High power density generators and motors are advantageous when noise, size, and weight are critical. Applications such as marine propulsion and aircraft power are prime examples. 


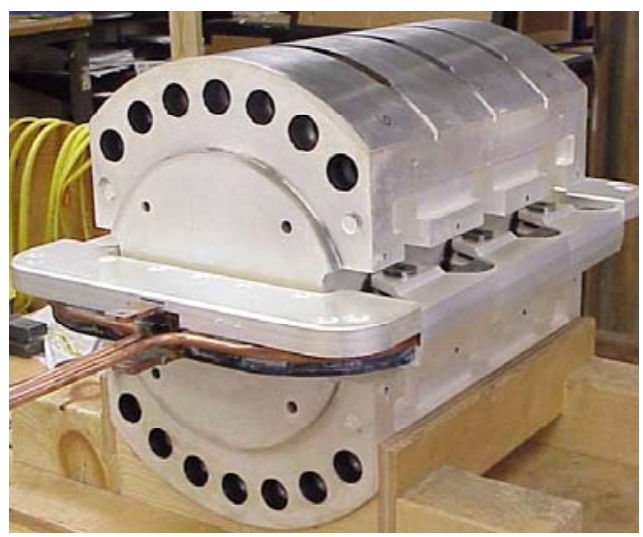

Figure 1-1 - Magnetic Pole and HTS Coil Assembly of the 1.5 MW Warm Iron Rotor HTS Generator Demonstrator

On the other hand, generators in utility power plants usually offer no premium for small size. In a typical power plant, the generator may occupy a very small portion of the total power island footprint. In fact, until the gas turbine or steam turbine achieves comparable power density levels, high power density HTS generators can be difficult to integrate into the conventional power island.

GE's warm iron rotor concept recognizes two dominant utility concerns: cost of ownership and operating reliability. Owners want a generator with very high reliability. Reliability levels typically achieved by conventional equipment are in the range of 99.8 99.9\%. The HTS generator that replaces a conventional generator will be expected to be equally reliable. GE's warm iron rotor concept addresses this prime concern by retaining the conventional generator stator core and armature winding. It discards high power density, for which there is no apparent economic value, in favor of the assured reliability of time-proven stator construction.

The warm iron rotor concept also addresses cost of ownership. Compared to a high power density HTS generator with an air-gap armature winding, the warm iron rotor HTS generator dramatically reduces the volume of HTS wire needed to construct a typical 100 - 500 MW utility generator. Compared to the warm iron rotor option and based on present 1G HTS wire costs of $\$ 150 / \mathrm{kA}-\mathrm{m}$, the additional wire cost for a 500 MW air-gap HTS generator will be on the order of $\$ 4$ million. This cost increment does not include the higher costs to manufacture the air gap winding. 


\subsection{Major Program Successes}

The 100 MVA HTS Generator program extended HTS technology in the following areas:

- Successfully built and tested a 1.5 MW demonstrator rotor in a conventional stator.

- Demonstrated that the concept of the warm iron rotor HTS generator was a practical alternative to air core HTS machines.

- Demonstrated that an HTS coil could be suitably supported in the extreme environment of a rotating electric machine.

- Demonstrated that while current Generation 1 BSSCO HTS wire may be suitable for smaller or slower electric machines, practical high-speed machines will require a wire that is much stronger.

- Provided benchmark costs needed for HTS wire to be competitive in utility generators and flagged the need for higher operating temperatures to reduce refrigeration costs

- Developed acceptable insulation systems for BSCCO wire

- Created a statistical database for the strain sensitivity of BSCCO tapes suitable for detailed design of operating field coils

- Developed and verified the analytical tools needed to extend the design of an HTS generator to ratings of $100 \mathrm{MVA}$ and larger.

- Developed and tested a helium transfer coupling suitable for a 100 MVA HTS generator.

\subsection{Remaining Challenges}

GE observes that good progress is being made in a number of technologies that would improve the prospects of HTS technology in the power industry. Nonetheless, there remain challenges that must be overcome before an HTS generator displaces large conventional generators in utility applications. They are directly related to the initial cost of the generator and include:

- HTS wire of any generation must become much less expensive than the current wire. Benchmark prices of $\$ 5 / \mathrm{kA}-\mathrm{m}$ are likely to be the maximum acceptable for large-scale adoption of this technology.

- The technical performance of the wire should increase so that operation at temperatures of $50-70 \mathrm{~K}$ in magnetic fields of $1-2$ tesla is possible.

- Increase the ability of the wire to withstand compressive, tensile, and cyclic strain by a factor of four. This now appears to be occurring with the G2 (YBCO) tapes.

- Low cost, highly reliable refrigeration units should be developed. 


\section{Program Management}

The 100 MVA HTS Generator program, as proposed to the Department of Energy, was to span 42 months. This section discusses the program tasks, program participants, key milestones, and the decision by GE and the Department of Energy to stop the program.

\subsection{Program Tasks}

The program was organized into six tasks, as shown in Table 2-1. Work was performed on all of the tasks, and Tasks 1 and 3 have been completed.

Table 2-1 - 100 MVA HTS Generator Program Tasks

\begin{tabular}{clc}
\hline Task & \multicolumn{1}{c}{ Task Scope } & Status \\
\hline Task 1 & $\begin{array}{l}\text { Conceptual design of the 100 MVA HTS } \\
\text { generator including power plant integration } \\
\text { and economic assessment }\end{array}$ & Complete \\
\hline Task 2 & $\begin{array}{l}\text { Development of key HTS technologies such } \\
\text { as refrigeration, quench detection, and } \\
\text { transfer couplings. }\end{array}$ & $\begin{array}{c}\text { Largely complete except for } \\
\text { final work on wire } \\
\text { processing and coil winding } \\
\text { techniques }\end{array}$ \\
\hline Task 3 & $\begin{array}{l}\text { Design, manufacture, and testing of a 1.5 } \\
\text { MW HTS Demonstrator }\end{array}$ & \multicolumn{1}{c}{ Complete } \\
\hline Task 4 & $\begin{array}{l}\text { Detailed design of a 100 MVA HTS } \\
\text { generator }\end{array}$ & $\begin{array}{c}\text { Completed through } \\
\text { Preliminary Design Review }\end{array}$ \\
\hline Task 5 & $\begin{array}{l}\text { Manufacture of the 100 MVA HTS generator } \\
\text { Completed manufacturing } \\
\text { studies on coil winding and } \\
\text { assembly }\end{array}$ \\
\hline Task 6 & $\begin{array}{l}\text { Factory testing of the 100 MVA HTS } \\
\text { generator }\end{array}$ & \begin{tabular}{c} 
Initial preparation underway \\
\hline
\end{tabular} \\
\hline
\end{tabular}

Task 1 concentrated largely on the conceptual design for the 100 MVA and, in particular, the selection of key design parameters, such as the HTS coil temperature, refrigeration choices, and the rotor structural configuration. Work was done to understand how a warm iron rotor HTS generator would be integrated into a power station. Finally, an economic model was developed that balanced the HTS generator against the value of its efficiency benefits. 
Task 2 was directed to the development of technology basic to the HTS generator, including the refrigeration system, quench detection, the transfer coupling, and emissivity controls.

Task 3 addressed the design and testing of the Demonstrator, which was to serve as a proof of concept for the warm iron rotor HTS generator.

Task 4 pertained to the preliminary and detailed design of the prototype 100 MVA generator. The deliverables for this task would be the complete set of engineering drawings suitable for manufacture. This task was taken through to the Preliminary Design Review stage, at which point most of the engineering work was complete, a Unigraphics solid model was complete, and the creation of detailed drawings was to start.

Task 5 covered manufacturing aspects of the project. This task was active at various levels throughout the program in order that the manufacturability of the generator could be assessed. In particular, work under this task addressed how to wind the full-size HTS coil, assemble the multi-piece rotor shaft, and perform high-speed precision balancing of the rotor.

Task 6 covered the factory test of the full-size 100 MVA generator. The major questions addressed in this task were related to initial test requirements, adaptation of the test facility to the HTS generator, types of tests to be performed, and the extent of sensors and instrumentation.

\subsection{Program Highlights}

Table 2-2 lists key achievements and milestones in the program.

Table 2-2 - Key Milestones in the 100 MVA HTS Generator Program

\begin{tabular}{lc}
\hline \multicolumn{1}{c}{ Milestone } & Date \\
\hline Demonstrator Concept Design Review & March 2002 \\
\hline Demonstrator Test Review & March 2003 \\
\hline 100 MVA Concept Design Review & July 2003 \\
\hline Purchase of HTS wire from AMSC & February 2004 \\
\hline HTS Coil Readiness Review & April 2005 \\
\hline HTS Coil Support \& EM Shield Readiness Review & July 2005 \\
\hline 100 MVA Generator Preliminary Design Review & November 2005 \\
\hline
\end{tabular}




\subsection{Program Participants}

Numerous organizations contributed to the work done in this program.

GE-Global Research contributed in the areas of applied superconductivity, vacuum and cryogenic technology, rotating machine design, and the design and testing of the Demonstrator. GE-Global Research was the initial prime contractor under the contract with DOE.

GE-Energy contributed in the areas of economic/commercial evaluation, generator design, design of high speed rotating machinery, testing, and manufacturing support. GEEnergy assumed the responsibility as prime contractor in October 2003.

GE-Advisory Services performed analyses of how the HTS generator would perform on the power system. Their work included analyzing interactions of the HTS rotor with the excitation system, fault studies, dynamic and transient stability studies, and overall system protection.

Los Alamos National Laboratory (LANL) gave valuable help to the project through a CRADA. They provided information on vacuum outgassing of materials and getters, necessary for system vacuum integrity, AC loss predictions for HTS tape, rotating heat pipe evaluations, exciter design suggestions, and G2 conductor information.

Oak Ridge National Laboratory (ORNL) also gave valuable help to the project through a CRADA. They provided consultation on BSCCO wire insulation, BSCCO wire and coil testing, cryogenics, and G2 conductor assessments. They also led the readiness reviews required by DOE.

American Electric Power (AEP) performed system stability studies for the HTS generator on the AEP grid and also examined how such a unit could be integrated into a power system.

American Superconductor (AMSC) was the vendor for all of the HTS (BSCCO) wire used during the program.

Sumitomo Heavy Industries (SHI) and Air Liquide helped develop Gifford-McMahon and Brayton cycle refrigeration systems respectively.

\subsection{Program Closure}

In November 2005, GE and the Department of Energy agreed to discontinue work and close the 100 MVA High Temperature Superconducting (HTS) generator program. The decision was based on continuing and significant uncertainty in the economic viability of the generator's technology. This decision was reached after completion of the Preliminary Design Review that examined all aspects of the HTS rotor, the refrigeration system, the excitation system, and the conventional stator. 
The economic viability of utility class HTS generators depends on both the cost of the technology and its economic benefits. The cost to incorporate the technology is higher than initially expected. The most significant costs include

- $\quad$ The HTS wire

- The refrigeration system

- The support of the HTS coil

GE's warm iron rotor concept significantly reduces the length of HTS wire needed for a large generator and the volume of material that must be at cryogenic temperatures. However, there are additional factors beyond the control of an equipment manufacturer that directly drive the overall cost of the generator including the cost of the wire, its operating temperature, and its strength. Although a 100 MVA generator is an appropriate class of machine for the development of HTS generators, it is too small to be a costeffective product. The efficiency benefit is not sufficiently great nor do these smaller generators necessarily operate enough to recoup the added cost of the technology.

GE believes that the economic breakpoint for a utility class HTS generator will be a based loaded unit rated above $500 \mathrm{MW}$. At these higher ratings, the fixed costs, such as the refrigeration and other auxiliary equipment, can be amortized over a greater efficiency benefit. However, the current vision of technology development does not support the near term design of units at these output ratings.

GE has observed that in the present energy marketplace, where the spot market price of natural gas has recently been greater than \$10/MM BTU, operators of combustion turbines are shifting larger units to cyclic operation and supporting the base load with less expensive fuels such as coal and nuclear. This shift in generation dispatch may undercut the economic benefit of the HTS generator.

As a result, GE sees significant uncertainty in both the costs and the benefits of the HTS generator and anticipates a significant time period before the economics might become favorable. GE believes an appropriate course at this time would be to focus on driving the wire and refrigeration technology to cost/performance levels that make the HTS generator practical even in a volatile energy marketplace. 


\section{$3 \quad 1.5$ MW Demonstrator}

Task 3 of the HTS program was to develop and test a scale model of a warm iron rotor HTS generator. The technology used on this Demonstrator should either be scalable to a larger commercially practical machine or be directly transferable to such a generator (for example, the transfer coupling).

This section discusses the design of that generator and the tests that were performed at GE’s Global Research Center in Niskayuna, NY in support of the larger program.

\subsection{Demonstrator Objectives}

The test vehicle was a 2-pole, $4160 \mathrm{~V}, 2000 \mathrm{HP}$ induction motor which GE had acquired for other programs. The squirrel cage rotor was removed and replaced by a scale warm iron HTS rotor. No changes to the stator were required. Because of facility limitations, it was not possible nor planned to conduct full-load tests on the Demonstrator. Rather, a suite of tests to prove mechanical, electrical, and thermal performance were planned and executed. Although the rotor and stator for the Demonstrator were significantly scaled down from a commercial 100 MVA generator, a number of the components within the system were suitable for use in the larger generator.

The test of the Demonstrator was conducted between July 2002 and February 2003. The overall objectives of the test were to:

- Demonstrate mechanical, electrical, and thermal performance of the HTS generator system

- Verify system integration of following new components

o Three-piece shaft

o Superconducting coil

o Bore components

o Cryogenic refrigeration system

o Vacuum enclosure

o Transfer coupling

- Establish test measurement requirements

Table 3-1 lists specific objectives for each of the main technology areas covered by the Demonstrator. 
Table 3-1 - Summary of Demonstrator Test Objectives

\begin{tabular}{cccc}
\hline Mechanical & Cryogenic & Electrical & $\begin{array}{c}\text { Component } \\
\text { Performance }\end{array}$ \\
\hline $\begin{array}{c}\text { Vibration } \\
\text { characteristics }\end{array}$ & Thermal/heat load & $\begin{array}{c}\text { Critical current at } \\
\text { various stages }\end{array}$ & $\begin{array}{c}\text { System } \\
\text { performance }\end{array}$ \\
\cline { 3 - 3 } Balancing response & Vacuum level & $\begin{array}{c}\text { Synchronous } \\
\text { impedance }\end{array}$ & $\begin{array}{c}\text { Coil performance at } \\
\text { operating loads }\end{array}$ \\
\cline { 3 - 3 } $\begin{array}{c}\text { Mechanical } \\
\text { integrity }\end{array}$ & $\begin{array}{c}\text { Open circuit } \\
\text { saturation } \\
\text { Transfer coupling } \\
\text { with vibration } \\
\text { loading }\end{array}$ \\
\cline { 1 - 2 } $\begin{array}{c}\text { Overspeed } \\
\text { performance }\end{array}$ & Phase imbalance & $\begin{array}{c}\text { Refrigeration } \\
\text { system }\end{array}$ \\
\cline { 1 - 2 } Gravity sag & Sudden short circuit \\
\hline
\end{tabular}

\subsection{Demonstrator Test Set-up}

The Demonstrator test set-up included the 2000 HP induction motor stator with the HTS rotor within, the helium transfer coupling, the cryocooler, the excitation system, and related instrumentation.

The Demonstrator was driven by a motor large enough to spin it in air at no-load conditions (either open circuit or short circuit). The drive motor did not have the capacity to place the Demonstrator under any load nor were there any facilities available to receive power from the generator. Fans provided cooling air for the stator.

This same set-up was used for high speed balancing of the HTS rotor.

\subsection{Electrical Design}

Though the stator was not the focus of the investigation, a detailed electrical design was needed in order to predict performance. The stator was arranged in a three-phase, 54-slot, 2-circuit winding.

Generation 1 HTS wire from AMSC was used for the field winding of the generator. The field winding was formed in a single coil of 605 turns positioned at the quadrature axis along the side of a salient magnetic pole. The wire was insulated with Teflon tape with layer separators between adjacent layers. The entire coil was cured in a mold.

The coil was supported by Inconel U-channels that were held in place using three support studs that extend through the center of the pole along the quadrature axis. Drawings of 
the rotor configuration are shown in Figure 3-1 and pertinent design information is given in Table 3-2. The mechanical gap and shield information are for the as-built condition. The aluminum shield was removed part way through the Demonstrator testing because of excessive open circuit pole face loss.

Since the generator includes a traditional magnetic steel stator core, the flux densities during operation are also at levels typical in electric machinery.

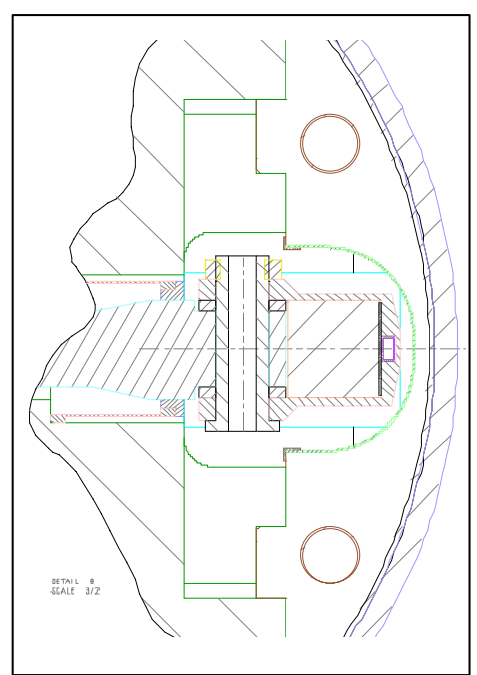

Section A-A

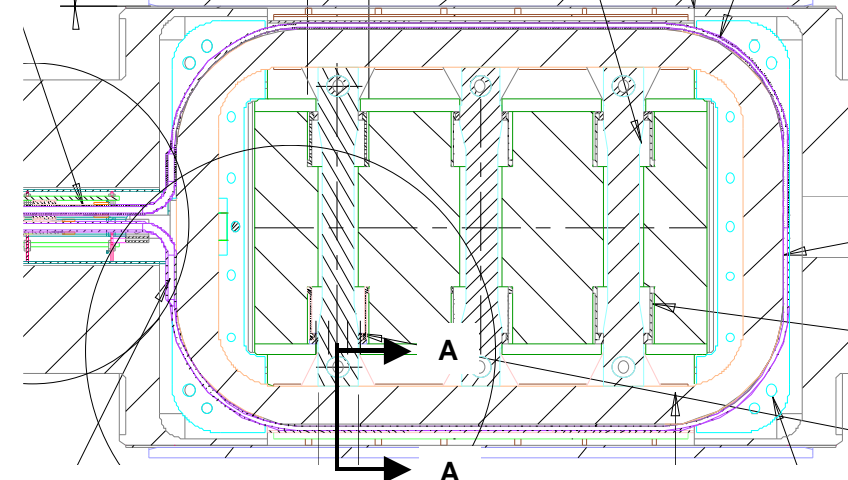

A

Figure 3-1 - Demonstrator Superconducting Field Coil And Support System

\subsubsection{Excitation Analysis}

The original excitation analysis was performed using a 2-D finite element model. During this analysis care was taken to account for end effects and the effect of the coil support system. The open circuit saturation excitation curve is shown in Figure 3-2.

End effects and coil support saturation were more significant than anticipated, so a 3-D analysis done after the test was found to be the most accurate predictor of excitation. A summary of results showing several analyses is in Table 3-3. 
Table 3-2 - Demonstrator Design Information

\begin{tabular}{|c|c|c|}
\hline 2000 HP Induction Motor & Units & Value \\
\hline Generator Rating & MVA & 1.84 \\
\hline Rated Voltage & $\mathrm{kV}$ & 4.16 \\
\hline Rated Current & $\mathrm{A}$ & 255.5 \\
\hline Power Factor & --- & 0.85 \\
\hline Magnetic Gap & in & 0.60 \\
\hline Full Load Field Current & A & 110 \\
\hline No Load Field Current (test) & $\mathrm{A}$ & 45 \\
\hline Stator OD & in & 40 \\
\hline Stator ID & in & 19 \\
\hline Winding Arrangement (slots/circuits) & --- & $54 / 2$ \\
\hline Slot Width & in & 0.635 \\
\hline Slot Height & in & 3.9 \\
\hline Active Length & in & 17.5 \\
\hline Mechanical Air Gap (with shield) & in & 0.113 \\
\hline Electromagnetic Shield Thickness & in & 0.3865 \\
\hline Pole OD & in & 17.8 \\
\hline Pole Width & in & 12.95 \\
\hline Pole Angle & degrees & 87 \\
\hline Number of field turns - entire coil & --- & $\begin{array}{l}605 \text { (302 turns per } \\
\text { pole) }\end{array}$ \\
\hline Coil ID & in & 13 \\
\hline Coil Width (along pole) & in & 1.63 \\
\hline Coil Height (perpendicular to pole) & in & 1.60 \\
\hline $\begin{array}{l}\text { Wire critical current at } 30 \mathrm{~K} \text { operating } \\
\text { temp }\end{array}$ & A & 180 \\
\hline
\end{tabular}


No Load Sat. Curve

No Load Sat. Curve _.... Modified Air Gap

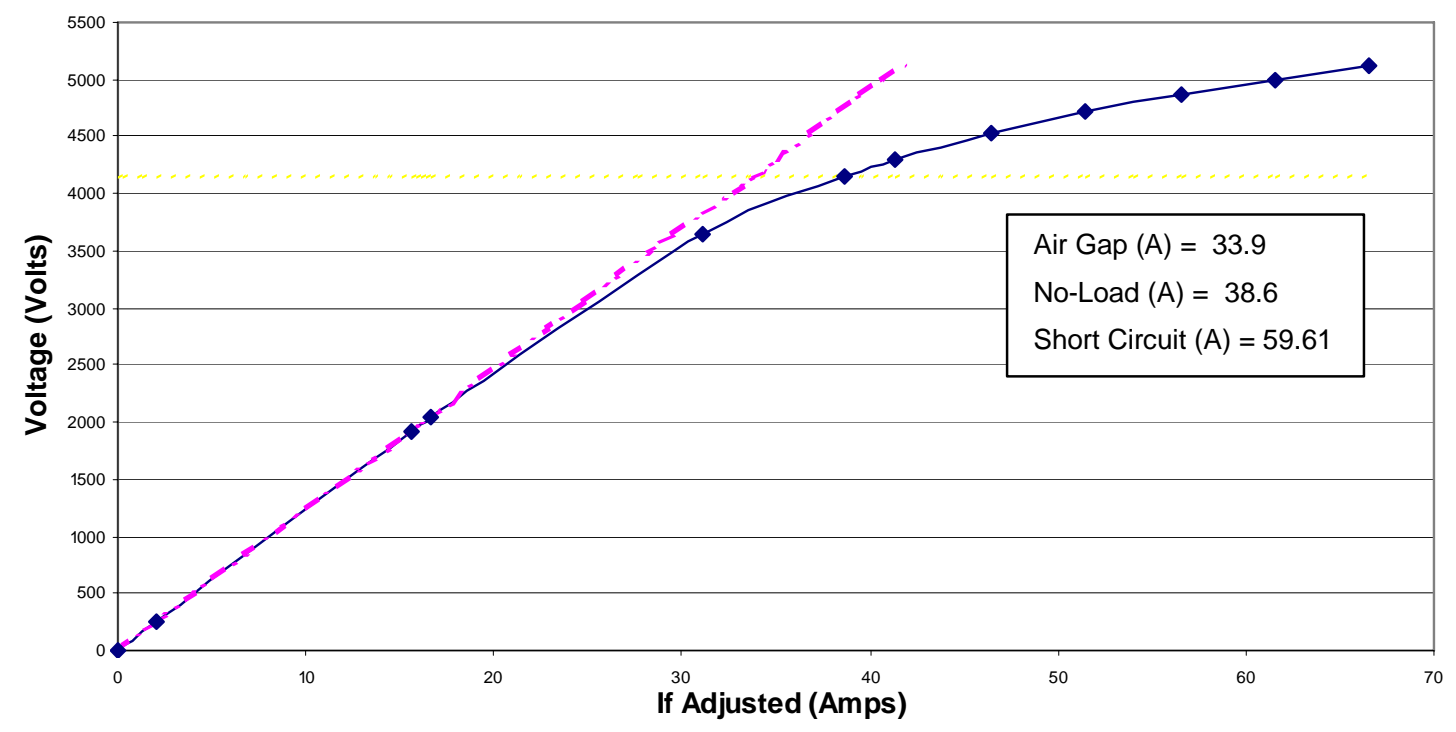

Figure 3-2 - Calculated Demonstrator Saturation Curve (2D Model)

Table 3-3 - Excitation Calculations to Understand Saturation and Modeling After the Test

\begin{tabular}{lcc}
\hline & $\begin{array}{c}\text { Air Gap Field } \\
\text { Current (A) }\end{array}$ & $\begin{array}{c}\text { No-Load Field } \\
\text { Current (A) }\end{array}$ \\
\cline { 2 - 3 } Test & 31.26 & 44.6 \\
2-D with end corrections & 33.9 & 38.6 \\
3-D Model & 32.0 & 40.1 \\
\hline
\end{tabular}

\subsubsection{HTS Coil}

The HTS coil for the Demonstrator, shown in Figure 3-3, was wound in a racetrack fashion. The HTS wire was laminated with stainless steel strips on each side to provide increased capability to withstand compressive and tensile strains and insulated with Teflon tape.

Each of the 77 layers in the coil had eight turns. A glass separator impregnated with epoxy resin was placed between adjacent layers. That resin flowed throughout the coil during the molding and curing process. 


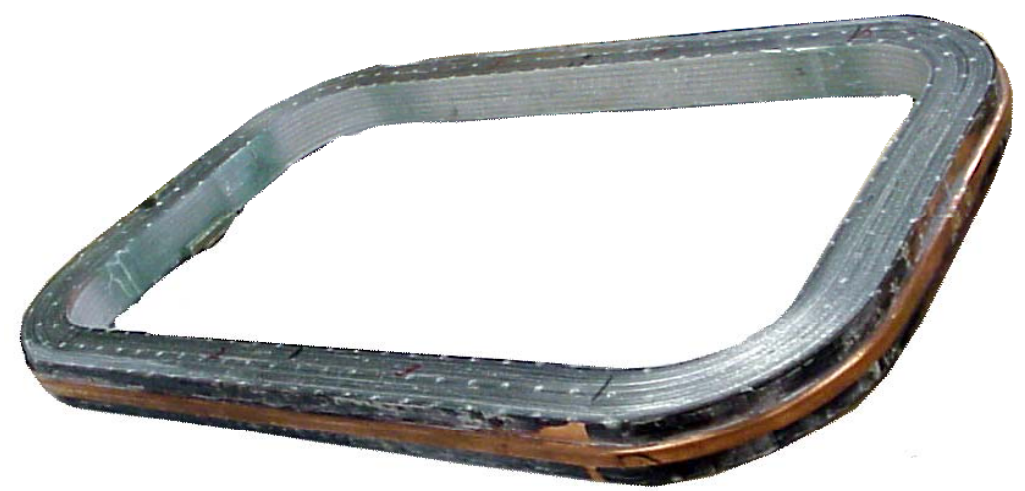

Figure 3-3 - HTS Coil for the Demonstrator

A copper cooling tube, shown in the figure, enclosed the coil. During operation, gaseous helium circulated through the tube and heat flowed from the coil to the tube by conduction.

\subsection{Electrical Tests}

The electrical tests for the Demonstrator were developed to verify the performance of the warm iron rotor electromagnetic concept and to provide data to validate analytical tools. The specific objectives included:

- Demonstrate operation of the HTS coil at rated speed, flux, and no-load current

- Determine limits of the HTS coil current carrying capability

- Demonstrate the EM shield effectiveness and calibrate design tools

- Demonstrate that the coil support structure, the EM shield, and vacuum enclosure could handle fault torques

- Validate EM reactances and machine characteristics

- Validate excitation requirements

- Obtain performance data to validate analytical models.

- Identify unknown failure modes and mechanisms.

\subsubsection{Steady State Short Circuit Tests}

As noted in Table 3-2, the nominal mechanical gap between the Demonstrator stator and rotor surface was 0.113 inches. With assembly tolerance stack-ups, the minimum clearance was closer to 0.065 inches.

The Demonstrator finished a synchronous impedance test with the aluminum shield on, though excessive heating was noted. The open circuit saturation test ended abruptly at 0.15 pu voltage when the aluminum shield rubbed the stator because of overheating at the 
pole tip. The generator was shut down, cleaned, and the aluminum shield was removed from the rotor. The stainless steel vacuum enclosure was left intact. The synchronous impedance and open circuit saturation tests were completed again without the shield.

Removal of the shield limited the tests that could be performed on the generator and also changed the subtransient impedances. The comparison between sudden short circuit test results and initial design estimates such as those found using the standstill frequency response (SSFR) tests became more difficult. On the other hand, it was now possible to measure harmonics and loss in the HTS coil without an EM shield.

\subsubsection{Synchronous Impedance Test}

The synchronous impedance test curve is shown in Figure 3-4. The test was completed at $3000 \mathrm{rpm}$ to limit mechanical stress and short circuit pole face loss in the initial test. The tested field current was 57.4 A, which compares well to the calculated value of 57.7 A.

The second run of the synchronous impedance test, completed without the EM shield, was used to validate AC loss calculations that had been completed using FE tools. The measured sixth harmonic field current, shown in Table 3-4, is somewhat less than predicted using the finite element models.

Loss in the coil and coil support (cold components) was obtained using the cold head temperature rise during the short circuit test, then subtracting the loss with zero current and calculated lead loss. The total losses are $8-14$ watts, which agree with the FE loss calculation in Section 3.4.1.3. At the maximum loss point the coil experienced a selflimiting quench. The test results are shown in Figure 3-5.

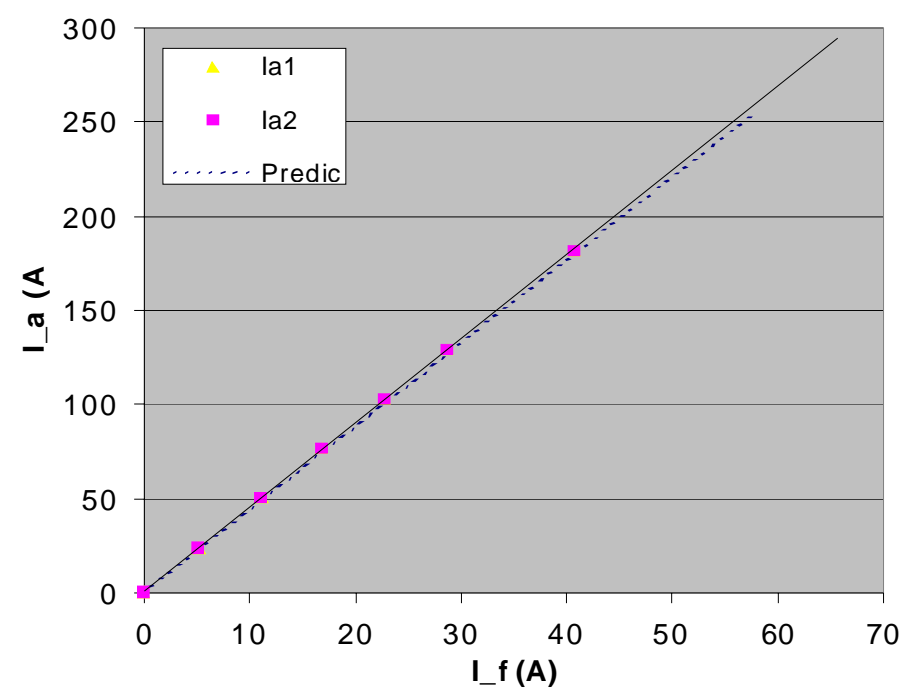

Figure 3-4 - Synchronous Impedance Curve For HTS Demonstrator - Test And Prediction 
Table 3-4 - Field Current Harmonics During Second Short Circuit Test

\begin{tabular}{cccc}
\hline $\begin{array}{c}\text { Nominal Field } \\
\text { Current (A) }\end{array}$ & $\begin{array}{c}\text { Measured Field } \\
\text { Current (A) }\end{array}$ & \multicolumn{2}{c}{$\mathbf{6}^{\text {th }}$ Harmonic Current (A rms) } \\
Measured & Predicted \\
\hline 10 & 9.91 & 0.05 & 0.08 \\
15 & 14.50 & 0.09 & 0.12 \\
20 & 19.43 & 0.13 & 0.16 \\
\hline
\end{tabular}

Coil and Support Loss for Various Frequencies

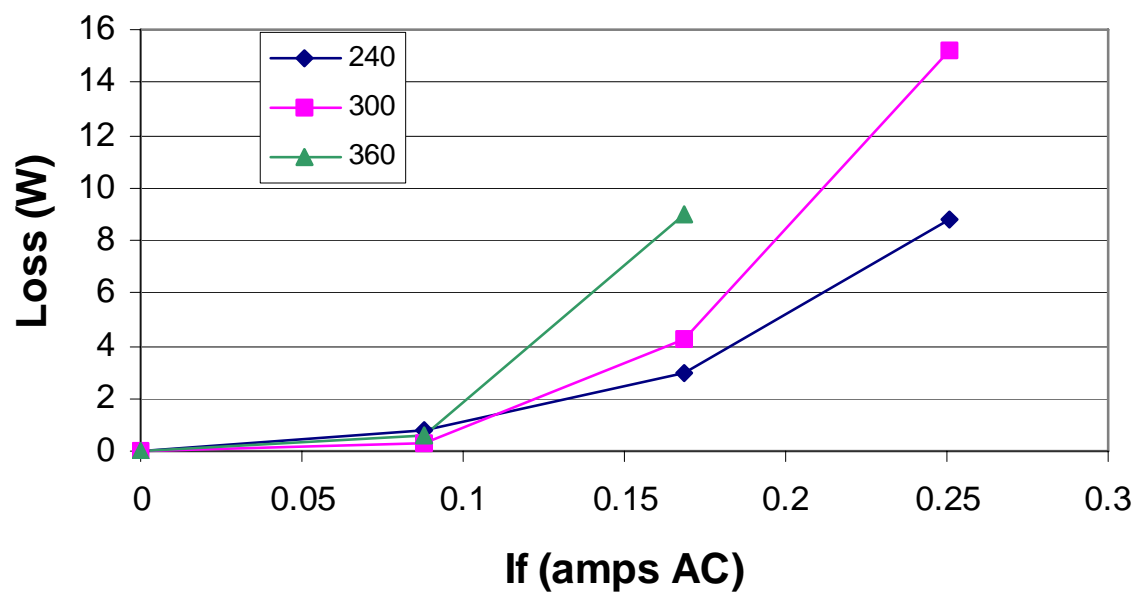

Figure 3-5 - AC Loss in Coil and Coil Support During Synchronous Impedance Test

\subsubsection{Steady State Short Circuit Heat Runs}

The EM shield was on the rotor during the short circuit heat runs. The generator terminals were short circuited through a copper bar. The machine was taken to $2300 \mathrm{rpm}$ and run with zero excitation until steady state temperatures were observed in the cryogenic cooling circuit and the rotor. This took about $1 \frac{1 / 2}{2}$ hours. The field excitation was then increased in steps of $10 \mathrm{~A}$ and run until thermal equilibrium was reached. Temperatures and vibration data were monitored and recorded.

\subsubsection{Shield and Coil Heating Under Short Circuit}

High short circuit pole face loss was anticipated during the Demonstrator test, but open circuit pole face loss turned out to be more significant. The latter part of the test series 
was completed without the aluminum shield to limit that heating. This section gives an overview of the finite element loss analysis completed to evaluate loss before and after the removal of the EM shield.

Shield heating due to slot passing frequencies in the air gap is larger than normal in the Demonstrator because of the small gap to slot pitch ratio. A finite element analysis was performed to obtain an estimate of the losses. Figure 3-6 shows the air gap flux density profile and harmonics. Significant harmonics around multiples of 54 (the slot passing frequency) were present.

With these harmonics present losses on the order of $10 \mathrm{~kW}$ were predicted in the EM shield at $3000 \mathrm{rpm}$. Table 3-5 summarizes the losses at other speeds.
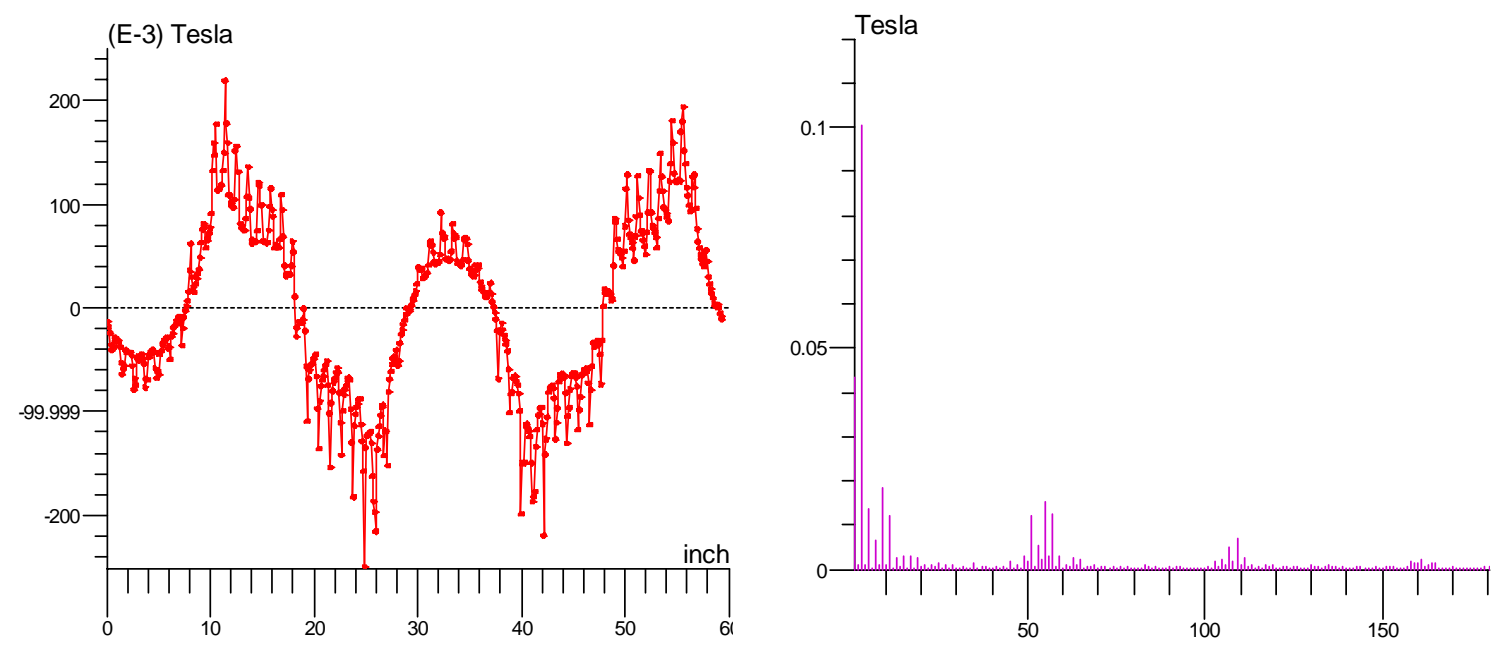

Figure 3-6 - Air Gap Flux Density Profile and Harmonic Contents Under Short Circuit Conditions

Table 3-5 - Short Circuit Shield Losses vs. Rotor Speed for $I_{f}=40 A$

\begin{tabular}{cc}
\hline $\begin{array}{c}\text { Speed } \\
\mathbf{( r p m )}\end{array}$ & Shield Losses $(\mathbf{k W})$ \\
\hline 2300 & 8.2 \\
3000 & 10 \\
3600 & 11.8 \\
\hline
\end{tabular}




\subsubsection{Steady State Open Circuit Tests}

The Demonstrator with the EM shield ran under open circuit conditions at field currents of 4A and 6A ( $0.15 \mathrm{pu}$ armature voltage). High losses in the shield were observed even at these low levels of excitation. At 6A, the hottest air gap thermocouple was beginning to stabilize at around 60C when the rotor starting rubbing, and the machine was shut down.

After the EM shield had been removed, the open circuit saturation test was repeated at $3000 \mathrm{rpm}$ and $3600 \mathrm{rpm}$. Both tests were continued to 100\% armature voltage. The tests indicated that saturation in the machine is much greater than anticipated using finite element methods (Section 3.3.1). The test no-load field current was $44.8 \mathrm{~A}$, compared to predictions of 39 to 41 A. The test saturation curve is shown in Figure 3-7.

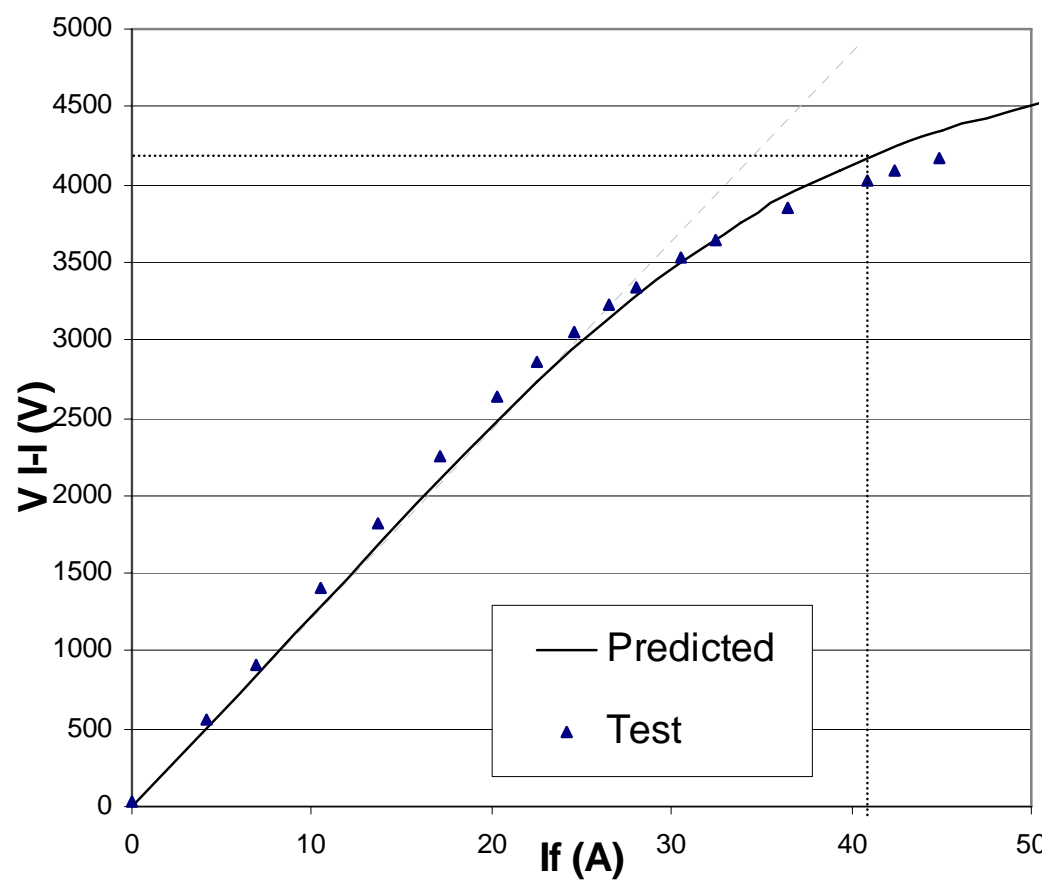

Figure 3-7 - HTS Demonstrator Test Saturation Curve

\subsubsection{Sudden Short Circuit Tests}

A series of three-phase sudden short circuit tests was conducted successfully on the generator up to 0.54 per unit armature voltage. The main objective of the test was to apply torque to the coil and coil-support structure equivalent to $150 \%$ of duty at rated load.

The test was conducted by operating the generator with no load (open circuit) at various voltages and then closing a contactor at the terminals of the machine to short all three phases simultaneously. The armature winding was "WYE" connected, with the neutral impedance grounded. 
Plots for the short circuit currents for the 0.54 pu voltage test are shown in Figure 3-8 and Figure 3-9. The predictions are based on a 2D finite element (Flux2D) rotating grid (time stepping) analysis of the generator without a shield.
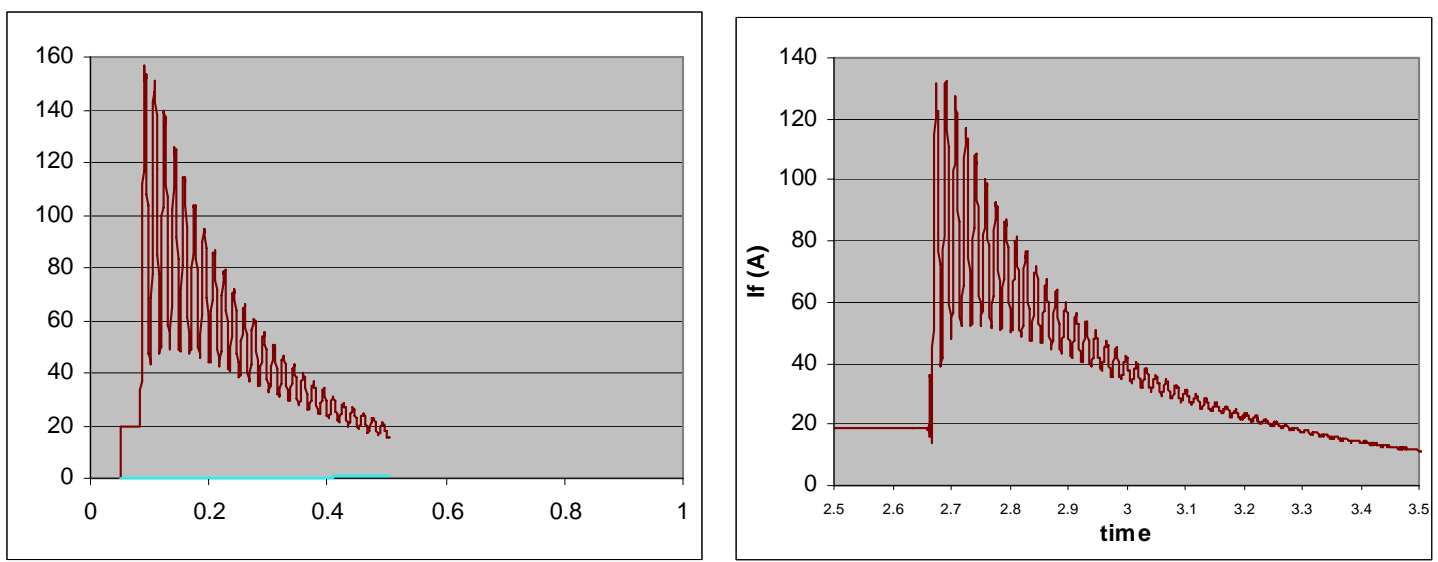

Figure 3-8 - Field Current Trace for 0.54 pu SSC From No Load - Measured (Left) and Simulation (Right)
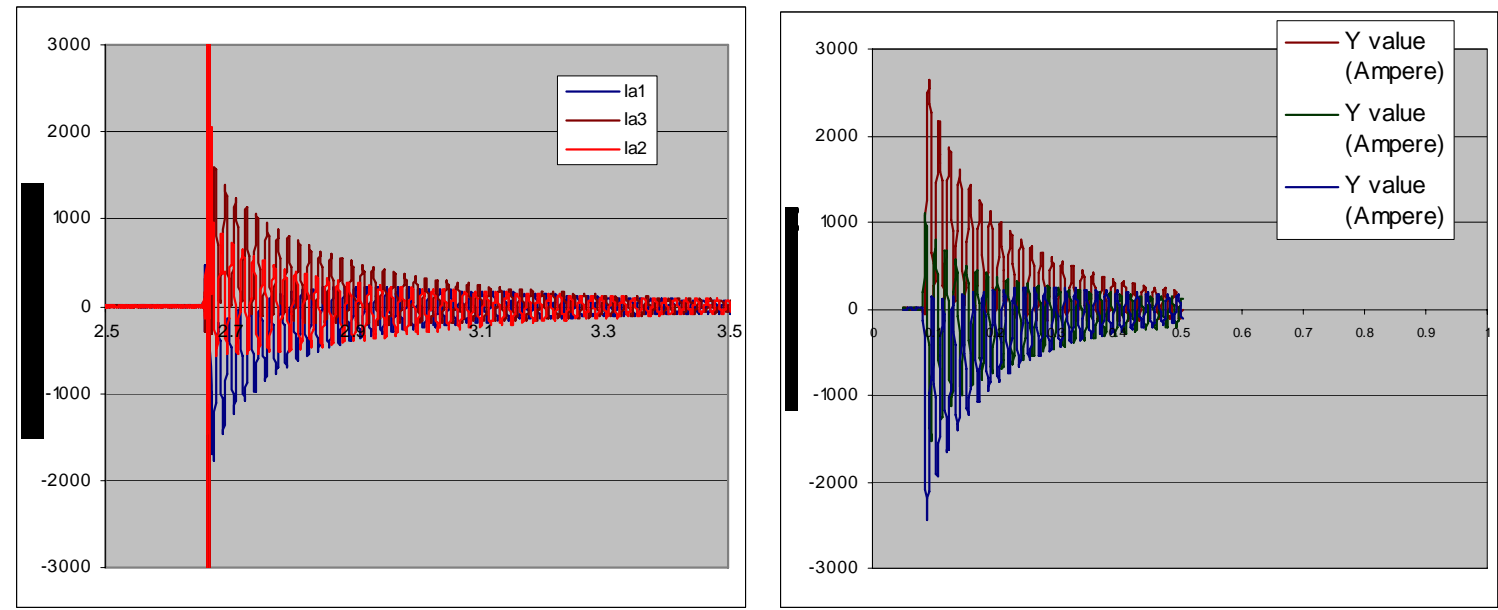

Figure 3-9 - Armature Current Traces for 0.54 pu Voltage SSC - Measured (Left) and Simulation (Right)

\subsubsection{Operational Impedance Tests}

Because of the unique configuration of the HTS rotor, it was expected that the generator operational impedances $\left(\mathrm{L}_{\mathrm{d}}(\mathrm{s}), \mathrm{L}_{\mathrm{q}}(\mathrm{s}), \mathrm{L}_{\mathrm{ffd}}(\mathrm{s})\right)$ would be significantly different than those of conventional generators. The HTS winding and the EM shield are both inherently low in losses, so the greatest differences were likely to be observed in the generator time constants. These have a large impact on the generator operation on the power system, especially with regard to damping and the generator response to excitation. 
The operational impedances were obtained using a frequency domain FE model, a standstill frequency response test, and sudden short circuit tests.

A frequency domain finite element model was created for the Demonstrator crosssection. This FE analysis had been developed for and used to create a generator model and run subsequent power systems analyses in the 1994/1995 DOE Superconducting Generator project. An AC current of varying frequency is injected into first the stator winding and then the field winding. Flux linkages are calculated for the stator and field winding to obtain self and mutual impedances across the frequency spectrum.

For power systems studies, GE uses lumped-circuit models of the generator direct and quadrature axes that are derived from the operational impedances by a curve-fitting algorithm, SIMOFIT_FE. The results of the frequency domain FE analysis have been fitted by SIMOFIT_FE.

The initial SSFR test was strictly stator-excited. The results of an abbreviated frequency response test on the field winding are shown in Figure 3-12. This plot uses a logarithmic vertical axis to emphasize the comparison of high frequency reactances.

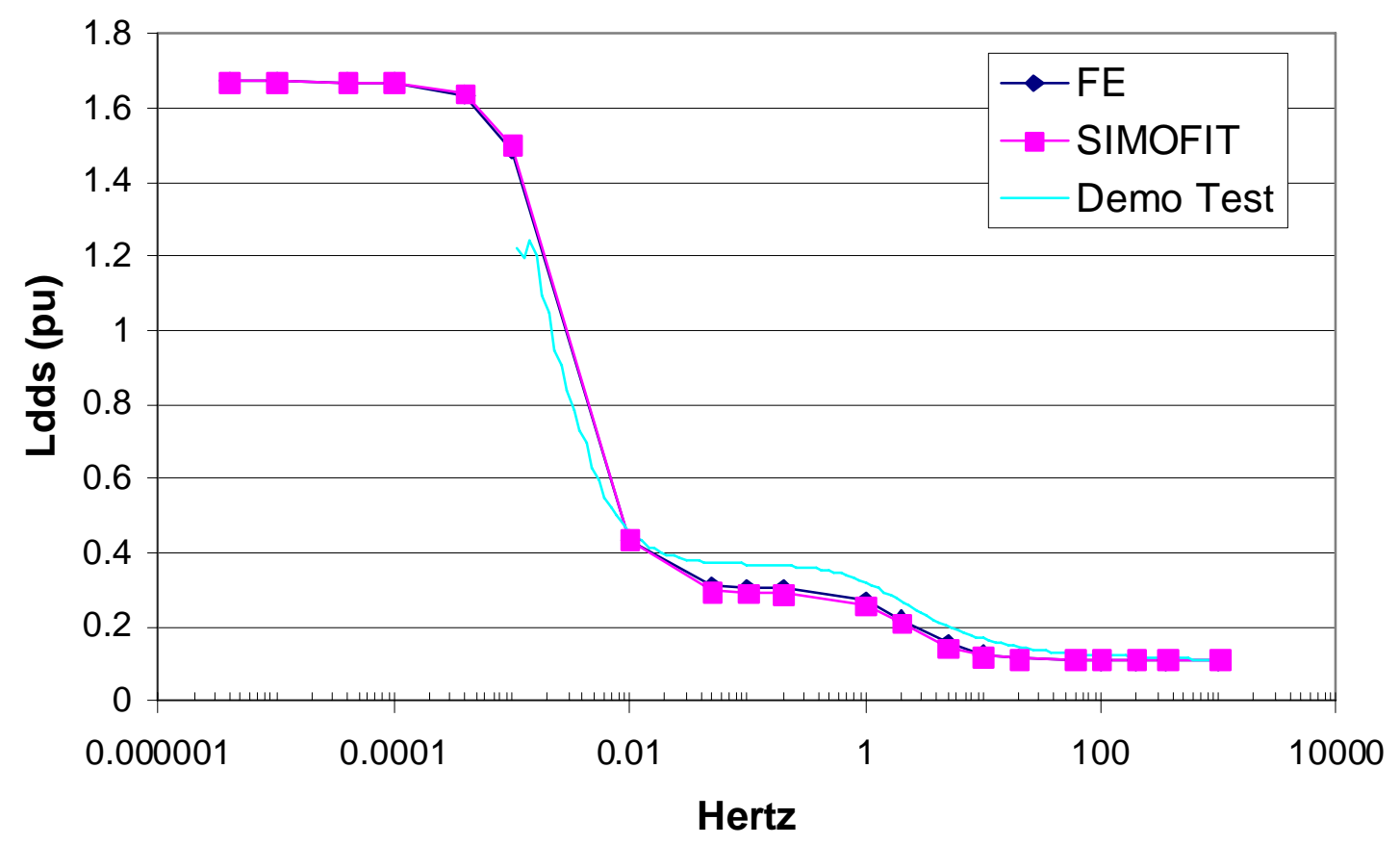

Figure 3-10 - $X_{d}(s)$ by Finite Element Analysis and SSFR Tests 
Table 3-6 - Comparison of FE/SIMOFIT_FE Terminal Reactance to Test Results

\begin{tabular}{|c|c|c|c|c|c|}
\hline Reactance or Time Constant & Symbol & Units & $\begin{array}{c}\text { Finite } \\
\text { Element } \\
\text { Model }\end{array}$ & $\begin{array}{c}\text { SSFR } \\
\text { Test }\end{array}$ & $\begin{array}{l}\text { Difference } \\
\quad(\%)\end{array}$ \\
\hline $\begin{array}{l}\text { Synchronous reactance, direct } \\
\text { axis }\end{array}$ & $X_{d}$ & $\mathrm{pu}$ & 1.67 & 1.67 & 0 \\
\hline Transient reactance, direct axis & $X_{d}^{\prime}$ & $\mathrm{pu}$ & 0.38 & 0.37 & 3.3 \\
\hline $\begin{array}{l}\text { Subtransient reactance, direct } \\
\text { axis }\end{array}$ & $X^{\prime \prime}$ & $\mathrm{pu}$ & 0.11 & 0.13 & -14 \\
\hline $\begin{array}{l}\text { Transient time constant, direct } \\
\text { axis, short circuit }\end{array}$ & $\mathrm{T}_{\mathrm{d}}^{\prime}$ & $\mathrm{s}$ & 13.9 & 18.9 & -27 \\
\hline $\begin{array}{l}\text { Transient time constant, direct } \\
\text { axis, open circuit }\end{array}$ & $\mathrm{T}^{\prime}{ }_{\text {do }}$ & $\mathrm{s}$ & 78.9 & 85.3 & -7.5 \\
\hline $\begin{array}{l}\text { Subtransient time constant, } \\
\text { direct axis, short circuit }\end{array}$ & $\mathrm{T}_{\mathrm{d}}$ & $\mathrm{s}$ & 0.04 & 0.02 & 78 \\
\hline $\begin{array}{l}\text { Subtransient time constant, } \\
\text { direct axis, open circuit }\end{array}$ & $\mathrm{T}^{\prime \prime}$ do & $\mathrm{s}$ & 0.07 & 0.06 & 18 \\
\hline $\begin{array}{l}\text { Armature leakage reactance, } \\
\text { rated voltage }\end{array}$ & $\mathrm{X}_{\mathrm{lv}}$ & $\mathrm{pu}$ & 0.11 & 0.11 & 0 \\
\hline $\begin{array}{l}\text { Synchronous reactance, } \\
\text { quadrature axis }\end{array}$ & $X_{q}$ & $\mathrm{pu}$ & 0.87 & 0.91 & -3.9 \\
\hline $\begin{array}{l}\text { Transient reactance, quadrature } \\
\text { axis }\end{array}$ & $X^{\prime}{ }_{q}$ & $\mathrm{pu}$ & 0.36 & 0.21 & 75 \\
\hline $\begin{array}{l}\text { Subtransient reactance, } \\
\text { quadrature axis }\end{array}$ & $X{ }_{q}$ & $\mathrm{pu}$ & 0.11 & 0.13 & -9 \\
\hline $\begin{array}{l}\text { Transient time constant, } \\
\text { quadrature axis, short circuit }\end{array}$ & $\mathrm{T}_{\mathrm{q}}^{\prime}$ & $\mathrm{s}$ & 0.2 & 0 & 380 \\
\hline $\begin{array}{l}\text { Transient time constant, } \\
\text { quadrature axis, open circuit }\end{array}$ & $\mathrm{T}_{\text {qo }}^{\prime}$ & $\mathrm{s}$ & 0.5 & 0.2 & 139 \\
\hline $\begin{array}{l}\text { Subtransient time constant, } \\
\text { quadrature axis, short circuit }\end{array}$ & $T^{\prime \prime}{ }_{q}$ & $\mathrm{~s}$ & 0.03 & 0.01 & 90 \\
\hline $\begin{array}{l}\text { Subtransient time constant, } \\
\text { quadrature axis, open circuit }\end{array}$ & $\mathrm{T}_{\text {qо }}$ & s & 0.10 & 0.2 & 125 \\
\hline
\end{tabular}




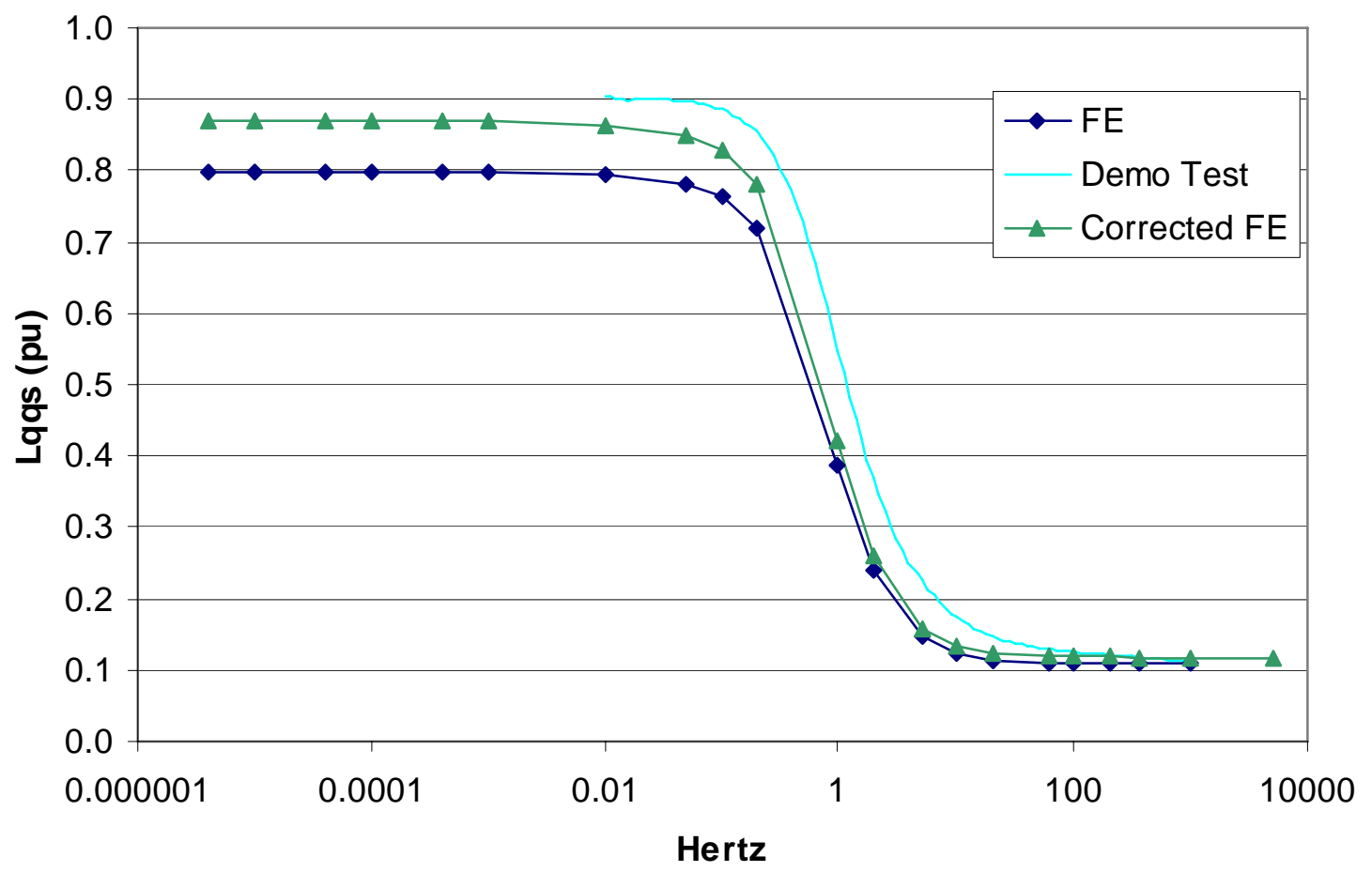

Figure 3-11 $-X_{q}(s)$ by Finite Element Analysis and SSFR Tests

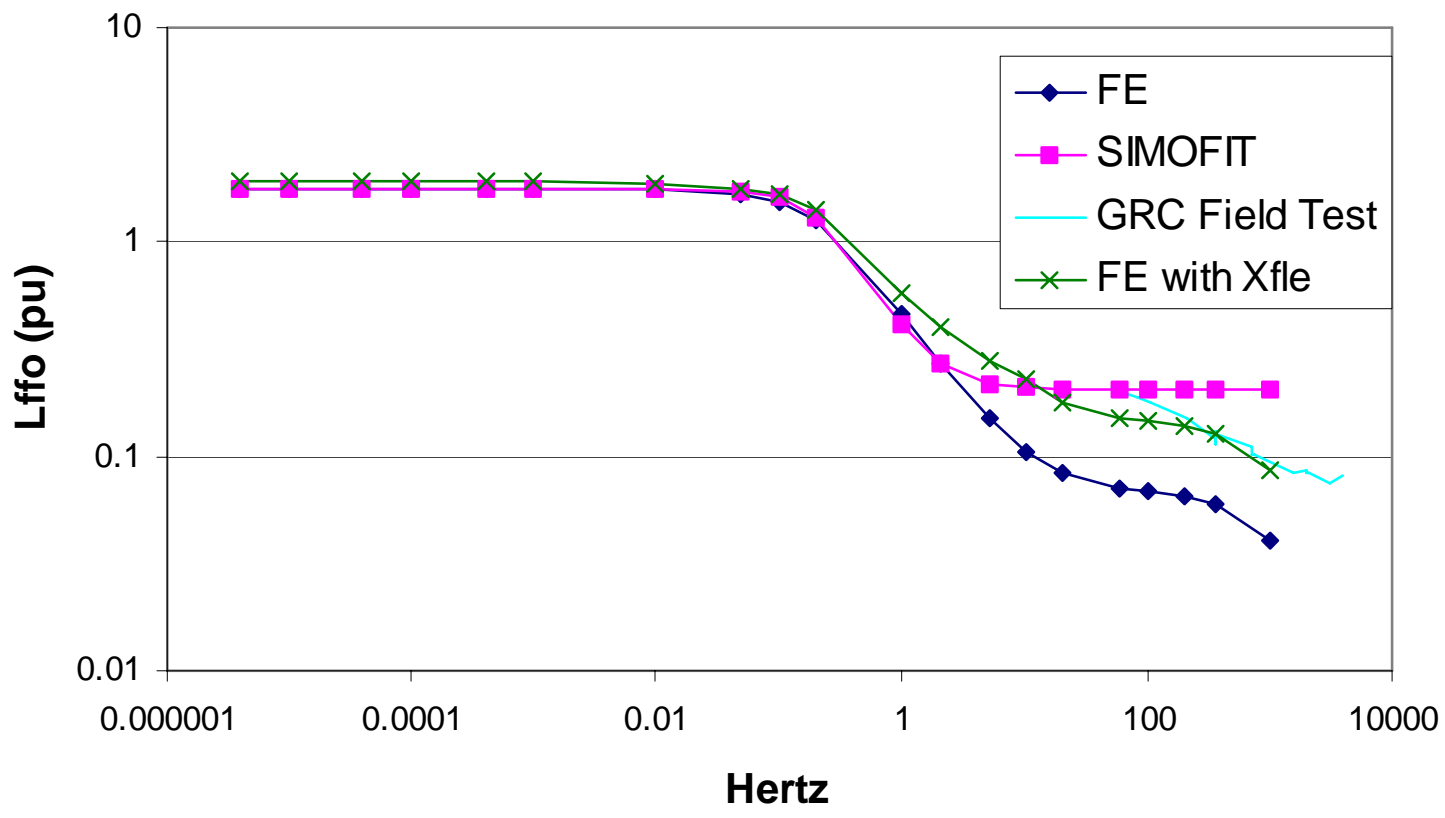

Figure 3-12 - Field Self-Reactance Comparison 


\subsubsection{Coil I-V Tests}

The I-V or Ic (critical current) test was used as a proof of operability test on the superconducting coil. The test uses a DC source to impose a current in the coil. The I-V test was run a number of times during the Demonstrator test sequence, as shown in Figure 3-13. The initial test showed very low voltages up to $140 \mathrm{~A}$. After this first test, the coil sustained a quench during operation. The next and subsequent I-V tests show the voltage characteristic being higher than the initial test. Figure 3-14 compares the voltage at a typical operating current of $45 \mathrm{~A}$ for all the I-V tests after the initial one. The voltage does not show an upward trend even through a second quench event and sudden short circuit testing.

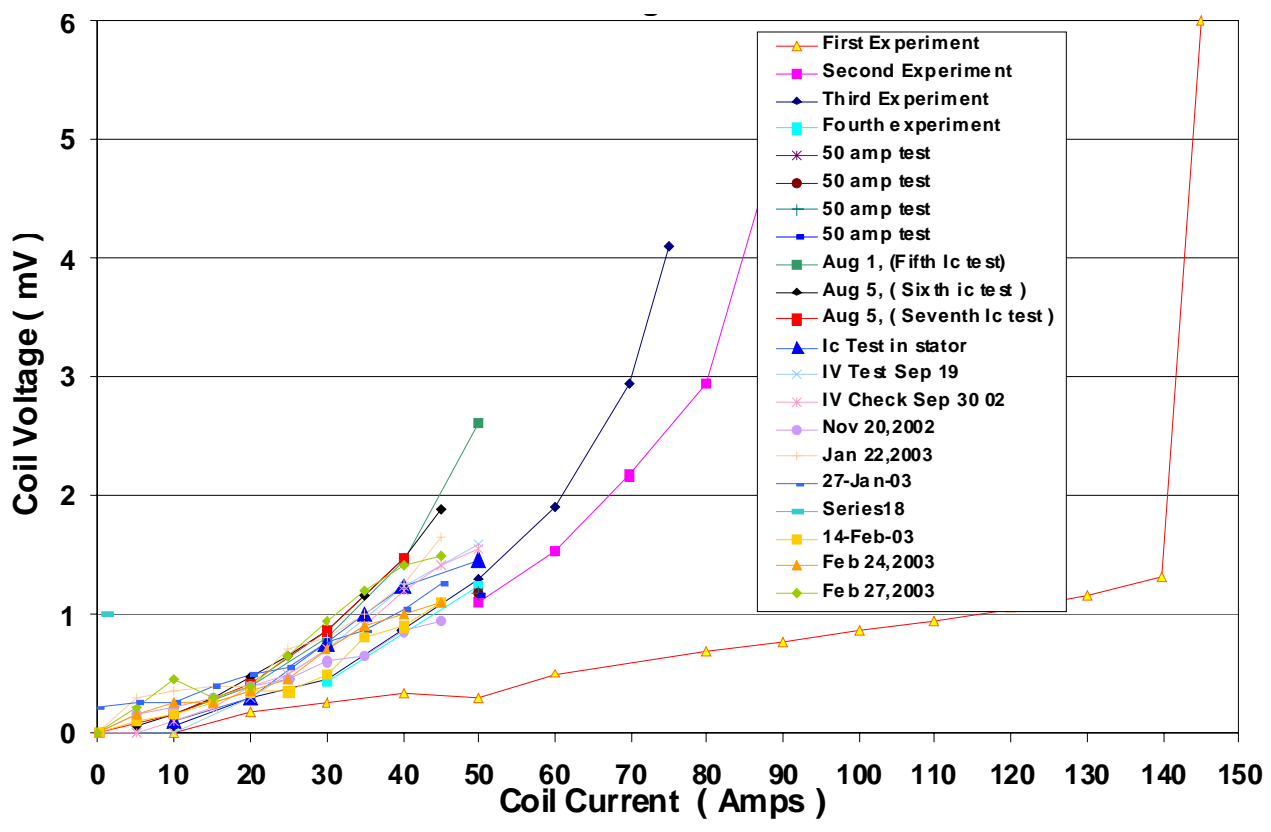

Figure 3-13 - Compiled Coil I-V Test Results

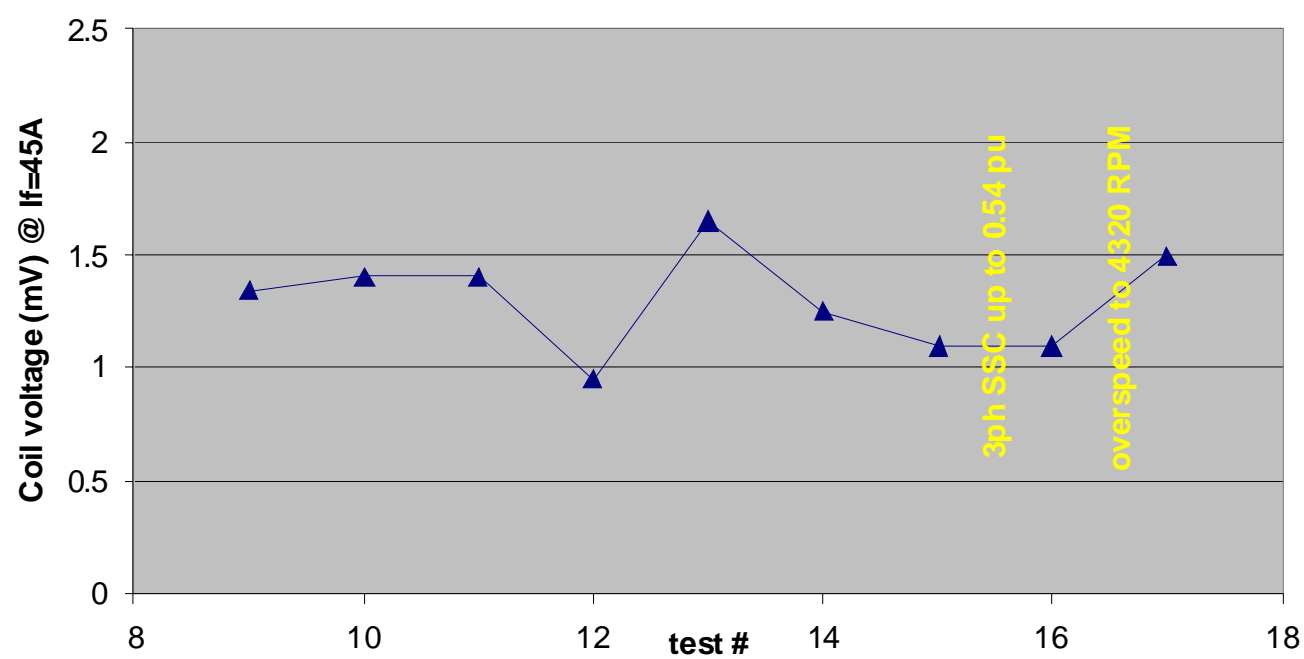

Figure 3-14 - Time History of I-V Coil Lead Test Voltage at 45 A 


\subsection{Demonstrator Mechanical Design}

The HTS coil is intolerant of both mechanical strain and heating. A successful mechanical design of the Demonstrator rotor was critical to maintaining the coil at cryogenic temperatures and within acceptable levels of strain.

\subsubsection{Thermal Design Considerations}

\subsubsection{Conduction Heat Loads}

One of the main design challenges for the cryogenic engineer is to reduce heat loads to the cold components. Smaller heat loads mean smaller, less expensive refrigerators and lower costs. It is here that the implications of using a warm, iron-core design become apparent. For air-core machines, one must redesign the stator in order to benefit from the high flux densities possible. Also, the rotor body itself may be operated cold since there is no need to retain the magnetic properties of the steel. The transition to the room temperature ends of the rotor where the bearings and torque transmission occur must be done though a low-conductivity, usually composite, material.

A warm pole body offers two powerful benefits: 1) Fewer ampere-turns and a lesser quantity of expensive superconductor are needed to excite the generator; 2) The rotor can be retrofit into existing stators. The difficulty is that the cold coil cannot be attached directly to the warm rotor body without imposing a tremendous thermal load on the refrigerator.

The coil support structure must carry a number of superimposed loads. These include 1) centripetal loads, 2) load torques, 3) sudden short-circuit loads, 4) dynamic or vibratory loads, and 5) differential thermal-contraction loads. The requirement is not only to carry the loads without failure or fatigue but also to limit the coil strain to avoid coil degradation. The coil support is discussed in detail in Section 3.5.2.

The strain requirement is the dominant constraint, with centripetal loads being the largest contributor. To support the huge centripetal loads via direct connection to the rotor body would impose an unacceptably large conductive heat loss. In addition, materials with low thermal conductivity across the desired temperature range also tend to have relatively low elastic moduli. Increasing the support cross-section in order to decrease coil strain is a double-edged sword. The penalty is made in increased heat conduction to the cryogenic system. The design used on the Demonstrator avoids carrying centripetal loads to the rotor body entirely. The equal and opposite radially outward loads on the coil legs are balanced against each other by tying the two halves of the coil together with cold struts, as shown in Figure 3-15.

Thermal conduction is minimized but not eliminated with this approach, and one is free to use stiff, high strength materials. The design may be optimized to reduce strain without 
regard to the conductive penalty. A high degree of accuracy was expected in modeling the conductive heat load to the Demonstrator. The only uncertainty in the analysis was the measured statistical variation of the material thermal conductivity and the very small variation in the geometric cross-section of the various components.

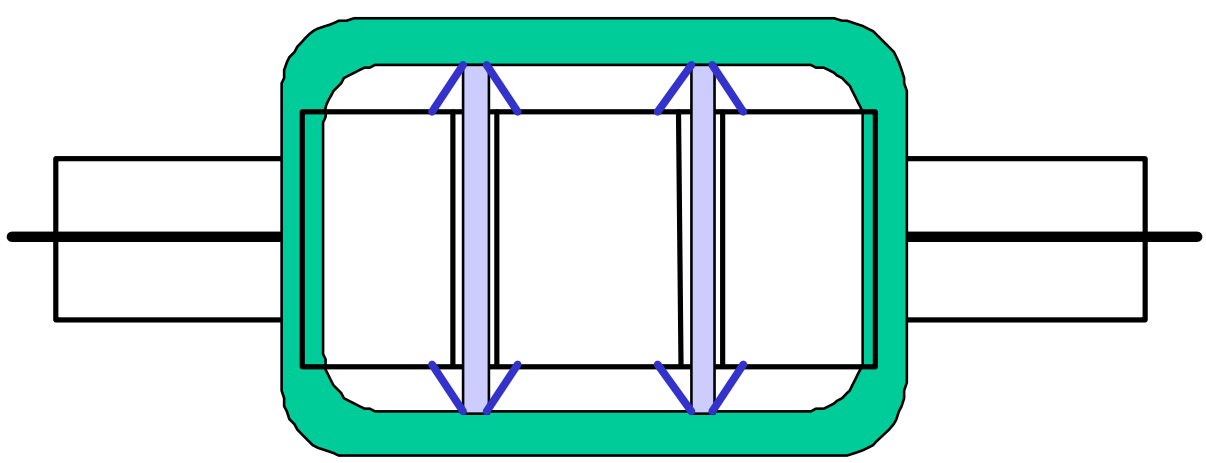

Figure 3-15 - The Cold Coil Support System

\subsubsection{Radiation Heat Loads}

For the Demonstrator, the radiation portion of the heat load to the cryogenic system was over thirty percent of the total thermal budget. The standard practice for cryogenic systems is to use MLI to reduce these radiation losses. However, the centripetal acceleration on the rotor at $3600 \mathrm{rpm}$ would force all the layers together making them isothermal and therefore no more effective than just a single layer. Likewise, mechanically separating the layers with low-conductivity standoffs is difficult. Blocking the radiation with a low-density filler, such as an aero-gel or silica filler, was considered. In practice, it was found that any reduction in the radiation heat load was more than offset by increased conduction through the media to the cold components.

The approach used on the Demonstrator was to apply low emissivity coatings to only the warm and cold facing surfaces. No radiation barriers at intermediate temperatures were employed. A laboratory emissivity tester was used to study the emissivity of different surfaces and coatings. Eventually, a coating was found with an emissivity as low as half that of aluminized Mylar $(\varepsilon=0.04)$. A significant effort was being made to understand the variables affecting surface emissivity and the process factors to minimize its value and variation.

\subsubsection{Other Thermal Loads}

In addition to the loads discussed above, there are four other thermal loads imposed on the generator. These include the parasitic losses associated with the operation of the transfer coupling. The transfer-coupling loads have conductive, convective and radiative 
components. Understanding of the transfer-coupling losses is fairly complete at this point having been both modeled analytically and measured experimentally.

Conduction and joule heating to the main copper coil leads also contribute to the overall heat load. The leads have an optimized length/area ratio such that the sum of the joule and conductive heating components are minimized at the operating current level.

A fourth loss is the coil AC heating component. Extensive analytical work has been performed to determine these losses both at GE and at Los Alamos National Laboratory. Experiments were performed where alternating current was directly injected into the coil and the increase in heat load measured.

A final heat load is that which is parasitic to the refrigerator itself. This would include the radiative and conductive loads within the refrigerator cold box and, as was discussed previously, the heat load resulting from transferring a portion of the helium flow to ambient temperature and back through a heat exchanger. All of the loads discussed in the "other" category are approximately fixed, regardless of the generator size. The exceptions are the refrigerator losses, which tend to scale linearly with refrigerator capacity.

\subsubsection{Experimental Results}

One result became clear only after running the Demonstrator continuously for several hours. This was the variation in rotor heat load between the static and dynamic cases. The data in Figure 3-16 shows the refrigerator cold head temperature and derived heat load as a function of time from rotor startup.

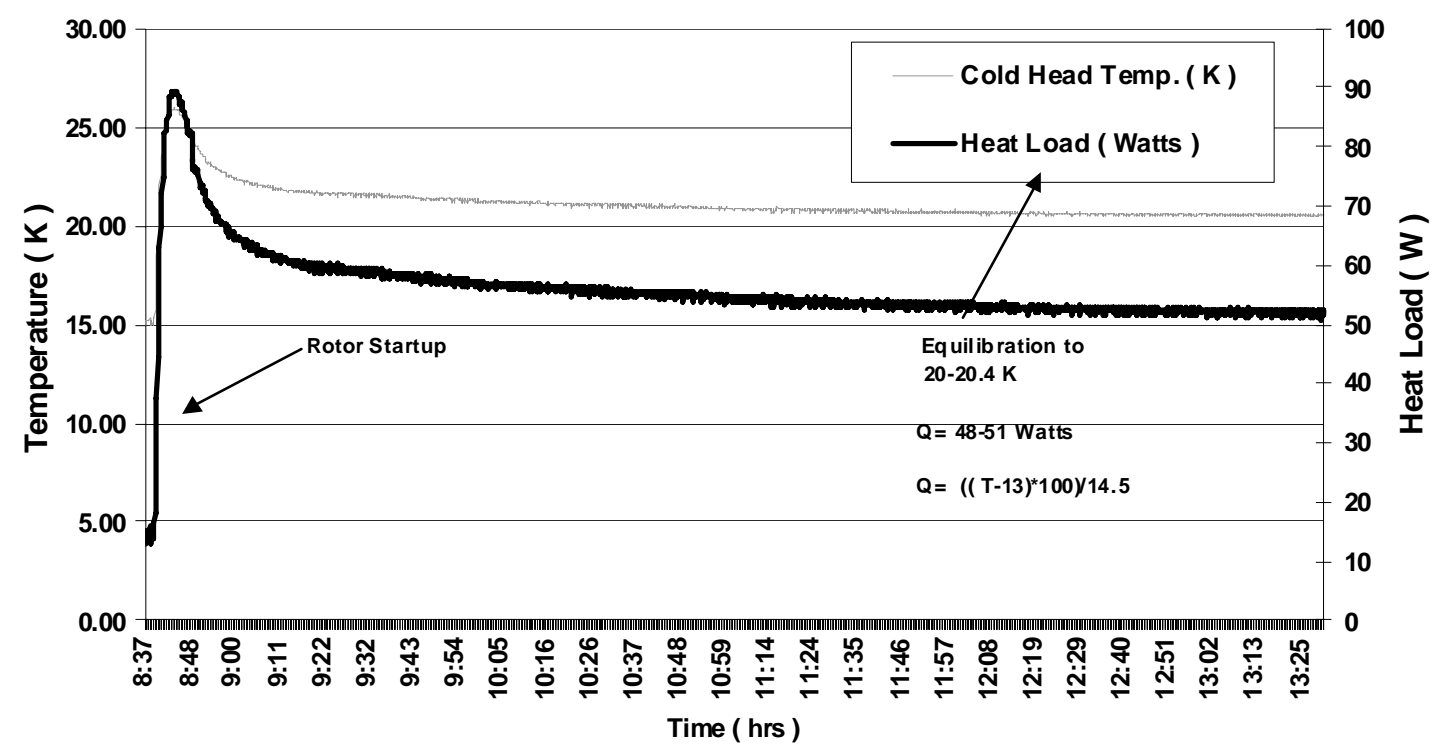

Figure 3-16 - Refrigerator Cold Head Temperature and Heat Load vs. Time at 3600 rpm 
The static heat-load profile is at first significantly low compared to predictions. After startup, it then rises well above the predicted heat load of $38 \mathrm{~W}$ and then equilibrates just above $50 \mathrm{~W}$ at $3600 \mathrm{rpm}$. The data presented in the figure was obtained without excitation on the generator. Therefore, there is no uncertainty associated with AC losses. The source of the behavior is two parts:

1) At standstill, there is a high contact resistance between the cold coil and the coil support structure. The coil is essentially being held at only a few point contact locations along the coil that represent high thermal resistances in series with portions of the conduction and radiation heat loads. As the coil spins up to $3600 \mathrm{rpm}$, centripetal forces push the coil tightly into the support structure. Now, the contact resistance is greatly reduced and the equilibrium heat loads are higher. The coil temperature overshoot results from the fact that as the rotor spins up, the thermal resistance drops and heat must be removed to cool the coil support structure to a lower equilibrium temperature. The engineering changes required to correct this behavior are now known and easily implemented.

2) The second anomaly is thermal equilibration at $3600 \mathrm{rpm}$ with a higher than predicted heat load. Predicted heat loads for the given test condition were $38 \mathrm{~W}$. The actual heat load was $52 \mathrm{~W}$. Initially, the $14 \mathrm{~W}$ difference was attributed to higher than anticipated radiation heat loads. This was thought to be due to higher than anticipated surface emissivity. Laboratory measurements of the emissivity of selected surfaces confirmed the $38 \mathrm{~W}$ initial prediction. After the successful completion of testing, the rotor was disassembled and inspected. At that time, the source of the additional heat load was clearly revealed. At $3600 \mathrm{rpm}$, the coil had shifted position slightly allowing portions of the cold coil support structure to contact the warm rotor body. This resulted in a contact heat load of $14 \mathrm{~W}$. The coil support system will be modified slightly on future designs in order to eliminate this possible mode of coil movement.

The heat load to the rotor was measured by recording the GM cold-head temperature and comparing it the to the previously measured load line or temperature vs. heat load characteristic for the refrigerator. The equilibrium temperature of the rotor was recorded for a period of at least one month. The data, shown in Figure 3-17, indicate that there is no significant change in the rotor total thermal load over the approximately one month period it was measured. The implication is over that period there was no significant emissivity degradation. If it did occur, it happened very soon after cool down and stabilized at an acceptably low level. 


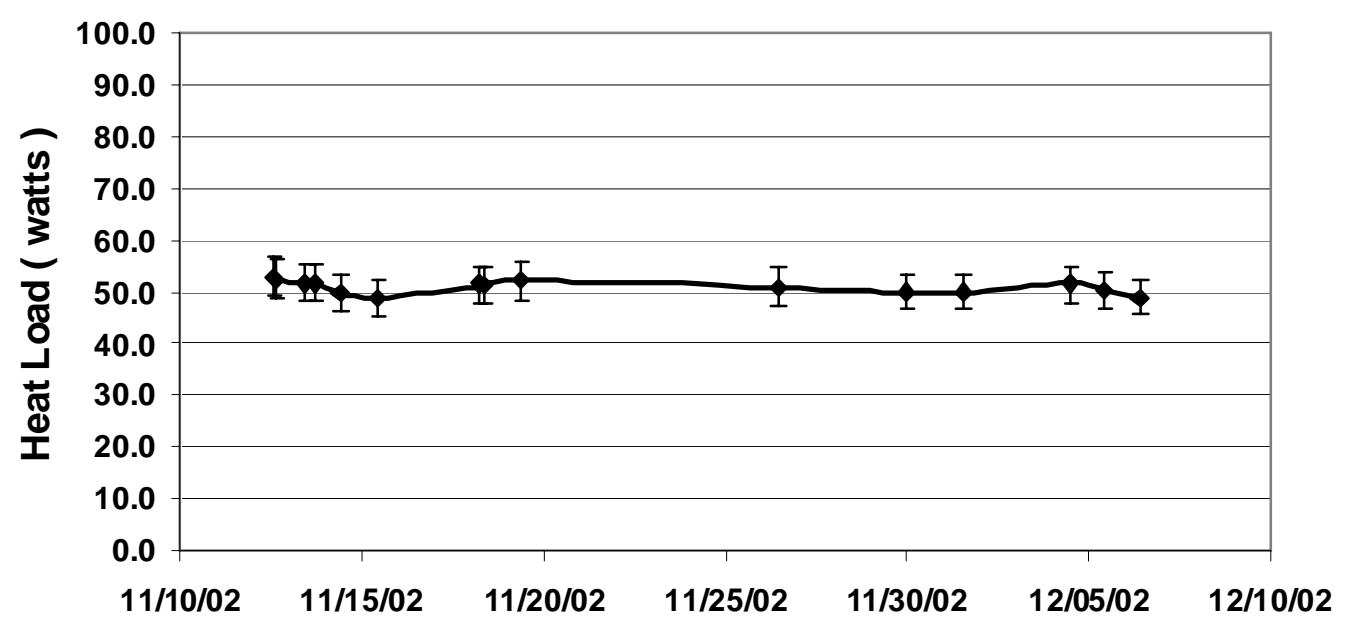

Figure 3-17 - Rotor Dynamic Heat Load vs. Time

\subsubsection{Coil Support Subsystem}

The functional requirements of the coil support system are:

- Control coil strain

- Maintain structural integrity at over-speed

- Transmit torque due to rated load

- Transmit torque due to transient events

- Maintain adequate low cycle fatigue (LCF) life for stresses due to thermal loads and centrifugal loads

- Maintain adequate high cycle fatigue (HCF) life for stresses due to support system vibration

- Minimize heat load to the coil

The strain limits of the HTS wire and manufacturing simplicity dictate that the coil be formed in a simple racetrack configuration. Early tradeoff studies were performed to evaluate several coil support concepts. In order to minimize heat load and hence minimize refrigeration system size and cost the single coil cold support concept was selected. In this concept the through stud, which is at the coil temperature, takes the large centrifugal loads. In this way the centrifugal loads do not have to pass across the thermal isolator, which, in turn allows the cross-section of the thermal isolator to be minimized thus also minimizing the heat load. The U-channel provides support around the HTS coil and transfers the coil loads to the studs by shear pins, as shown in Figure 3-18. The Uchannel geometry is determined so as to minimize its weight and deflection, which directly affect the HTS coil deflection and strain. 


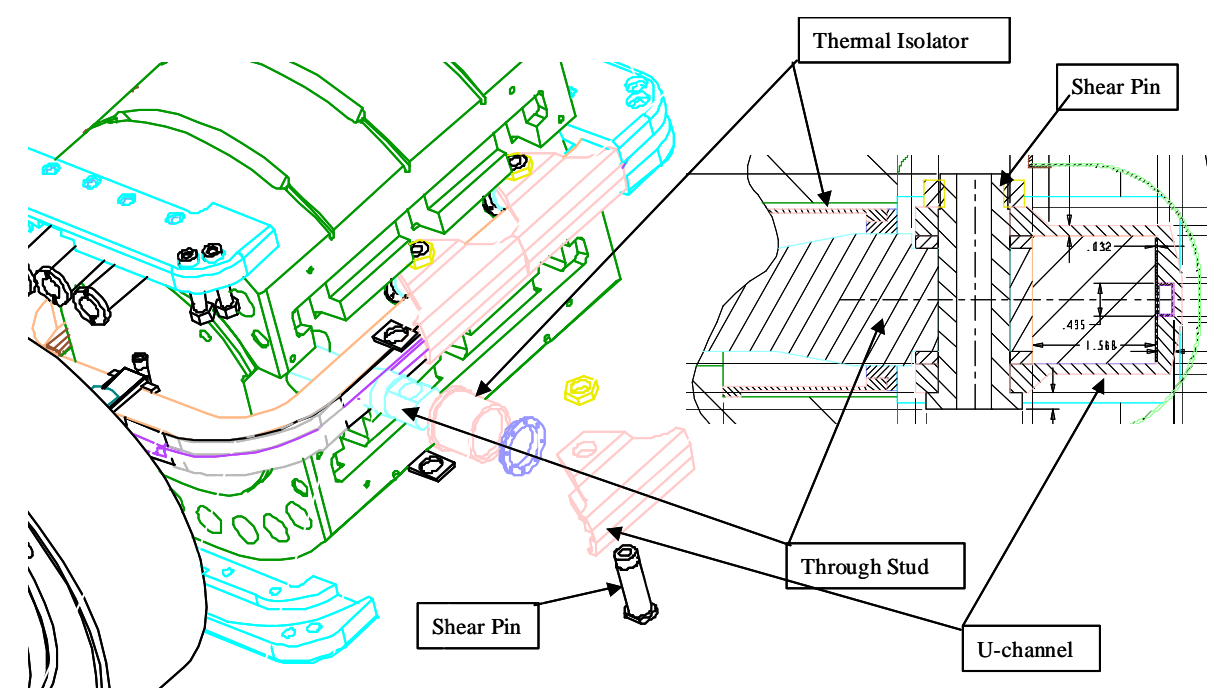

Figure 3-18 - Demonstrator Coil Support Design

The design of the thermal isolators involves balancing many conflicting design requirements. From a thermal isolation point of view, the cross-section of the isolator needs to be minimized and the length maximized to reduce heat flow into the cold mass. The isolators must accommodate the differential thermal expansion between the coil, which remains cold, and the rotor body, which heats up during operation. The volume the isolator occupies removes material for carrying magnetic flux through the rotor body.

\subsubsection{Analysis Results}

The key operating points for evaluation of the coil support structures are

- 3600 rpm when the coil and support are at room temperature. This determines a condition when the turbine-generator is being balanced before the generator has been cooled down.

- 3600 rpm when the coil and support are at cryogenic operating conditions and the magnetic pole is at operating temperature. The stress levels at this operating point determine the amount of start/stop fatigue cycles on components and transverse force on thermal isolators.

- 4500 rpm when the coil and support are at cryogenic operating conditions and the magnetic pole is at operating temperature. The stress levels at this operating point determine the over-speed low cycle fatigue performance.

A detailed FE model of the coil support system was created, as shown in Figure 3-19. The analysis at these various operating conditions is shown in Table 3-7. The operating point at which the coil experiences maximum strain is at $4500 \mathrm{rpm}$. This case is shown in Figure 3-20. 

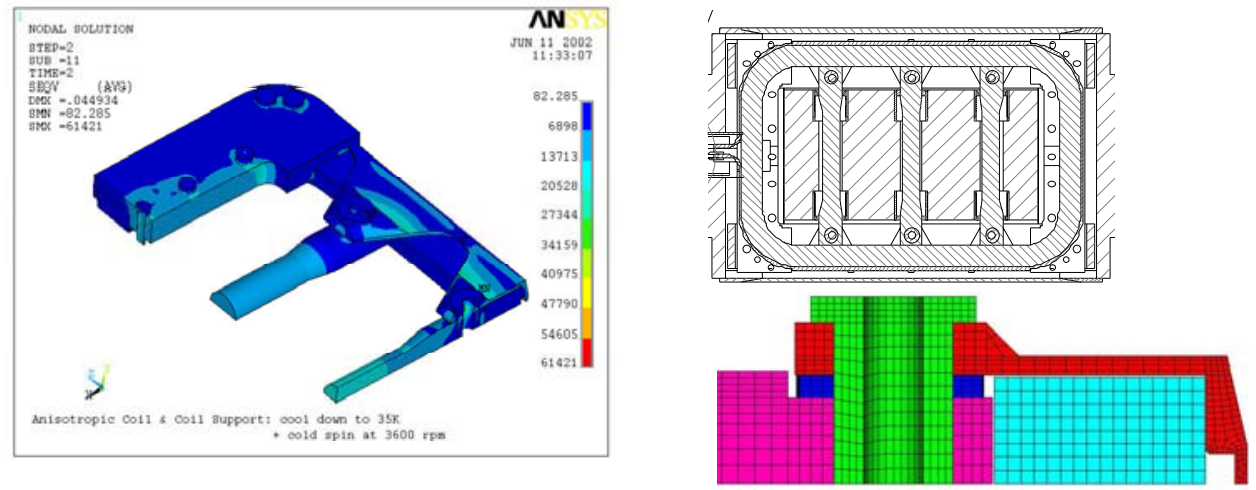

Figure 3-19 - Demonstrator Coil Support Finite Element Model

Table 3-7 - Summary of Coil Support Stress \& Strain Levels

\begin{tabular}{lc}
\hline \multicolumn{1}{c}{ Component } & Value \\
\hline HTS Coil & \\
Coil Tensile Strain (\%) & 0.13 \\
$\quad$ Coil Compressive Strain (\%) & 0.18 \\
Coil Support & \\
Start/stop (cold \& warm cycles) & 7000 \\
Overspeed (cycles) & 2000 \\
G10 Tube & 19.4 \\
$\quad$ Cold spin at rated load + \\
transverse force of 400 lbs (ksi)
\end{tabular}
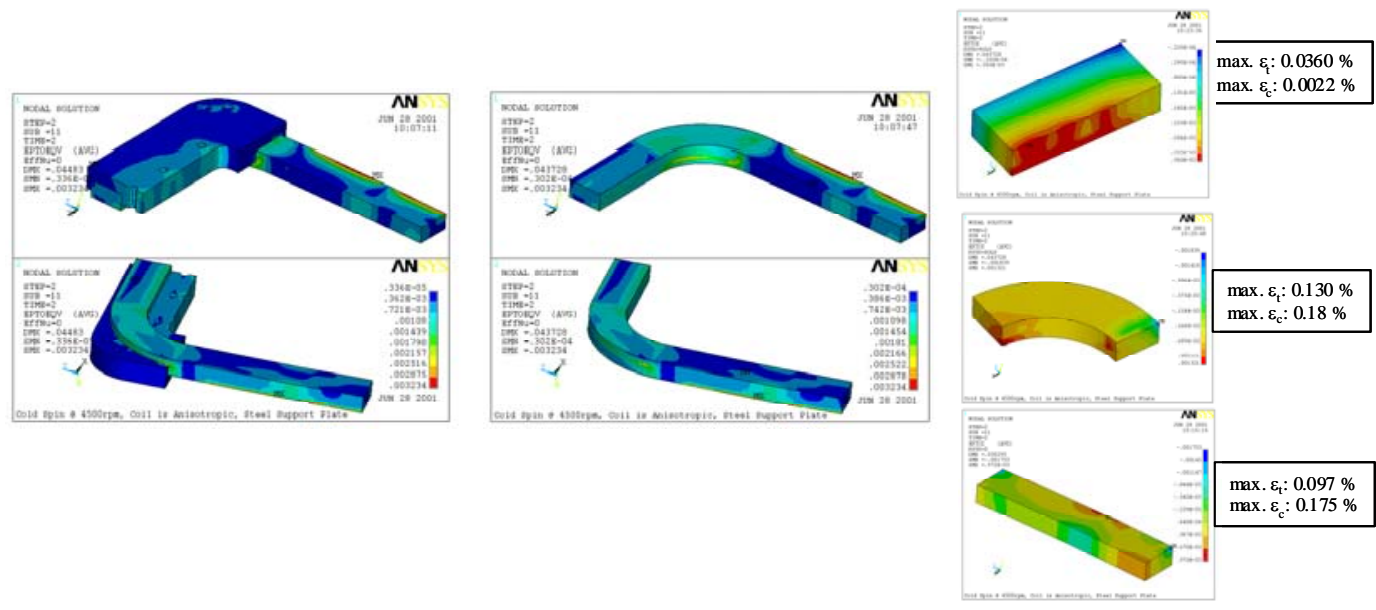

Figure 3-20 - Demonstrator Coil Strain at 4500 rpm 


\subsubsection{Demonstrator EM Shield}

The HTS generator requires an electromagnetic shield and a vacuum enclosure. Table 3-8 lists key functions that the vacuum enclosure/EM shield must perform. The generator designers can choose to combine these two functions into a single assembly or use separate assemblies. The EM shield isolates the HTS coil from AC magnetic field components. The vacuum enclosure provides an insulating vacuum enclosure for the cryogenic system components. See Section 3.5.4 for discussion of the vacuum environment.

Changing external magnetic fields induce currents in the rotor via induction. These currents act to oppose or cancel the initial magnetic field AC component. As such, the shield isolates, in part, the rotor field coil from transient force components and also limits heating within the coil.

During fault conditions large currents and corresponding forces are imposed on the EM shield. The forces are such that they produce a large deceleration torque on the shield as well as high crushing pressures. The shield acts to reduce the fault current loads delivered to the coil.

The currents induced in the EM shield also produce joule heating, which may result in a high temperature rise of the shield and consequently a differential thermal expansion of the shield relative to the rotor. The supporting structure of the EM shield must have sufficient strength and stiffness to transmit the deceleration torque but also have sufficient compliance to accommodate any relative thermal expansion between the EM shield and the rotor shaft.

Table 3-8 - Vacuum Enclosure/EM Shield Functions

\begin{tabular}{cl}
\hline Design Requirement & \multicolumn{1}{c}{ Comments } \\
\hline Structural Function & $\begin{array}{l}\text { Must not fail under the two dominant loads: centripetal } \\
\text { loads and fault current torques. Secondary loads include } \\
\text { vibratory loads and loads due to differential thermal } \\
\text { expansion. }\end{array}$ \\
\hline EM Shield Function & $\begin{array}{l}\text { Must surround the coil and provide close to one skin depth } \\
\text { at 60 Hz. Some reduction in this requirement may be } \\
\text { possible. }\end{array}$ \\
\hline Vacuum Function & $\begin{array}{l}\text { Must form part of vacuum enclosure. } \\
\text { No O-rings permitted. } \\
\text { Part of system must form a weldable seal with the stub } \\
\text { shafts. }\end{array}$ \\
\hline Other Requirements & $\begin{array}{l}\text { Must be manufacturable and easy to assemble. } \\
\text { Lowest cost compatible with the above requirements. }\end{array}$ \\
\hline
\end{tabular}


The vacuum system enclosure must provide a hermetic barrier against air leakage for a period of at least five years between periods of scheduled rotor maintenance. Because of the high centripetal loads and vibrations that the shield is subjected to in service, O-ring seals are not acceptable. All sealing must be by welds.

\subsubsection{Demonstrator EM Shield Design}

The EM shielding function requires a material with high conductivity and strength, which limits the possible materials to either aluminum or chrome copper alloys. The vacuum requirement requires a material that is readily weldable to the stub shafts. The initial design approach used a central chrome copper shield cylinder with two stainless steel ends. The joint between the different sections was made by hydrogen furnace brazing. This approach was later abandoned when sample tests of the chrome copper alloy indicated creep and yielding occurred at unacceptably low stress levels.

The final design employed a 1/8-inch thick stainless steel inner liner. This liner formed the vacuum enclosure for the system and was welded at both ends to the stub shafts. A 0.43-inch thick aluminum alloy conductive shell was shrunk outside of the stainless steel vacuum enclosure fit. To avoid welds in the conductive shell the aluminum cylindrical section was spun cast and machined. The aluminum shell was then bonded with a high temperature epoxy to the inner stainless steel vacuum shell. An ANSYS analysis and subscale tests were performed to verify that the bond shear strength was sufficient to take all anticipated, dynamic and thermal loads. The arrangement is shown in Figure 3-21. The completed rotor is shown in Figure 3-22.
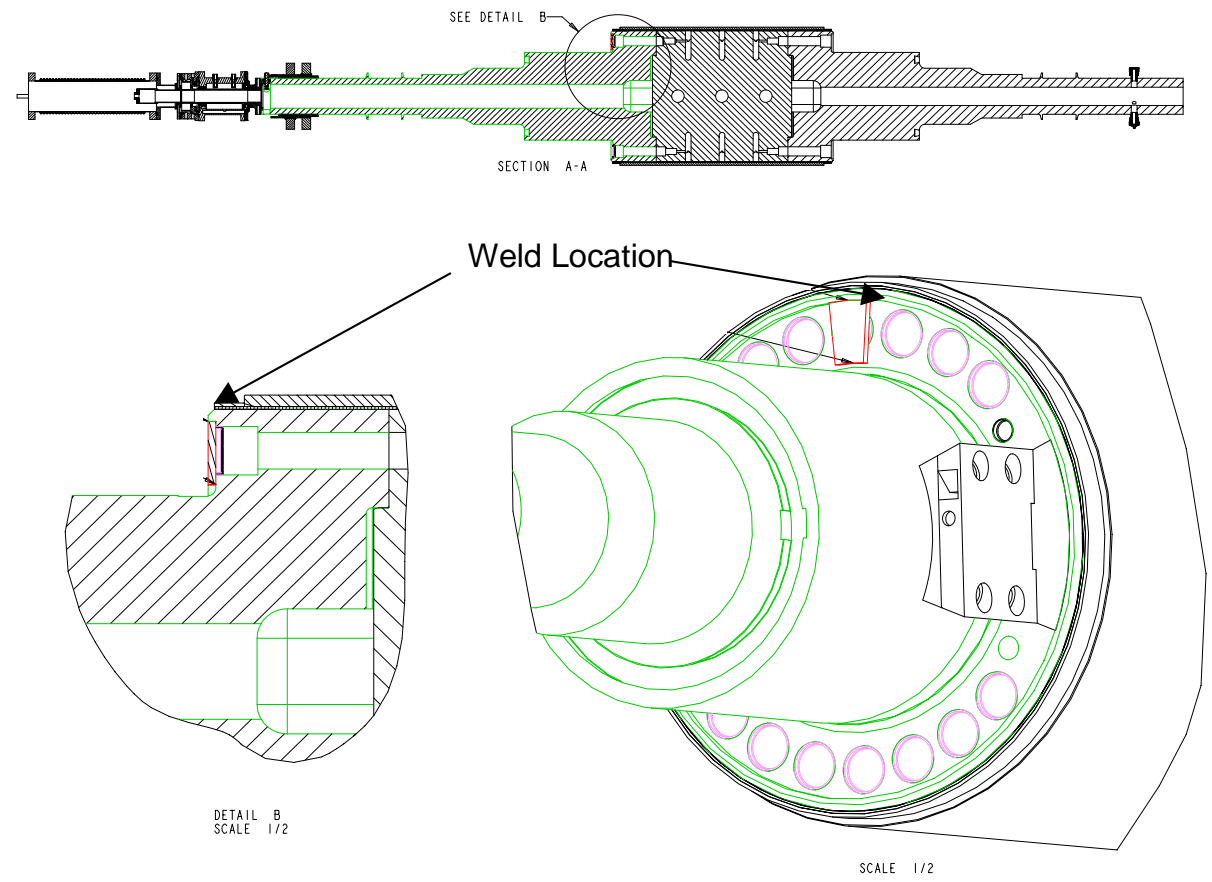

Figure 3-21 - Drawings of the Composite Aluminum and Steel Shield System 


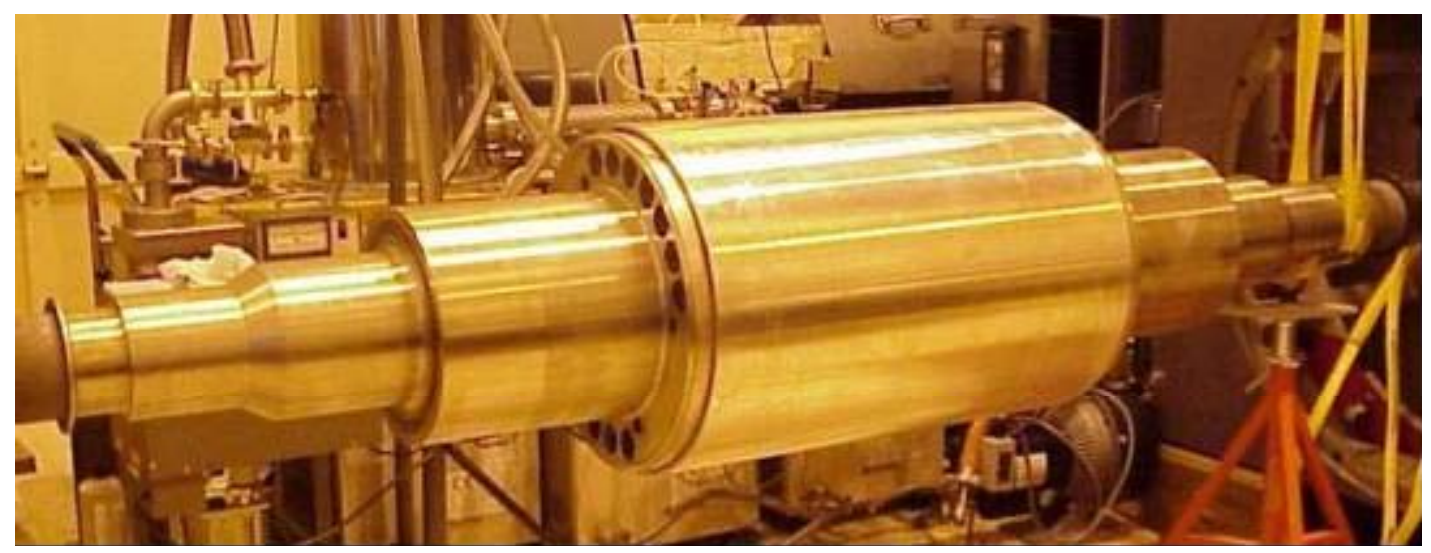

Figure 3-22 - The Demonstrator EM Shield Assembly

\subsubsection{EM Shield Force Analysis}

The two dominant load cases are the three-phase sudden short circuit tests and the steady state centripetal loads. The calculated sudden short circuit force is shown in Figure 3-23.
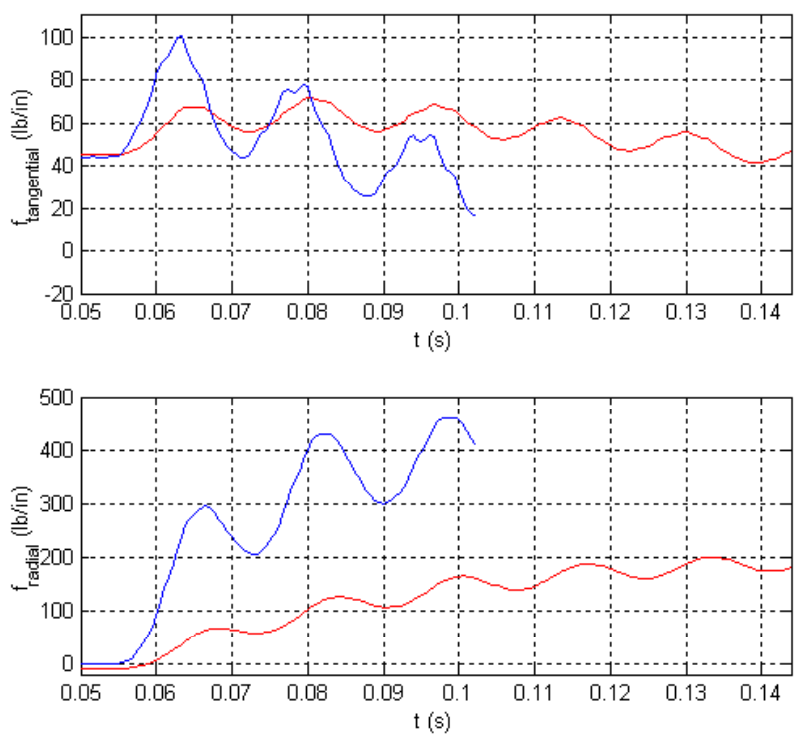

Figure 3-23 - Shield Forces (Per Unit Length) During a Three-Phase Sudden Short Circuit

\subsubsection{Vacuum System Performance}

To limit convective and conductive heat leaks, the rotor pole body and field coil are contained within a vacuum jacket. It is necessary to maintain the pressure below about $10^{-5}$ Torr over many years without requiring periodic pumpdowns. This challenge is 
made more difficult because the vacuum system has both a small volume and a large surface area to volume ratio. It is also, by necessity, filled with materials known to have high outgassing rates, such as G-10 and the epoxies used in coil fabrication.

The vacuum system of the Demonstrator underwent vacuum testing and system verification tests over the past several years. Initial cold tests of the system indicated an unacceptably high rate of pressure rise in the vacuum system. This resulted in a high parasitic heat load to the cryogenic system due to residual gas conduction.

Following this discovery, a root cause analysis, shown in Figure 3-24, was performed on the system to identify potential causes and solutions that led to three remedial steps:

- The 28 bolts connecting the stub shafts to the pole piece were drilled to eliminate any potential virtual leaks.

- The gettering system for removing hydrogen was re-activated at a higher temperature.

- The system was baked to $150 \mathrm{~F}$ help remove adsorbed gases.

These steps were taken sequentially with the result of each being recorded on the vacuum system. Some of these results are shown in Figure 3-25.

As a result, a pressure of below $10^{-5}$ Torr was achieved in the vacuum system. This was sufficient to provide the insulating vacuum required for continued testing of the rotor. The testing provided valuable lessons for the design of vacuum systems on superconducting generators. In particular, for all systems operating above $20 \mathrm{~K}$, one must pay strict attention to quantify all potential sources of hydrogen to the vacuum system. All systems need to be equipped with robust gettering systems capable of handling any anticipated hydrogen load.

An important part of Demonstrator program was to verify the effectiveness and longevity of the vacuum insulation system. The period of electrical testing from October to December of 2002 saw the first long-term operation of the rotor without periodic reconnection to the vacuum pumping system. Ideally, one would like to record the rotor internal pressure with time. Continuous direct measurement of the rotor vacuum level during this period proved impossible because of the failure of the cold cathode pressure sensors located on the rotor. An indirect measurement of the vacuum level was made, however, by recording the rotor cold head and coil temperatures as a function of time. Alternatively, the heat load to the rotor cold components could be calculated from the temperature difference between the inlet and outlet helium flows. See Figure 3-26.

The data indicates that the heat load to the rotor was approximately constant over the one-month period the rotor was cold and non-pumped. This indicated that the contribution to the heat load from residual gas conduction was small and not increasing during the test period. The small changes in the heat load shown in Figure 3-26 are the result of fluctuations in the helium circulation loop pressure or changes to the bypass valve settings of the refrigeration compressors. Periodic connection of an external ion gauge to the system indicated pressures were maintained in the $10^{-6}$ Torr range. When the 
cryogenic cooling system was turned off and the rotor was allowed to warm up it was found that the pressure rose into the $10^{-4}$ Torr range indicating that cryopumping as well as gettering was responsible for maintaining the low vacuum pressure. When the system was again re-cooled from room temperature, it was found that the getters needed to be reactivated in order for the vacuum system to be maintained without pumping. Thus far the getters have been re-activated six times and there appears to be no degradation in their performance. This is consistent with the performance specified by the getter manufacturer, which indicates that the getters may be activated many tens of times without significant degradation of their hydrogen pumping performance.

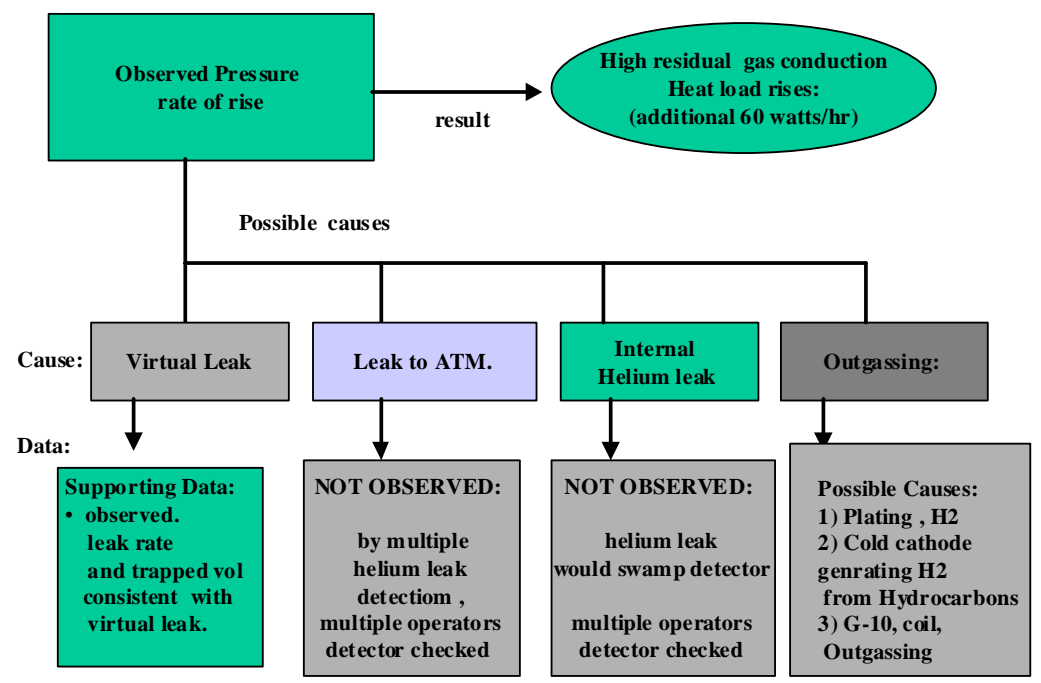

Figure 3-24 - Root Cause Analysis for Loss of Vacuum

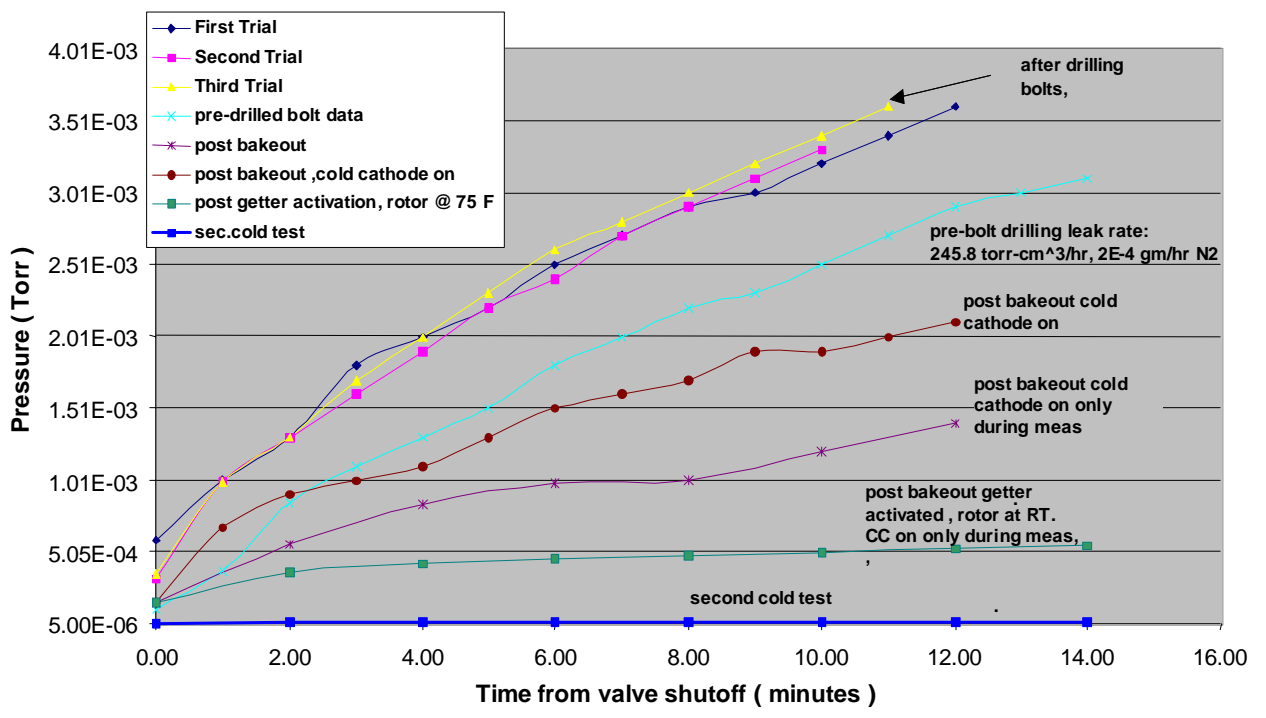

Figure 3-25 - Demonstrator Vacuum Integrity Tests 


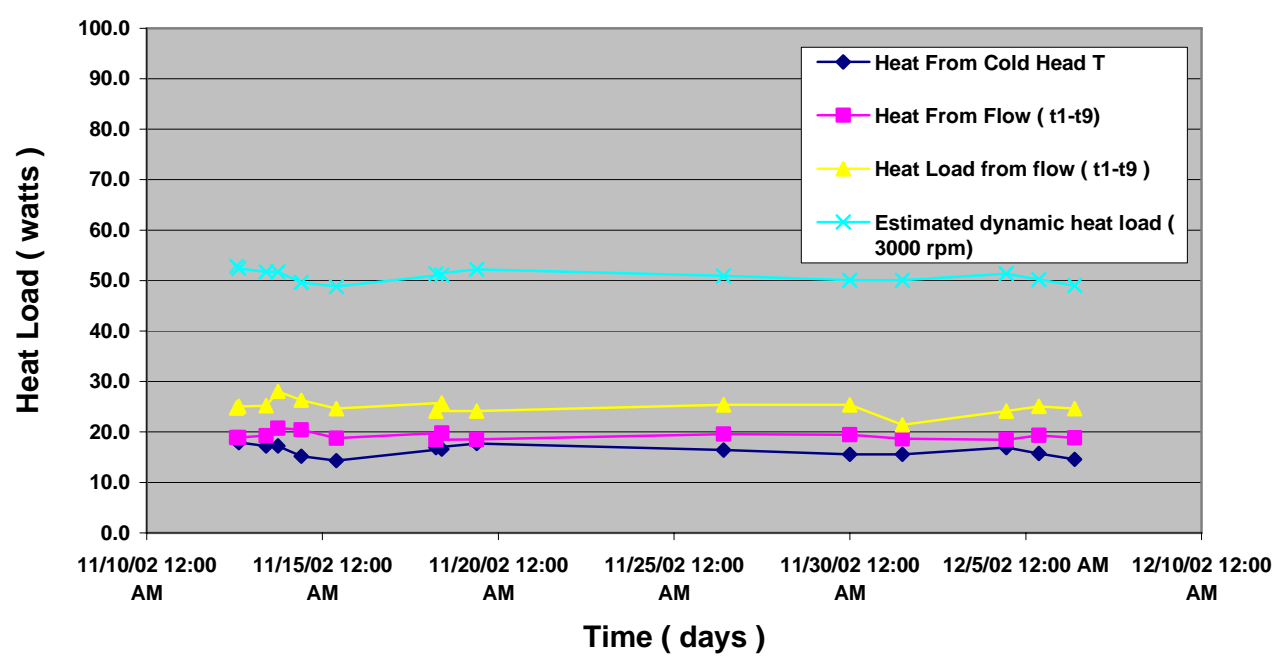

Figure 3-26 - Heat Load History on Demonstrator

\subsubsection{Vacuum Gettering System}

The vacuum system enclosure must provide a level of vacuum below $10^{-5}$ Torr for at least five years. During this period the rotor coil and suspension system are expected to be cold. These cold surfaces aid in maintaining a high vacuum in that condensable gases such as nitrogen and water vapor can be trapped both on the cold surfaces and on special packages of activated charcoal placed on the cold surfaces. Some gases like hydrogen are non-condensable at the coil operating temperature so they must be actively pumped or "gettered". The gettering system employed in the Demonstrator consisted of eight SAES ST-172 zirconium getters. These getters, shown in Figure 3-27, are activated by electrically heating them in a vacuum. After activation, the getter acts like a solid-state pump for the removal of hydrogen.

The getters are assembled into the bore of the rotor opposite the transfer coupling. Placing the units along in the bore has the benefit of reducing the centripetal loading on the assembly. The overall getter module with electric feed-through for activation is shown in Figure 3-28.

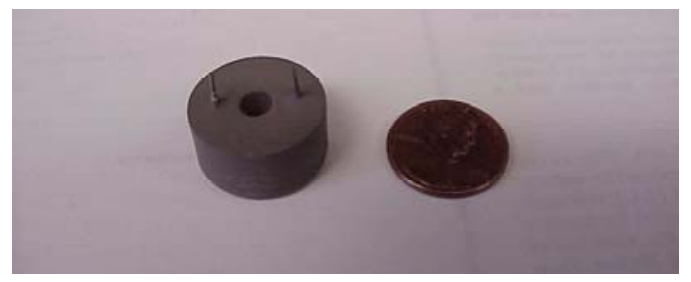

Figure 3-27 - SAES ST-172 getter unit 


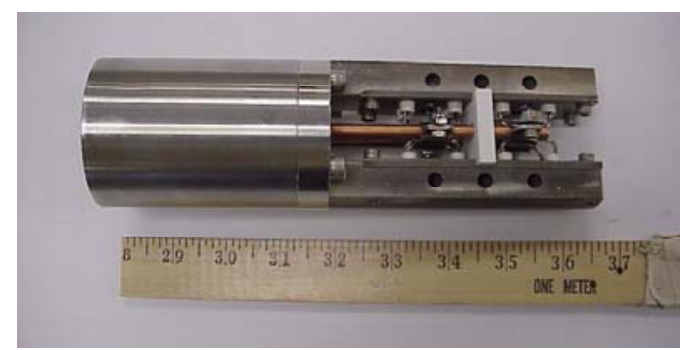

Figure 3-28 - The Getter Module Assembly for the Demonstrator

\subsubsection{Rotor Structural Design}

\subsubsection{Background and Scope}

The design for the Demonstrator involves several components that are unlike their counterparts in conventional generators. It is necessary to understand the impact of these new components on the vibration response of the generator. Some of the major new components include: a three piece shaft, the superconducting coil, bore components, cryogenic refrigeration system, vacuum enclosure, transfer coupling.

\subsubsection{Modal Analyses and Validation}

Free-free modal shape and frequency analyses on components and assemblies were performed using the XLTRC software package. This software was developed by Texas A\&M University and is an accepted rotor dynamic analysis tool. The analyses were validated using results from impact modal tests on the components and assemblies. The rotor and components were hung free with flexible slings to evaluate the free-free modes. Figure 3-29 shows the test set up for the rotor subassembly. Triaxial accelerometers and a calibrated hammer were used in the test. Acceleration data at various stations shown in Figure 3-30 were processed to evaluate mode shapes and frequencies.

A comparison of frequencies predicted through XLTRC analysis and frequencies measured during impact modal tests is given in Table 3-9. The values compare well. The measured frequencies indicate an asymmetry in the rotor bending stiffness along the vertical and horizontal axes. 


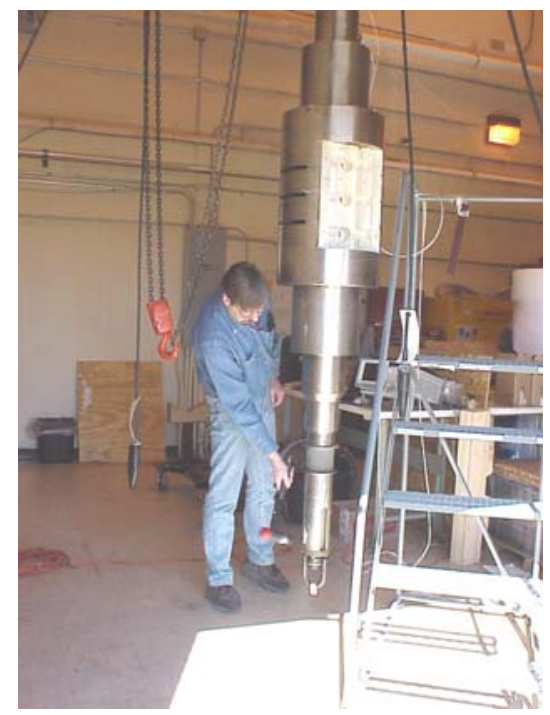

Figure 3-29 - Impact Modal Test on the Rotor Subassembly

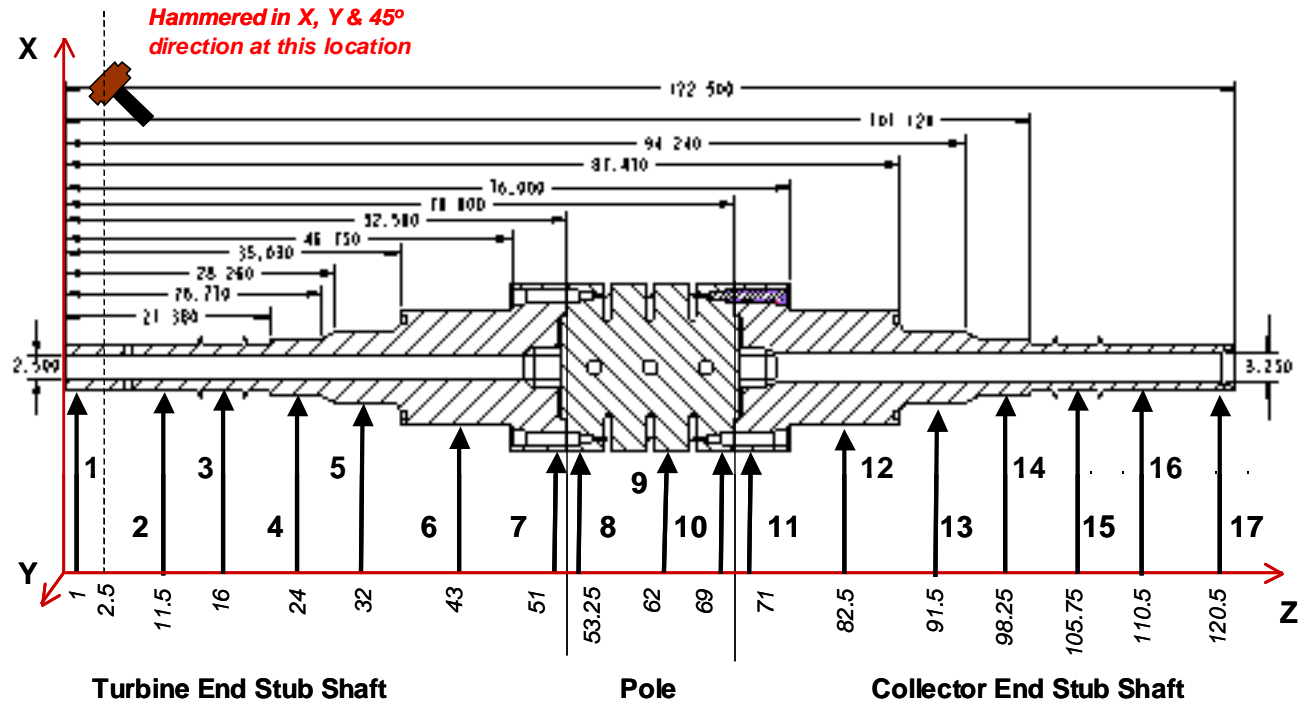

Figure 3-30 - Accelerometer Probe Locations 
Table 3-9 - Summary of Predicted and Measured Modal Frequencies for Components and Subassemblies

\begin{tabular}{cccc}
\hline $\begin{array}{c}\text { Component } / \\
\text { Assembly }\end{array}$ & Mode & $\begin{array}{c}\text { Predicted } \\
\text { Frequency (Hz) }\end{array}$ & $\begin{array}{c}\text { Measured } \\
\text { Frequency (Hz) }\end{array}$ \\
\hline \multirow{3}{*}{ CE Stub Shaft } & $1^{\text {st }}$ Bending & 305 & 297 \\
& $2^{\text {nd }}$ Bending & 1014 & 1005 \\
& $1^{\text {st }}$ Torsional & 1237 & 1140 \\
\hline \multirow{3}{*}{ TE Stub Shaft } & $1^{\text {st }}$ Bending & 310 & 290 \\
& $2^{\text {nd }}$ Bending & 1039 & 953 \\
& $1^{\text {st }}$ Torsional & 1218 & 1134 \\
\hline \multirow{2}{*}{ Shaft Assembly } & $1^{\text {st }}$ Bending & 168 & $152-170$ \\
& $2^{\text {nd }}$ Bending & 231 & $210-218$ \\
\hline \multirow{2}{*}{ Shaft Assembly } & $1^{\text {st }}$ Bending & 166 & $161-174$ \\
w/Coil & $2^{\text {nd }}$ Bending & 228 & 235 \\
& $3^{\text {rd }}$ Bending & 452 & $470-514$ \\
\hline \multirow{2}{*}{ Shaft Assembly } & $1^{\text {st }}$ Bending & 175 & $163-208$ \\
w/Coil \& Shield & $2^{\text {nd }}$ Bending & 237 & $262-264$ \\
& $3^{\text {rd }}$ Bending & 439 & $477-514$ \\
\hline
\end{tabular}

\subsubsection{Rotor Dynamic Analysis}

Rotor dynamic analyses on the Demonstrator were performed using XLTRC. The model incorporated the rotor, the electric drive motor, coupling, bearings and mechanical properties of the foundation, which had been tested earlier in the same stator. Figure 3-31 shows the rotor dynamic model developed for the entire rotor assembly. This model assumed an average moment of inertia for asymmetric sections and an effective forging diameter of 10.7 inches, based on a sag analysis. Coil and bore components were represented as equivalent masses and inertias.

\subsubsection{Critical Speeds}

A damped eigenvalue response analysis was performed on the model using XLTRC. The critical speeds and damping ratios (Q) are given in Figure 3-32. The mode shapes for the $1 \mathrm{X}$ and $2 \mathrm{X}$ frequencies are given in Figure 3-34. Some observations: $1 \mathrm{X}$ modes 1, 4, and 5 are within the range of $1 \mathrm{X}$ excitation, $1 \mathrm{X}$ modes 2 and 3 are in an unacceptable range; 
and require a more detailed analysis. Two-X modes 6-7 are within the range of $2 \mathrm{X}$ excitation, and $2 \mathrm{X}$ mode 8 is in an unacceptable region. High Q modes 2 and 3 are related to foundation resonance. Two-X modes 6 and 7 relate to transfer coupling motion. Mode 8 shows high $\mathrm{Q}$ and significant motor coupling motion.

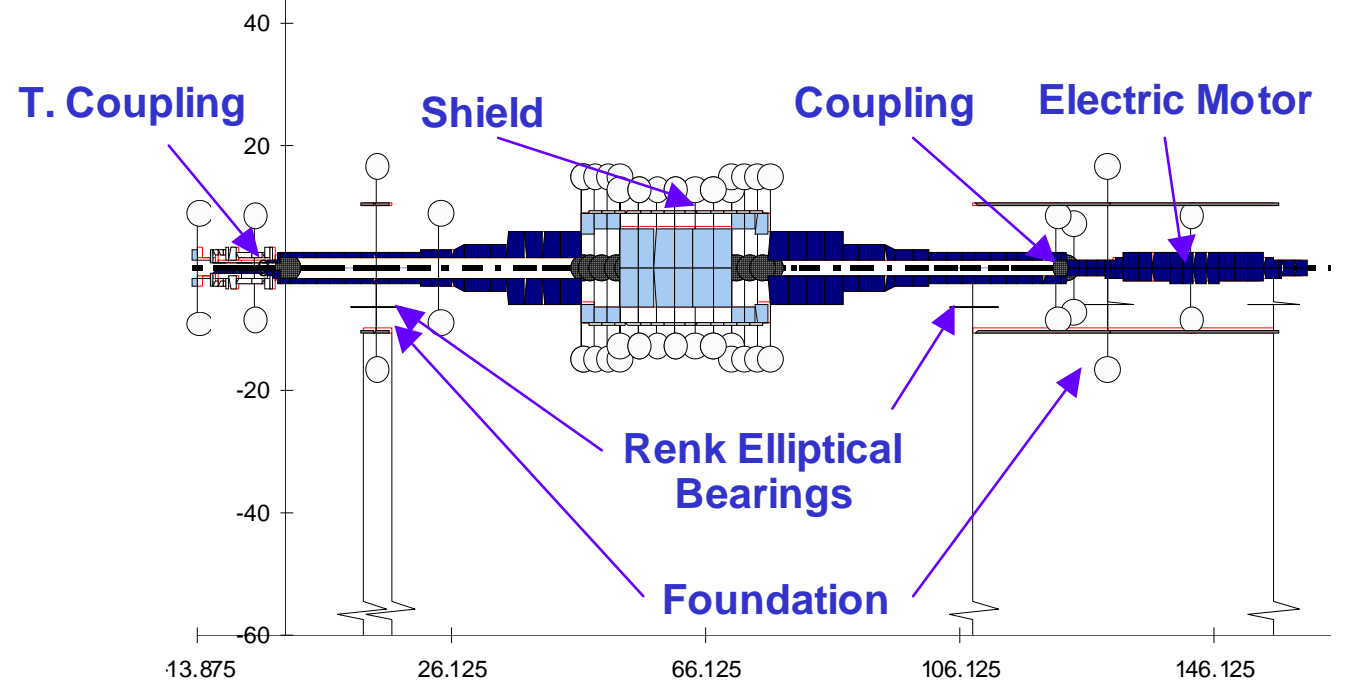

Figure 3-31 - Rotor Dynamic Model for the Rotor Assembly

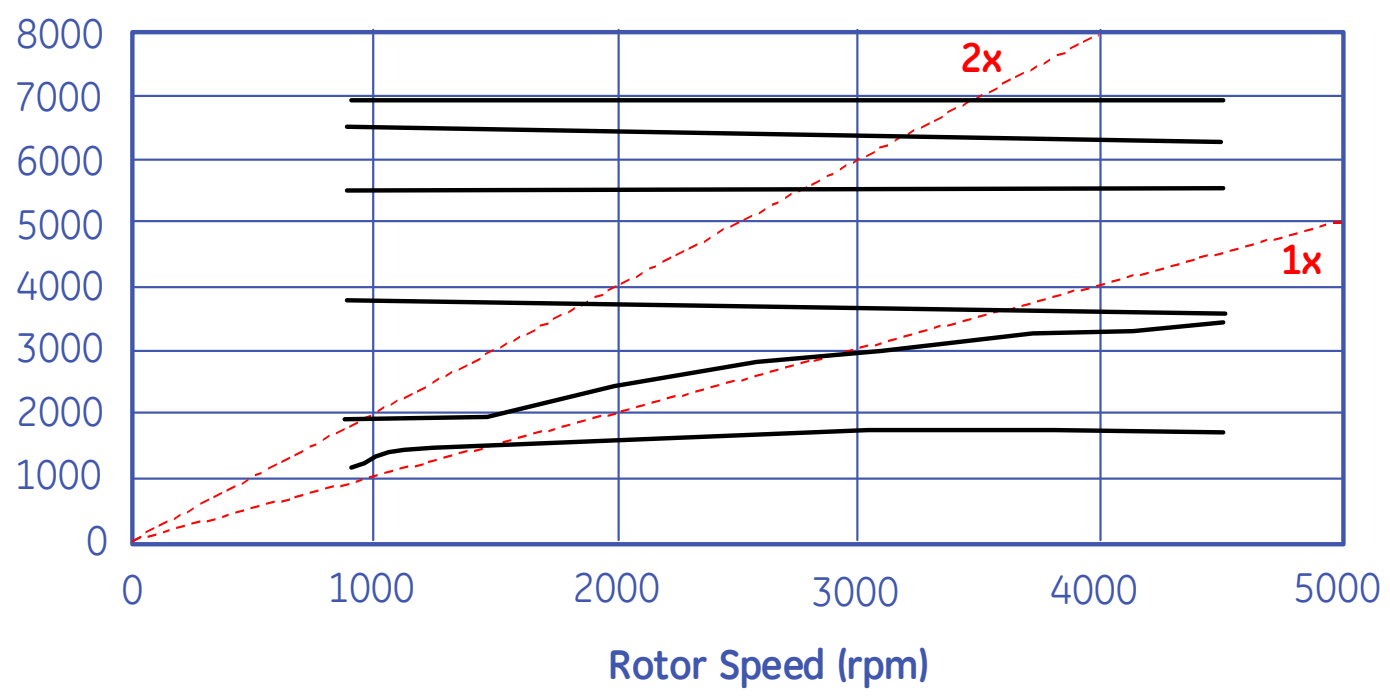

Figure 3-32 - Damped Natural Frequency Map 


\subsubsection{Torsional Rotor Dynamics}

Finite element analysis on the rotor model with coupling, shown in Figure 3-33, was performed to evaluate the torsional modes of the system. Analysis showed that the fundamental torsional frequency was $89 \mathrm{~Hz}$, which well above the operating speed.

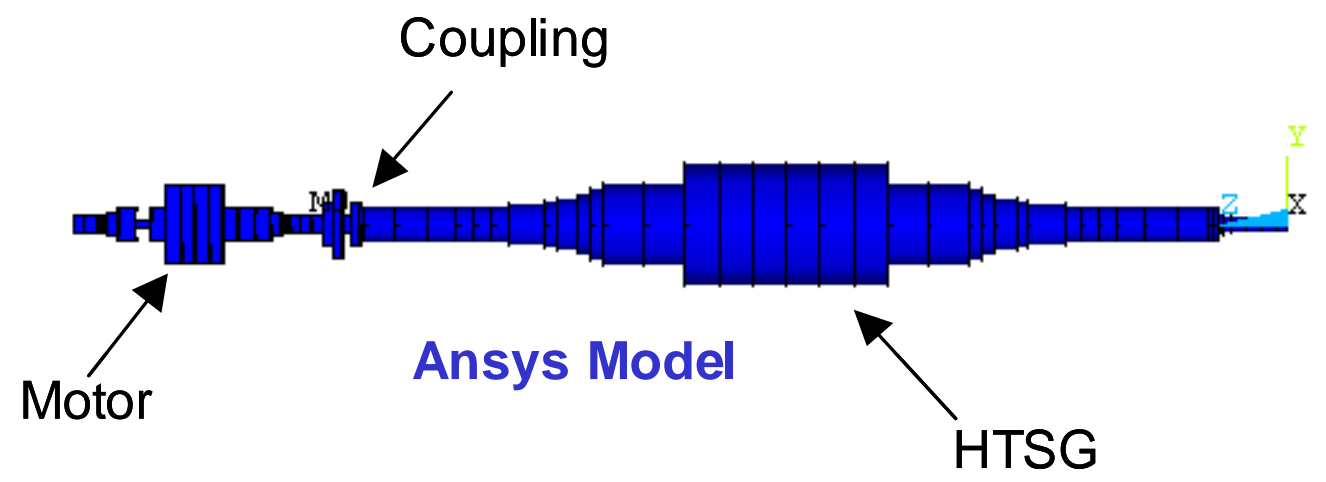

Figure 3-33 - Torsional Analysis Using ANSYS

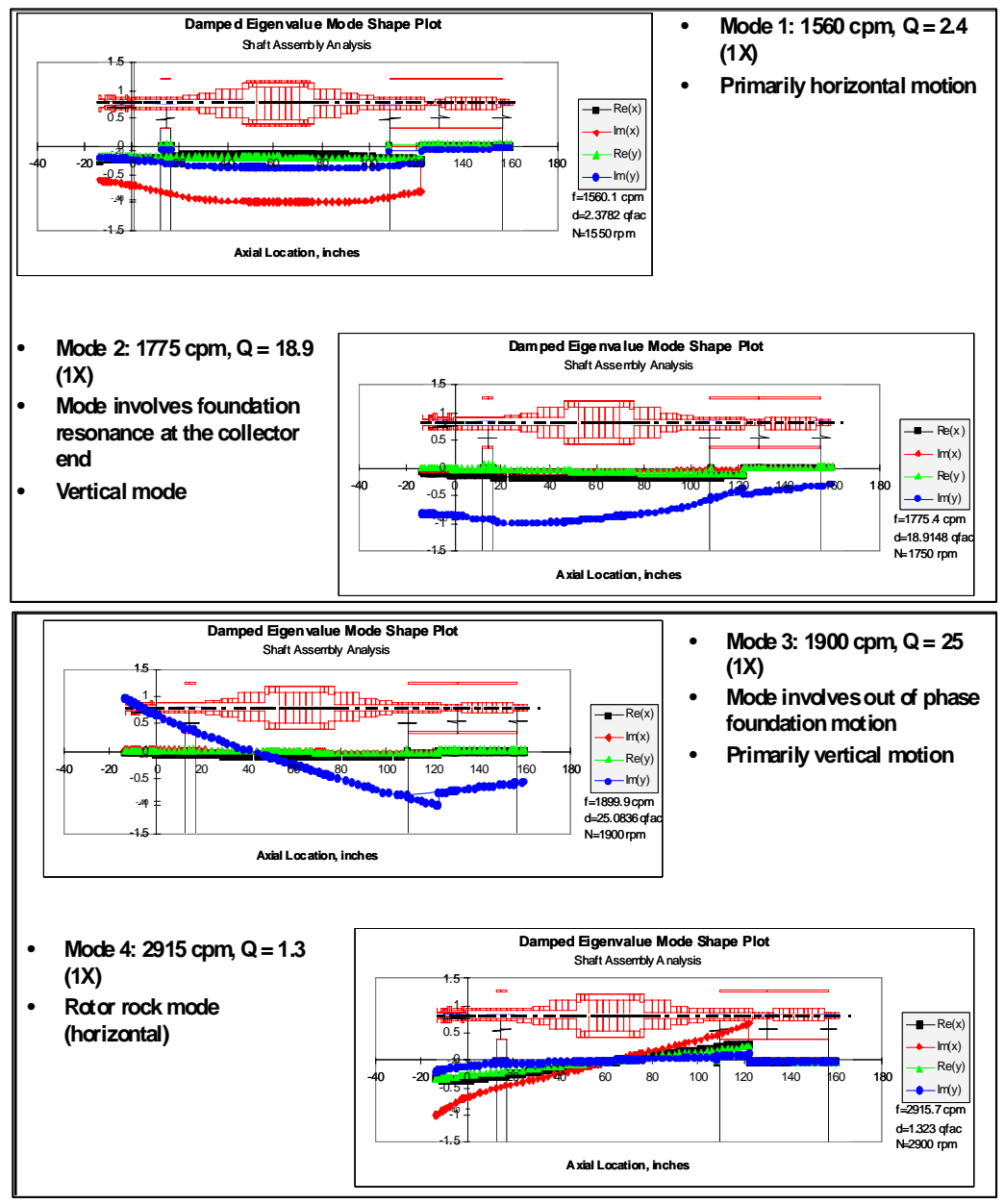

Figure 3-34a - Demonstrator Mode Shapes 1 - 4 

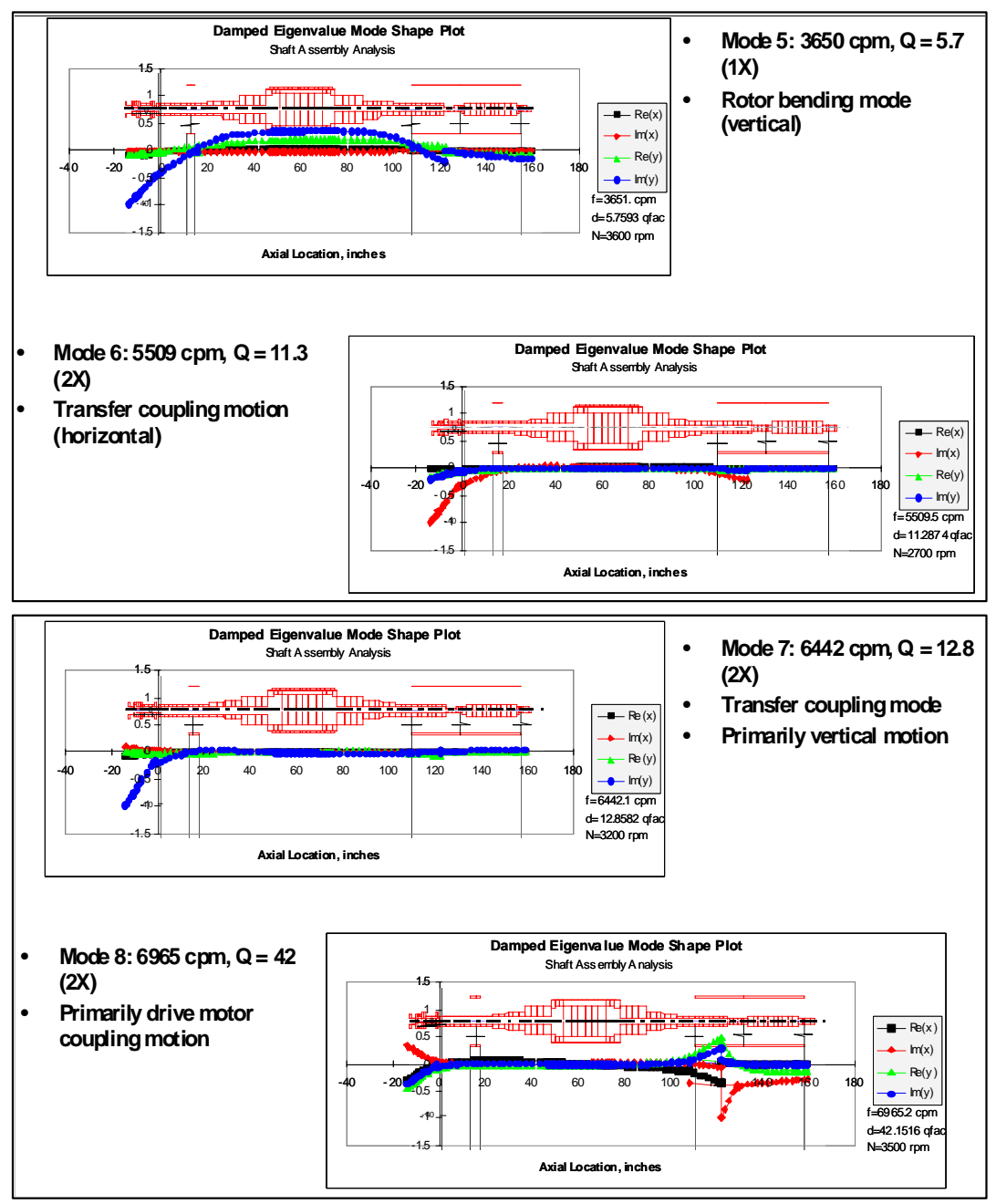

Figure 3-34b - Demonstrator Mode Shapes 5 - 8

\subsubsection{Mechanical Tests of Rotor}

The primary objective of testing the Demonstrator rotor was to demonstrate and understand the mechanical, electrical, and thermal performance of the HTS rotor system. There are several components in the HTS rotor system that are different than conventional generators, namely: a three piece shaft, the superconducting coil, bore components, the cryogenic refrigeration system, the vacuum enclosure, and the transfer coupling. The Demonstrator test program addressed the response of these new subsystems to mechanical, electrical, and thermal loads. The mechanical test objectives are to understand vibration characteristics, balance response, mechanical integrity and over speed performance of the system. 


\section{Rotor Balancing}

The rotor was balanced warm at low speed (600 rpm) in a balance bunker at GE's Albany, NY Service Shop in order to reduce rigid body unbalance in the system. The rotor was then installed in the stator and the HTS coil was cooled down to $35^{\circ} \mathrm{K}$. The balance procedure has following steps:

- Rotor cool down to $40 \mathrm{~K}$

- Rotor alignment using laser alignment tools

- Run the rotor at $200 \pm 10 \mathrm{rpm}$ and record slow roll vibration (runout)

- Increase rotor speed by $600 \pm 10 \mathrm{rpm}$ until the compensated vibration response reaches allowable value

- Execute balancing procedure

- Measure critical current / I-V performance

- Repeat steps 3-5 until reaching max speed of 3600 rpm

- Trim balance for overhang vibration at the two additional balance planes near couplings

Two major and two trim balance planes were used to balance the rotor. Proximity probes in conjunction with ADRE viewing system were used to monitor and record vibration performance of the rotor.

\section{Vibration Performance}

The rotor was balanced to $3000 \mathrm{rpm}$ without any major issues. Three balance planes, two on the rotor Drive End (DE) and Collector End (CE) and one plane on the Drive End Coupling (DEC) were used for balancing the machine. The rotor was then attempted to ramp up to $3600 \mathrm{rpm}$, at which point significant change in vibration (phase and amplitude) was observed (Figure 3-35).

A root cause analysis of this event determined that the coil and coil support system had shifted slightly at the higher speed. After the $3550 \mathrm{rpm}$ vibration shift event, it was decided to rebalance to rotor and continue all testing at $3000 \mathrm{rpm}$ and lower. 

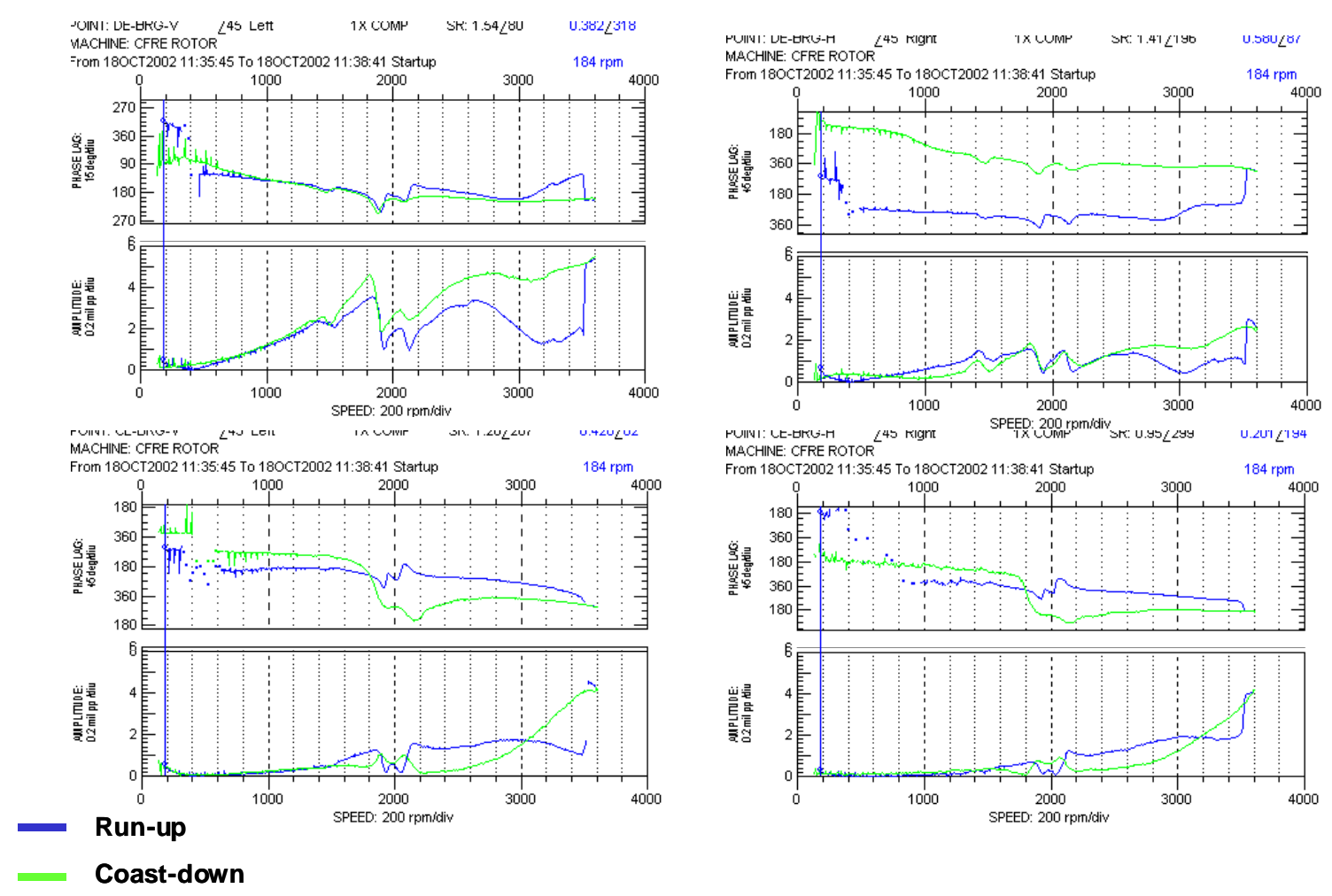

Figure 3-35 - Vibration Change at 3600 rpm

\subsection{Demonstrator Refrigeration System}

The refrigeration system for the Demonstrator was developed with the following objectives:

- High-performance cooling system, and

- Form a partnership with an established cryorefrigerator manufacturer.

The specific goals were: 100 watts cooling with the rotor-outlet gas temperature less than 40 Kelvin, a refrigeration cost below $\$ 100,000$, and mean time between failure (MTBF) of five years. This heat load was over twice what was expected for the Demonstrator (39 watts).

A closed-cycle Gifford-McMahon (GM) refrigerator was selected to provide the cooling power. A single-phase gas system was chosen using helium as the working fluid. The decision to use with this method of cooling rather than a closed-cycle Brayton or Sterling Cycle was motivated, in part, by the large body of operational data accrued by GEHealthcare with GM-type refrigerators in their magnetic resonance imaging (MRI) magnets. Sumitomo Heavy Industries Ltd. (SHI) was selected to design and build the system. SHI had the benefit of a having a large, well-developed distribution system. As a supplier to GE-Healthcare, reliability data would come from a large data set. The 
refrigerators themselves would also have the benefit of a mature, evolved design, made possible through years of experience and product evolution.

Providing the required gaseous-helium mass flow at cryogenic temperatures presented some challenges. Several design options were available, each with their own plusses and minuses. One approach was to bring the entire flow back up to ambient temperature through a counterflow heat exchanger, pump it with a fan or compressor, and return it via the heat exchanger back to low temperatures. The benefit would be that the pumping could be done with a low cost, highly reliable "off-the-shelf” compressor.

The negative aspect is that an additional low temperature thermal load is imposed as a result of the limited heat exchanger efficiency. For example, even with a 98 percent effective heat exchanger operating between 300 and $30 \mathrm{~K}$ there is imposed an additional $57 \mathrm{~W}$ to the refrigerator heat load. An alternative approach is to do all pumping at low temperatures. Sealed gas bearing, magnetic drive, centripetal blowers were investigated, but they are expensive and their reliability has not been established from a large database. The approach selected by SHI was a compromise approach. In the bypass approach, only a fraction of the main helium flow is pumped at room temperature, thereby limiting the parasitic heat exchanger losses. This high-pressure bypass flow drives an ejector pump on the low-temperature side of the flow circuit. The ejector has the benefit of both low cost and no moving parts.

The proposed Demonstrator refrigeration system included a large GM with two supporting helium compressors. In addition, it included another identical compressor and separate helium circuit to circulate cold gaseous helium through the generator rotor. A two-stage, 98\%-efficient heat exchanger and an ejector were included in the circulation loop to minimize the heat load associated with the helium being compressed at room temperature. The cold components were housed within the "cold box". The cold box is a thermos-bottle type vacuum chamber. The resulting system is shown in Figure 3-36 and Figure 3-37.

In addition to the equipment shown in the figures, the refrigeration system required a source of continuous cooling water for the compressors, a helium buffer tank to absorb circulation-circuit transients during rotor cool-down and warm-up, and a vacuum pump for initial setup.

The system employed was operated remotely by a computer display interface. Throughout the Demonstrator test period, the refrigeration system performed quite well.

The refrigeration system was tested at SHI's factory before shipment and further tested with a variable heat load at GE and finally with the Demonstrator rotor. 


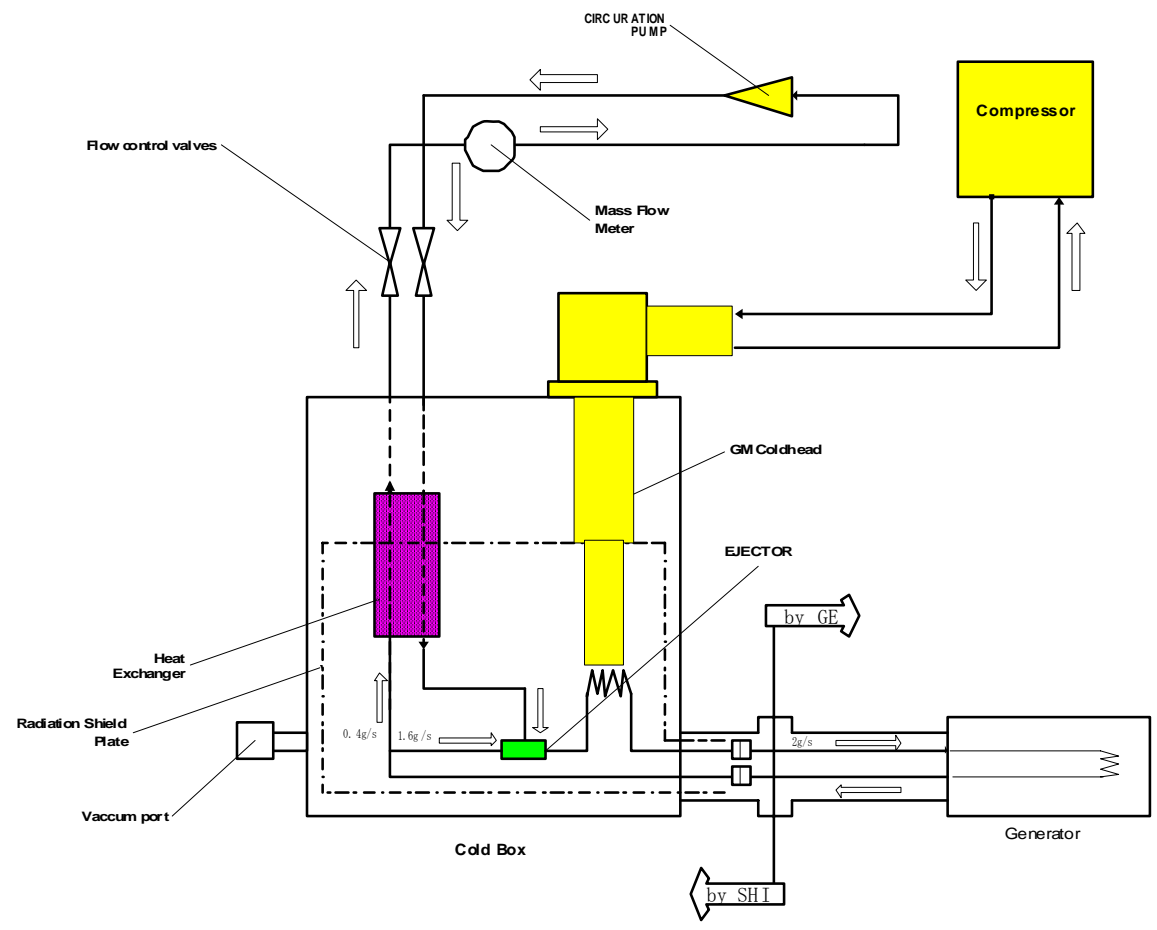

Figure 3-36 - Functional Diagram of the SHI Refrigeration System for the Demonstrator

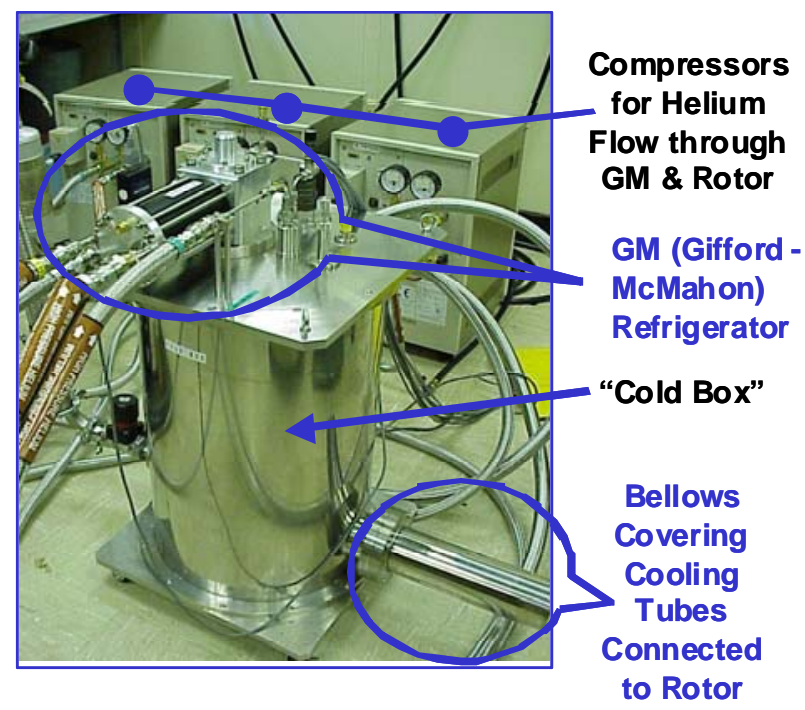

Figure 3-37 - SHI Refrigeration System for the Demonstrator 


\subsection{Transfer Coupling}

The helium transfer coupling connects the rotating generator components to the stationary cryogenic cooling system. The coupling used for the Demonstrator was designed to meet the following major requirements:

- Gaseous helium at $30 \mathrm{~K}$ must be transferred from the cooling system to the rotor with a minimum rise in temperature of the helium and pressure drop.

- Operate continuously for two years without servicing and with high reliability.

- The natural vibration modes of the transfer coupling must not be located near multiples of the operating frequency $(60 \mathrm{~Hz})$.

Figure 3-38 presents the coupling design for the Demonstrator.

In the design, the cold helium from the cooling system flows through the stationary bayonet into the rotor and returns through a rotating outer tube. A cold close clearance carbon seal prevents leakage between the inlet and outlet flows and a Ferro-fluidic seal prevents helium leakage out of the system. The stationary housing is supported from the rotating shaft by two precision ball bearings and the rotating shaft is mounted to the rotor shaft. Two prototype couplings have been fabricated and one tested on a simulated rotor test stand. The thermal performance of the coupling matched the analytical design predictions closely with a total heat leak of $23 \mathrm{~W}$.
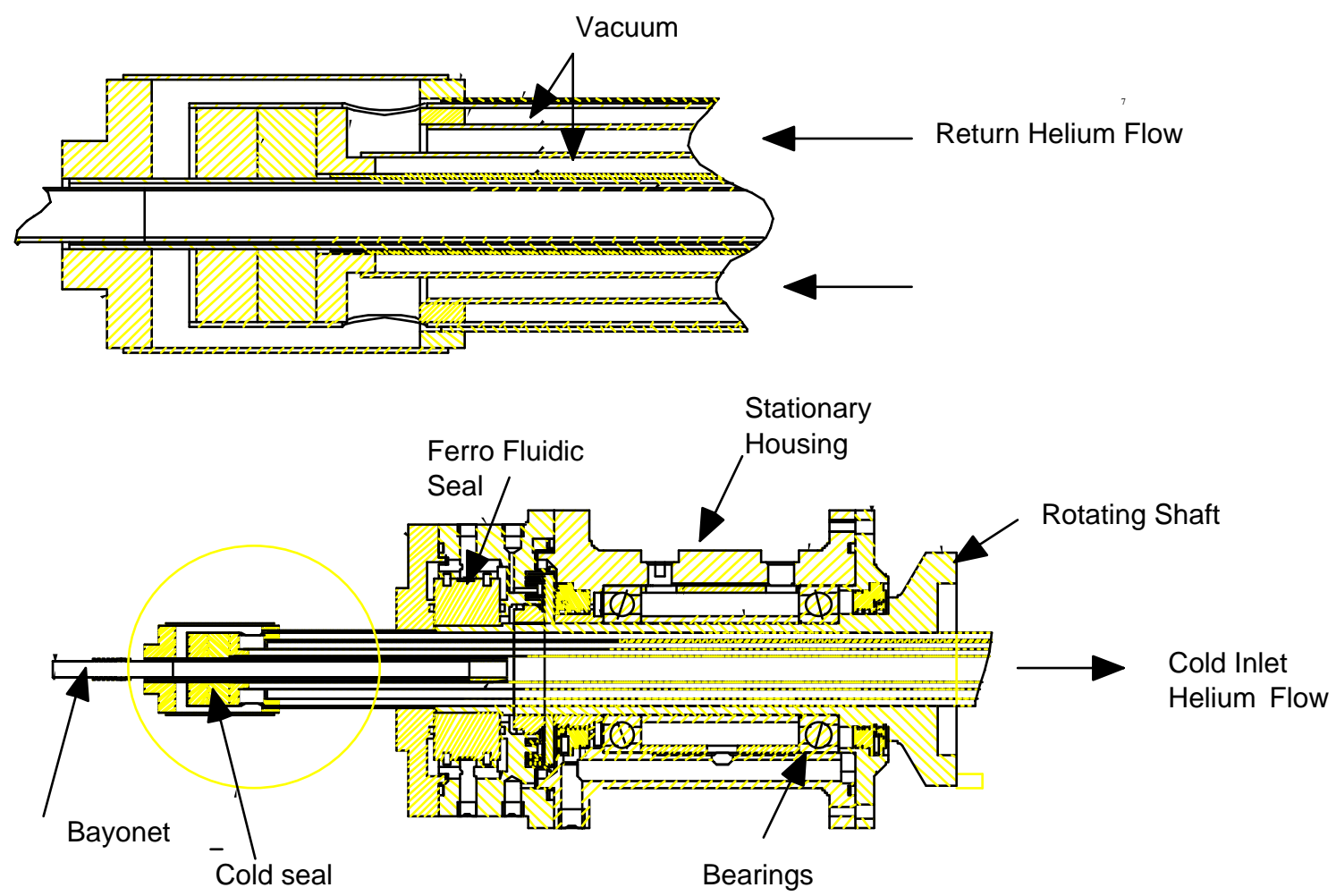

Figure 3-38 - Demonstrator Transfer Coupling 


\section{Technology Development}

Task 2 of the HTS program was to develop technology that would be needed for a 100 MVA HTS generator. The tests on the Demonstrator showed that the warm iron rotor concept is feasible and that it is likely that such as rotor concept can be scaled to a size needed for a 100 MVA commercial generator.

\subsection{Refrigeration Development}

\subsubsection{Gifford McMahon}

The original intent was that the refrigeration system purchased for the Demonstrator would be adequate for the 100 MVA prototype as well. As the program progressed, however, the Demonstrator unit was determined to have inadequate cooling capacity and reliability for service in a commercial utility generator.

The Demonstrator refrigerator provided 100 watts of cooling with a rotor-outlet helium gas temperature of nearly 45K. Following the Demonstrator tests, the HTS coil design and operating point were revised, and consequently the upper specification limit (USL) for the continuous coil temperature and consequently the continuous, rotor-outlet gas temperature were reduced to $30 \mathrm{~K}$. Lowering the coil temperature also increased the heat transferred to the coil by radiation, so the lower specification limit (LSL) for the refrigerator cooling load was increased to 150 watts.

In addition, a reliability analysis of the refrigeration system, using data from SHI and GEHealthcare, concluded that it was necessary to perform GM maintenance with the refrigeration system on-line and to add some form of redundant cooling to keep the coil below $30 \mathrm{~K}$ during planned and unplanned maintenance.

These changes had a compounding effect on the refrigerator duty, which meant adding more GMs, as well as increased complexity and cost to the system. The resulting system schematic from SHI is shown in Figure 4-1, including both a redundant GM and extra thermal mass (cold storage).

An evaluation of the reliability of this system indicates that a system MTBF of 60,000 hours is feasible with a backup cryocooler, backup circulation compressor, cryocooler sleeves, and thermal storage in the system.

The estimated heat load was further refined based on updated geometry of coil and coil supports plus emissivity measurements from both LANL and ORNL. It was calibrated with the test results of the Demonstrator. The largest contributor was from radiation. The calculated mean heat load of 198 watts meant the required number of GMs would be greater than the six in the system being designed by SHI unless the cooling capacity of the GMs could be increased, the helium circulation rate could be increased, or the coil temperature could be increased. 


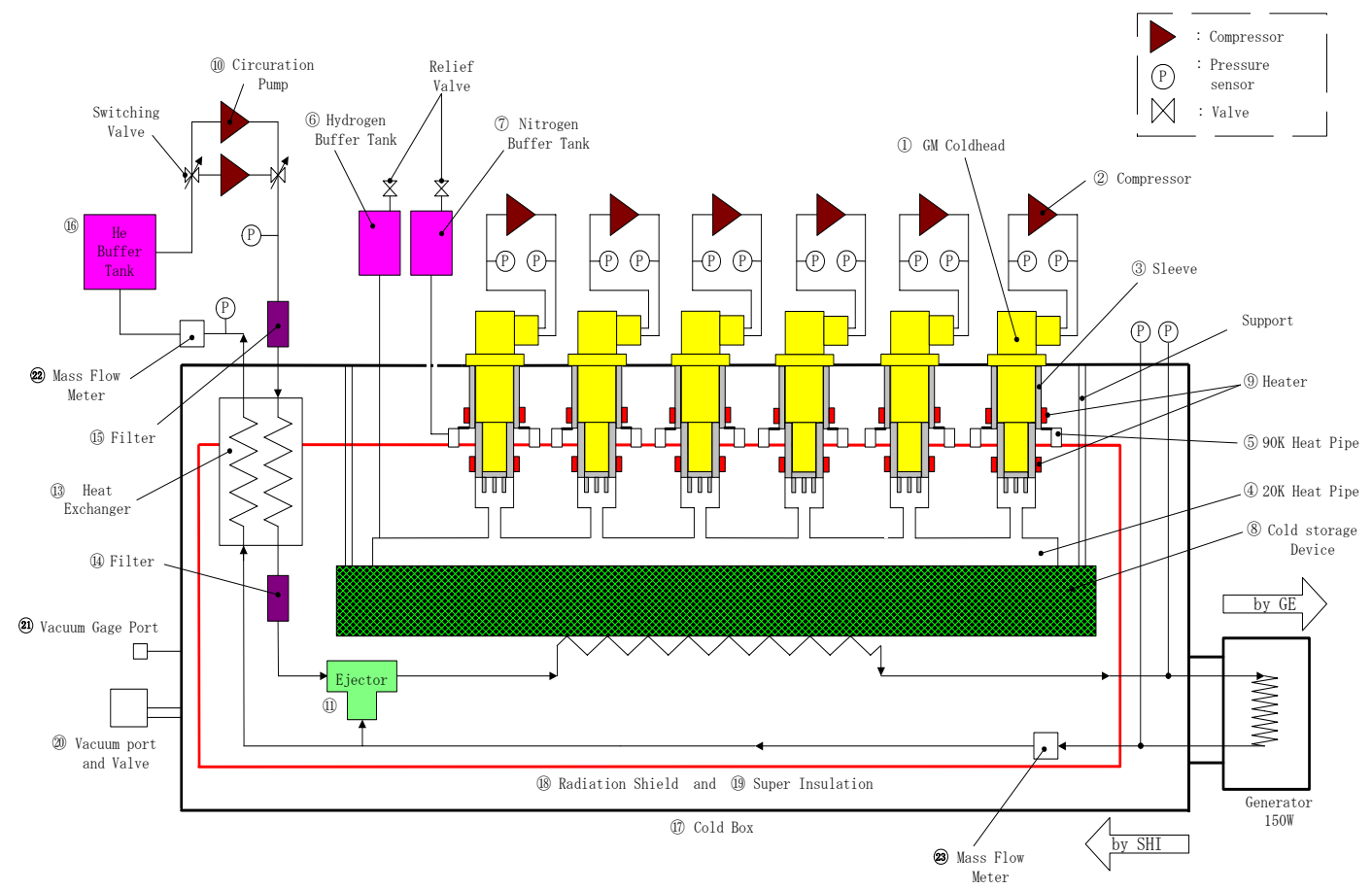

Figure 4-1 - SHI Refrigerator for 100 MVA Generator

\subsubsection{Tradeoff Analysis}

As the projected heat load for the 100 MVA-generator's refrigeration system continued to grow, the risk of insufficient cooling capacity with a GM-based system also grew. A trade-off study was performed to determine what alternative cooling systems were available for the prototype generator and whether they could be scaled up for future, larger systems. The systems evaluated were:

- An expanded version of SHI’s GM-based system cooling gaseous helium

- GM-based system cooling liquid neon

- Pulse tube refrigerator (from PRAXAIR or Cryomech) cooling gaseous helium

- Reverse-Brayton system cooling gaseous helium

- Reverse-Brayton system cooling liquid neon

Other factors that were included in the trade-off evaluation were: cooling capacity, cost, reliability, maintenance cost, availability in the time frame of this project, power consumption, and physical size. This study was reviewed in a meeting that included two GE chief engineers and representatives from ORNL (Michael Gouge), DoE (Paul Bakke), and GE-Healthcare. The results of the study were:

- The heat load of this system is much larger than the practical capability of GMs and pulse tubes (both as individual units or in groups). However, it is significantly 
smaller than those to which Reverse-Brayton systems have historically been applied. Therefore, the challenge for the Reverse-Brayton system suppliers would be to provide an economical system that is not overly complex for this application.

- The Reverse-Brayton system could easily be scaled up until such time as the HTS coil and coil support technology mature to the point where the heat load could be reduced to match a simpler, less expensive refrigeration technology.

- Pulse Tube (PT) refrigeration technology had not advanced far enough to use a PT cooling system for the prototype generator. This technology has the potential of lower cost and higher reliability than GMs, so it should be evaluated for future generator systems.

- The complexity of boiling within the rotor and subsequent rotor imbalance of the liquid systems did not warrant further pursuit of a liquid system.

- The Reverse-Brayton systems had the greatest potential for meeting the needs of this program, so the two available Reverse-Brayton systems (Air Liquide and Linde Kryotechnic) were to be evaluated further for final selection for this program.

\subsubsection{Reverse Brayton System}

Following completion of the tradeoff analysis, the technical requirements were refined and issued as a general specification. Similar proposals from the two key suppliers of Reverse-Brayton refrigeration systems in the size range of this project, Air Liquide and Linde-Kryotechnic, were received and reviewed. Air Liquide's system was selected for purchase. See Figure 4-2.

Reliability analyses were completed for the Reverse-Brayton refrigeration systems to support the refrigeration system selection. A key goal of this program was to provide an HTS generator for which reliability, availability, and maintainability (RAM) were equal to or superior to a conventional generator. In order to meet this goal, the refrigeration system and its auxiliaries were required to operate with major overhauls only at intervals of ten years or more, and with five-day, planned, off-line maintenance periods only at 2year intervals.

Both vendors were able to meet the RAM requirements with the addition of redundant compressors.

The thermal analyses concluded that the Air Liquide system would provide adequate cooling for the HTS prototype rotor and provided a means to evaluate the cooling performance at off-design conditions (different ambient temperatures, different rotor heat loads, cool down, and warm up). The analyses predicted the refrigerator would be capable of easily cooling the rotor cold parts from room temperature to $30 \mathrm{~K}$ in 24 hours, but the coil thermal transients would need further analysis and evaluation. 


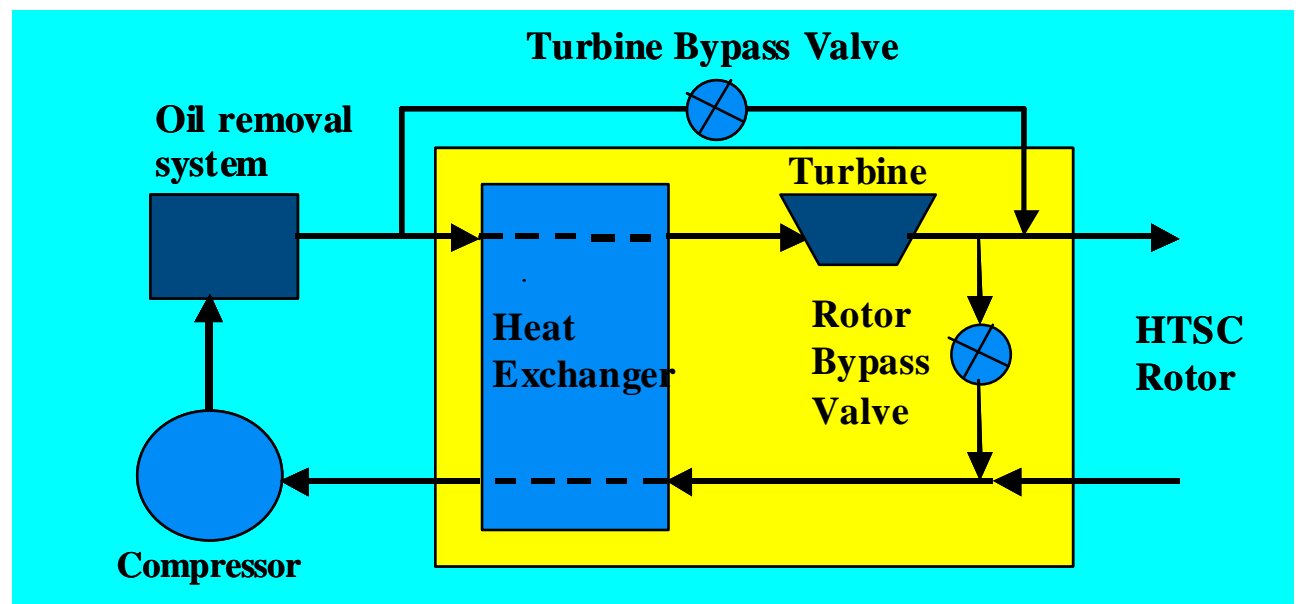

Figure 4-2 - Schematic of Air Liquide Reverse-Brayton Refrigerator

\subsection{HTS Wire Development}

GE selected AMSC wire for the HTS coil in the Demonstrator as well as the 100 MVA generator. AMSC was responsible for the basic wire technology, including the losses within the wire, the strain withstand capability, and the mechanical, electrical, and thermal characteristics.

The effort within the program was to thoroughly understand and, for some aspects, independently verify the performance of the wire.

\subsubsection{HTS Wire Specification}

It is necessary to write careful specifications for HTS wire in order to insure the quality and performance of wire received from vendors. In this project, AMSC was the exclusive vendor for HTS wire, so all communications concerning specifications were between GE and AMSC. The wire was AMSC's standard powder-in-tube BSCCO-2223, but laminated between two strips of stainless steel for added strength. These specifications refer to that wire only, since other varieties (e.g., not laminated with stainless) are available, and other vendors may have different offerings. However, the general areas covered in these specifications must be covered for any HTS wire considered for rotating wound-field electrical machines.

\section{Electrical Characteristics}

Critical current $\left(\mathrm{I}_{\mathrm{c}}\right)$ is defined as the maximum supercurrent that the HTS wire can carry until it shows a specified resistance at a specified temperature and magnetic field. The required critical current was $125 \mathrm{~A}$ and required further that prior to splicing, the wire was 
to be qualified end-to-end using the continuous $\mathrm{I}_{\mathrm{C}}$ machine to measure wire performance every 10 meters. The minimum $10 \mathrm{~m}$ critical current was to be measured at $77 \mathrm{~K}$, selffield, using a 1 microvolt/cm criterion.

$\mathrm{N}$-value is defined as the exponent in the relationship $\mathrm{V}=\mathrm{I}^{\mathrm{N}}$, where $\mathrm{V}$ is the voltage and $\mathrm{I}$ is the current at the transition from the superconducting to normal state. $\mathrm{N}$-value is usually larger for higher-quality HTS wire. The $\mathrm{N}$ value was to be measured on the entire wire for every spool using inductive I-V measurements from $10^{-9} \mathrm{volt} / \mathrm{cm}$ to $10^{-6} \mathrm{volt} / \mathrm{cm}$. Best-fit $\mathrm{N}$ values was to be determined for each decade and be greater than or equal to 12 for each decade.

\section{Mechanical}

The mechanical requirements include tensile and compressive strain requirements as a function of number of cycles at a specified temperature. The HTS wire $I_{c}$ must not to degrade more than $5 \%$ under these tests. That requirement translated into strain in the longitudinal direction as listed in Table 4-1.

In addition, wires were to only be tested for 100 cycle specifications. The representative test was a single sample proof test to check that the values exceeded the limits given in the table. Mechanical cyclical strain tests were done from zero strain to the specified strain values using representative samples to check process control.

Thermal cycling strain is also important. $\mathrm{I}_{\mathrm{c}}$ must not degrade more than $5 \%$ after at least 100 temperature cycles of the wire between 77 Kelvin and room temperature. Thermal cycles were done on unrestrained wire using representative samples to check process control.

Table 4-1 - HTS Wire Tensile and Compressive Strain Requirements

\begin{tabular}{cc}
\hline Strain Requirement (along wire) & Strain (\%) \\
\hline Required cyclic tensile strain: & 0.32 \\
For 100 cycles & 0.21 \\
For 10,000 cycles & \\
Required cyclic compressive strain: & 0.11 \\
For 100 cycles & 0.11 \\
For 10,000 cycles & \\
\hline
\end{tabular}




\section{Wire splices}

Since perfectly made splices between HTS wires are slightly resistive, their resistance and number should be specified. Accordingly, the HTS wire must be capable of making splices, at least of the overlap type, with the following properties:

- Resistance less than $0.2\left(10^{-6}\right)$ ohms at $77 \mathrm{~K}$ for a $10 \mathrm{~cm}$ overlap splice. Resistance measurements were done on representative sample of splices to check process control.

- Maximum splice width: $5.0 \mathrm{~mm}$

- Number of splices: No more than five for $800 \mathrm{~m}$ piece length.

\section{Wire Dimensions}

Wire dimensional control is usually important and specified. For tapes, the camber (inplane bend) of the wire is also important for winding but may be hard for the vendor to control. The minimum piece length of the wire was to be $800 \mathrm{~m}$ and could include splices. The HTS wire cross-section was to have the dimensional criteria:

- Maximum average thickness $0.315 \mathrm{~mm}$ per spool

- Maximum width $5.0 \mathrm{~mm}$

\subsubsection{HTS Wire Characteristics}

\subsubsection{Introduction}

One of the key factors in designing electrical machines using HTS wires is the degradation of $\mathrm{I}_{\mathrm{c}}$ because of mechanical strain. In the 100 MVA HTS generator, the HTS wire in the rotor coil would experience both tensile and compressive strain due to centrifugal loading and differential thermal contraction during cool-down/warm-up of the rotor. The HTS coil must survive thousands of thermal and start-up loading cycles.

There are many experiments and reports on $\mathrm{I}_{\mathrm{c}}$ degradation by mechanical strains. Most of them investigate monotonic tensile strains. A series of $I_{c}$ degradation experiments to investigate degradation were conducted under both tensile and compressive strains. Measurement of $I_{C}$ as a function of the number of strain cycles at different strain levels enables the fatigue behavior of the HTS wire to be determined. The degradation of $\mathrm{I}_{\mathrm{C}}$ due to cyclic strain has been measured by a number of groups. Data measured by GE, AMSC, and the University of Twente are presented here. 


\subsubsection{Materials, Apparatus and Definitions}

\section{Definitions}

Zero strain: The strain condition of a wire at $77 \mathrm{~K}$ after cooling without mechanical restraint. During measurements this condition is approximated by bonding the wire to a stainless steel substrate. (The coefficient of thermal expansion of stainless steel is well matched to that of the wire.)

Strain limits: The wire strain corresponding to an $\mathrm{I}_{\mathrm{c}}$ retention of $95 \%$ of its value at zero strain. This type of test may underestimate the magnitude of the strain to failure because the $5 \%$ loss of $I_{c}$ may be due to a small fraction of the filaments near the outer surface of the wire that experience a higher strain than the rest of the wire. For data analysis the strain is taken at the mid-plane of the HTS wire.

Cyclic strain: The mechanical strain applied to the HTS wire by repeated monotonic transitions between two strain values. The wire is maintained at a constant temperature during the cycling. A single strain cycle consists of a transition from the start point to the end point and back to the start.

\section{Materials}

The measurement samples was silver/alloy BSCCO-2223 HTS tape with stainless steel reinforcement manufactured by AMSC using the powder-in-tube (PIT) technique. Samples were selected from different batches of the HTS wire ordered from AMSC for this program. Some tape characteristics are given in Table 4-2.

Table 4-2 - Characteristics of AMSC BSCCO-2223 Tape Used for Strain Measurements

\begin{tabular}{lcc}
\hline \multicolumn{1}{c}{ Wire Characteristics } & Units & Value \\
\hline Critical current (77K, self field) & $\mathrm{A}$ & $124-138$ \\
Thickness (average) & $\mathrm{mm}$ & 0.29 \\
Width (average) & $\mathrm{mm}$ & 4.93 \\
\hline
\end{tabular}

\section{Measurement Apparatus and Procedure}

Measurements were made using different means at GE, AMSC and the University of Twente. In all cases, the HTS wire sample was bonded to one face of a stainless steel substrate and a cyclic strain was applied by bending and straightening the substrate. The GE test used a four-point bending apparatus, as shown in Figure 4-3. An electric actuator 
pushed the center rods down to a predefined displacement. This four-point bending arrangement gave uniform bending and thus a uniform strain over the length of sample between the inner bending points. The set-up enabled the determination of $\mathrm{I}_{\mathrm{c}}$ in high strain ranges $( \pm 1 \%)$, depending on the thickness of the substrate and the bending displacement at the center. Critical current was measured at $77 \mathrm{~K}$ using the $0.1 \mu \mathrm{V} / \mathrm{cm}$ criterion with voltage taps spaced $5 \mathrm{~cm}$ apart. The procedure was automated by a programmable power supply with a 2 A current step. The $I_{c}$ was determined by a simple interpolation. The sample strain was monitored by a strain gauge mounted on the surface of the HTS wire. To obtain the relation between $\mathrm{I}_{\mathrm{c}}$ and the number of strain cycles $\mathrm{N}$, the cyclic loading was stopped after a certain number of cycles and a V-I measurement was carried out at the predefined peak strain and at zero when the strain was relieved.

AMSC and Twente used a 'bending spring' apparatus similar to that shown in Figure 4-4 and described in [1]. In this type of apparatus, the bending is not uniform over the sample, so only a short length $(1 \mathrm{~cm})$ is used for $\mathrm{I}_{\mathrm{c}}$ measurement.

The copper rods on the sides are fixed in position while the stainless steel rods at the center move up and down to bend the substrate by a programmable electric actuator located at the top of the apparatus but not shown in the figure. Voltage and current leads are flexible copper wires.

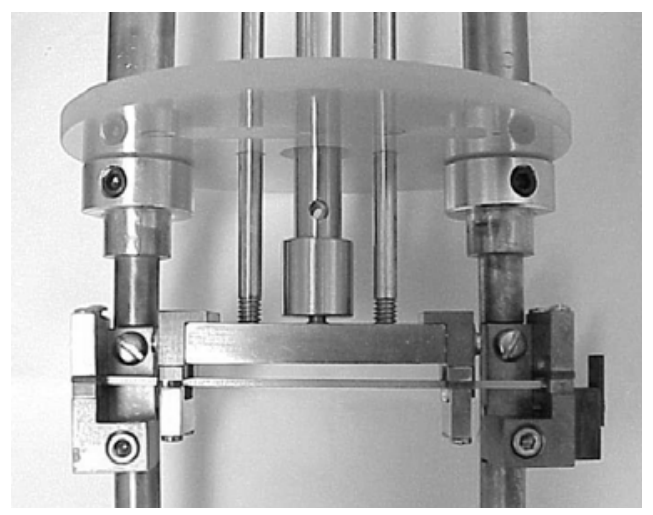

Figure 4-3 - The GE Four-Point Bending Apparatus

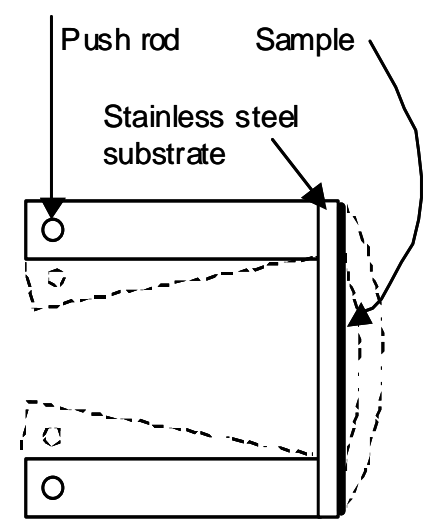

Figure 4-4 - Schematic of a Bending Spring 


\subsubsection{Measured Strain Capability}

Results are plotted in Figure 4-5, which shows $\mathrm{I}_{\mathrm{c}}$ retention under tensile and compressive cyclic strains. To determine the strain limits corresponding to $5 \% \mathrm{I}_{\mathrm{c}}$ degradation, the measurements were carried out focusing on the tensile and compressive strains at which the $5 \% \mathrm{I}_{\mathrm{c}}$ degradation was observed. These strains are around $-0.15 \%$ and $0.38 \%$ (negative values denoting compression). The open symbols in the figure represent retention after 100 cycles, and the shaded symbols represent saturation, which means no further degradation is observed when the number of cycles is increased to more than 1000. Typically, saturation was observed after 100 - 300 cycles. All of the tests at GE continued to 10,000 cycles; most runs at Twente continued to 1000 cycles. The error bars indicate plus or minus one standard deviation of the $I_{C}$ values after saturation. As shown in the figure, the behavior of the tape under compressive and tensile cycles is different.

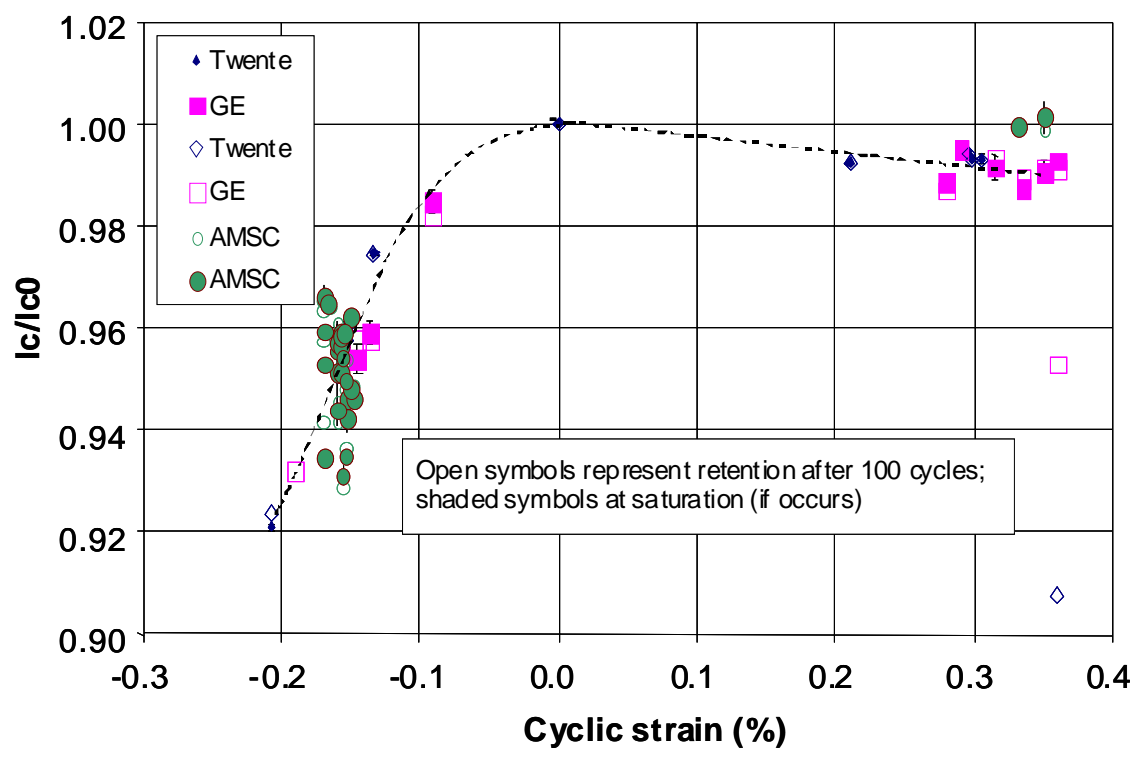

Figure 4-5 - Critical Current Retention Under Tensile and Compressive Cyclic Strain

\section{Tensile Strain}

The behavior of the HTS tape under tensile strain cycles is as shown on the right hand side in Figure 4-6. Up to a strain of $0.36 \%$, the $\mathrm{I}_{\mathrm{c}}$ remains almost constant or shows a minimal reduction. Larger strain results in a dramatic reduction of $I_{c}$ to lower than 0.92 at $0.38 \%$ strain. This suggests that the peak tensile strain that the wire will experience in any application should remain lower than $0.35 \%$ with an adequate margin when such an HTS conductor is used. The pink dots are the data measured at the peak strain of the cycle, while the blue dots were measured after the strain was relieved to zero. As expected, the reduction is larger at peak strain than at zero. These results are similar to 
those described of many BSCCO/Ag conductors without stainless steel reinforcement. In the strain range between 0.2 to $0.35 \%$, the degradation saturated by 100 cycles. This indicates that, if the wire meets the specifications for 100 cycles, it should automatically meet less stringent requirements for 10,000 cycles.

Nineteen samples were measured under tensile strain cycles. The critical strain follows a normal distribution. The mean value and the standard deviation are shown in Figure 4-7.

To analyze the variation of the HTS wire from batch to batch, samples were randomly selected from four different spools of wire from AMSC. Table 4-3 shows the statistical data of each batch.

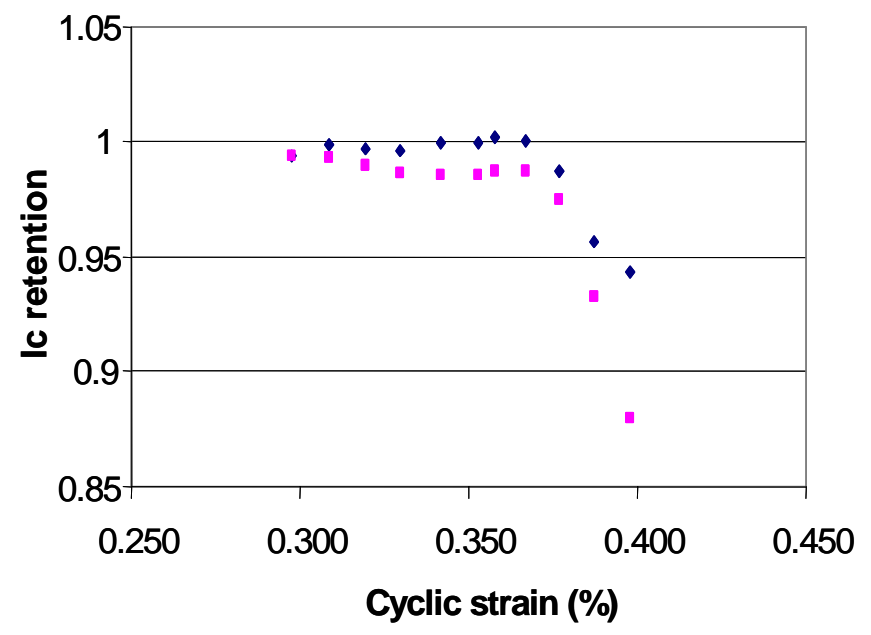

Figure 4-6 - Typical $I_{c}$ Degradation as a Function of Tensile Strain

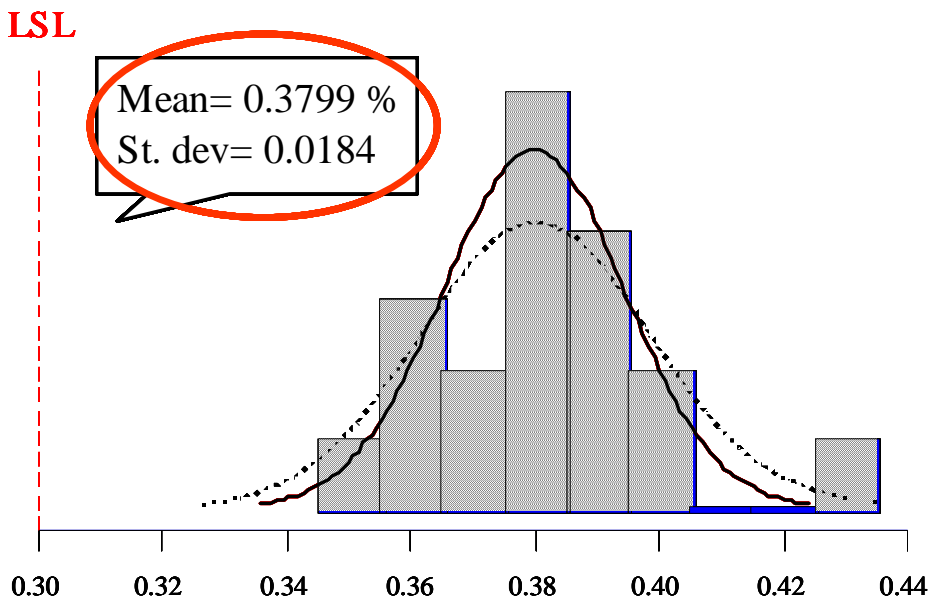

Figure 4-7 - Statistical Analysis of the Critical Strain Under Tensile Strain Cycles 
To compare the measurements made at different locations with different facilities, a statistical analysis was mode of the critical strains obtained by GE and ASMC as shown in Table 4-4. The results are consistent.

Table 4-3 - Batch-to-Batch Variation of Critical Strains in the Tensile Test

\begin{tabular}{cccc}
\hline Batch Number & $\begin{array}{c}\text { Number of } \\
\text { Samples }\end{array}$ & $\begin{array}{c}\text { Mean } \\
\mathbf{( \% )}\end{array}$ & $\begin{array}{c}\text { Standard } \\
\text { Deviation } \\
\mathbf{( \% )}\end{array}$ \\
\hline 3 & 5 & 0.371 & 0.0117 \\
5 & 6 & 0.385 & 0.0245 \\
16 & 5 & 0.383 & 0.0118 \\
17 & 4 & 0.376 & 0.0201 \\
\hline
\end{tabular}

Table 4-4 - Comparison of the Measurements at Different Sites

\begin{tabular}{cccc}
\hline Site & $\begin{array}{c}\text { Number of } \\
\text { Samples }\end{array}$ & $\begin{array}{c}\text { Mean } \\
\mathbf{( \% )}\end{array}$ & $\begin{array}{c}\text { Standard } \\
\text { Deviation } \\
\mathbf{( \% )}\end{array}$ \\
\hline AMSC & 7 & 0.384 & 0.0109 \\
GE & 18 & 0.381 & 0.0179 \\
\hline
\end{tabular}

\section{Compressive Strain}

Figure 4-8 shows $\mathrm{I}_{\mathrm{c}}$ degradation observed during a typical repetitive run of compressive (longitudinal) strain cycles. The degradation is smaller at the peak compressive strain than at zero strain. Unlike tensile cycling, $\mathrm{I}_{\mathrm{c}}$ reduction is observed even at small strains of $0.08 \%$. The degradation becomes larger with increasing strain. Saturation of $I_{c}$ with cycle number was seen at higher compressive strain levels (to at least $0.2 \%$ compressive). The transfer function for critical compressive strain versus a specific $I_{c}$ retention at different cycle numbers is

$$
\varepsilon_{c}=5.324-12.8994 \frac{I_{c}}{I_{c 0}}+7.476\left(\frac{I_{c}}{I_{c 0}}\right)^{2}+0.00835 \ln (N)-0.006645 \ln ^{2}(N)
$$

where $\varepsilon_{\mathrm{c}}$ is the critical strain for $\left(\mathrm{I}_{\mathrm{c}} / \mathrm{I}_{\mathrm{c} 0}\right)$ retention, and $\mathrm{N}$ is the number of cycles. Substituting 0.95 for $I_{C} / I_{c 0}$ in the transfer function, obtains the predicted strain for $95 \%$ Ic 
retention at 100 cycles and 10000 cycles. Table $4-5$ gives the predicted critical strains and their standard deviations.

Table 4-5 - The Predicted Compressive Strand for 95\% $\mathbf{I}_{\mathrm{c}}$ Retention

\begin{tabular}{cccc}
\hline & & $\begin{array}{c}\mathbf{1 0 0} \\
\text { Cycles }\end{array}$ & $\begin{array}{c}\mathbf{1 0 0 0 0} \\
\text { Cycles }\end{array}$ \\
\hline $\begin{array}{c}\text { Predicted Strain for } \\
\text { 95\% } \mathrm{I}_{\mathrm{C}} \text { retention }\end{array}$ & Mean & $-0.163 \%$ & $-0.151 \%$ \\
& St. Dev. & $0.016 \%$ & $0.015 \%$ \\
\hline
\end{tabular}

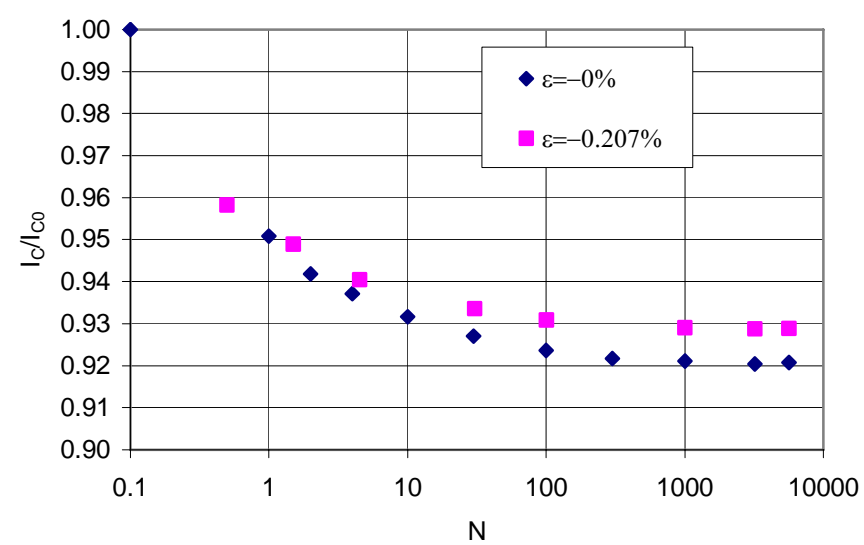

Figure 4-8 - Normalized $I_{c}$ as a Function of the Number of Cycles With a Cyclic Compressive Strain of $\mathbf{0 . 2 0 7 \%}$

\section{Tensile Cycling at Room Temperature}

Spin tests, needed to balance a generator rotor at room temperature during rotor assembly, impose tensile strains arising from the centrifugal loading on the rotor. It is important to know if strain cycles at room temperature affect the HTS wire performance.

Room temperature cyclic testing was carried out at GE. Samples were cycled 100 times to a fixed strain, the strain was then increased in $0.01 \%$ steps and the cycles repeated until 95\% $\mathrm{I}_{\mathrm{C}}$ retention was observed. An $\mathrm{I}_{\mathrm{c}}$ measurement was made initially and then after every 100 cycles. It was observed that the critical strain at room temperature was $0.254 \%$, which is smaller than the $0.38 \%$ observed at liquid nitrogen temperature. 


\subsubsection{Conclusions}

- The fatigue behavior of $\mathrm{I}_{\mathrm{c}}$ of BSCCO HTS wire was investigated under tensile and compressive load at liquid nitrogen temperature and at room temperature.

- The measurements that were carried out at three different locations with different test facilities gave consistent results.

- The $\mathrm{I}_{\mathrm{C}}$ degradation at liquid nitrogen temperature is less than $5 \%$ after

o 100 cycles of 0 to $0.35 \%$ tensile strain or 0 to $0.2 \%$ compressive strain; and

o 10,000 cycles of 0 to $0.21 \%$ tensile strain or 0 to $0.15 \%$ compressive strain.

A transfer function for compressive regime was developed from the data obtained in the compressive cyclic tests. It was used to determine critical compressive strain for 95\% Ic retention at 100 and 10,000 cycles.

For tensile strains, a dramatic degradation is observed around $0.36 \%$ at $77 \mathrm{~K}$, but which decreases to $0.25 \%$ at room temperature. This suggests that margin should be kept in the tensile strain for application design.

$I_{c}$ degradation saturated by 100 cycles in the strain range between $-0.2 \%$ and $0.35 \%$. Therefore, to characterize the $\mathrm{I}_{\mathrm{c}}$ performance at 10,000 cycles or higher, a 100-cycle test is sufficient.

\subsubsection{Wire Splicing Methods}

HTS wire splices usually occur from two sources. First, the vendor will make splices in the wire as part of their production process to achieve certain specified lengths. Normally, especially while HTS wire is still being developed, vendors cannot consistently meet requested long lengths (approximately $1 \mathrm{~km}$, depending on applications) because of flaws in their production wire that must be spliced out or simple limitations in wire length handling. Second, the coil producer must make additional splices in the wire to add new lengths of wire into the coil, remove mistakes or flaws, or position other splices acceptably within the coil.

\subsubsection{AC Loss Characteristics of HTS Wire}

Superconductors have zero resistance only with direct current and have some loss in any AC field or current. This loss leads to heating of the superconductor, which may in turn drive it normal if not properly compensated by cryogenic cooling. How much loss it has depends on the geometry of its construction. The construction desired is similar to copper Litz wire, which employs fine filaments that are twisted and transposed to reduce AC losses. The same principles apply to low-AC-loss superconductors, but at present there 
are no HTS that are available in these geometries. Specifically, commercially available BSCCO HTS tape is not very AC capable and is therefore suitable for AC applications only in very low fields, such as the self-fields of a transmission cable. The generator field application being considered in this project is substantially a DC application, but there are some AC effects forced onto the HTS wire that must be considered. In particular,

- Stator AC fields which may leak through the EM shield during operation and impinge on the HTS,

- Ramping of the field coil by the exciter, and

- AC noise/harmonics injected into the field coil by the exciter current supply.

AC fields and noise can be controlled by design of the EM shield and exciter; field current ramping can be quantified for standard generator operation. Therefore, imposed AC loads are known, but the missing information is the precise response of the HTS wire to imposed AC fields and currents. Various theories/models have been created in the literature, and the program took the approach of using these to calculate the AC loss response of the HTS to the imposed AC fields and currents. Specifically, GE used models by Rabbers et al.[5] and S. P. Ashworth and M. Suenaga[6,7] for these calculations. These models do not give the same results in all circumstances, so one must be careful to use them within their valid ranges and, on occasion, interpolate between predictions.

Therefore, precise prediction of AC loss of HTS is at present an unsolved problem. The model results, when compared with experimental information, such as losses in the Demonstrator test or test coils, are reasonable. Such comparisons are imprecise because there are various other sources of AC loss within complex machinery, such as eddy currents or magnetic hysteresis losses, which make separation of the HTS AC losses problematic. Even the HTS tape itself contains much metal (Ag), which can contribute eddy current losses. Also, outer tapes within coils tend to shield inner tapes from imposed AC fields (but not fields from injected AC currents). Section 4.4.2 covers a separate investigation by LANL of AC losses of HTS coils.

AC loss in HTS tapes under simultaneously imposed AC fields and currents (perhaps not in phase) must be considered a problem without precise solution at present for all desirable engineering conditions. It is an area which future research can benefit.

\subsubsection{Wire Insulation}

The insulation applied to the AMSC wire was a point of considerable development. The Demonstrator coil used Teflon insulation, but tests of dielectric properties and bond strength indicated that Kapton tape was preferable. Accordingly, the field winding coil for the 100 MVA prototype was designed to accommodate Kapton tape. The tape would be applied in two half-lapped layers.

Wire insulated with Kapton was used to make a duplicate Demonstrator coil for further risk reduction tests. When this coil was first excited, it was found to have a shorted turn that was likely to be between adjacent turns within a layer. The root cause assessment of 
the shorted turn considered whether the Kapton tape in conjunction with the stainless steel laminations of the HTS wire gave rise to the short. Figure 4-9 shows a photomicrograph of a cross-section of insulated HTS wires molded into a coil package. The edges of the stainless steel strips are clearly evident along with the solder used to bond the strips to the raw HTS tape. One concern is that adjacent turns may shorted through the Kapton insulation via the relatively sharp stainless steel layers.

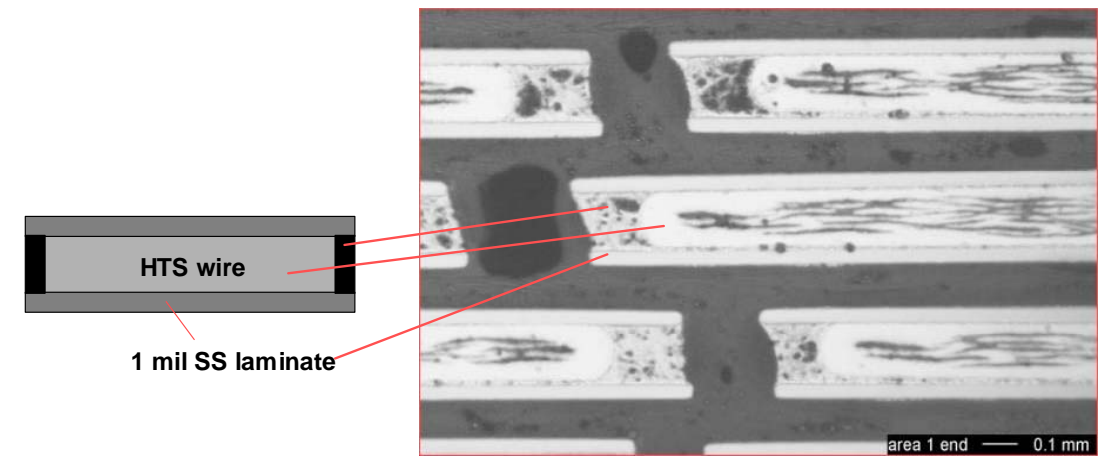

Figure 4-9 - Photomicrograph of HTS Wire Lay-up

\subsection{Quench Technology}

\subsubsection{Introduction}

A quench in a superconducting coil is the process which occurs when part of the superconducting coil goes irreversibly from the superconducting to the normal resistive state. As illustrated in Figure 4-10, the critical current, $I_{c}$, is a function of the temperature and the magnetic field. An HTS coil is stable when it operates below its critical current with some safety margin. However, the HTS field coil in the generator will go through transient fault conditions that can result in significant over-currents. The peak current during a fault can be two to three times higher than the normal operating current. Moreover, the sharp increase in current raises the local magnetic field in the coil, resulting in significant decrease in the critical current of the HTS conductors. It is not cost effective to design the coil to remain within its critical current limits in a fault condition. Therefore, it is acceptable to allow short "normal" current periods during a fault to reduce the cost of the HTS conductor. During a fault event, the current may exceed the critical current for a short time, generating heat and raising the temperature. The design requirement is that the HTS coil sustain an over-current fault and retain full current capability once the fault is cleared. One designs the coil to have adequate thermal capacity to ride though the fault and return to the superconducting state. In addition, it is necessary to develop a quench detection/protection system to protect the coil. Repeated over-current faults or loss of cooling may cause a thermal run-away or quench of the coil. The protection system has to be able to detect the quench on time and run down the coil current before the temperature of the quench zone rises high enough to cause damage. 

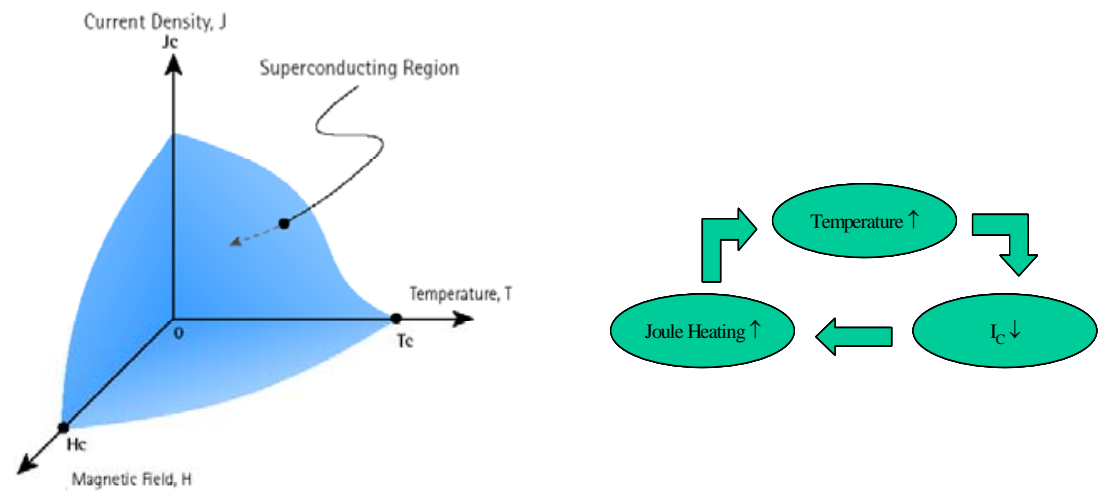

Figure 4-10 - Superconducting Operating Region and a Thermal Run-Away Event

\subsubsection{Coil Over-Current Analysis for an 18-Cycle Fault}

The HTS coil capability is evaluated by computing the over-currents during a selected severe fault. The fault is a 3-phase sudden short circuit at the high side of the transformer up to the critical fault clearing time of 18 cycles followed by the subsequent recovery. The temperatures are predicted using an ANSYS quench model.

\subsubsection{Over-Current Model}

The fault currents are computed using a system model with a 2D FE electromagnetic model of the generator coupled to an external mechanical and electrical circuit in Flux2D, as shown in Figure 4-11. The field current and peak flux density in the coil section are shown in Figure 4-12. The field current rises to about 160A during the fault and reaches a peak of 180A during the recovery. Peak fields of 2.6T are obtained during this period.

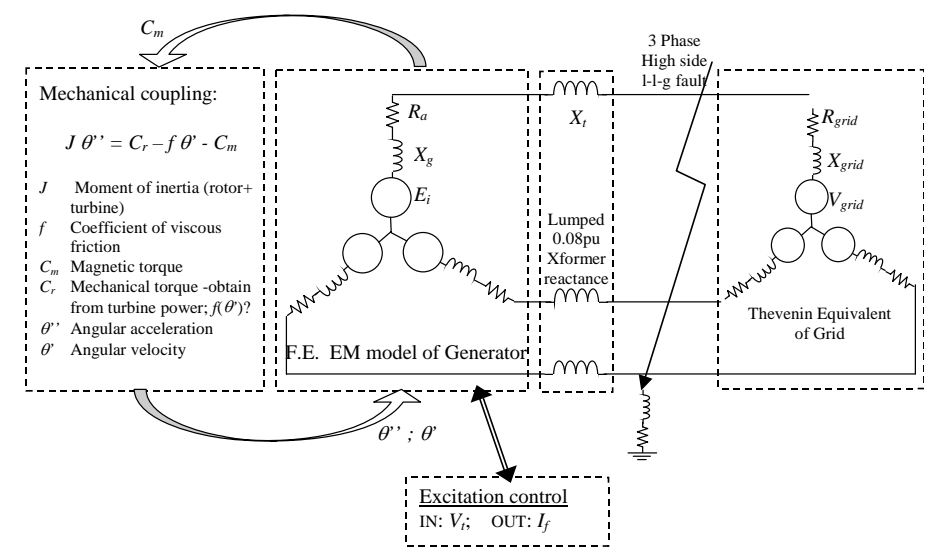

Figure 4-11 - System Model for Fault Current Analysis 


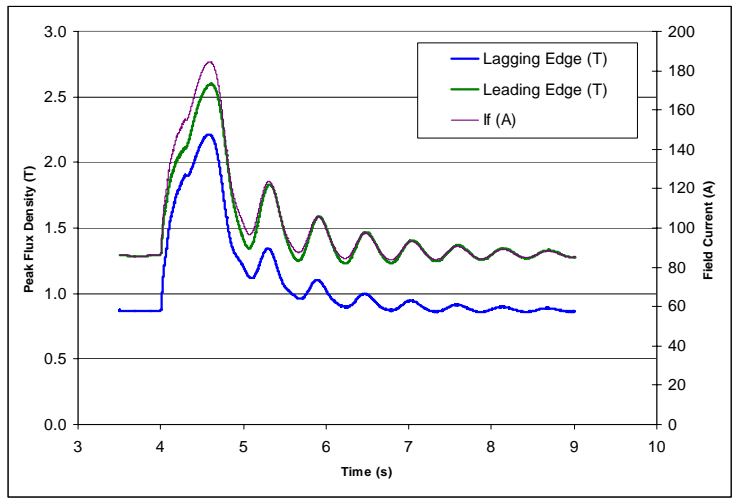

Figure 4-12 - Field Current and Coil Flux Density During Fault and Recovery

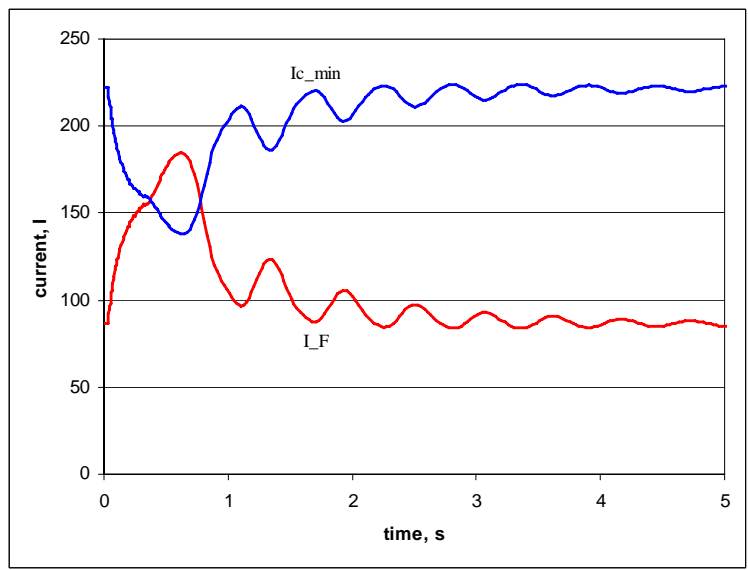

Figure 4-13 - Field Current and Minimum $I_{c}$ During an 18-Cycle Fault \& Recovery

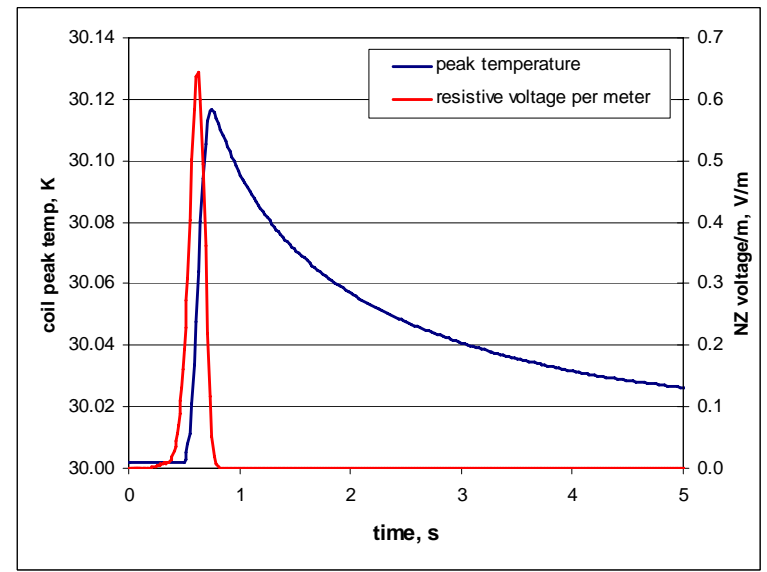

Figure 4-14 - Coil Temperature and Voltage During an 18-Cycle Fault \& Recovery

\subsubsection{Quench Detection \& Protection Strategies}


Even though the coil is designed to ride though over-current conditions, repeated faults and/or loss of cooling can cause a thermal run-away, as illustrated in Figure 4-15.

\section{Quench Prediction by a Thermal Model}

The condition of the HTS coil can be predicted by a thermal/quench simulation model. The model includes the following:

- A fast thermal model of the HTS conductor that can calculate the conductor temperature during a fast over-current event,

- The HTS conductor $I_{c}$ as a function of temperature and magnetic field,

- The HTS conductor and coil material properties, and

- Coil peak field calculation.

During operation, the control system takes the coil current and the refrigeration system operation conditions (coolant temperature, coolant flow rate) as inputs, continuously estimates the coil operating condition and its current carrying capacity, and takes necessary actions to protect the coil and the system when necessary.

Two key real-time results are continuously fed into the control system: the coil peak temperature and the critical current at that temperature and the current magnetic field. As illustrated in Figure 4-15, protection actions are taken when the coil peak temperature exceeds a threshold temperature, $\mathrm{T}_{\mathrm{S}}$, where the control system will activate the quench protection circuit and trip the system to dump the current and protect the coil.

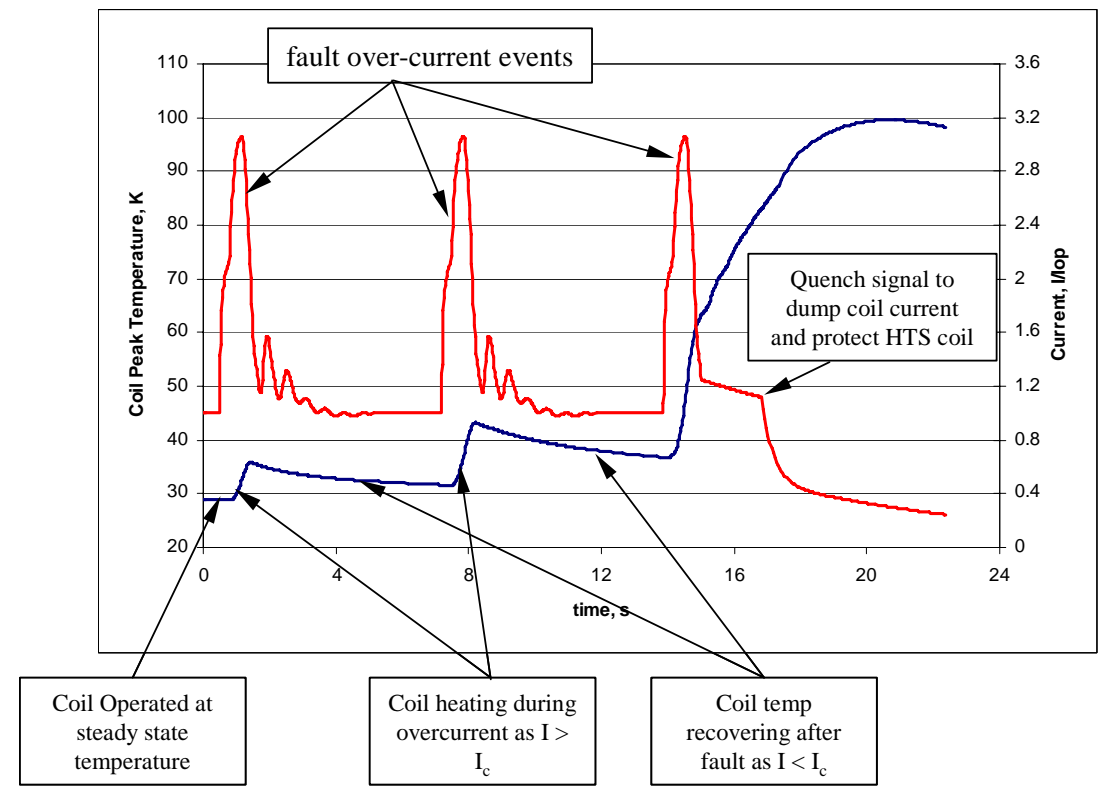

Figure 4-15 - Repeated Faults Cause Thermal Run-Away 


\section{Experiment Design and Setup}

A small HTS coil was developed and tested to verify the calculation results and to study further the performance of HTS coil under over-current conditions. This test investigated the performance of the HTS coil when over-current pulses were added on top of the operation current. The experiment arrangement is shown in Figure 4-16. The coil was suspended in a vacuum enclosure and linked to the cold box containing the cryocooler, heat exchanger and helium circulation system. The coil temperature was controlled using a heater on the helium flow tube. To minimize the heat generation around the coil, HTS superconducting leads were use for the connection between the coil and the thermal station.

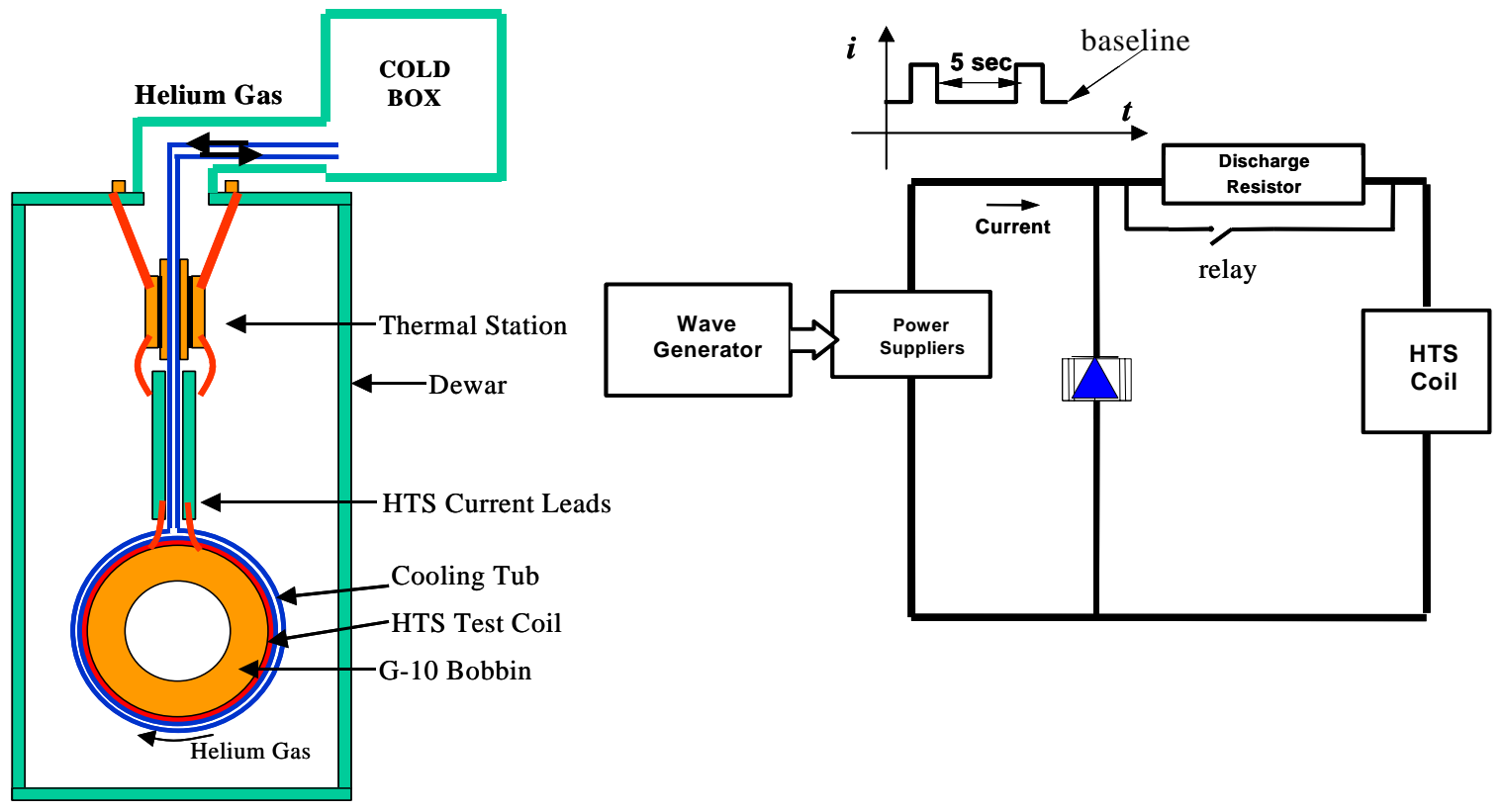

Figure 4-16 - HTS Quench Protection Experimental Arrangement

The test program had two phases. First, the test coil would be exposed to lower magnetic fields than the actual field coil, so the coil was set at a higher temperature such that the critical current was about the same as the actual 100 MVA coil. Based on the $0.1 \mathrm{~V} / \mathrm{cm}$ criterion for the critical current, the critical temperature was $52 \mathrm{~K}$. The over-current test was conducted at this temperature. The baseline current was kept at $100 \mathrm{~A}$, and overcurrent pulses were added to make the total peak current of $230 \mathrm{~A}$. The relaxation time defined as the duration from the end of a pulse to the beginning of the next pulse was kept at 5 seconds. During the pulse the coil was in normal state and generated heat because the current exceeded the coil $\mathrm{I}_{\mathrm{C}}$.

When the pulse time was less than one second, no temperature rise was observed after over 20 pulses. The coil fully recovered to a superconducting state during the relaxation time. When the pulse time was increased to two seconds as shown in Figure 4-17, 
temperature signals started increasing and a thermal run-away occurred at the end of the sixth pulse.
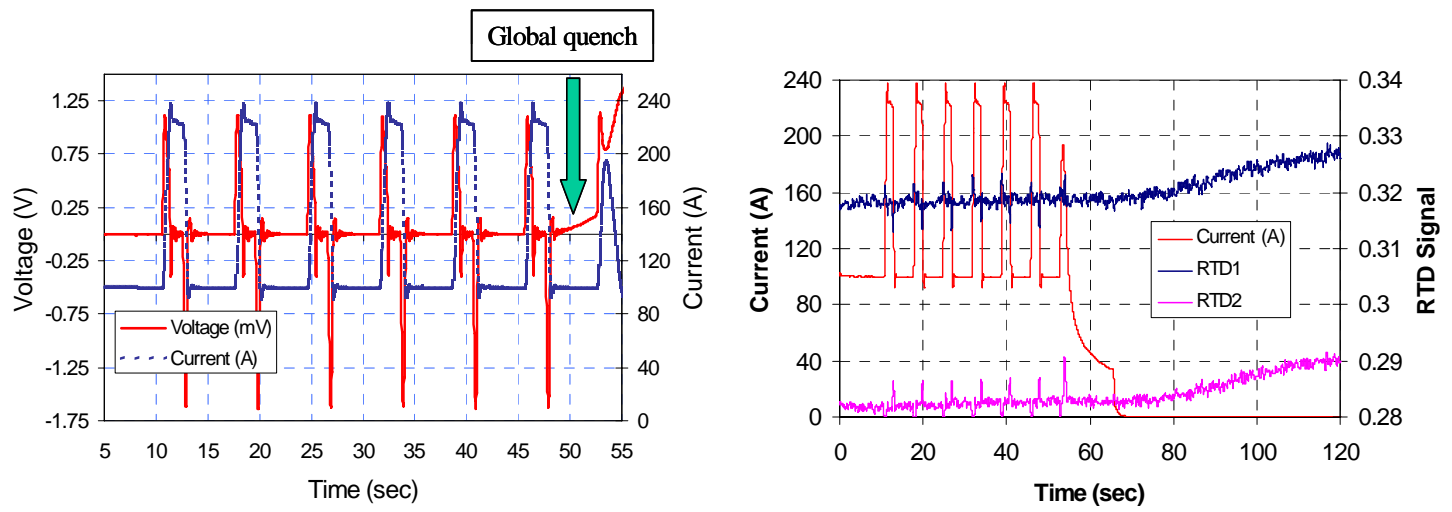

Figure 4-17 - Coil Voltage, Current and RTD Signal During an Over-Current Test with 2 Second Pulse Width and 5 Second Relaxation Time

\subsection{HTS Coil}

\subsubsection{Coil Resonance}

It is well known that coils such as the HTS coil in the Demonstrator will have specific resonant frequencies that are determined by the layer-layer inductance and capacitance. The specific resonant frequencies of the 100 MVA HTS coil were of a particular concern since the static excitation system would impose a wide spectrum of harmonic currents and voltages on the terminals of the coil. The response of the coil must be known to insure excessive heating or destructive voltages did not occur within the coil.

Figure 4-18 shows a measured frequency response of the original Demonstrator coil. The data for the coil were obtained after the coil had been removed from the disassembled Demonstrator rotor. During this test the coil was placed upon a bench away for any large electrically conductive or magnetic objects. The resonant frequencies, corresponding to the dips in the response, are listed in Table 4-6. The table also shows the calculated resonant frequencies based on a distributed inductance and capacitance model.

Based upon these results, it is possible to predict the resonant frequencies of the 100 MVA coil sufficiently well to understand any interaction of the coil and the static excitation system. 


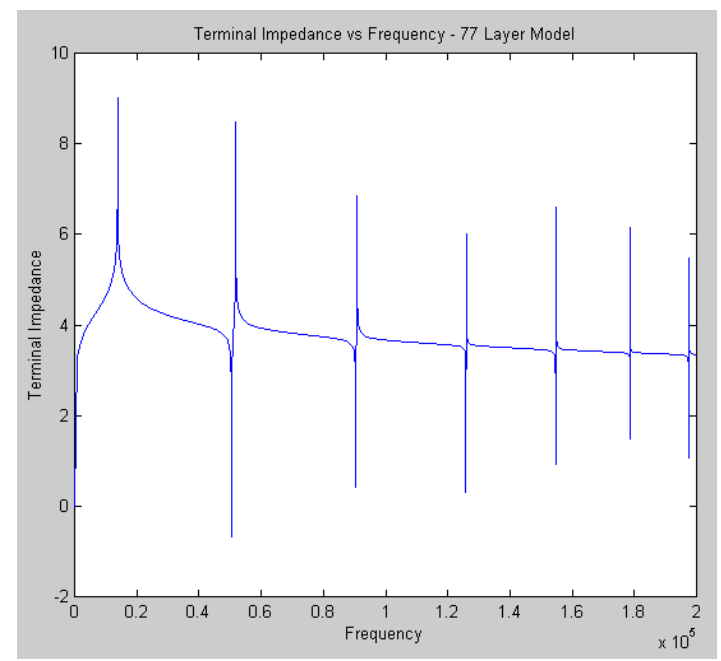

Figure 4-18 - Resonant Frequencies of the Demonstrator HTS Coil in Free Space

Table 4-6 - Comparison of Measured and Calculated Resonant Frequencies for the Demonstrator Coil

\begin{tabular}{ccc}
\hline Resonance & $\begin{array}{c}\text { Calculated } \\
\text { (kHz) }\end{array}$ & $\begin{array}{c}\text { Measured } \\
\text { (kHz) }\end{array}$ \\
\cline { 2 - 3 } 1 & 50.5 & 50 \\
2 & 90.4 & 86.5 \\
3 & 125.9 & 125 \\
4 & 154.7 & 163 \\
\hline
\end{tabular}

\subsubsection{AC Coil Loss}

Los Alamos National Lab began a study to evaluate the AC loss in the HTS wire and coil. One source of AC loss was the steady state contribution from exciter harmonics and the second was a $60 \mathrm{~Hz}$ fault current scenario. The initial strategy was to separate the problem in two parts. The first was to study the AC loss characteristics of an individual stainless steel clad BSCCO tape for given working conditions (AC/DC transport current and external field). The actual coil is composed of approximately 1400 turns. The single tape study would lead to the second part, which was to estimate of the AC losses in some 'critical' positions inside the overall coil cross-section (see Figure 4-19). In this later case, the applied external field would be replaced by discrete bulk current sources. It was the intent that the coarse mapping of approximately 8 locations in the coil would develop a heat generation profile, which could then have thermal analyses performed on it. 


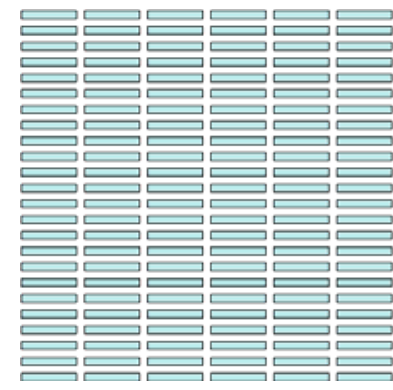

individual tapes of actual coil

Repeat heat loss per unit length calculation for $\sim 8$ discrete locations in coil and interpolate for thermal model

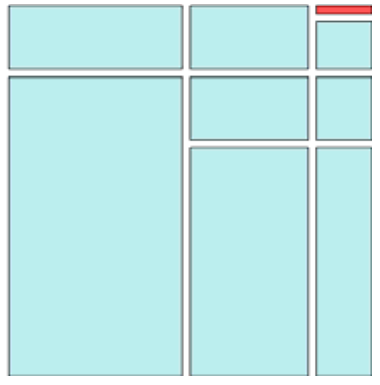

discretized bulk coil current sources and single tape of interest

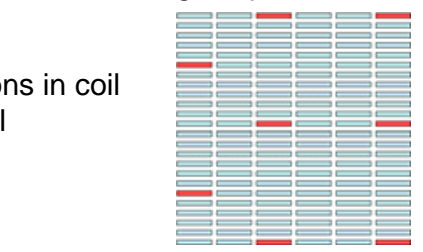

\section{Figure 4-19 - Full Coil Cross-Section Modeling Approach}

A single 'test' tape in the actual coil was used at various critical positions of the coil. The advantage is that only the test tape and the surrounding region need a fine mesh; the rest of the coil can be modeled as a series of different 'bulk' regions with a coarser mesh. This kept the model size at a manageable level.

The chosen tool for predicting the AC losses in such a complex configuration was the FE analysis ${ }^{1}$, which allows computing in detail the current density and magnetic field distribution inside each conductor (tape). In particular, LANL used the FE software FLUX, which allows performing 2D calculations with a given transport current flowing in the superconducting tape and a given imposed magnetic field. The cross-section of the single conductor is shown in Figure 4-20. The central ellipsoidal region represents the superconductor, replacing individual BSCCO strands.

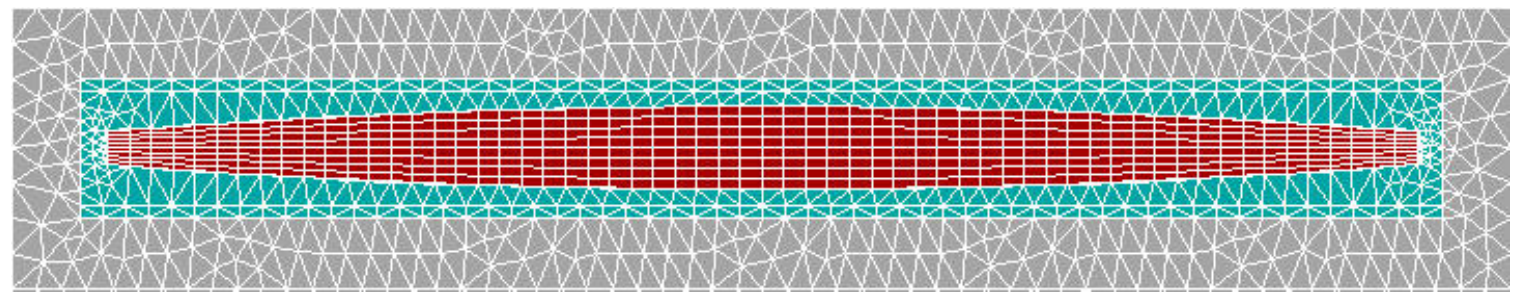

Figure 4-20 - Meshing of single conductor tape (red = superconductor, cyan = Ag, gray = air) for FEA analysis

The study addressed evaluating the AC losses in a situation where there is a flowing DC transport current and an external DC magnetic field (generated by the neighboring tapes),

\footnotetext{
${ }^{1}$ See for example S. Stavrev et al., "Comparison of numerical methods for modeling of superconductors”, IEEE Transactions on Magnetics, Vol.38, n.2, pp. 849-852, 2002.
} 
both with a superimposed AC oscillation. The tape critical current was assumed to be 200 A. The frequency of concern from the exciter was approximately $2 \mathrm{kHz}$.

Initially, results for this were calculated for 3 cycles for varying current oscillation and a 1.5T magnetic field. The resulting voltage per unit length was calculated and the current amplitude was continually reduced until the total voltage was approximately $40 \mathrm{~V}$. It was assumed that this would be a good approximation of the losses due to this harmonic. The validity of this assumption is somewhat uncertain because this is a total voltage.

It has to be mentioned that while the simulation in the presence of AC current and/or field is a standard practice, the presence of DC components makes the problem more complicated because of the induced initial currents and the time necessary for them to disappear. When a DC field is applied, for example, there are induced currents, which tend to decay in the order of seconds. While this time interval is very short in a real experiment, in the simulations it is extremely long. LANL tried to apply the DC component gradually (for example with a linear ramp or an exponential increase) to decrease simulation time, but this did not give any benefit for the problem of the decaying currents. Therefore simulations were run with an initial step from zero.

The $0.05 \%$ oscillation about $113 \mathrm{~A}$ results appeared to be in the correct order of magnitude for voltage. The short-term result for the loss is shown in Figure 4-21 as an example for $113+/-0.05 \%$ A and $1.5 T$ DC field. In Figure 4-21, the loss values are continuing to decay, at the last time step they were about $0.1 \mathrm{~W} / \mathrm{m}(2000 \mathrm{~W})$; however it is difficult to say with the scatter.

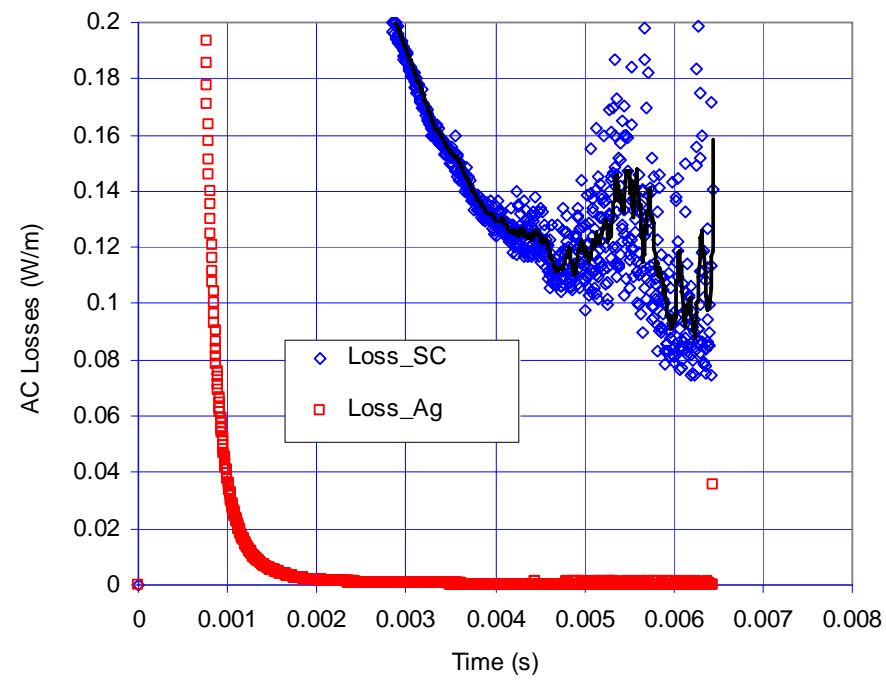

Figure 4-21 - AC Losses for 0.05\%, 113A, 2040 Hz, 1.5T Field. - Solid Line is Moving Average of Loss_SC 
The total heat loss for $2040 \mathrm{~Hz}$ is significantly larger than would be expected and it is believed that the value will continue to decay with increased cycles. To investigate this phenomenon and to understand better the relationship to the applied field, simulations were then run without an applied field and losses were compared for AC only and DC+AC current. Simulations were also run at higher current oscillation to avoid the scatter issue for the time being. At $2040 \mathrm{~Hz}$, a simulation was run with $10 \%$ oscillation but without the applied field for long time shown in Figure 4-22. After $8 \mathrm{msec}$, the AC loss has dropped to $7.5 \mathrm{~mW} / \mathrm{m}$ (150W), however it continues to decay with time. It is still significantly higher than the AC only term.

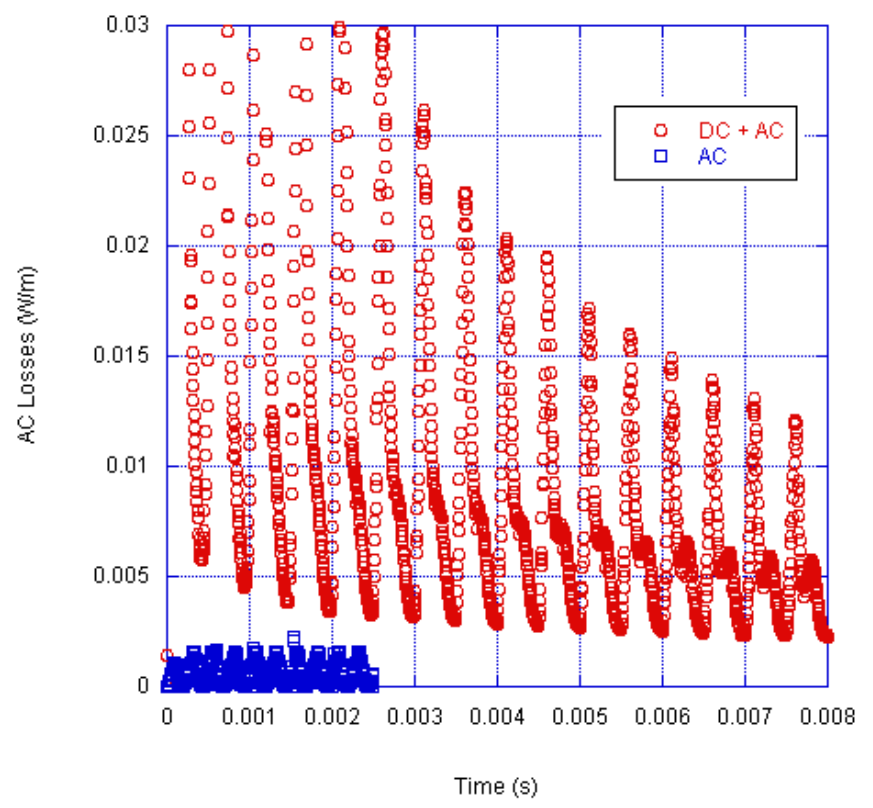

Figure 4-22 - AC Losses for 10\% AC Current with 113A DC, 2040 Hz, 0T Field

In preparation for looking at a fault current of a lower frequency, simulations were also run at $50 \mathrm{~Hz}$ without an applied field. Figure 4-23 is the evolution of the AC losses with a magnification in Figure 4-24. It was the goal of this analysis to determine if the AC+DC losses would approach the AC only losses. If this were the case, then the AC only could be modeled in a drastically shorter time for parametric studies that would approximate the $\mathrm{AC}+\mathrm{DC}$ values.

Figure 4-24 shows the losses of the DC+AC case (without the initial ramp) on a longer time interval (15 periods). The loss continues to decay, however it can serve as an upper bound on the losses. Using the average value from Figure 4-24, q $=0.25 \mathrm{~mW} / \mathrm{m}$. Over the length of the coil $(20,000 \mathrm{~km})$ this represents approximately $5 \mathrm{~W}$. The AC only peak is $\sim 0.070 \mathrm{~mW} / \mathrm{m}$. 


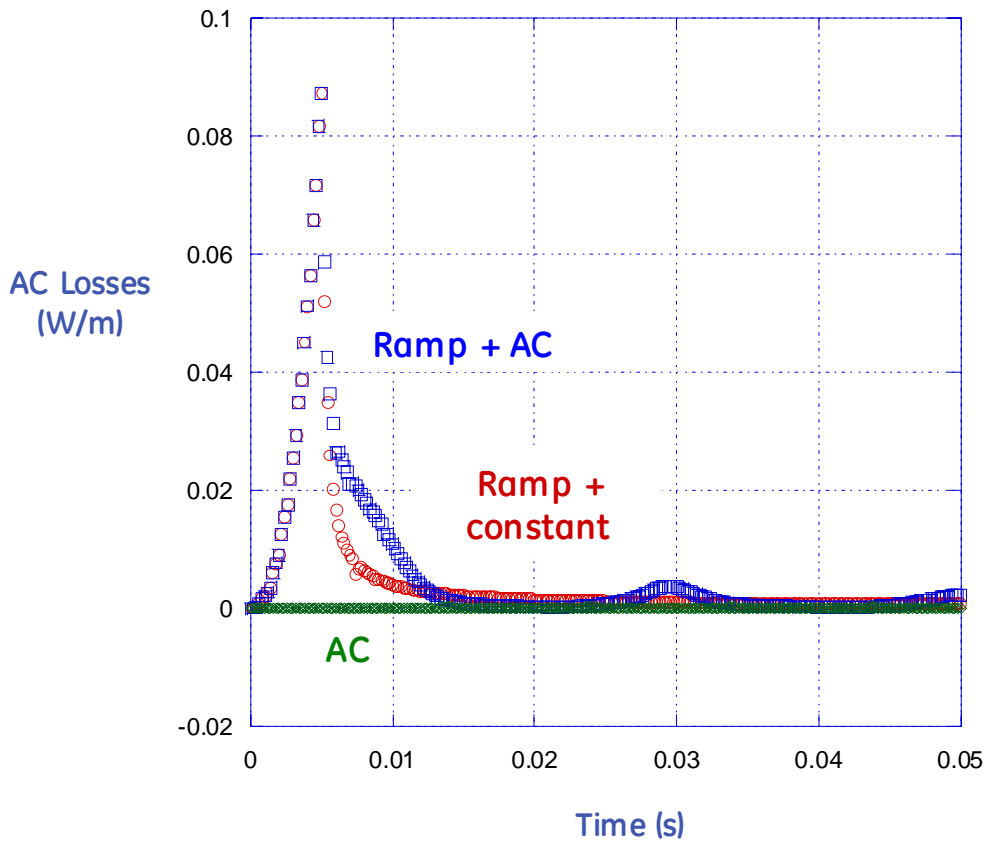

Figure 4-23 - Evolution of the AC Losses for the Three 50hz Cases - A Constant Current Reached with a Ramp (Red); A Constant Current with AC Oscillation Reached with a Ramp (Blue); A Pure AC Oscillation (Green). The Frequency is 50 Hz, 113 +/- 10\% DC A, 0T
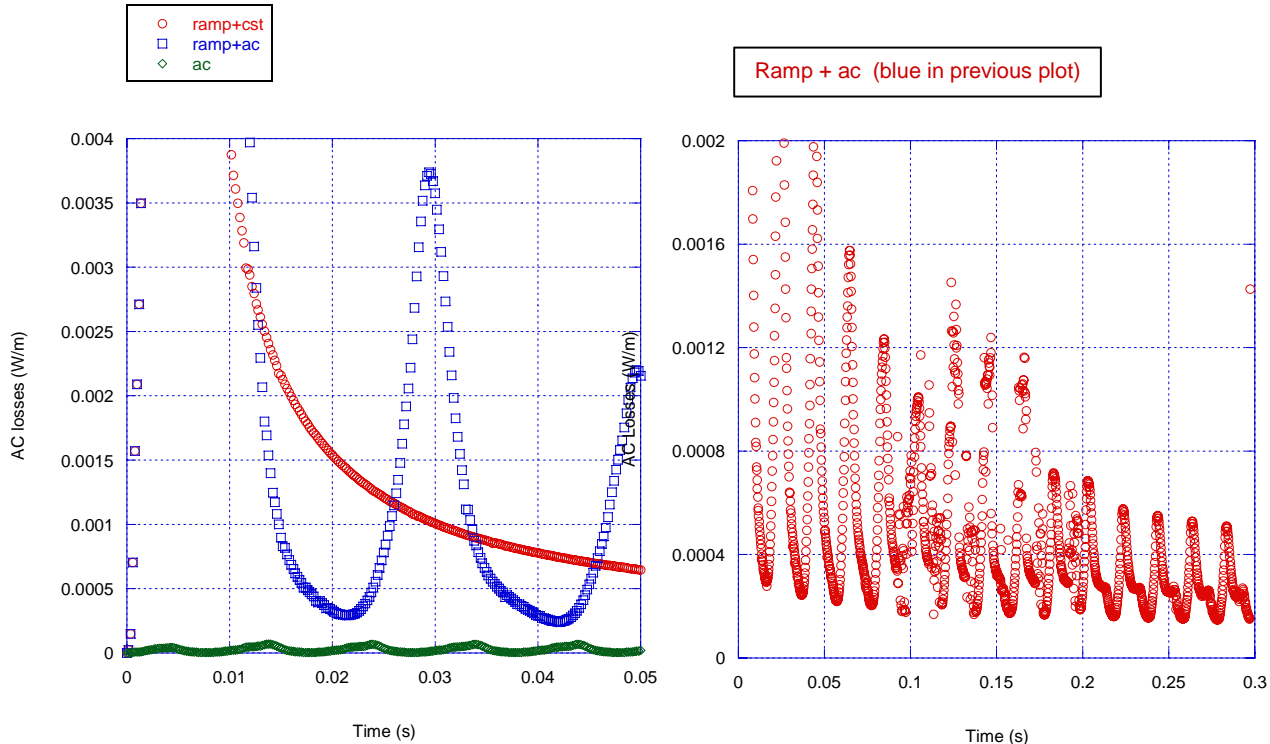

Figure 4-24 - Magnification of Figure 4-23 


\subsection{Excitation System}

The development of an excitation system designed specifically for the 100 MVA HTS generator was outside the scope of the program. The work expended on the excitation system was directed toward two goals:

- Understand how an excitation system might impose loads (voltages or currents) on the HTS coil, and

- Understand how an existing excitation system could be adapted for use in the factory test of the 100 MVA generator (Task 6 of the program).

A GE EX2100 exciter was determined to be appropriate for the application, with a ceiling voltage of 750 volts, and an exciter design current of 231 amps. Except for quench protection, options and protections are similar to the standard model.

Quench protection is expected to evolve with experience. On the prototype model, the exciter was expected to accept quench trip signals from an external source. Later on, when specific protocols are established, it would be possible for the exciter to sense and determine the need for a quench invert (negative forcing) or trip. 


\section{MVA Generator Design}

Task 1 of the 100 MVA program concerned the conceptual design of the full-size generator. Task 4 pertained to the detailed design of the generator and the components within the generator. This section covers those design tasks.

In all cases, the design options and design choices that were made reflected the need to develop a generator that could be scaled up to 250 MVA. In addition, the team considered scale-up to even larger generators in view of the poor economic prospects for smaller generators. See also Section 6.

\subsection{Product Requirements}

The design of the 100 MVA HTS generator followed GE-Energy processes for new product development programs. Customer requirements were formally defined in a Generator Product Specification. Other technical requirements not addressed by that specification or by industry standards would be covered by proprietary GE Design Practices.

The generator is expected to meet the applicable elements of IEEE C50.13. It shall also meet IEC 60034-1 and IEC 60034-3 to the extent those standards do not conflict with C50.10 and C50.13.

It is recognized that certain aspects of these standards, such as the short-term thermal overload for field windings may need interpretation in light of the HTS technology and other sections, such as the temperature limits for the field winding are entirely inapplicable.

The product specification is summarized in Table 5-1.

\section{Expected Operational Requirements}

The following items are related to operational considerations within the power station that the HTS generator must be capable of meeting to be considered as "operationally equivalent" to a conventional generator.

Static Start Operation - In the case of a combustion turbine-generator, the unit must be capable of being started by driving the generator with a power converter in variable speed mode.

Refrigeration System - Must be capable of operating with the generator at any speed within the its allowable range, including standstill. Furthermore, it must be capable of 
cooling the rotor indefinitely when the rotor is out of the generator for maintenance on the balance of the generator.

Rotor Vibration - The HTS generator shall meet the same requirements for rotor vibration as may be applied to conventional generators.

Table 5-1 - Highlights of the Product Specification for the 100 MVA HTS Generator

\begin{tabular}{|c|c|c|}
\hline Requirement & Value & Units \\
\hline Generator rating & 112 & MVA \\
\hline Speed & 3600 & rpm \\
\hline Allowable speed variation at full load & $95-103$ & $\%$ \\
\hline Armature voltage & 13,800 & $\mathrm{~V}$ \\
\hline Allowable armature voltage variation at full load & $95-105$ & $\%$ \\
\hline Power factor at rated MVA (overexcited) & 0.85 & --- \\
\hline Power factor at rated MVA (underexcited) & 0.95 & --- \\
\hline Short circuit ratio, minimum & 0.50 & --- \\
\hline Cooling gas temperature & 40 & $\operatorname{deg} \mathrm{C}$ \\
\hline Rotor cool-down time, maximum & 48 & hrs \\
\hline $\begin{array}{l}\text { Start-up time, maximum } \\
\text { (standstill to full load, rotor cold) }\end{array}$ & 10 & $\min$ \\
\hline Rotor warm-up time, maximum & 72 & hrs \\
\hline Rotor overspeed, warm, minimum & 4320 & rpm \\
\hline Number of warm overspeeds, minimum & 100 & --- \\
\hline Rotor overspeed, cold, minimum & 4500 & rpm \\
\hline Number of cold overspeeds, minimum & 100 & --- \\
\hline $\begin{array}{l}\text { Thermal cycles, minimum } \\
(298 \mathrm{~K} \rightarrow 30 \mathrm{~K} \rightarrow 298 \mathrm{~K})\end{array}$ & 100 & --- \\
\hline Vacuum pump-down time, maximum & 72 & hrs \\
\hline Vacuum getter recharge time, maximum & 24 & hrs \\
\hline Interval between vacuum maintenance, minimum & 3 & yrs \\
\hline $\begin{array}{l}\text { Start/stop cycles, minimum } \\
(0 \mathrm{rpm} \rightarrow 3600 \mathrm{rpm} \rightarrow 0 \mathrm{rpm})\end{array}$ & 10,000 & --- \\
\hline
\end{tabular}




\subsection{Electromagnetic Design}

\subsubsection{Electrical Design}

The 100 MVA (HTS) field generator is based on a Model 7A6 generator for a GE 7E gas turbine. A conventional armature would be used in conjunction with a superconducting field.

The HTS field coil comprises approximately 2740 turns of BSCCO-2223 HTS wire wound around a warm salient magnetic steel pole. The coil is held in place by a series of U-channels and studs that extend through the center of the pole and are in tension during rotation. See Figure 5-1 and Figure 5-2. The salient pole rotor is encased in a magnetic steel vacuum enclosure, sealed by welds at the ends so that the vacuum and cold areas can be maintained. An inch-thick aluminum EM shield is placed over the vacuum enclosure to protect the HTS coil from time varying magnetic fields, both transient and steady state, that would be present in the air gap.

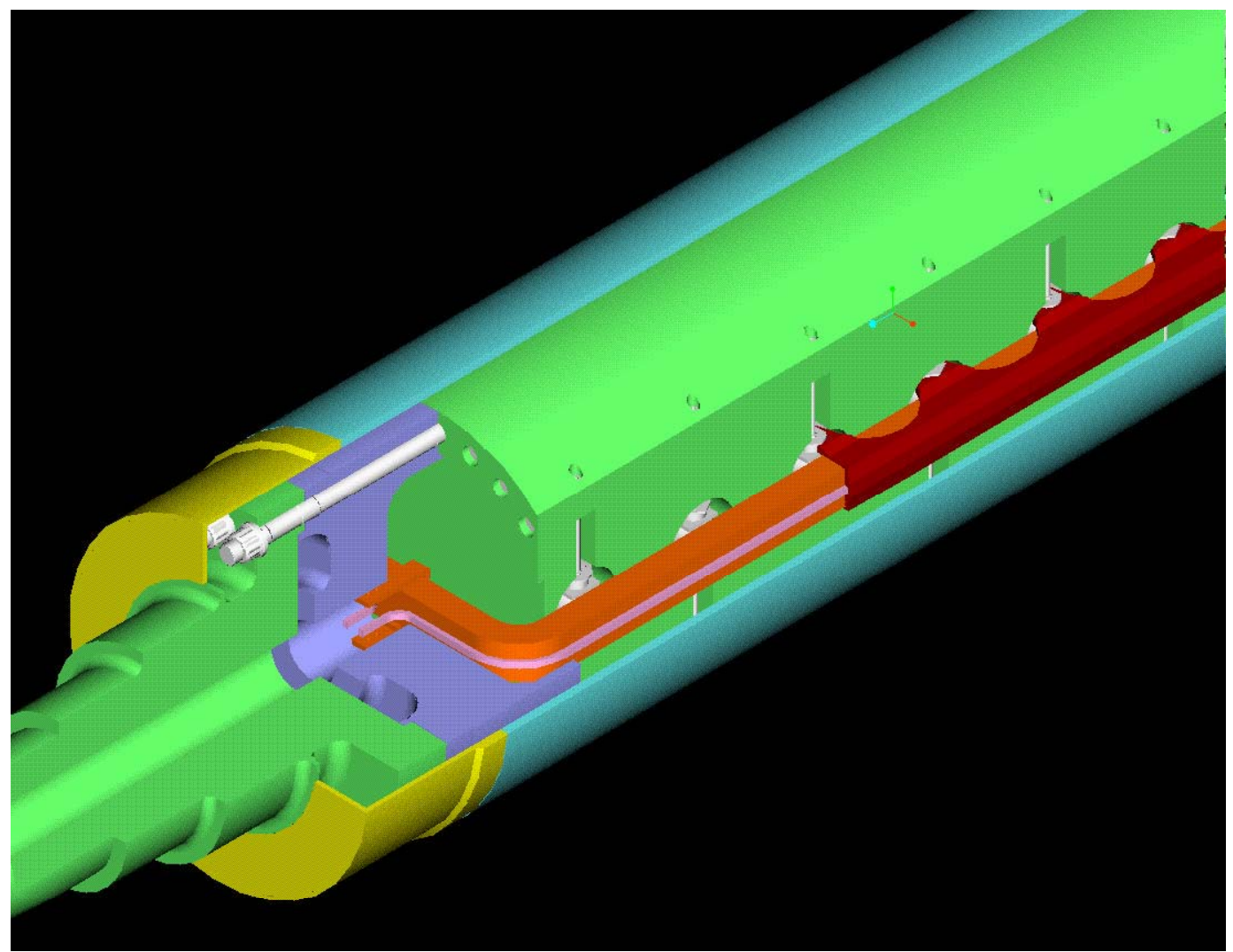

Figure 5-1 - 3D Cut-Away View Of The HTS Field Rotor. - Field Coil Is In Red, Helium Duct Is Pink, Magnetic Pole Is Green, Non-Magnetic Spacer Is Dark Blue, U-Channel Is Brick Red, And Electromagnetic Shield Is Light Blue 


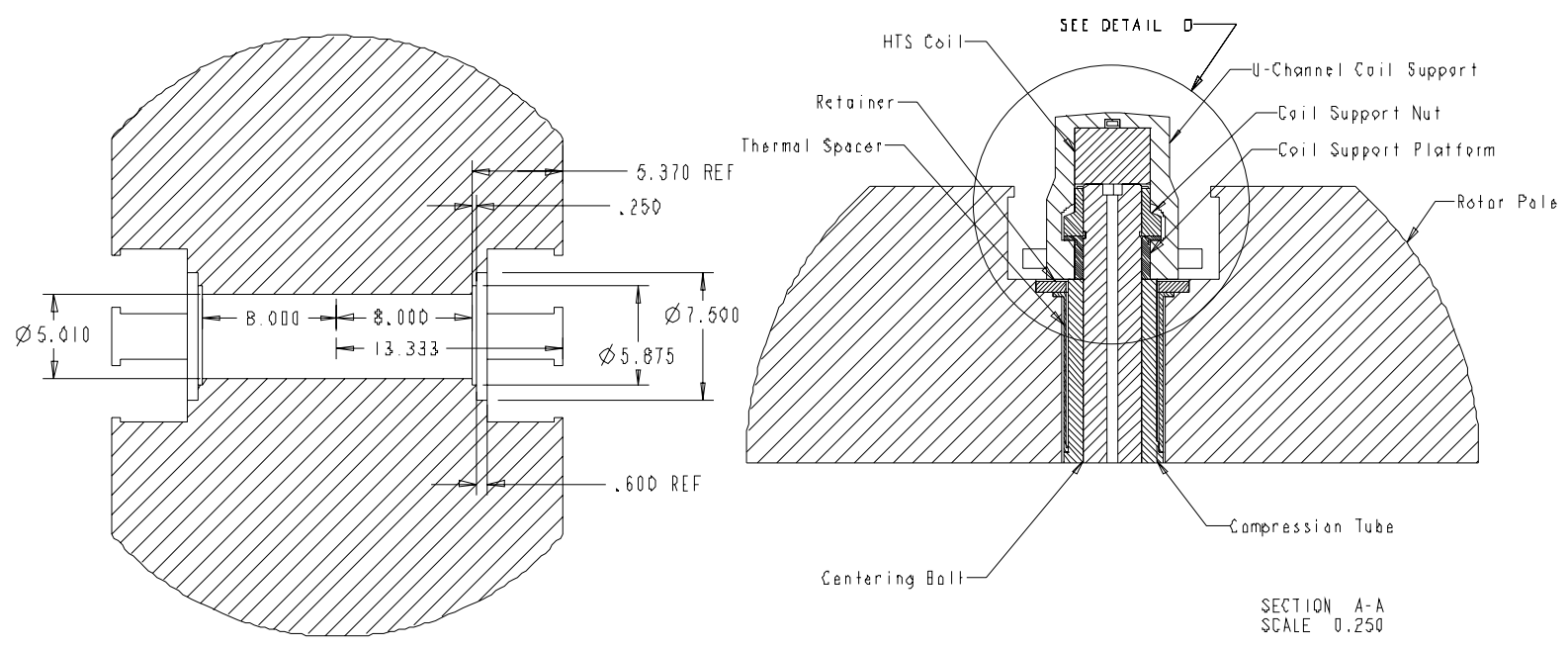

Figure 5-2 - Section Views of the HTS Rotor; Pole Cross-section Through Support Hole (Left) And Assembly Of Coil And Coil Support (Right)

Much of the analysis to be discussed in the following sections is based on a November 2003 design iteration. The design had a single aluminum shield functioning as both the vacuum enclosure and the EM shield. The model thus created is used not only in the excitation analysis, but also (with material property changes) in the frequency domain terminal reactance and rotating grid analyses.

In 2005 another design iteration was needed to add the magnetic vacuum enclosure under the aluminum EM shield. The coil support U-channels had changed from Inconel to aluminum with a different thickness. The coil and through-hole machining design had changed slightly. Excitation and loss calculations for this new design were performed to understand how it would operate in steady state.

Table 5-2 shows the reduction in losses of the HTS generator compared to the conventional generator. This efficiency benefit applies to an HTS rotor being adapted to an existing generator stator. It could be increased for a generator designed specifically for an HTS rotor. The benefit would be higher with a hydrogen-cooled machine, in which the field winding $\mathrm{I}^{2} \mathrm{R}$ loss is a greater portion of the total losses.

The reduction in the fan and windage loss is attributed to no cooling power allocated to the rotor via ventilation. That is offset by the refrigeration power requirements in the miscellaneous loss component. The stray load loss is reduced because of the more favorable rotor surface. The open circuit core loss is reduced because of somewhat lower flux densities in the stator teeth. The exciter loss is reduced because of the lower field current requirements. 
Table 5-2 - Change in Losses for the HTS Generator Compared to the Conventional Generator

\begin{tabular}{lcc}
\hline \multicolumn{1}{c}{ Loss Component } & $\begin{array}{c}\text { Improvement over } \\
\text { Conventional }\end{array}$ \\
\hline Fan \& Windage Loss & -45 & $\mathrm{~kW}$ \\
OC Core Loss & -14 & $\mathrm{~kW}$ \\
Stray Load Loss & -29 & $\mathrm{~kW}$ \\
Armature I'R Loss & -2 & $\mathrm{~kW}$ \\
Field I'R Loss & -216 & $\mathrm{~kW}$ \\
Exciter Loss & -17 & $\mathrm{~kW}$ \\
Miscellaneous Loss & +58 & $\mathrm{~kW}$ \\
Total Losses & $-\mathbf{2 6 5}$ & $\mathrm{kW}$ \\
\hline
\end{tabular}

\subsubsection{Excitation}

The HTS field pole cross-section is salient in nature with many machined features for coil support. The excitation calculation was completed using both 2D and 3D finite element methods.

The 2D excitation analysis was completed for many different design configurations, ending with the 2005 design for the Preliminary Design Review.

Dimensions for the 2D model are given in Table 5-3 with an explanation shown in Figure 5-3 and Figure 5-4. Figure 5-5 shows a solution of the 2D model at open circuit.

The 2D nature of the solution does not permit full representation of geometric features in the axial direction. In particular, the centering bolt diameters for the 2D model were reduced from their actual values to account for the fact that the bolts are round and the iron saturation of the pole center occurs for less than their entire diameter A 3D pole saturation analysis was performed on the 2005 design to check saturation. The model is shown in Figure 5-6. Table 5-4 shows results of the excitation analysis.

The excitation analysis was used to evaluate the steady state flux densities present at the coil surface. Flux density normal to the wire is a factor in determining the critical current of the superconducting wire. Figure 5-7 illustrates the flux density conditions at the coil under loaded conditions. The cold day rating is higher than rated day, because the prime mover can provide more torque. The bold-faced number (1.24 and 1.5 tesla) shows the maximum flux density normal to the wire in the coil. 
Table 5-3 - Rotor Dimensions - 2005 Design

\begin{tabular}{lcc}
\hline \multicolumn{1}{c}{ Dimension } & Variable & Value \\
\hline Pole top width & ptw & 26.74 \\
Pole tip depth & ptd & 6.55 \\
Pole top angle & pta & 0.00000 \\
Pole body center width & pctr & 17.70 \\
Pole radius (centered on 00) & prad & 17.75 \\
Inner shield thickness & s_th1 & 0.100 \\
Middle shield thickness & s_th2 & 0.250 \\
Outer shield thickness & s_th3 & 0.100 \\
Outer shield thickness & s_th4 & 1.000 \\
Coil Width (along pole) & cht & 3.641 \\
Coil Height (radial) & cwd & 2.745 \\
Coil distance from pole side & cdist & 4.553 \\
\hline
\end{tabular}

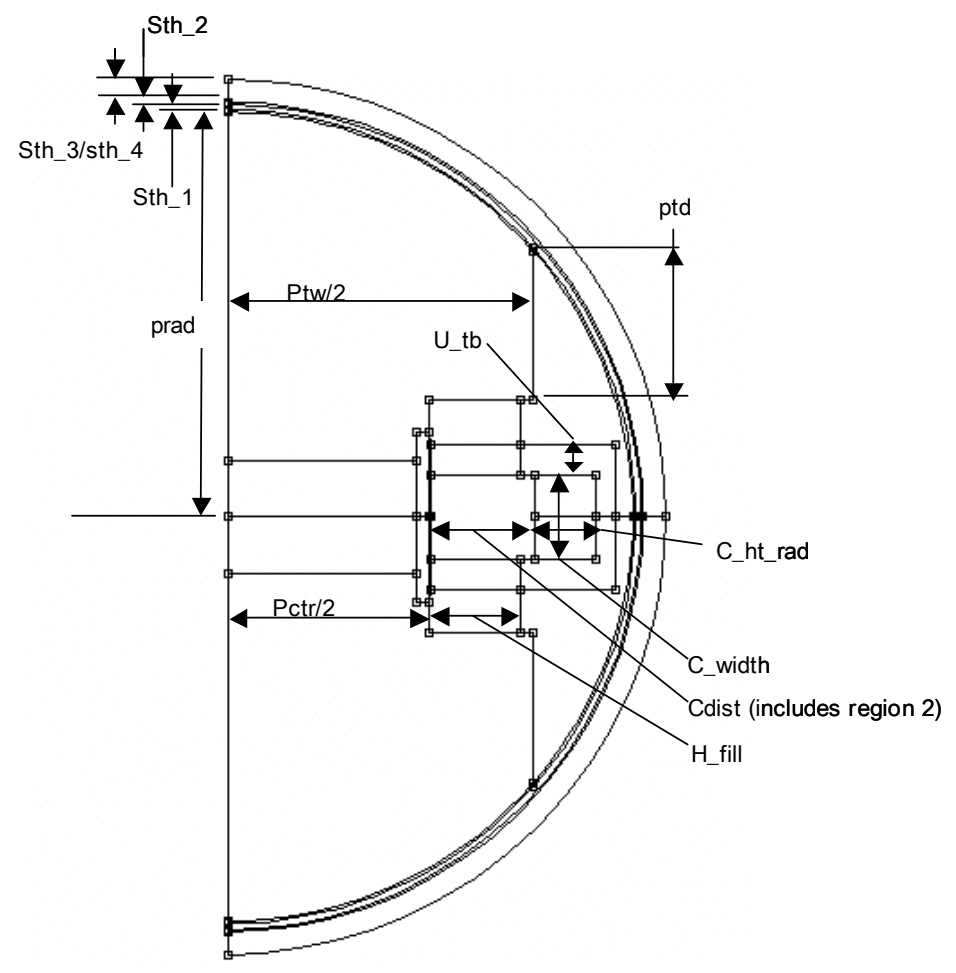

Figure 5-3 - Rotor Model And Input Variables 


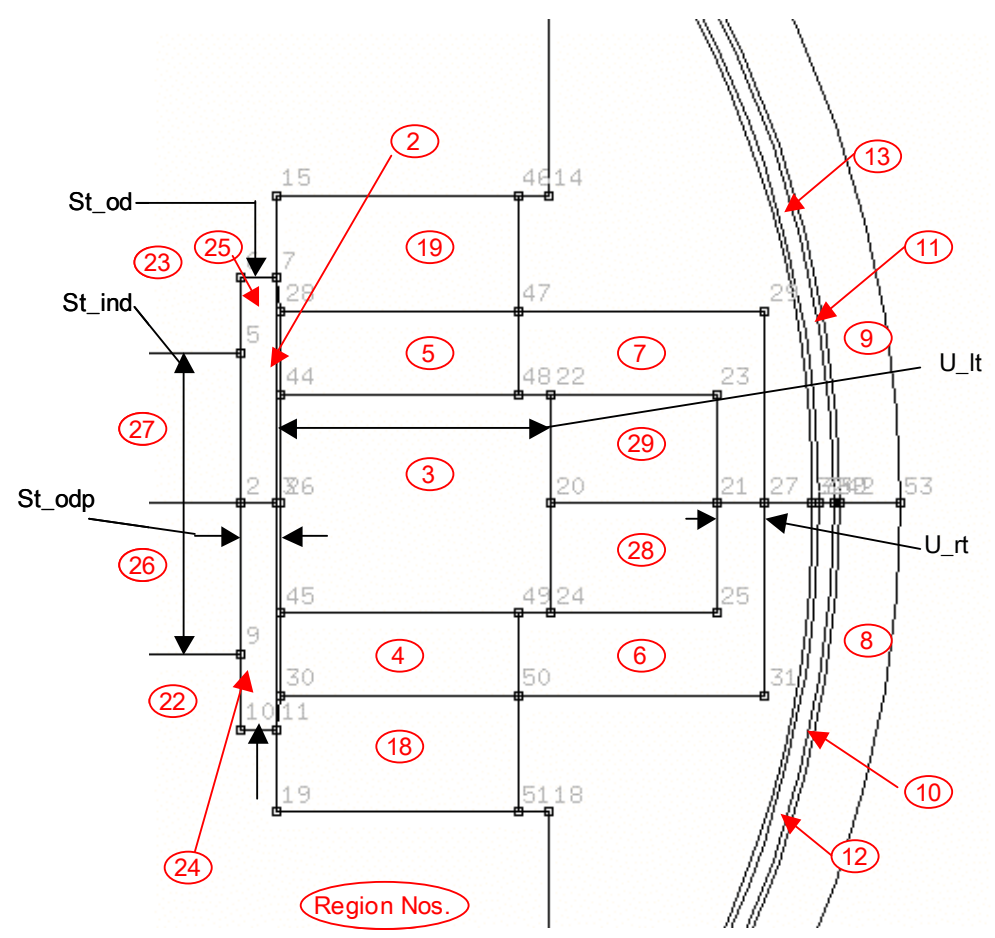

Figure 5-4 - Coil/Support Model

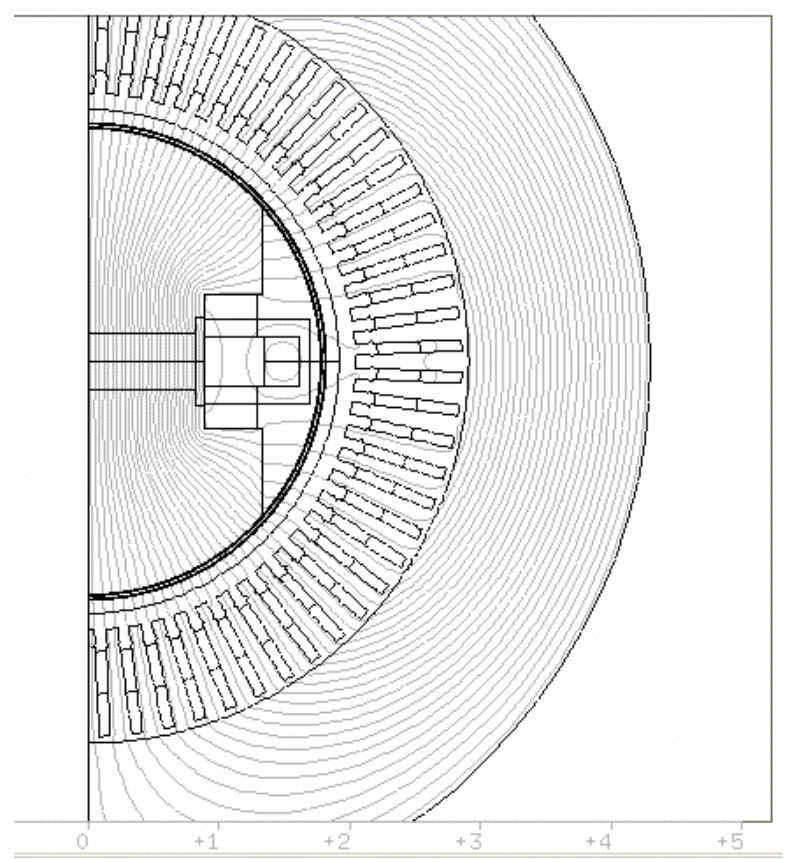

Figure 5-5 - 2D FE Excitation Solution for 2005 Design of the 100 MVA Generator 


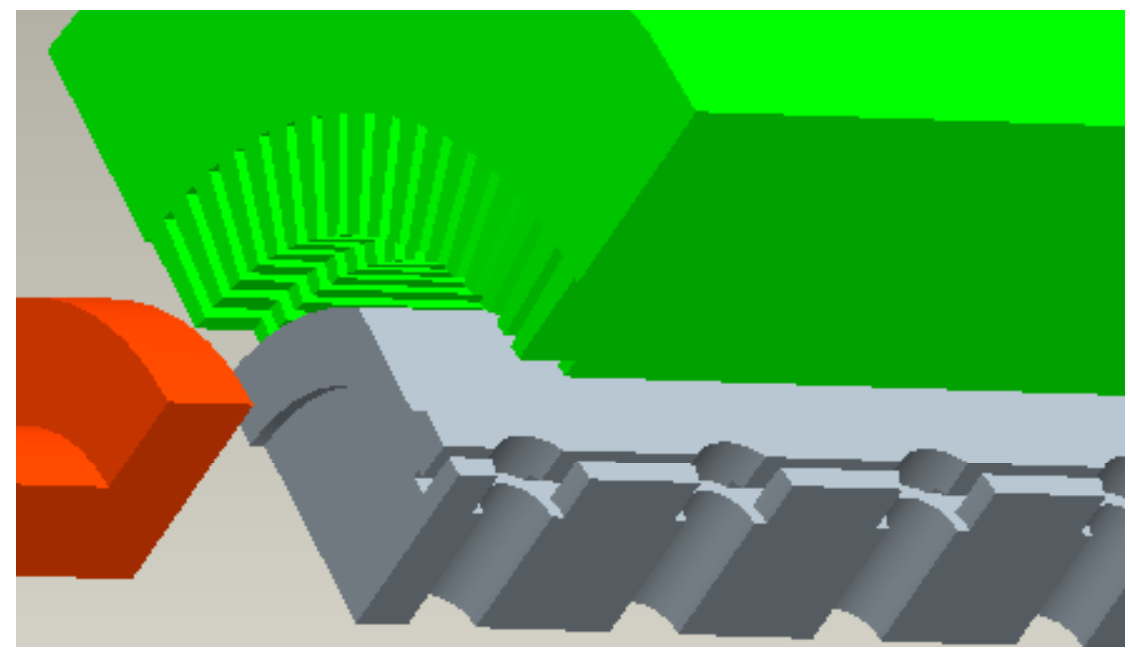

Figure 5-6 - 3D Model Used to Check MMF and Saturation

Table 5-4 - Summary of Excitation Results

\begin{tabular}{lccccc}
\hline & $\begin{array}{c}\text { Air Gap } \\
\text { Field }\end{array}$ & $\begin{array}{c}\text { No-Load } \\
\text { Field }\end{array}$ & $\begin{array}{c}\text { Synchronous } \\
\text { Impedance } \\
\text { Field }\end{array}$ & $\begin{array}{c}\text { Short } \\
\text { Circuit } \\
\text { Configuration }\end{array}$ & $\begin{array}{c}\text { Full Load } \\
\text { Field } \\
\text { Current (A) }\end{array}$ \\
\hline $\begin{array}{l}\text { Nov 2003 Design } \\
\text { PDR final w/reduced }\end{array}$ & 64.4 & 77.8 & 97.7 & 0.80 & 173.3 \\
thru hole & 56.2 & 85.5 & 94.2 & 0.908 & 181.8 \\
\hline
\end{tabular}

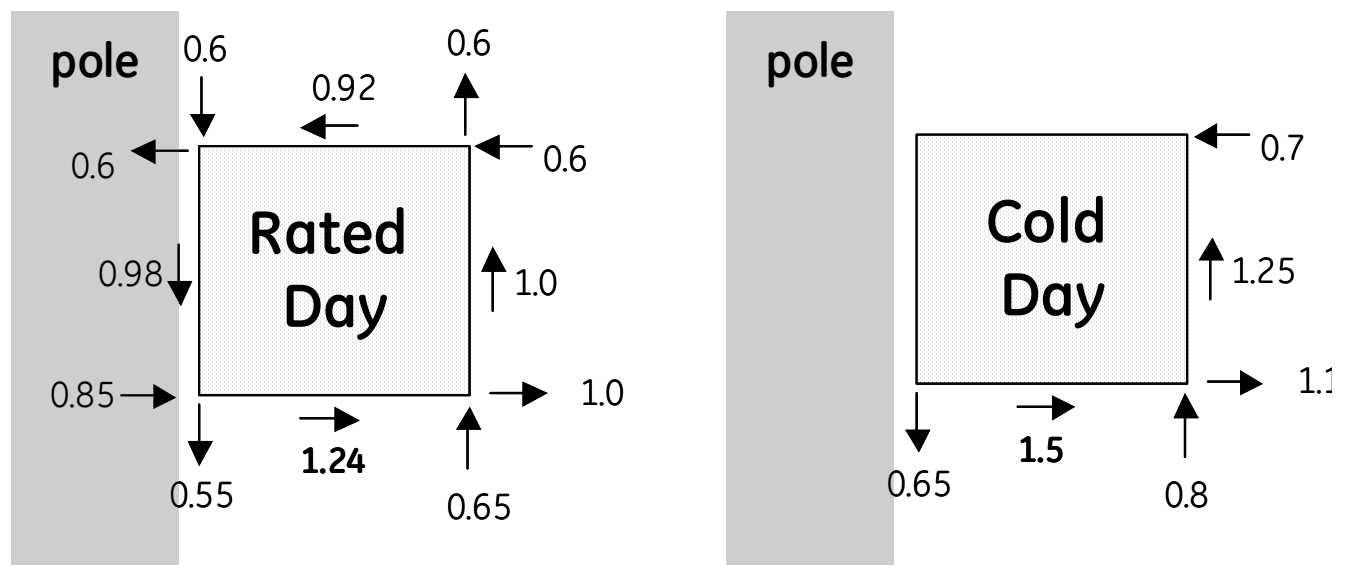

Figure 5-7 - HTS Coil DC Steady State Flux Density Exposure In Tesla For Rated Day And Cold Day Loads 


\subsubsection{Short Circuit Pole Face Loss}

The November 2003 design was analyzed in comparison to the conventional 7E design. In addition, the study compared finite element results to closed-form results found using a MathCAD tool that was later adopted for use on solid material rotor surfaces.

The loss was re-calculated using the MathCAD tool for the 2005 design. The short circuit pole face loss is $22.44 \mathrm{~kW}$ for the 2005 design. The conventional machine short circuit pole face loss is $51.8 \mathrm{~kW}$. The mechanical gap in the HTS machine is 1.25 inches, or 0.6 inches less than the conventional machine, which would typically lead to higher rotor surface loss. The difference is in the homogeneous aluminum surface that presents very low resistance to the circulating currents that will arise in response to the stator space harmonic MMFs in the gap.

\subsubsection{Unbalanced Loads}

Some level of load or current imbalance is a given in the power system. The generator must meet standard industry requirements for the capability to withstand steady state and transient negative sequence duty. In particular it must be able to withstand a $10 \%$ unbalance in armature current continuously and a transient $\mathrm{I}_{2}{ }^{2} \mathrm{t}$ product of 10 seconds.

The unbalanced armature currents create a counter-rotating MMF that produces doublefrequency eddy currents on the rotor surface that, in turn, cause resistance losses and heating that are dependent on the conductivity and permeability of the rotor surface. The material and rotor design both affect the conductivity. In conventional generators, loss concentrations and heating occur at discontinuities like wedge butt joints and rotor crossslots. In the HTS rotor, the aluminum EM shield is a good conductor and is continuous.

Based on both a closed form and a frequency domain FE analysis, the HTS generator will be able to meet both steady state and transient negative sequence requirements.

\subsubsection{Operational Impedances}

The terminal reactances and time constants, shown in Table 5-5, were found using the frequency scan method for the 2005 PDR design. The high degree of saturation in the direct axis drives the d-axis synchronous reactance to be less than the q-axis synchronous reactance. 
Table 5-5 - Results Of Frequency Response Analysis for the 2005 PDR Design and Others

\begin{tabular}{ccccc}
\hline Parameter & 2005 PDR Design & $\begin{array}{c}\text { November 2003 } \\
\text { Design }\end{array}$ & $\begin{array}{c}\text { Conventional } \\
\text { Generator }\end{array}$ & Units \\
\hline $\begin{array}{c}\text { Short Circuit } \\
\text { Ratio }\end{array}$ & 0.91 & 0.80 & 0.5 & --- \\
$\mathrm{X}_{\mathrm{d}}$ & 0.840 & 1.457 & 2.053 & $\mathrm{pu}$ \\
$\mathrm{X}_{\mathrm{dv}}^{\prime}$ & 0.294 & 0.356 & 0.216 & $\mathrm{pu}$ \\
$\mathrm{X}_{\mathrm{dv}}$ & 0.150 & 0.152 & 0.138 & $\mathrm{pu}$ \\
$\mathrm{T}_{\mathrm{do}}$ & 1919 & 4815 & 11.22 & $\mathrm{~s}$ \\
$\mathrm{~T}_{\mathrm{do}}$ & 1.15 & 0.285 & 0.232 & $\mathrm{~s}$ \\
$\mathrm{X}_{\mathrm{q}}$ & 0.999 & 0.915 & 2.003 & $\mathrm{pu}$ \\
$\mathrm{X}_{\mathrm{q}}^{\prime \prime}$ & 0.152 & 0.153 & 0.198 & $\mathrm{pu}$ \\
$\mathrm{T}_{\mathrm{q} o}^{\prime}$ & 1.1 & 32.5 & 5.93 & $\mathrm{~s}$ \\
$\mathrm{~T}_{\mathrm{q} \text { o }}$ & 0.004 & 0.817 & 0.252 & $\mathrm{~s}$ \\
$\mathrm{~L}_{\mathrm{ffd}}$ & 29.8 & 62.1 & 1.72 & $\mathrm{H}$ \\
\hline
\end{tabular}

\subsubsection{Transient Stability and Maximum Field Current}

The grid integration study in Section 8.1.1 discusses the scenario where, through backup protection action, a fault on the high side of the transformer can be left on the generator for a number of cycles. The generator has a transient stability characterized by how long a fault can remain before it pulls out of step with the power system. The grid integration study found the HTS generator transient stability to be comparable to that of the 7E conventional generator.

Part of the transient stability simulation was the recovery transient that occurs when the generator fault is cleared and the generator pulls back into step with the power system and resumes carrying load. The recovery from a critical length fault causes the highest field current transient known to occur in the generator.

Rotating Grid, a time-stepping FE code, was used to simulate the critical length fault and recovery transient on the November 2003 design generator. The goal of the study was to define the maximum field current, flux density, forces on the coil, crushing forces on the shield and rotor torques. Figure 5-8 shows the generator cross-section under load. 
Rotating Grid models the generator with time varying saturation and eddy currents during the transient. Other means were also used to study the event, and these had the advantage of simple set-up and solution. Table 5-6 shows a comparison of peak field current and critical fault clearing time for several tools. The analyses listed also explore the effect of changing the rotor inertia and fault duration.

Torque in the air gap and on components closely tied to the air gap such as the shield are electrically determined and are not dependent on the rotor inertia. Rotor inertia would have some effect on how this air gap torque is transmitted to the coupling.

The Rotating Grid field current transient is shown in Figure 5-9. Peak values for various means of analysis are compared in Table 5-6.

Table 5-6 - Comparison of Transient Stability Run by Various Methods

\begin{tabular}{|c|c|c|c|c|}
\hline $\begin{array}{c}\text { Calculation } \\
\text { Tool }\end{array}$ & $\begin{array}{l}\text { Analysis } \\
\text { SSC length } \\
\text { (cycles) }\end{array}$ & $\begin{array}{l}\text { Peak Field } \\
\text { Current (A) }\end{array}$ & $\begin{array}{c}\text { Inertia } \\
\left(\mathrm{kg}-\mathrm{m}^{2}\right)\end{array}$ & $\begin{array}{l}\text { Critical Fault } \\
\text { Clearing Time } \\
\text { (cycles) }\end{array}$ \\
\hline Flux2D & 18.0 & 183.0 & 7127 & 18.0 \\
\hline \multirow{3}{*}{ Rotating Grid } & 16.0 & 147.0 & 7127 & \\
\hline & 17.0 & 181.6 & 7127 & \\
\hline & 18.5 & 204.0 & 7127 & \\
\hline \multirow{5}{*}{ MathCAD } & 16.0 & 164.2 & 6304 & 16.7 \\
\hline & 16.5 & 173.9 & 6304 & 16.7 \\
\hline & 15.0 & 141.7 & 7127 & 17.7 \\
\hline & 17.0 & 167.4 & 7127 & 17.7 \\
\hline & 18.5 & 189.3 & 7600 & 18.3 \\
\hline (no recovery) & 19.0 & 193.2 & 7600 & 18.3 \\
\hline \multirow{2}{*}{ PSEC } & 18.0 & 230.0 & 7620 & 18.5 \\
\hline & 18.5 & 248.0 & 7620 & 18.5 \\
\hline
\end{tabular}




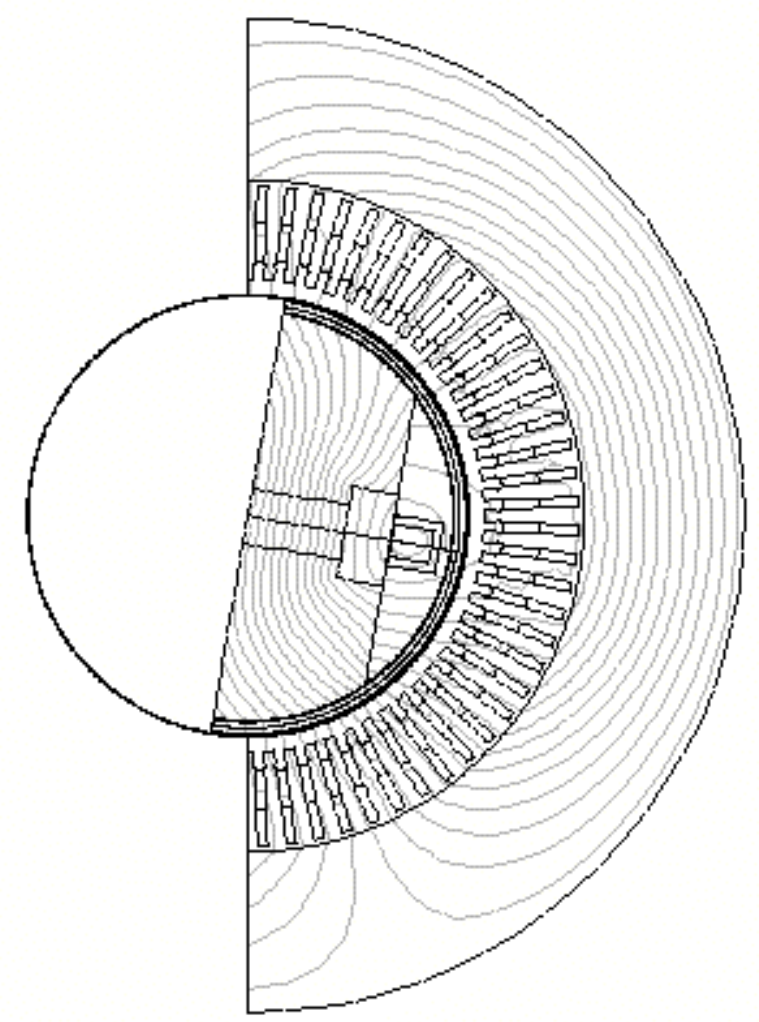

Figure 5-8 - Generator Cross-section at End of Full Load Run

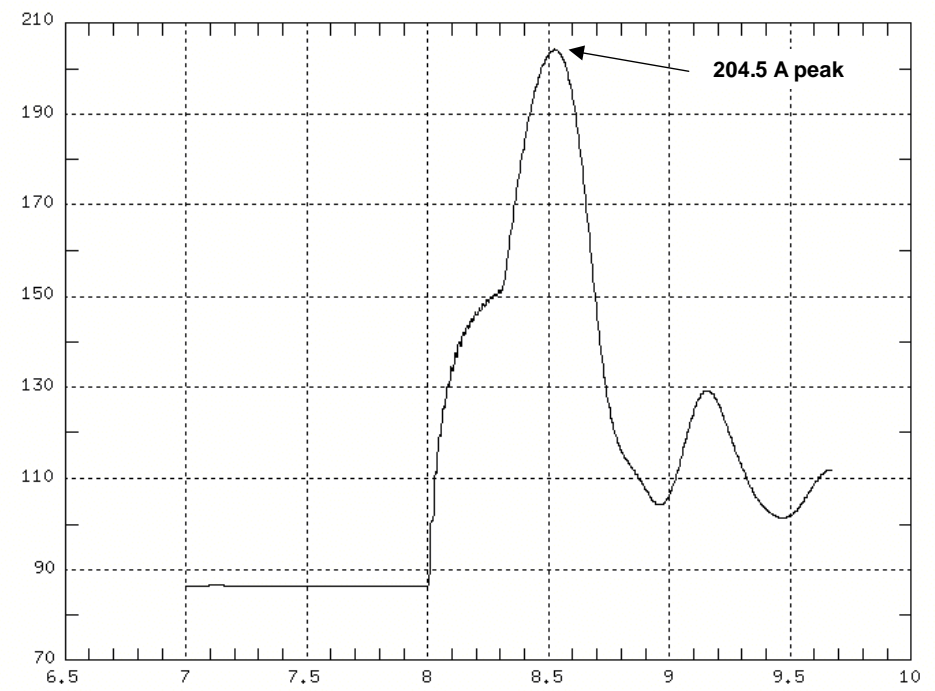

Figure 5-9 - Rotating Grid Field Circuit Current During Load, Sudden Short Circuit and Recovery 


\subsubsection{Generator Fault Duty}

The grid integration study subjected the generator and its excitation system to a number of faults and also studied sizing of the discharge resistor to limit $I^{2} t$ duty on the stator and rotor.

Rotating Grid simulated faults on the November 2003 design to determine internal forces, torques and flux densities. The initial load was applied as a simple inductor and resistor. At the end of the six-cycle fault, a discharge resistor (2.2 $\Omega$ ) was applied to remove excitation and de-energize the generator. When the discharge resistor was inserted into the field circuit, the turbine torque was scaled back to a nominal value of around $100 \mathrm{~N}$ m.

The three-phase and double line-to-ground faults were run through the entire simulation including discharge. The line-to-line fault was run only through the first six cycles and results were comparable to the line-to-line to ground fault because of the high-resistance neutral. The single line-to-ground fault would produce very little response in the armature and field because the generator has a high-resistance neutral.

A comparison of the results is given in Table 5-7. In general, the fault duty in the shield is most severe for the double line-to-ground fault. Fault duties on the coil and U-channel are most severe during the three-phase fault.

Table 5-7 - Comparison of Peak Duties for Terminal Faults

\begin{tabular}{lcc}
\hline & $\begin{array}{c}\text { Three Phase } \\
\text { Fault }\end{array}$ & $\begin{array}{c}\text { Line-Line- } \\
\text { Ground }\end{array}$ \\
\cline { 2 - 3 } & 348 & 292 \\
Peak $\mathrm{I}_{\mathrm{f}}$ (A) & 770 & 690 \\
${\text { Peak } \mathrm{V}_{\mathrm{f}} \text { (V) }}_{\text {Peak }_{\mathrm{a}} \text { (A) }}$ & 102,000 & 96,000 \\
Peak Shaft Torque (N-m) & $2.4\left(10^{6}\right)$ & $3.2\left(10^{6}\right)$ \\
Peak Shield Torque (N-m) & $2.1\left(10^{6}\right)$ & $2.9\left(10^{6}\right)$ \\
\hline
\end{tabular}

Graphical results follow, comparing various quantities between the three-phase and double line to ground fault.

- Armature current for the L-L-G fault: Figure 5-10.

- Field current: Figure 5-11 \& Figure 5-12

- Field voltage is taken at the discharge resistor: Figure 5-13

- Total shaft torque includes the entire rotor, and includes torque developed in the shield, forging, coil and U-Channel. Figure 5-14. 


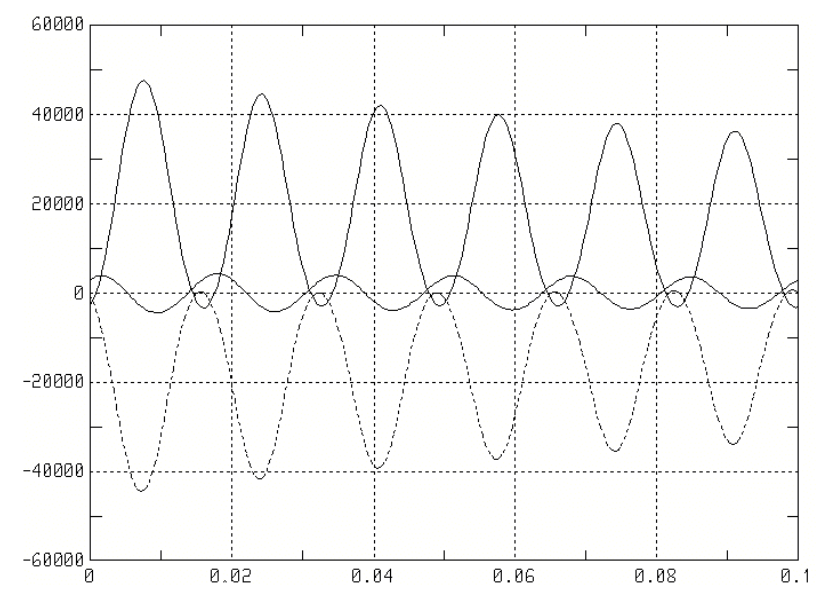

Figure 5-10 - Armature Circuit Current During Double Line-to-Ground Fault

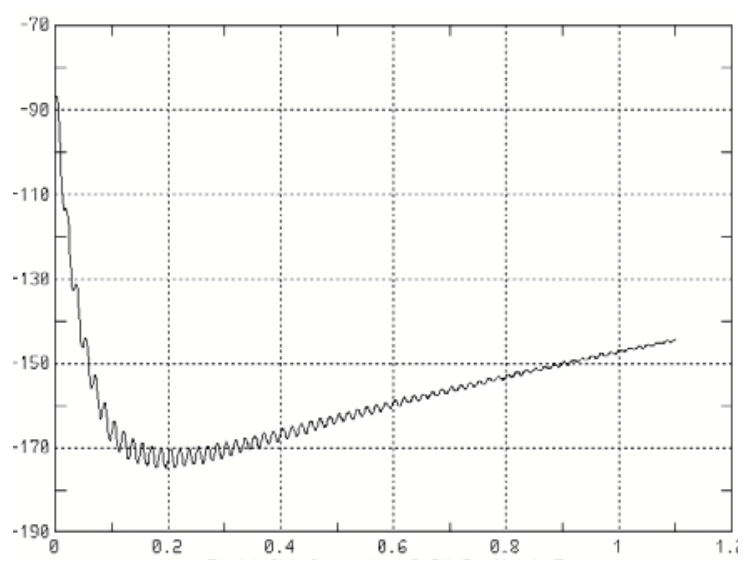

Figure 5-11 - Field Circuit Current During Three-Phase Fault at Terminal

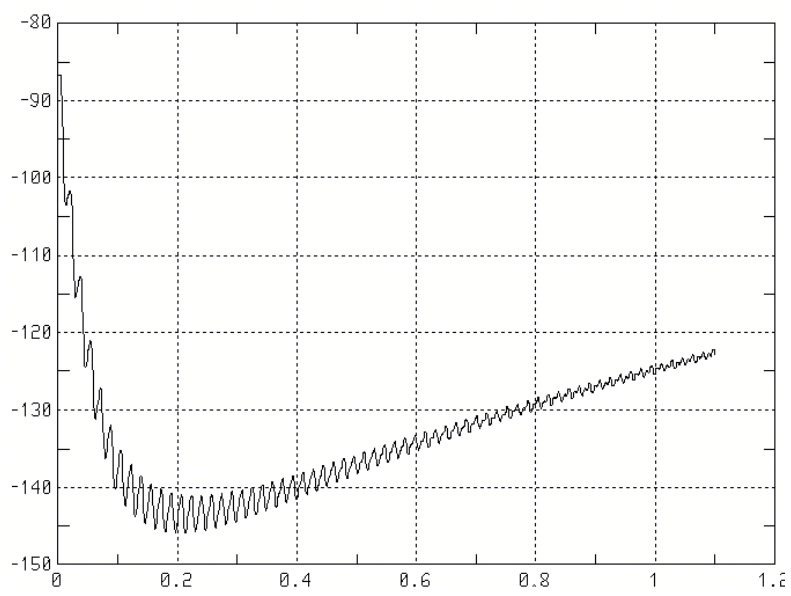

Figure 5-12 - Field Circuit Current During Double Line-to-Ground Fault 


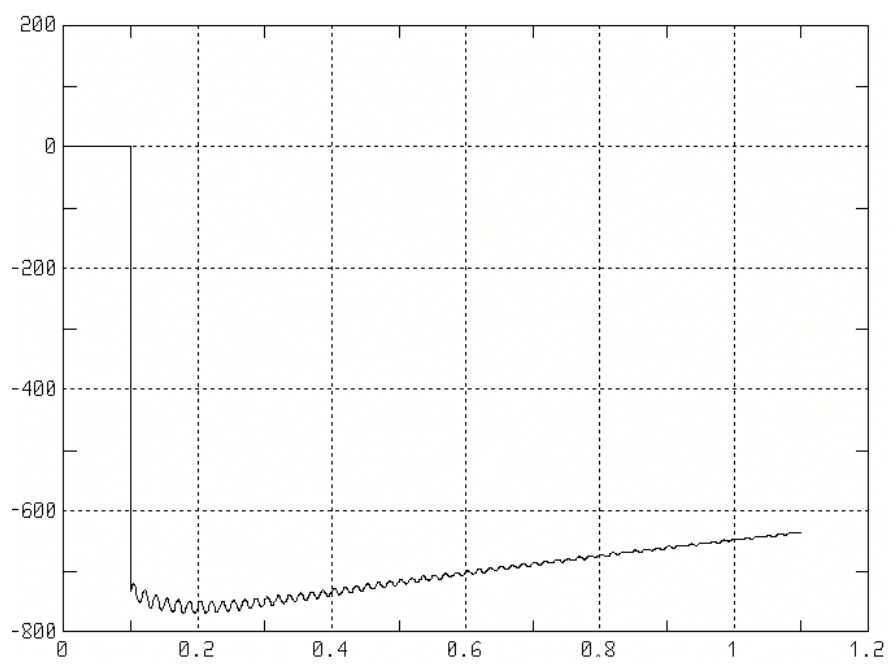

Figure 5-13 - Field Voltage During Three-Phase Fault

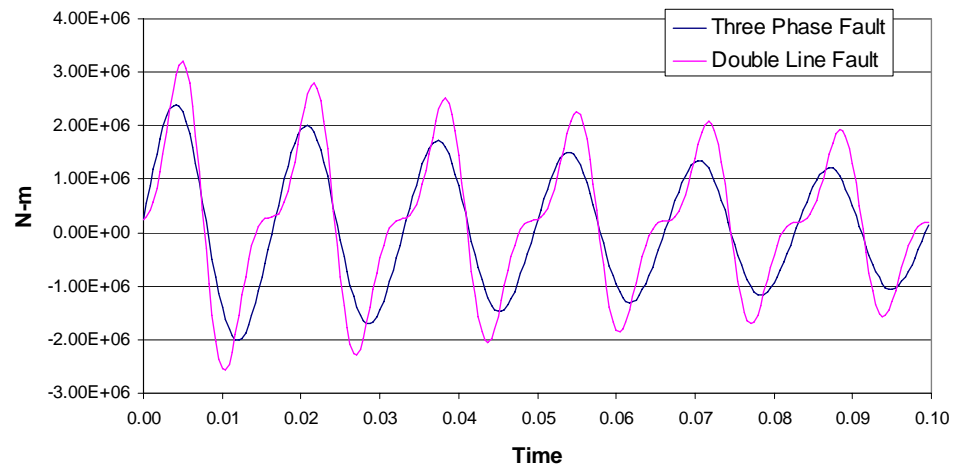

Figure 5-14 - Total Shaft Torque for Terminal Faults

\subsection{Machine Ventilation Design}

The HTS rotor will not use conventional ventilation schemes. Instead, the HTS coil will be cooled internally with the helium gas and will have limited thermal connection with the stator. Unlike a conventional generator, all of the ventilation flow created by the fan will occur only in the stator. Naturally, there will be no flow created from the rotor.

\subsubsection{Load Points}

Both the conventional and HTS generator were evaluated for three load cases. Some details of these load cases are provided in Table 5-8. 
Table 5-8 - Load Points for 7E HTS Generator Stator Ventilation Validation

\begin{tabular}{cccc}
\hline Load Case & $\begin{array}{c}\text { Generator } \\
\text { Output } \\
\text { (per unit) }\end{array}$ & $\begin{array}{c}\text { Voltage } \\
\text { (per unit) }\end{array}$ & $\begin{array}{c}\text { Cold Gas Temp } \\
\left({ }^{\circ} \mathbf{C}\right)\end{array}$ \\
\hline Load 1 - Base Load & 1.000 & 1.000 & 40 \\
Load 2 - Cold Day & 1.311 & 1.000 & 2.2 \\
Load 3 - Hot Day & 0.772 & 1.000 & 63.3 \\
\hline
\end{tabular}

\subsubsection{Stator Temperatures}

The calculated stator slot RTD temperatures for the conventional and HTS versions of the 7E generator are shown in Figure 5-15. The figure shows that for the most part, the RTD temperature in the HTS generator were lower than that of the conventional generator. The short section where the HTS RTD temperatures are higher than the conventional values is not a concern.

The air gap temperatures are important to the rotor thermal budget because they influence the temperature of the warm rotor components. Consequently, the air gap temperatures found in this study would be used in the thermal budget to determine the heat flow to the cold parts of the rotor. The average air gap temperatures are listed Table 5-9.

As with the stator slot RTD temperatures, the average air gap temperatures are lower for the HTS generator than for the conventional generator. These results also show that the highest air gap temperature for the HTS generator will be approximately $100^{\circ} \mathrm{C}$.

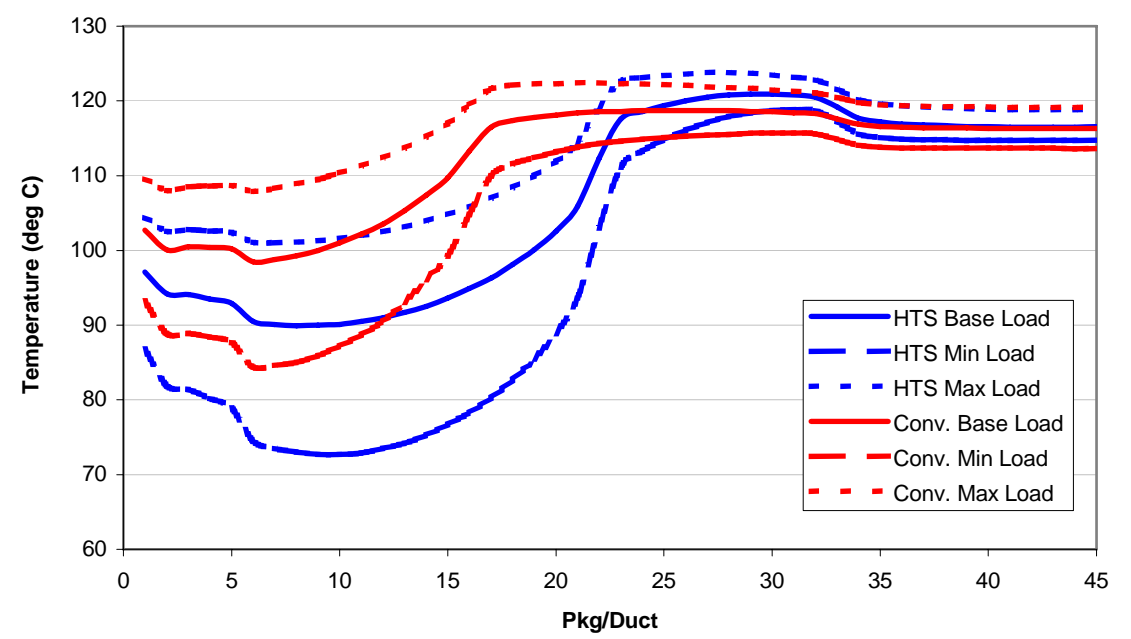

Figure 5-15 - RTD Temperatures for HTS and Conventional 7E Generators 
Table 5-9 - Average Air Gap Temperature for HTS and Conventional Generators

\begin{tabular}{|c|c|c|c|c|}
\hline & \multirow{2}{*}{$\begin{array}{l}\text { Generator } \\
\text { Output } \\
\text { (per unit) }\end{array}$} & \multirow{2}{*}{$\begin{array}{c}\text { Cold Air } \\
\text { Temperature } \\
\left({ }^{\circ} \mathrm{C}\right)\end{array}$} & \multicolumn{2}{|c|}{$\begin{array}{l}\text { Average Air Gap } \\
\text { Temperature }\left({ }^{\circ} \mathrm{C}\right)\end{array}$} \\
\hline & & & HTS & Conventional \\
\hline Base Load & 1.000 & 40 & 81.5 & 84.1 \\
\hline Cold Day & 1.311 & 2.2 & 55.2 & 59.6 \\
\hline Hot Day & 0.772 & 63.3 & 98.0 & 99.5 \\
\hline
\end{tabular}

\subsection{Rotor Mechanical Design - Rotor Shaft}

The rotor shaft is comprised of five major structural elements shown in Figure 5-16. In this arrangement, the rotor body segment accommodates the coil and coil support assembly. The spacers mounted at each end of the body are nonmagnetic in order to minimize rotor shaft saturation in these regions. Slots in the spacers at 90 degrees to the pole centerline permit the end windings of the continuous coil to pass completely around the rotor body. The stub shafts at the ends of the assembly are designed to satisfy all interface requirements imposed by the conventional rotor it would replace.

Collector rings (slip rings), which are used to transfer excitation current from a stationary source into the rotor, are mounted to the non-drive end stub shaft. In addition, the nondrive end stub shaft is bored to accommodate the electrical and refrigeration connections to the HTS coil, along with the associated insulating features.

The segments are assembled together by means of studs, which pass through the stub shafts and spacers and thread into the ends of the rotor body. The studs are tightened by means of hydraulic tensioning nuts.

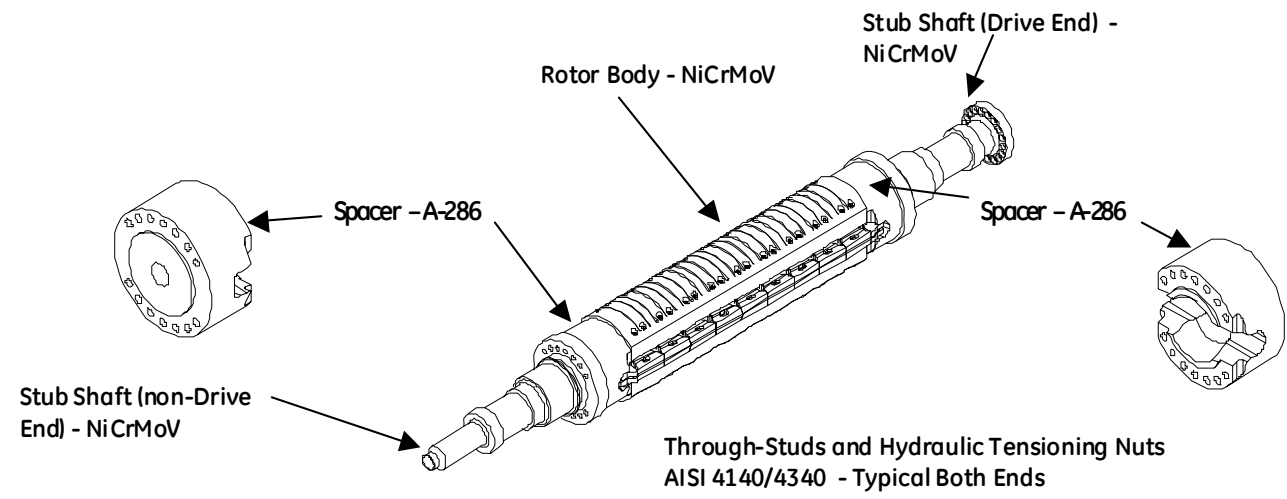

Figure 5-16 - HTS Rotor Structure Components 


\subsubsection{Primary Design Requirements}

The primary mechanical requirements of the HTS rotor structure involve considerations of both low- and high-cycle fatigue life, emergency over-speed capability, and normal and fault torque capability.

The rotor has been designed to meet requirements of 10,000 normal mission cycles and 100 minor over-speed cycles (to $25 \%$ above rated speed) without fatigue crack initiation or gross material yielding, as well as infinite high-cycle fatigue life. It also can survive an over-speed incident of twice the rated speed without rupture.

Besides addressing critical mechanical stresses, an important design goal is to equalize the transverse rotor stiffness about the pole and quadrature axes. This is necessary to limit a potential source of twice-per-revolution vibration stimulus. Finally, adequate corrective balance weight provisions are required to insure that once-per-revolution vibration can be maintained to within prescribed limits during operation.

\subsubsection{Body Cross-Slot Arrangement}

Provisions for the support of the HTS coil create an inherent lack of stiffness symmetry in the rotor body cross-section, the bodies of the spacer pieces, and the bolted joints. This asymmetry must be compensated for in the design, otherwise a constantly varying gravity sag in the rotor will occur during rotation. The sag variation will go through two complete excursions, or cycles, with each complete rotation. This forced cyclic motion will in turn tend to induce shaft vibrations at the same twice-per-revolution frequency. Cross-slots cut along the length of the rotor body at the poles are used to eliminate the stiffness asymmetry by reducing the overall stiffness of the poles in bending about the quadrature axis. Figure 5-17 shows the cross-slot design.

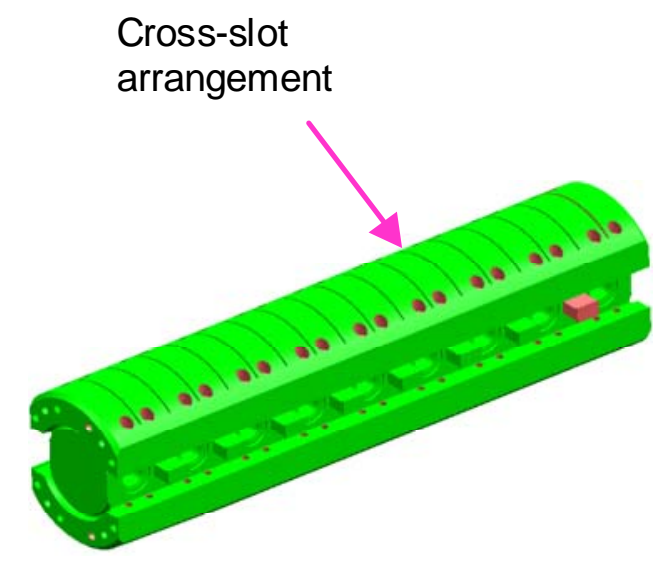

Figure 5-17 - Rotor Body Cross-Slotting

Cross-slots are produced by making saw cuts in the rotor in a plane normal to its rotational axis, using a circular blade. At the time of the Preliminary Design Review, it 
was anticipated that these cuts would be made using standard tooling, thus fixing the radius and width of the cross-slot geometry. Depth and pitch of the cuts were then optimized using a Design of Experiments approach, with the output being the predicted difference in sag of the rotor with poles vertical vs. poles horizontal.

\subsection{HTS Coil}

The HTS coil was a racetrack coil formed of 2740 turns of BSCCO-2223 wire from American Superconductor. The wire, as purchased from AMSC, was laminated with stainless steel strips to improve its ability to withstand compressive and tensile stresses. The wire insulation was half-lapped Kapton tape.

The coil, shown in schematic cross-section in Figure 5-18, consisted of the insulated wire arranged in 18 turns per layer and 153 layers. Each layer was separated from the adjacent layers by a 3.5 mil layer glass separator impregnated with epoxy resin.

The gross number of turns in the cross-section was 2754 turns. It was expected that layerto-layer transitions within the coil will reduce the actual number of turns to 2740 . Accordingly all electromagnetic calculations have been done with the lower turn count.

The formed coil was enclosed with a glass/Kapton laminate ground insulation (two 0.008” layers of Krempel TRIVOLTHERM ${ }^{\circledR}$ GKG) and copper cladding, which served to redistribute local heating. A copper cooling channel containing the gaseous helium coolant was mounted to the radially outer surface of the coil.

The coil would be wound on a bobbin that provides tight dimensional control over the span of the coil and its cross-sectional width. The wound coil would be cured in an oven following a prescribed time/temperature profile. The impregnated layer separators would provide the epoxy filler.

Kapton tape was the preferred wire insulation. It provided better lap shear strength and electrical performance at cryogenic temperatures than the Teflon tape used for the Demonstrator coil.

A significant amount of work was performed to understand how durable the Kapton tape would be. The laminated strips of stainless steel tape soldered to each side of the wire formed sharp edges that may have contributed to a shorted turn in a second Demonstrator coil made from Kapton insulated wire. As of the conclusion of the program, the shorted turn risk remained high and would deserve a concentrated effort in any follow-on program. 


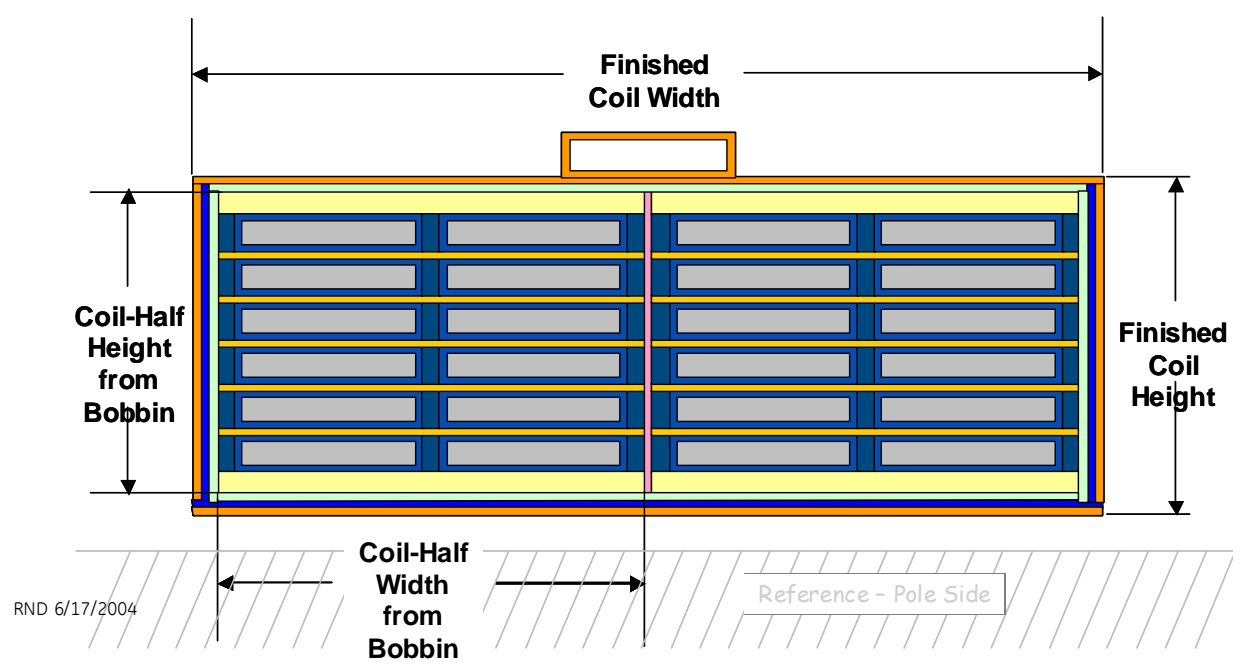

Figure 5-18 - Coil Construction Schematic. The Actual Coil Has 2740 Turns

\subsection{HTS Coil Support}

Mechanical support of the superconducting field coil of a turbine-generator using HTS wire is a very significant design challenge, requiring balancing many conflicting design goals. The mechanical support of the coil must at some point cross the thermal boundary between the cryogenically cooled coil and the main structural portions of the rotor. To minimize thermal loads on the cryogenic refrigerator, the cross-sectional area of this connection must be minimized and lengths maximized. On the other hand, to provide a secure and stable connection in the presence of the very large forces encountered in a large turbine-generator, large cross-sections and short lengths are desirable.

In a high-density superconducting generator the useful torque of the machine is generated on the HTS coil itself. The coil support in that configuration must transmit the full machine torque from the cryogenic coil to the ambient temperature shaft to the prime mover. The centrifugal forces can be largely contained within the cryogenic portion of the rotor structure. Designing for successful dynamic performance can also represent a significant design concern for the coil support of a high-density superconducting generator rotor.

The 100 MVA generator design uses a low-density warm iron design to minimize the structural design issues discussed above for the high-density concept. This was especially important given that a project goal for the 100 MVA design was to produce a design that could be scaled up to larger rated generators more typically used in commercial electric power generation.

The coil and coil support assembled on the rotor body is shown in Figure 5-19. A crosssection of the rotor and coil support is shown in Figure 5-20. The cold coil support concept uses a large cross-section Inconel centering bolt and compression tube combined with an Inconel coil support platform and an aluminum U-channel coil support to support 
the centrifugal loads of the coil. All of these components are maintained at cryogenic temperature. Lighter cross-section titanium pieces are used to attach the coil and coil support to the main rotor body and cross the thermal boundary from the cryogenic components to the warm rotor body. Figure 5-19 also shows the coil end support. The end support consists of two steel clamps that are bolted together and bonded to the coil end region. The end support minimizes radial strain in the end region of the coil as it joins the straight portion of the coil running in the axial direction of the rotor.

The functional requirements, design and reliability requirements of the coil support system are listed in Table 5-10.

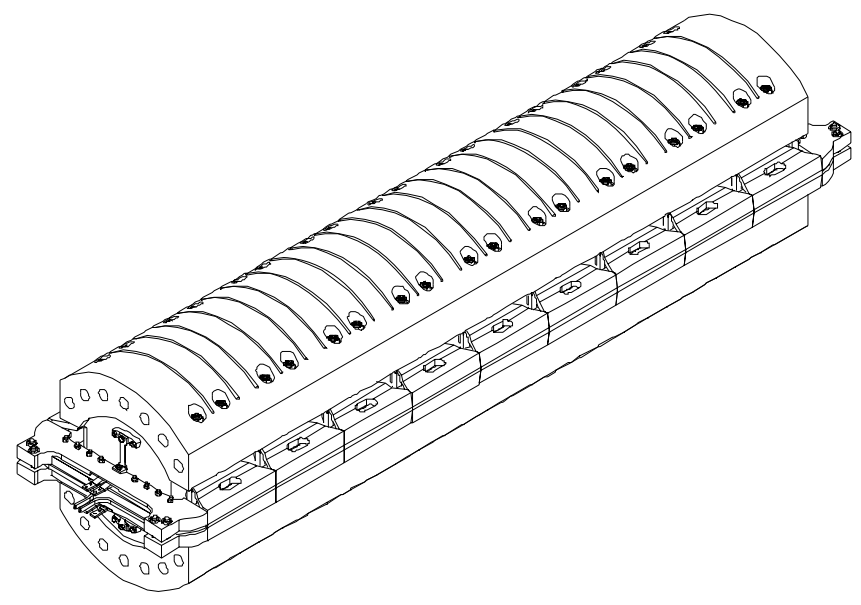

Figure 5-19 - 100 MVA Rotor Body, Coil and Coil Support

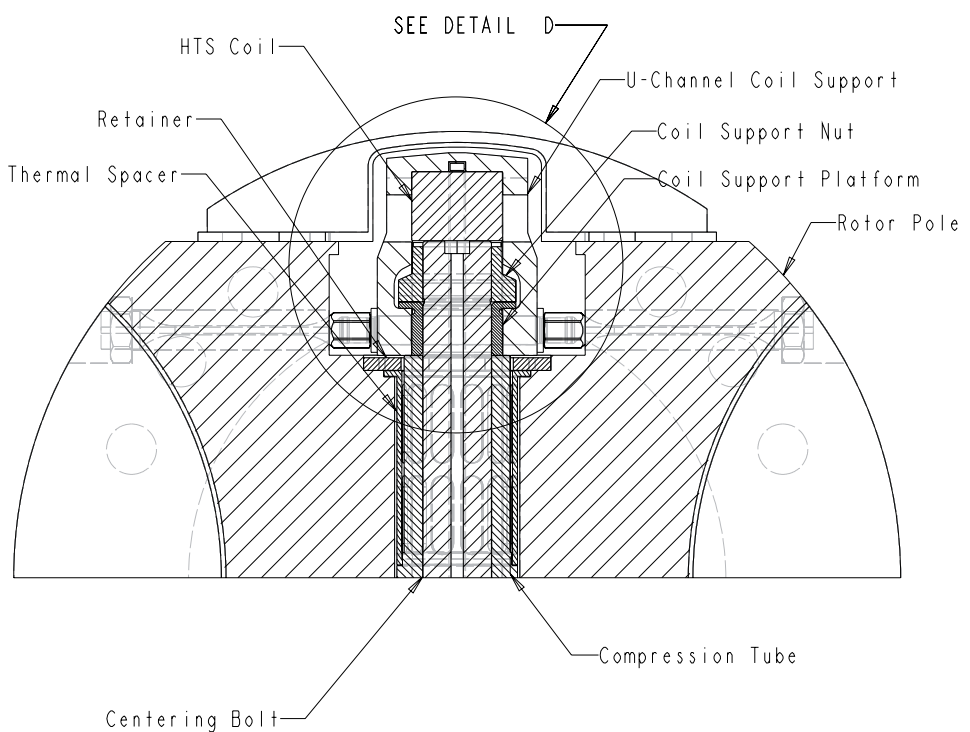

Figure 5-20 - Rotor Cross-section Through Coil Support Stud 
Table 5-10 - Coil Support Design Requirements

\begin{tabular}{|c|c|}
\hline \multirow{3}{*}{$\begin{array}{l}\text { Functional } \\
\text { Requirements }\end{array}$} & $\begin{array}{l}\text { Provide stable support for coil and maintain coil strain } \\
\text { within design limits for all design operating loads }\end{array}$ \\
\hline & Minimize heat load to cryogenic refrigeration system \\
\hline & Minimize loss of flux carrying capability of rotor pole \\
\hline \multirow{4}{*}{$\begin{array}{l}\text { Ambient and } \\
\text { Environmental } \\
\text { Conditions }\end{array}$} & Ambient gas: Air, 0-100\% relative humidity \\
\hline & Rotor: -40 deg C (non-operating) \\
\hline & Rotor: -20 deg C (min), $100 \operatorname{deg} C(\max )$ \\
\hline & Coil and coil support: $25 \mathrm{~K}$ \\
\hline \multirow{3}{*}{$\begin{array}{l}\text { Cyclic Duty } \\
\text { Requirements }\end{array}$} & $\begin{array}{l}10,000 \text { start/stop load cycles (rotor speed \& rotor } \\
\text { temperature) }\end{array}$ \\
\hline & 100 over-speed cycles \\
\hline & 100 coil cool down cycles \\
\hline \multirow{3}{*}{ Over Speed Capability } & $25 \%$ with cold coil - no damage \\
\hline & $10 \%$ with warm coil - no damage (required for balancing) \\
\hline & $50 \%$ rotor burst capability \\
\hline \multirow{3}{*}{$\begin{array}{l}\text { Fault Duty } \\
\text { Requirements }\end{array}$} & 2 per unit fault torque on rotor - no damage \\
\hline & 3-phase terminal fault - repairable \\
\hline & Max Sync Out of Phase - repairable \\
\hline \multirow{4}{*}{$\begin{array}{l}\text { Reliability and } \\
\text { Availability }\end{array}$} & Generator availability - 99.8\% \\
\hline & Generator reliability - 99.85\% \\
\hline & Coil support availability target - 100\% \\
\hline & Coil support reliability target - 100\% \\
\hline
\end{tabular}

The strain in the coil is controlled by the deflections of the coil support components but is also strongly influenced by the machining and assembly tolerances of the various components. Figure 5-21 shows the tolerances considered in the coil support design. Figure 5-22 shows a finite element model of the coil and coil support structure used to evaluate the effect of tolerances on the coil strain. The combination of preload and tolerances can result in strain reversal at certain locations in the coil. Various combinations of tolerances were evaluated. All combinations meet the design limits of coil strain. Figure 5-23 shows the calculated strain in the coil for a typical tolerance condition, the allowable strain conditions are within the area outlined in red. 
Figure 5-24 shows the model used to evaluate the stress in the thermal spacer that spans from the cryogenic components to the operating temperature rotor body. This figure shows the temperature distribution used in the calculations of stress. Figure 5-25 shows the stress range in the thermal spacer for a zero speed, cold coil state to a rated speed, cold coil, hot rotor operating condition.

A stress evaluation was performed to evaluate the overspeed capability of the coil support system. The design goal of $25 \%$ overspeed was missed slightly. The design goal stresses up to $21 \%$ were achieved. It is expected that a rotor designed with increased current density wire would be able to achieve the full $25 \%$ overspeed capability.

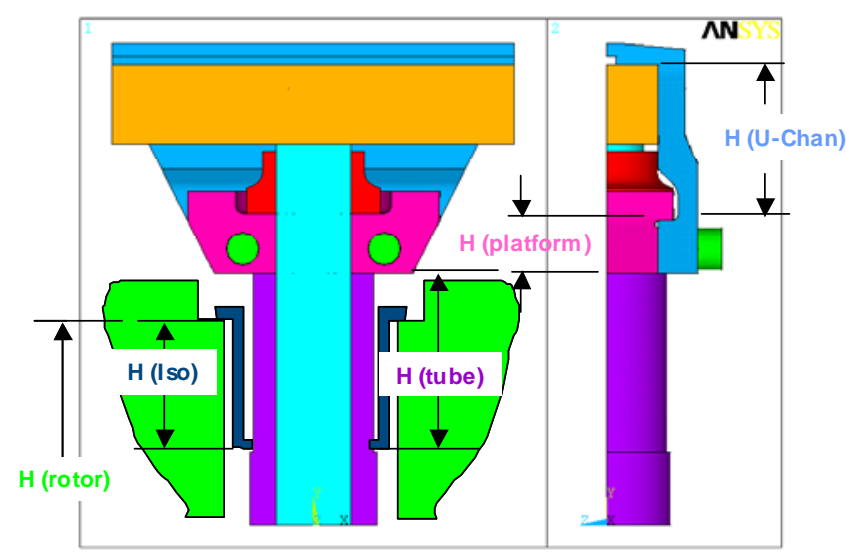

\begin{tabular}{ll}
\multicolumn{2}{l}{ Manufacturing Study } \\
\hline Dimension & Tolerance \\
H (rotor) & $+/-.005$ \\
H (iso) & $+/-.002$ \\
H (tube) & $+/-.002$ \\
H (platform) & $+/-.001$ \\
H (U-Chan) & $+/-.001$
\end{tabular}

Figure 5-21 - Coil Support Tolerances

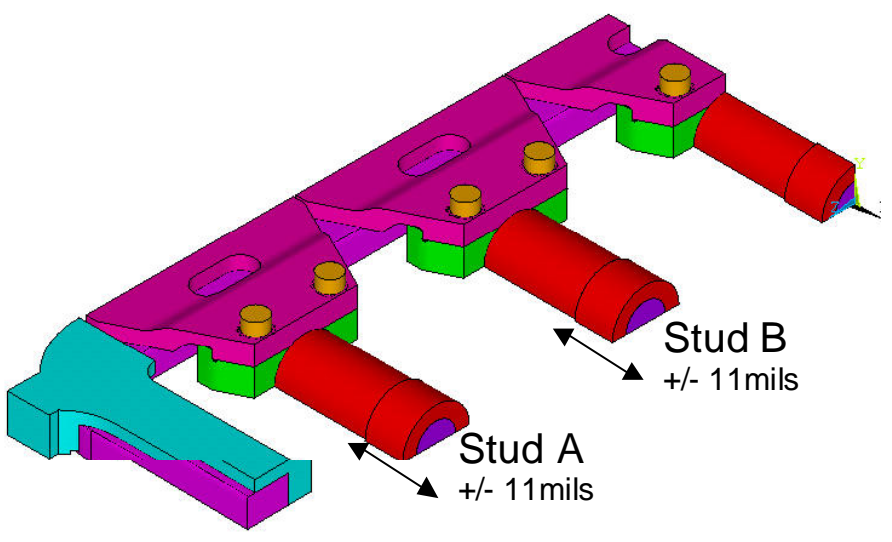

Figure 5-22 - Coil Support Finite Element Model 
Strain variation in coil from $0 \mathrm{rpm}$ to $4500 \mathrm{rpm}$

Tolerance: Stud $A=+11$ mils, Stud $B=-06$ mils

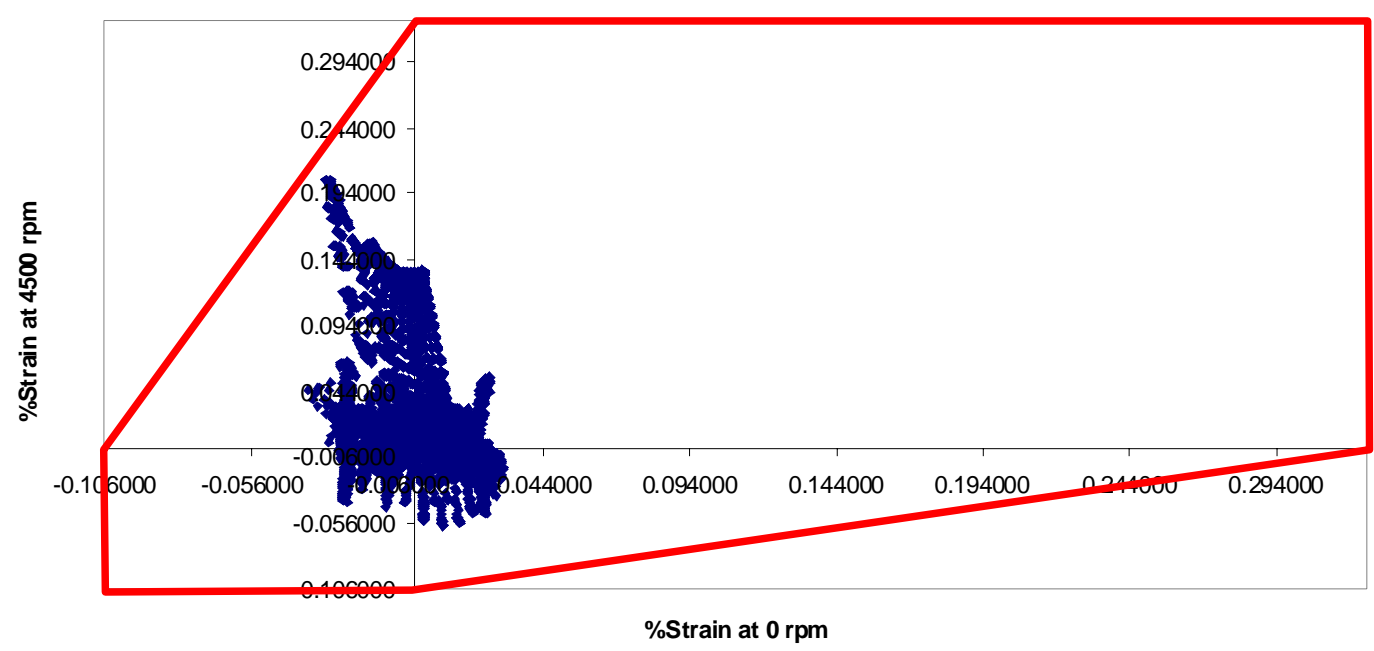

Figure 5-23 - Calculated Coil Strain for Typical Tolerance Condition

Slice model is solved for following 5-load steps

- Load step1: Pretension in U-channel bolts \& Through stud + Nut tightening

- Load step2: Load step1 + Coil cool-down

- Load step3: Load step2 + @3600 rpm

- Load step4: Load step3 + pole body heating + Axial displacement

- Load step5: Load step4 + @4500 rpm
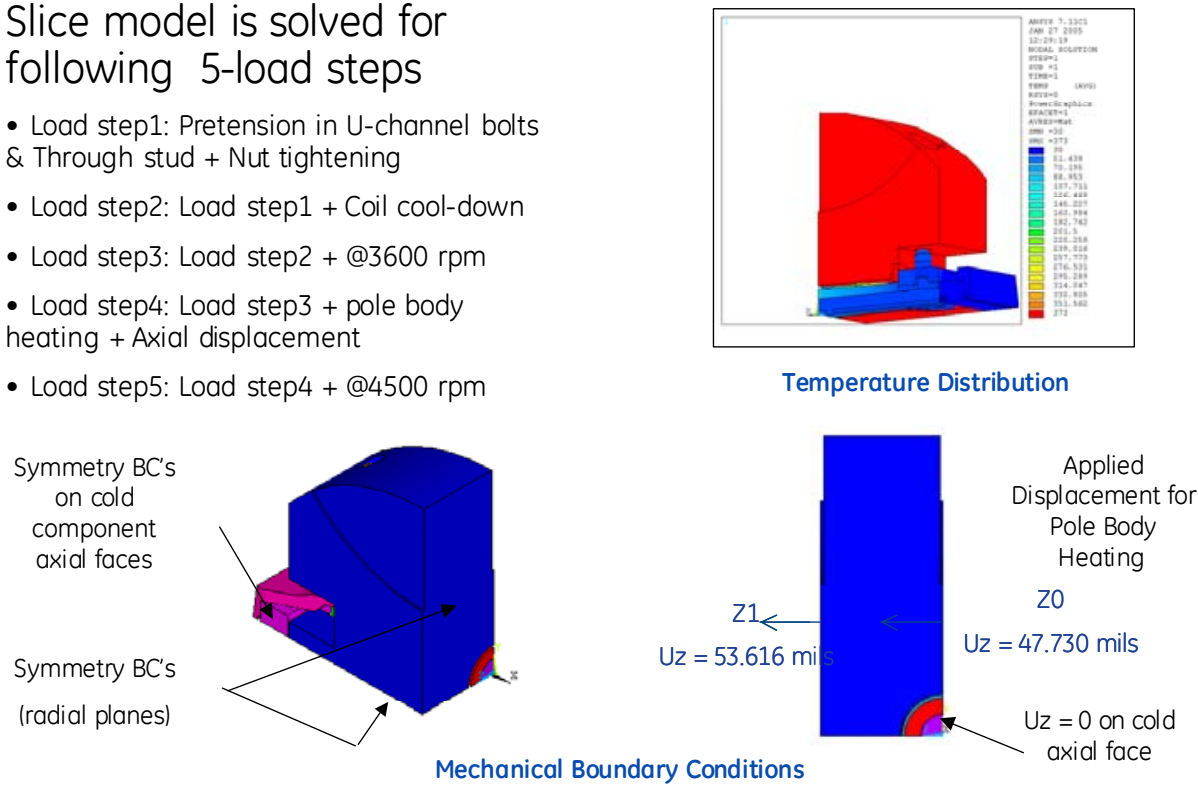

Temperature Distribution

Figure 5-24 - Rotor Thermal Stress Model 

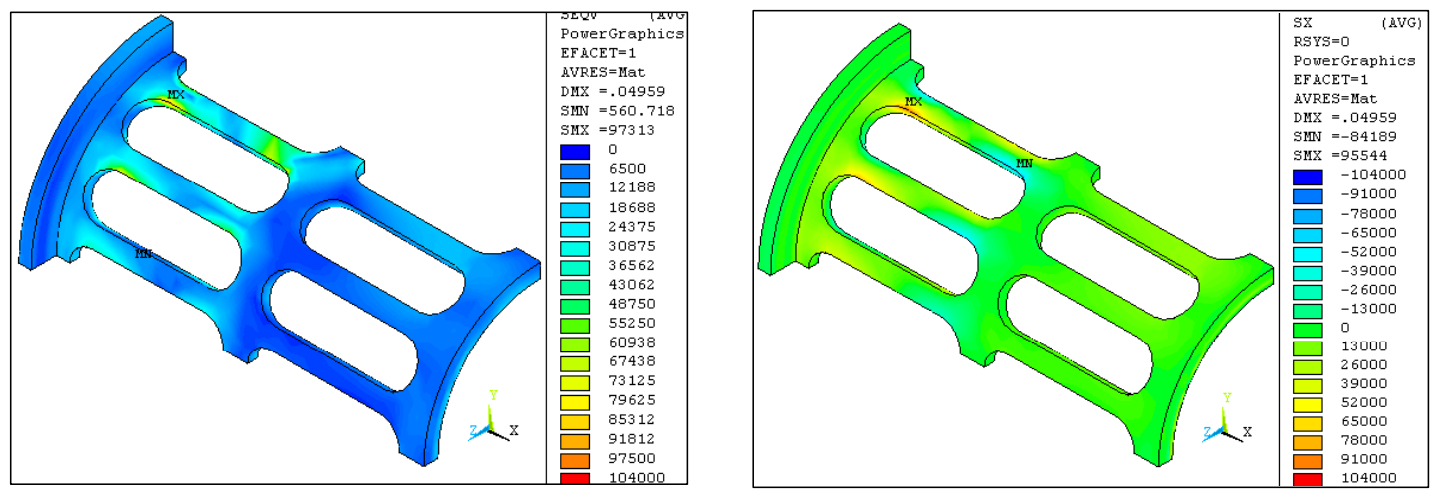

Figure 5-25 - Thermal Spacer Stress Range

\subsection{Rotor Dynamics}

Rotor dynamics considerations are important in any turbine-generator design. The HTS rotor design has some additional considerations that must be evaluated. The configuration of the rotor pole body to accommodate the HTS coil and cold coil support results in a more flexible rotor body. The rotor body combined with the bolted connections of the rotor structure result in greater stiffness dissymmetry than a conventional two-pole turbine-generator. Cross-slots have been designed and included in the rotor body to minimize this stiffness dissymmetry.

A clearance exists between the EM shield/vacuum enclosure and the main rotor body. This arrangement allows the EM shield vacuum/enclosure to vibrate independently of the rotor body. A multilevel rotor dynamics model is required to analyze this configuration. Provisions for balancing the rotor are also complicated by the presence of the EM shield/vacuum enclosure. The design of balance provisions must consider the independent unbalance and vibration of the main rotor body and the EM shield/vacuum enclosure. The vacuum enclosure also blocks access to the main rotor body, with the bulk of the rotor mass and unbalance, once the enclosure has been installed on the rotor. The design of the 100 MVA HTS rotor includes balance provisions on the main rotor body. The main rotor body will be balanced prior to assembly of the vacuum enclosure. The rotor will be rebalanced once the EM shield/vacuum enclosure is installed. Separate balance provisions are provided as part of the EM shield/vacuum enclosure.

As discussed Section 5.6, the HTS coil and cold coil support require a rather slender connection between the cryogenic temperature parts and the warm rotor body. This results in a rather flexible connection between the coil and coil support and the main rotor body. This in turn results in a third level in the rotor dynamics model. The stiffness and mass dissymmetry of the coil and coil support is potentially much greater than that of the rotor body. The dynamic evaluation and design of the coil and coil support, including the large dissymmetry, is essential to the reliable operation of the HTS rotor. 
Figure 5-26 shows the rotor dynamics model used to evaluate the 100 MVA HTS rotor. This model includes the main rotor connected to ground through a series of springs, dampers and mass elements to represent the hydrodynamic bearings and bearing support. The model also includes the EM shield/vacuum enclosure and the HTS coil as separate vibratory structures. Figure 5-27 through Figure 5-30 show the first four calculated mode frequencies and mode shapes of the 100 MVA rotor. The first three of these modes are typical of a conventional turbine-generator rotor of this size. The fourth mode is an axial mode of the coil and coil support. It is not expected that this mode would be strongly excited since the rotor unbalance forces are in a lateral direction.

Table 5-11 shows the three-step balance plan for the 100 MVA HTS rotor that accommodates the three-level rotor dynamic configuration.

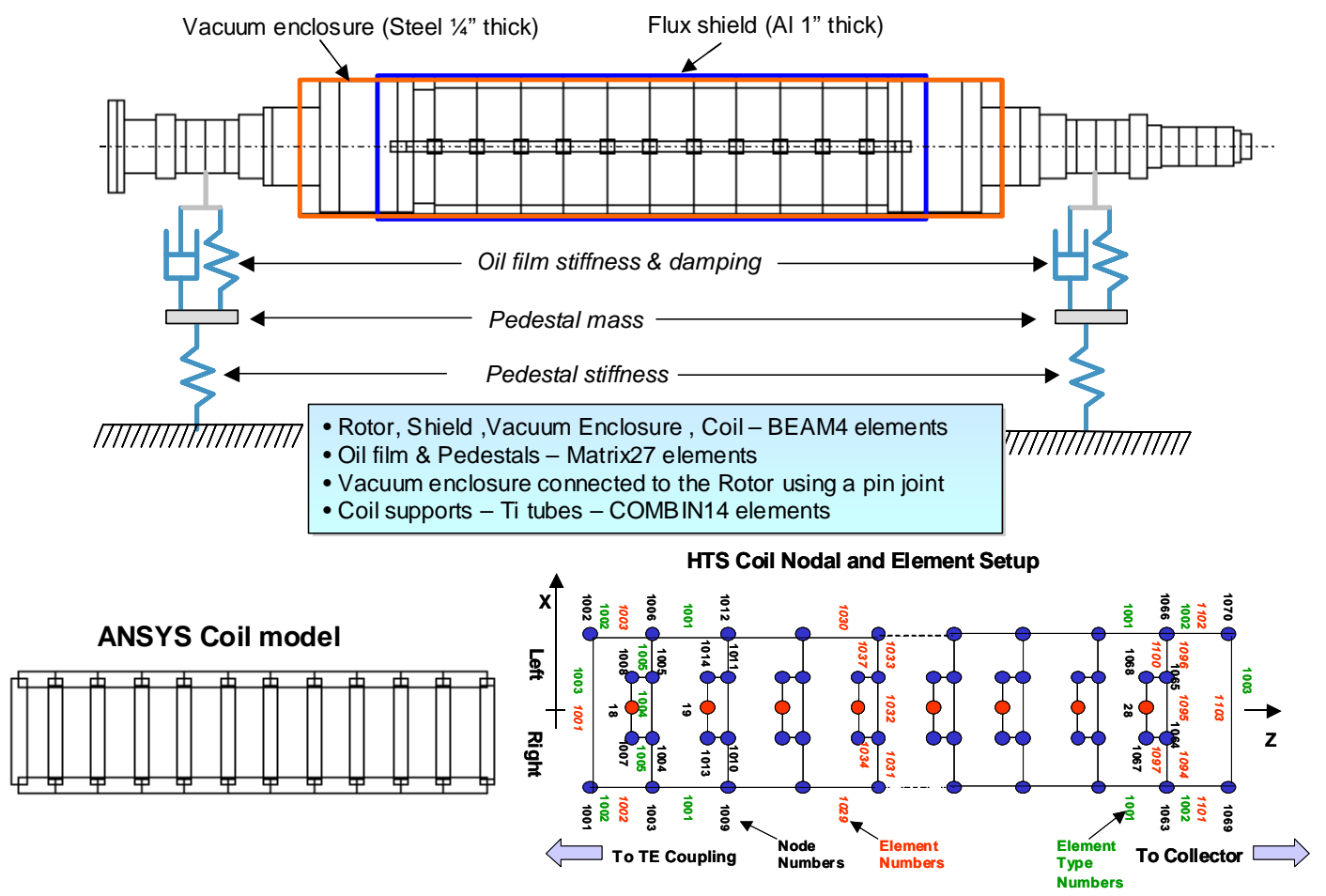

Figure 5-26 - 100 MVA HTS Rotor Dynamics Model 

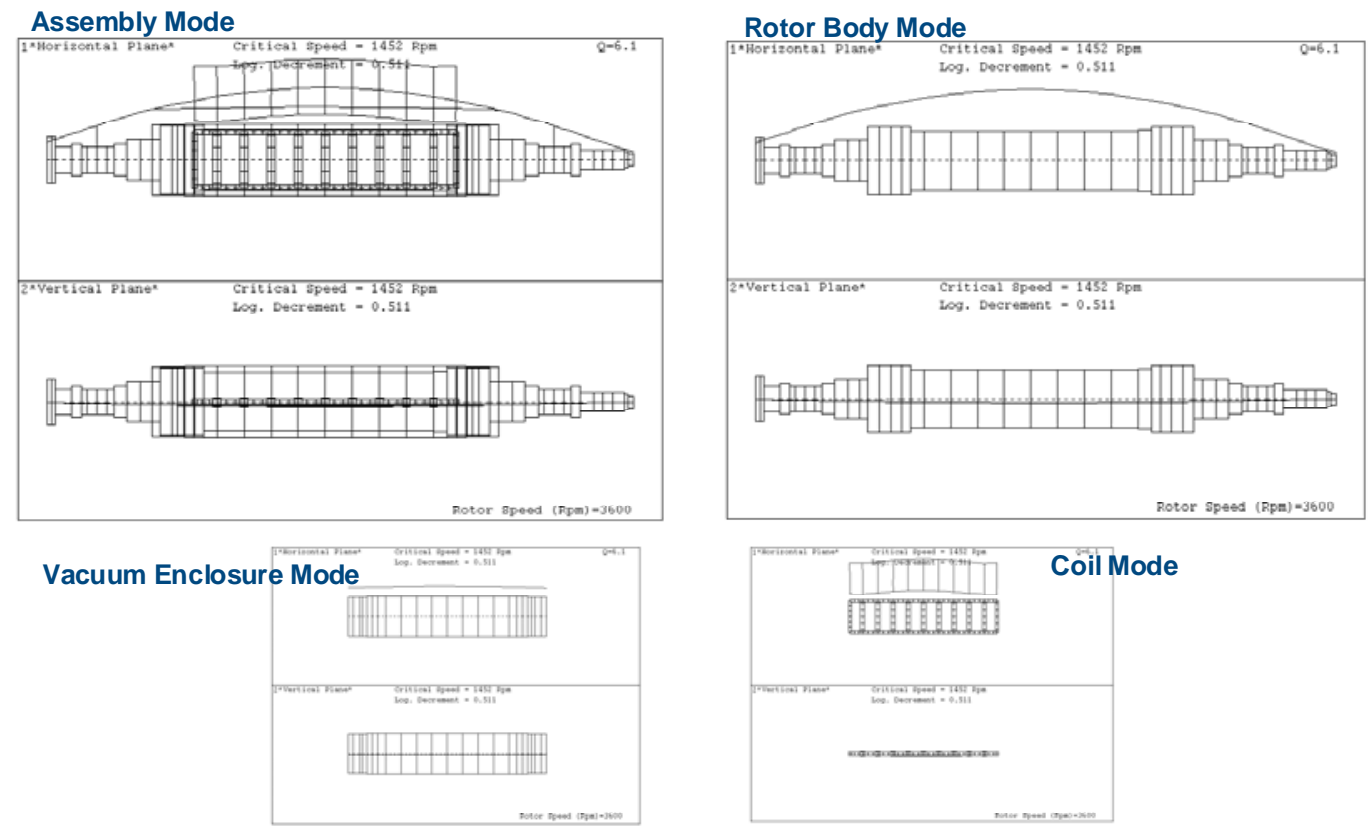

Mode $1-1^{\text {st }}$ Horiz Rotor (Freq = 1452 RPM ; Q=6.1)

Figure 5-27 - Rotor Mode 1 - 1st Horizontal Rotor Mode
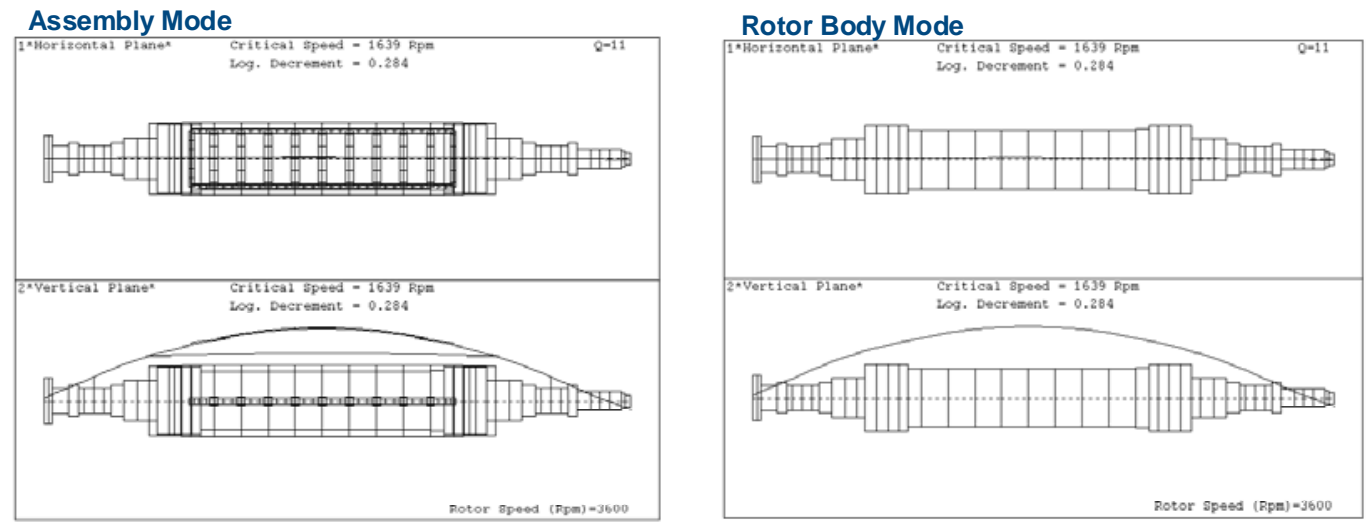

Vacuum Enclosure Mode
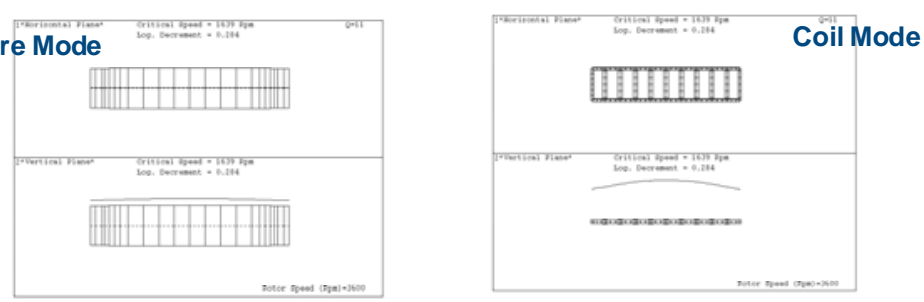

Mode $2-1^{\text {st }}$ Vertical Rotor (Freq = 1639 RPM ; Q=11)

Figure 5-28 - Rotor Mode 2 - 1st Vertical Rotor Mode 

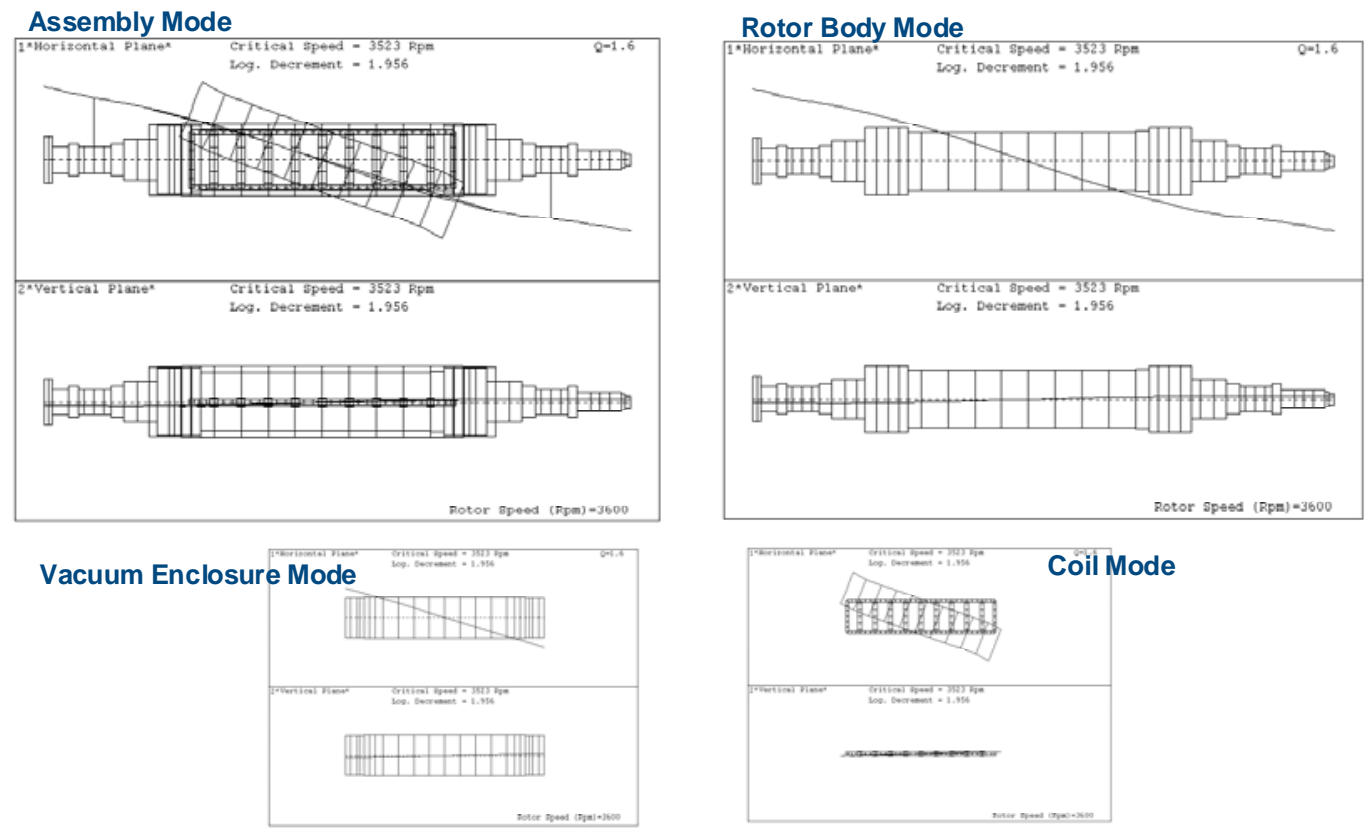

Mode $3-2^{\text {nd }}$ Horiz Rotor (Freq = 3523 RPM; Q=1.6)

Figure 5-29 - Rotor Mode 3 - 2nd Horizontal Rotor Mode
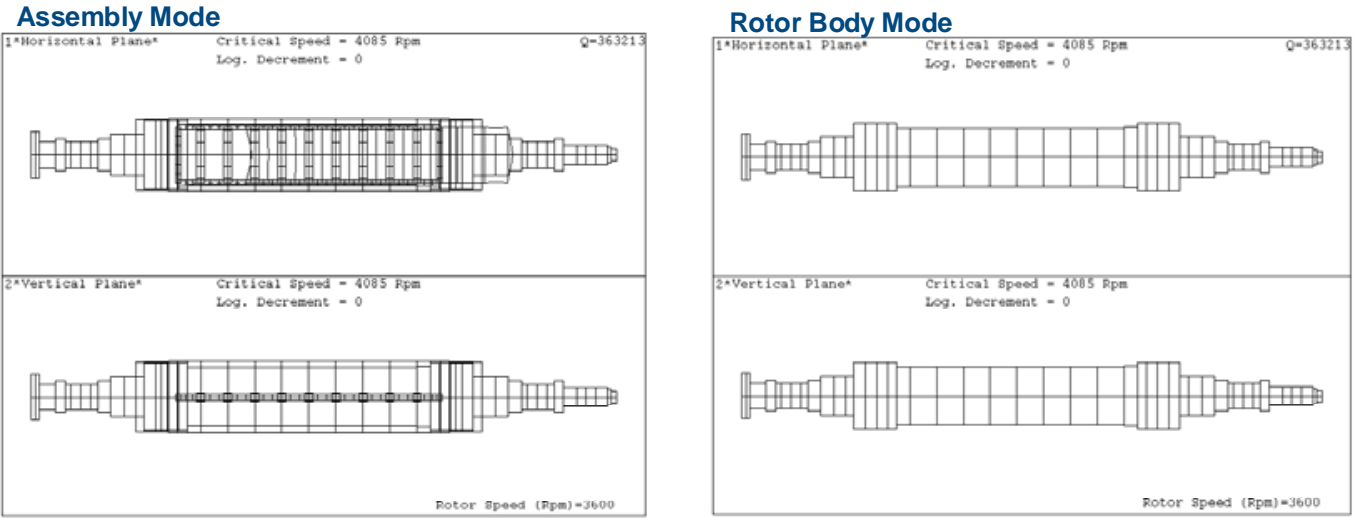

Vacuum Enclosure Mode
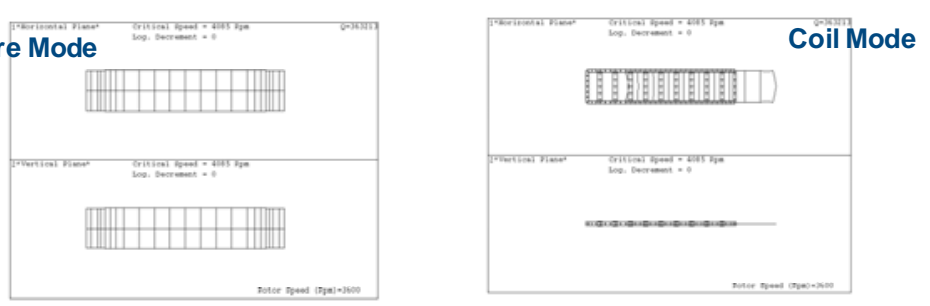

Mode $4-1^{\text {st }}$ Axial Coil (Freq $=4085$ RPM)

Figure 5-30 - Rotor Mode 4 - 1st Axial Coil Mode 
Table 5-11 - 100 MVA HTS Rotor 3 Step Balance Plan

\begin{tabular}{ll}
\hline \multicolumn{1}{c}{ Balance Step } & \multicolumn{1}{c}{ Comments } \\
\hline \multirow{2}{*}{$\begin{array}{l}\text { 1st Balance - Five } \\
\text { Piece Forging }\end{array}$} & $\begin{array}{l}\text { Bolt together five rotor forgings after machining is complete - } \\
\text { Oversized journals }\end{array}$ \\
\cline { 2 - 2 } & $\begin{array}{l}\text { Balance to correct major rotor unbalance - Use body balance } \\
\text { provisions }\end{array}$ \\
\hline & $\begin{array}{l}\text { Five piece rotor is disassembled for coil \& bore component assembly } \\
\text { Balance after assembly is complete except EM shield \& vacuum } \\
\text { enclosure }\end{array}$ \\
\cline { 2 - 2 } $\begin{array}{l}\text { 2nd Balance - } \\
\text { After Coil } \\
\text { Assembly }\end{array}$ & Balance to correct coil and bore component unbalance \\
\cline { 2 - 2 } & Body \& spindle balance provisions available \\
\cline { 2 - 2 } & Still oversized journals \\
\cline { 2 - 2 } Coil is warm - Coil warm strain limits will limit speed to 105-110\% \\
\hline After EM shield assembly and 3rd lathe - Final journal size \\
\cline { 2 - 2 } $\begin{array}{l}\text { Find Balance - } \\
\text { Balance }\end{array}$ & $\begin{array}{l}\text { Balance to correct EM shield - EM shield \& spindle balance } \\
\text { provisions available }\end{array}$ \\
\cline { 2 - 2 } & $\begin{array}{l}\text { Coil is cold - Need transfer coupling installed - Need cooling system } \\
\text { in bunker }\end{array}$ \\
\cline { 2 - 2 } & Overspeed proof test to 120 \% rated speed \\
\hline
\end{tabular}

Torsional dynamics also are a consideration when a turbine-generator rotor is connected to the electrical grid and generating power. Evaluation of torsional dynamics is based on two considerations: 1) Ensure torsional natural frequencies have adequate separation margin from once per revolution and twice per revolution frequencies and 2) Shaft stresses are acceptable for all fault conditions (synchronization out of phase, short circuits, full load rejection and half power load step).

For the 100 MVA HTS generator, a model of the full rotor train was assembled using a $7 \mathrm{E}$ gas turbine with a load coupling between the generator and the gas turbine. The 7E gas turbine is a $90 \mathrm{MW} 60 \mathrm{~Hz}$ gas turbine that GE has extensive experience with. The fully assembled model is shown in Figure 5-31.

Torsional frequencies and mode shapes calculated for this system are shown in Figure 5-32 and Figure 5-33. For this $60 \mathrm{~Hz}$ machine, the objective is to ensure that no modes exist in the 57-63 $\mathrm{Hz}$ range and the $114-126 \mathrm{~Hz}$ range.

With the HTS construction, in addition to the typical system modes that are seen (modes 1 and 2), local coil and coil support modes are also seen (modes 3, 4, 5 and 6). None of these modes, however, are in any exclusion zone for the current configuration of the rotor, coil and coil support system. 


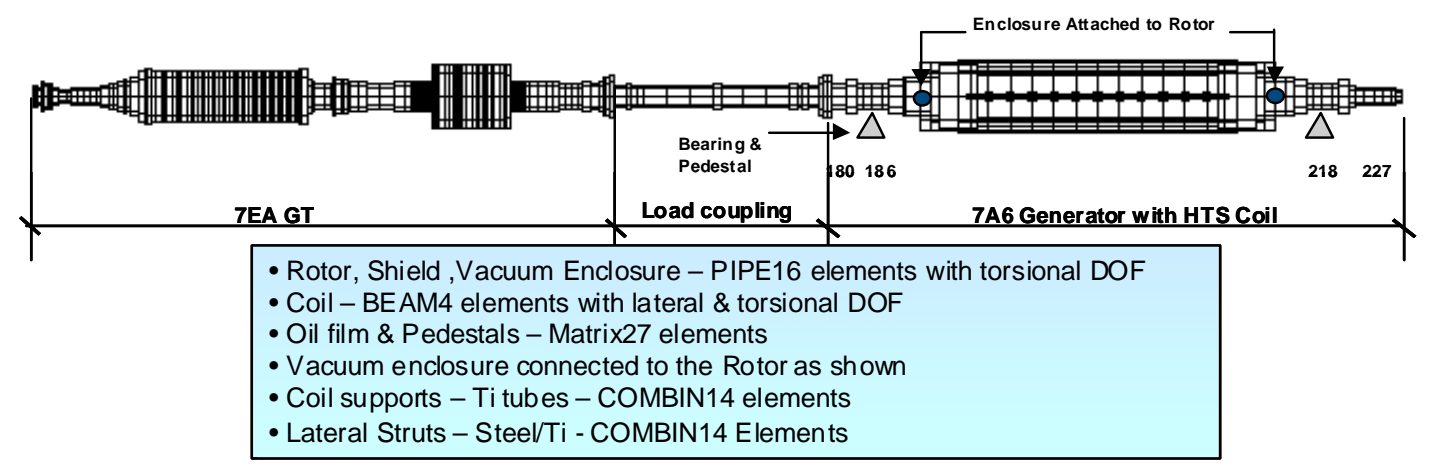

Figure 5-31 - Torsional Rotor Dynamics Model 7E GT - Load Coupling - 100 MVA HTS Generator

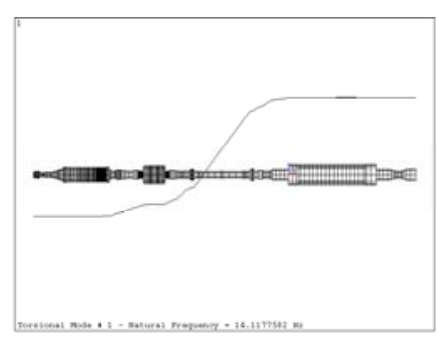

Mode 1 - System Mode $14.11 \mathrm{~Hz}$

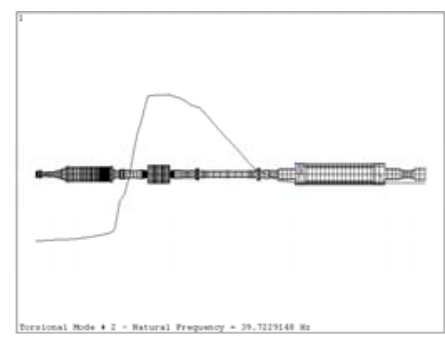

Mode 2 - Twisting at Marriage Flange $39.72 \mathrm{~Hz}$

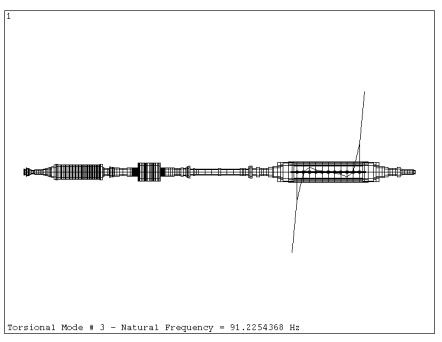

Mode 3 - Out of Plane (antisymmetric) Coil Bending $91.22 \mathrm{~Hz}$

\section{Figure 5-32 - Torsional Modes 1-3}

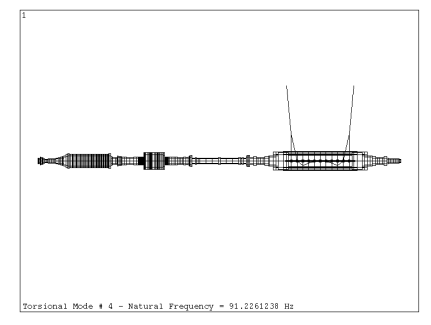

Mode 4 - Out of Plane (symmetric) Coil Bending $91.22 \mathrm{~Hz}$

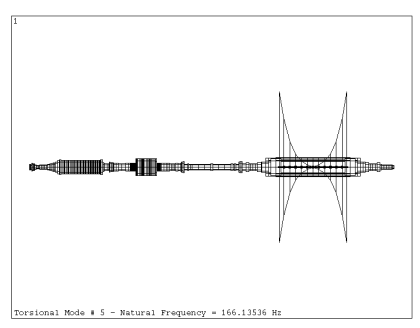

Mode 5 - Out of Plane Coil Twisting $166.14 \mathrm{~Hz}$

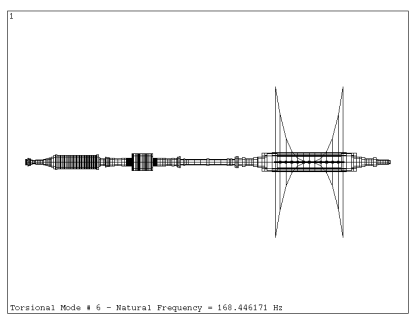

Mode 6 - Out of Plane Coil Twisting $168.54 \mathrm{~Hz}$

Figure 5-33 - Torsional Modes 4-6

For fault torques, the process involves evaluation of the applied torques on the generator rotor body and then analyzing the response of the full train to these fault torques. Based on these response torques, stresses at different sections of the shaft are calculated for acceptability. These torques are alternating torques with a magnitude considerably higher than the steady state torque. Due to the unique electrical design of this machine, the applied torques were generated by the electrical design team and then applied on the rotor train system. One example of the applied torque curve is shown in Figure 5-34. This applied torque is for a 3-phase short circuit. 
The applied torque on the shaft body is approximately 12 times the steady state torque. Shaft response and consequently stresses will also be at elevated levels due to this high applied torque. An example plot of the maximum response at different shaft sections, and the shaft shear stresses for the generator is shown in Figure 5-35.

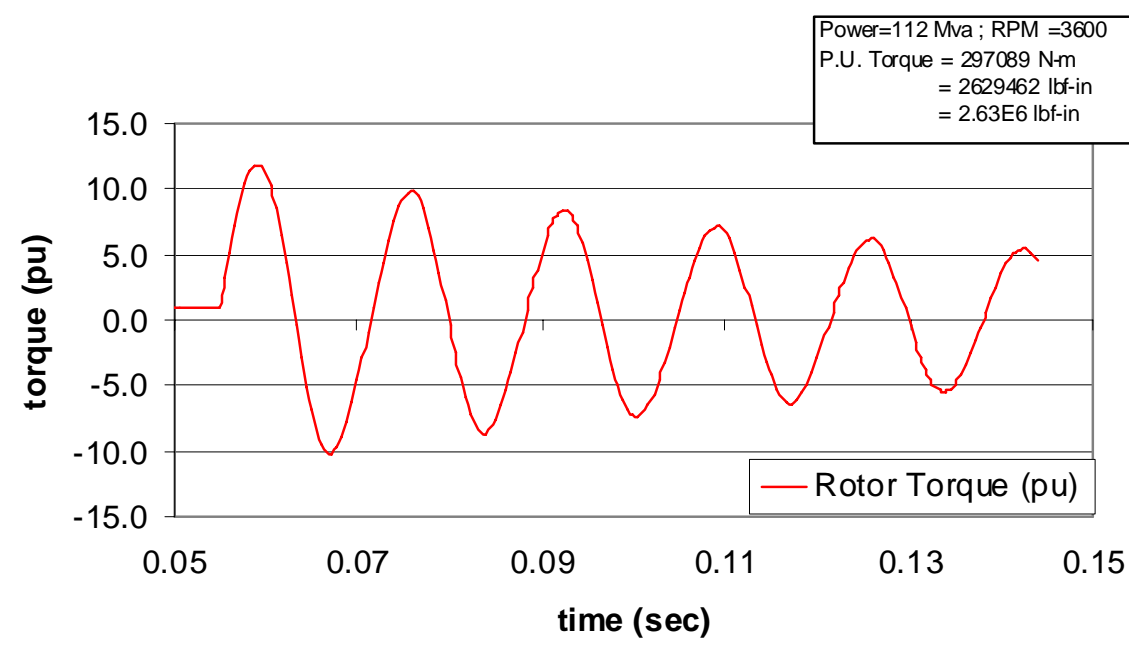

Figure 5-34 - Calculated Torque Due to 3 Phase Fault

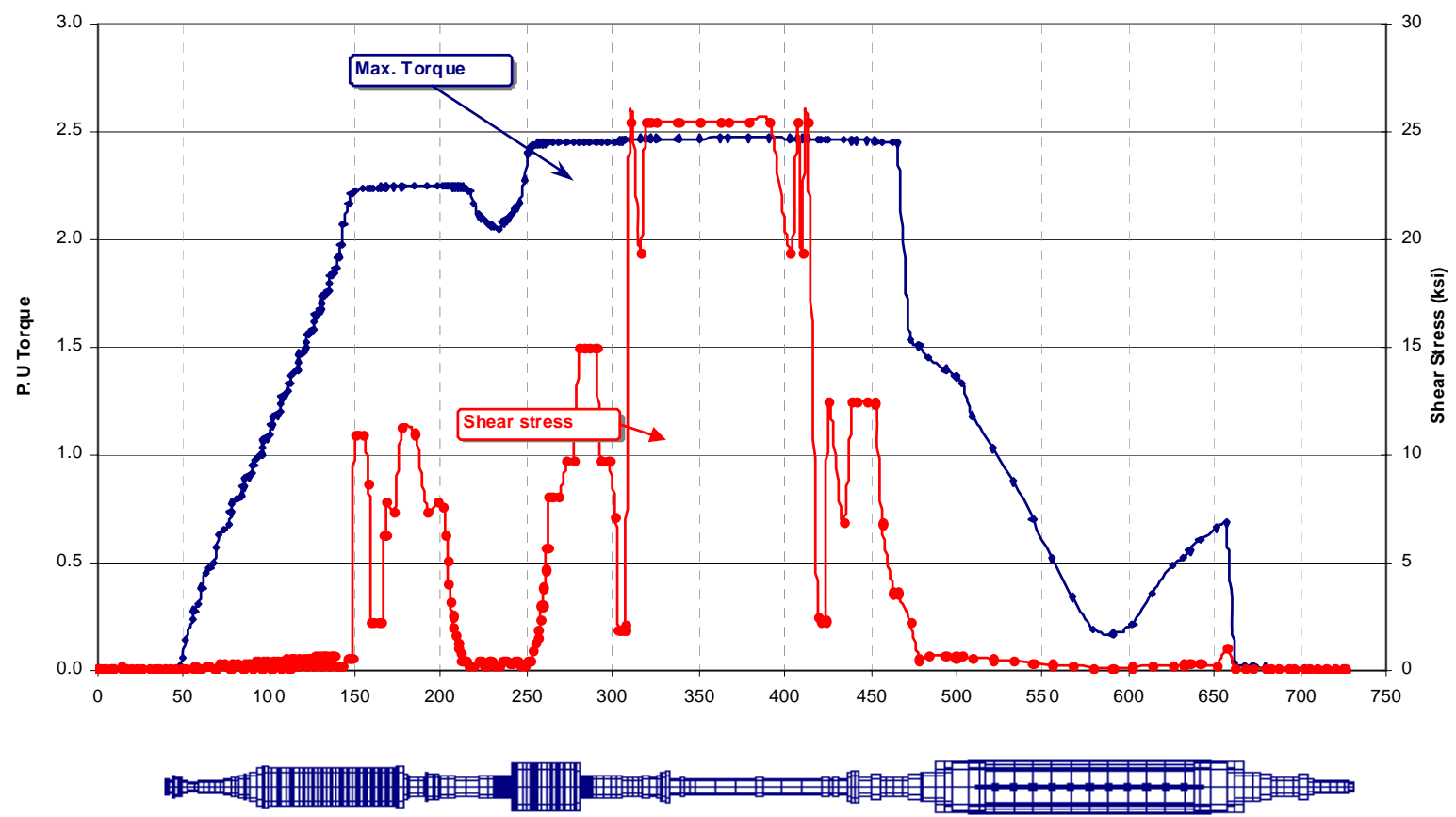

Figure 5-35 - Three-Phase Short Circuit Rotor Response Torque and Shear Stress 


\subsection{Electromagnetic Shield/Vacuum Enclosure}

The HTS generator rotor requires an EM shield over the rotor to isolate time varying magnetic flux from the HTS coil. A vacuum enclosure is also required over the rotor in order to maintain a vacuum surrounding the cryogenic components to eliminate the convective thermal load to the cryogenic components.

Figure 5-36 shows an overall view of the EM shield/vacuum enclosure on the rotor. Figure 5-37 shows the details of the connections at the end of the rotor. Figure 5-38 shows the details at the center of the rotor. The system consists of two concentric tubes. The inner tube forms the vacuum enclosure and consists of welded carbon steel cylinders. These cylinders are welded to each other and welded to the flanges of the shaft spindles. The welds are required to maintain vacuum integrity for long periods of time without requiring pumping the vacuum space. The EM shield consists of two aluminum cylinders. The cylinders are attached to the flanges of the shaft spindles at the ends by a heavy shrink fit supported by a steel shrink ring over the aluminum EM shield. Dowels are also provided at that interface to transmit the fault torque loads from the shield to the main rotor. The EM shield tubes have radial support to the rotor pole at the center of the rotor but are allowed to expand axially. Multilam ${ }^{\mathrm{TM}}$ connectors provide electrical connection between the two EM shield tubes. Rotor balance grooves are provided in the shrink rings at the end of the rotor body as well as a shrink ring at the center of the rotor located between the two EM shield tubes.

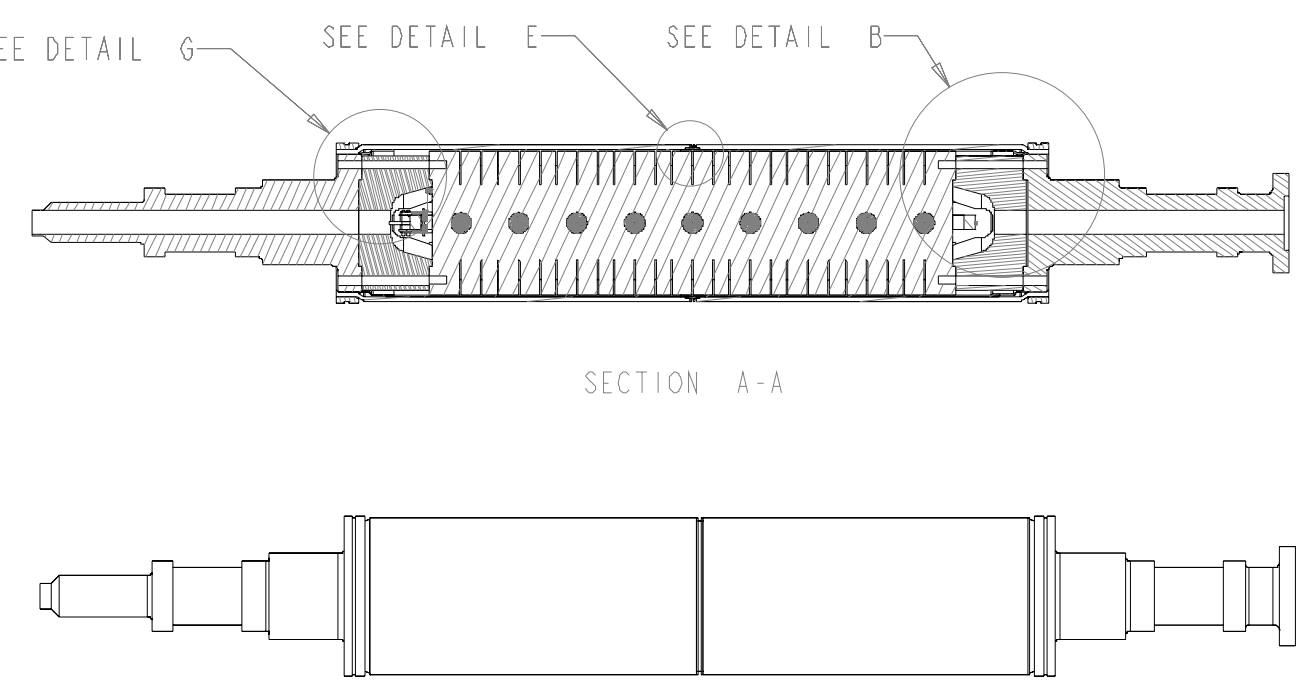

Figure 5-36 - Electromagnetic Shield/Vacuum Enclosure 

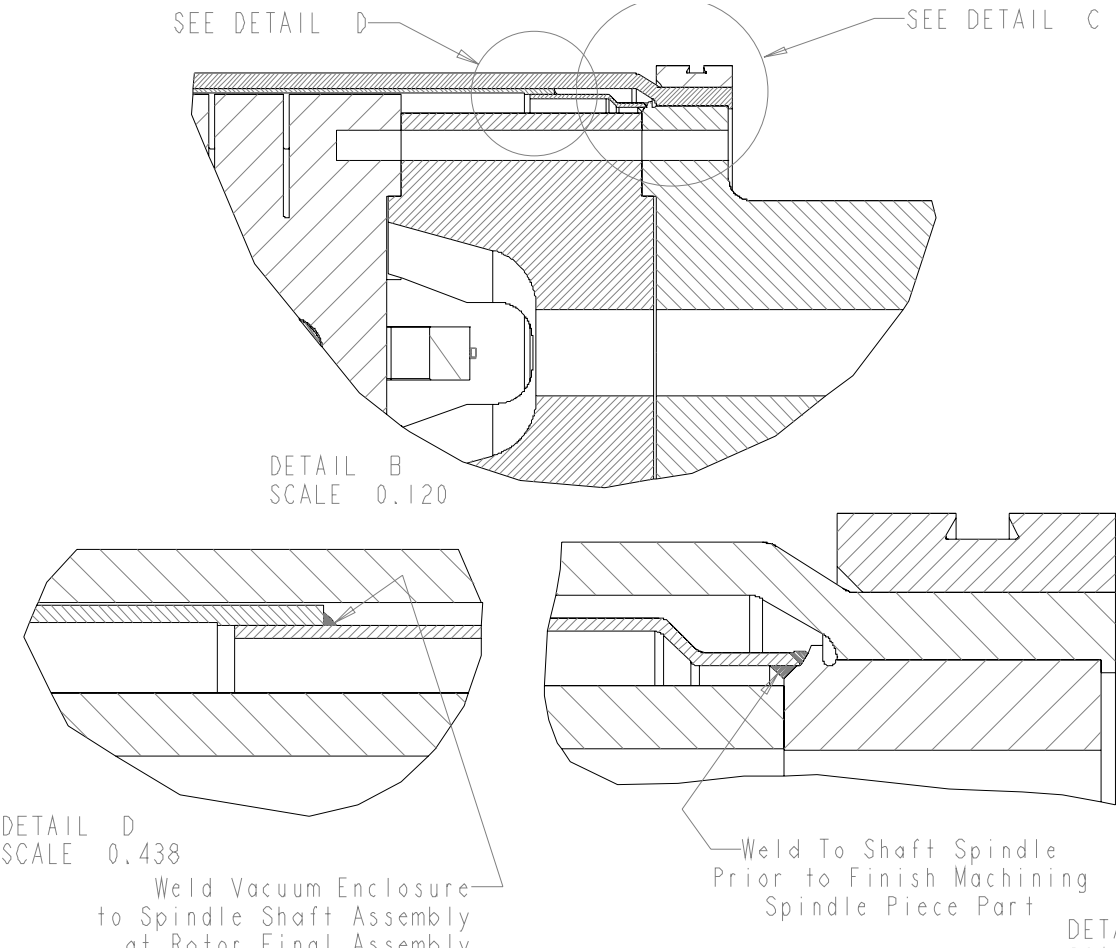

Figure 5-37 - Electromagnetic Shield/Vacuum Enclosure End Details
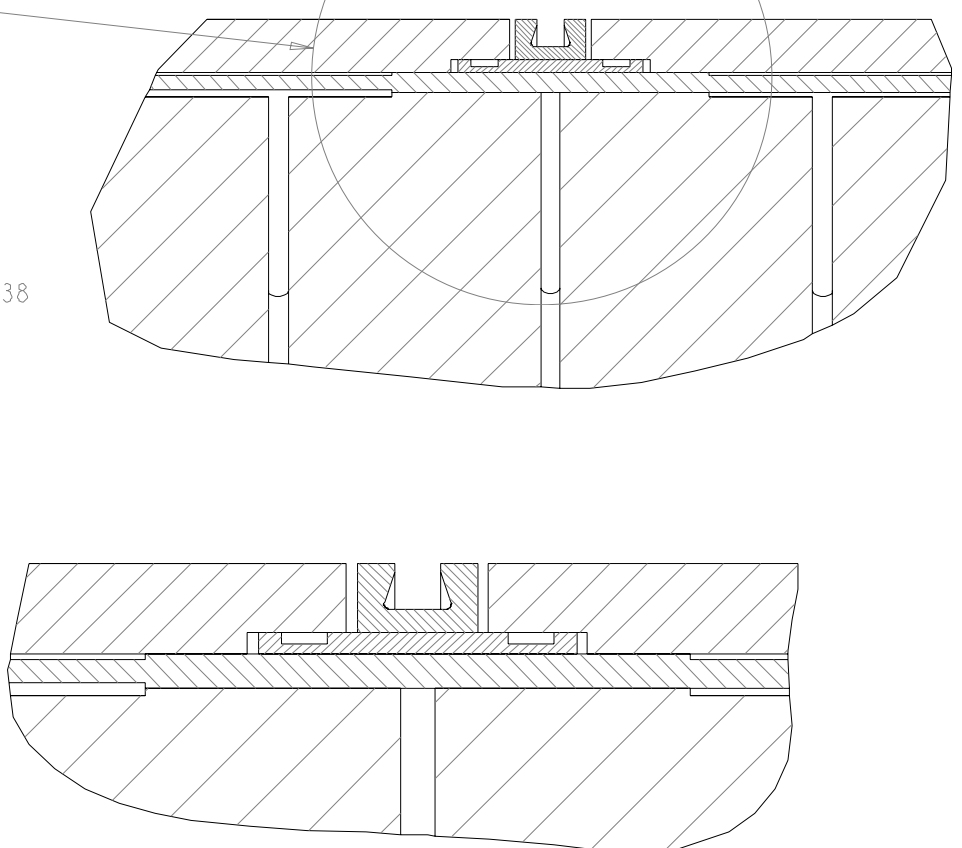

Figure 5-38 - Electromagnetic Shield/Vacuum Enclosure Center Details 
The mechanical functional and design requirements for the EM shield/vacuum enclosure are listed in Table 5-12. Under normal operating conditions the electromagnetic loads on the EM shield are moderate. The most significant loads are the centrifugal loads and thermal expansion loads. The thermal time constant of the rotor assembly is quite long. Although the heating in the EM shield is moderate under normal operating conditions, the gas temperature in the air gap surrounding the outer surface of the EM shield will reach 100 degrees $\mathrm{C}$. The EM shield will reach its maximum temperature within one hour of operation. The rotor body will take greater than a day to reach steady state temperature. This thermal transient is a significant design consideration for the design of the shrink fit at the ends and center of the rotor.

Figure 5-39 shows an axisymmetric finite element model used to evaluate the thermal transient loads on the EM shield/vacuum enclosure. Figure 5-40 shows the calculated temperature rise of the various rotor components at several time steps. Figure 5-41 is a plot of temperature vs. time at the shrink fit locations. Figure 5-42 shows the calculated radial load at the various shrink fits through the thermal transient including the centrifugal loads due to rated speed operation. It can be seen that positive radial interference is maintained at all times.

\section{Table 5-12 - Mechanical Functional and Design Requirements of the Electromagnetic Shield and Vacuum Enclosure}

\begin{tabular}{|c|c|}
\hline \multirow{5}{*}{$\begin{array}{l}\text { Functional } \\
\text { Requirements }\end{array}$} & $\begin{array}{l}\text { Transmit fault torque from EM shield to rotor assembly ( } 10 \\
\text { - } 12 \text { x rated torque) }\end{array}$ \\
\hline & Provide (a portion of) vacuum enclosure of rotor assembly \\
\hline & Provide balance capability \\
\hline & Standard rotor lifting capability \\
\hline & Standard rotor assembly into generator \\
\hline \multirow{3}{*}{$\begin{array}{l}\text { Cyclic Duty } \\
\text { Requirements }\end{array}$} & 10,000 cycles to rated speed, $75 \mathrm{C}$ rise \\
\hline & 100 cycles to $125 \%$ rated speed \\
\hline & Infinite life HCF \\
\hline \multirow{2}{*}{ Over Speed Capability } & $25 \%-$ no damage \\
\hline & $50 \%$ Burst speed \\
\hline \multirow{3}{*}{$\begin{array}{l}\text { Electromagnetic } \\
\text { Loading }\end{array}$} & $\begin{array}{l}\text { Fault torque transmission } \\
\text { - Major fault, } 12 \mathrm{pu} \text { - no gross structural failure }\end{array}$ \\
\hline & $\bullet \quad$ Minor fault, 2 pu - no damage \\
\hline & $\begin{array}{l}\text { EM crushing pressure capability } \\
\text { - } 150 \mathrm{kPa} 4 \text { nodal ( } \sim 22 \mathrm{psi}) \\
\text { - } 150 \mathrm{kPa} \text { unidirectional ( 22psi) }\end{array}$ \\
\hline
\end{tabular}




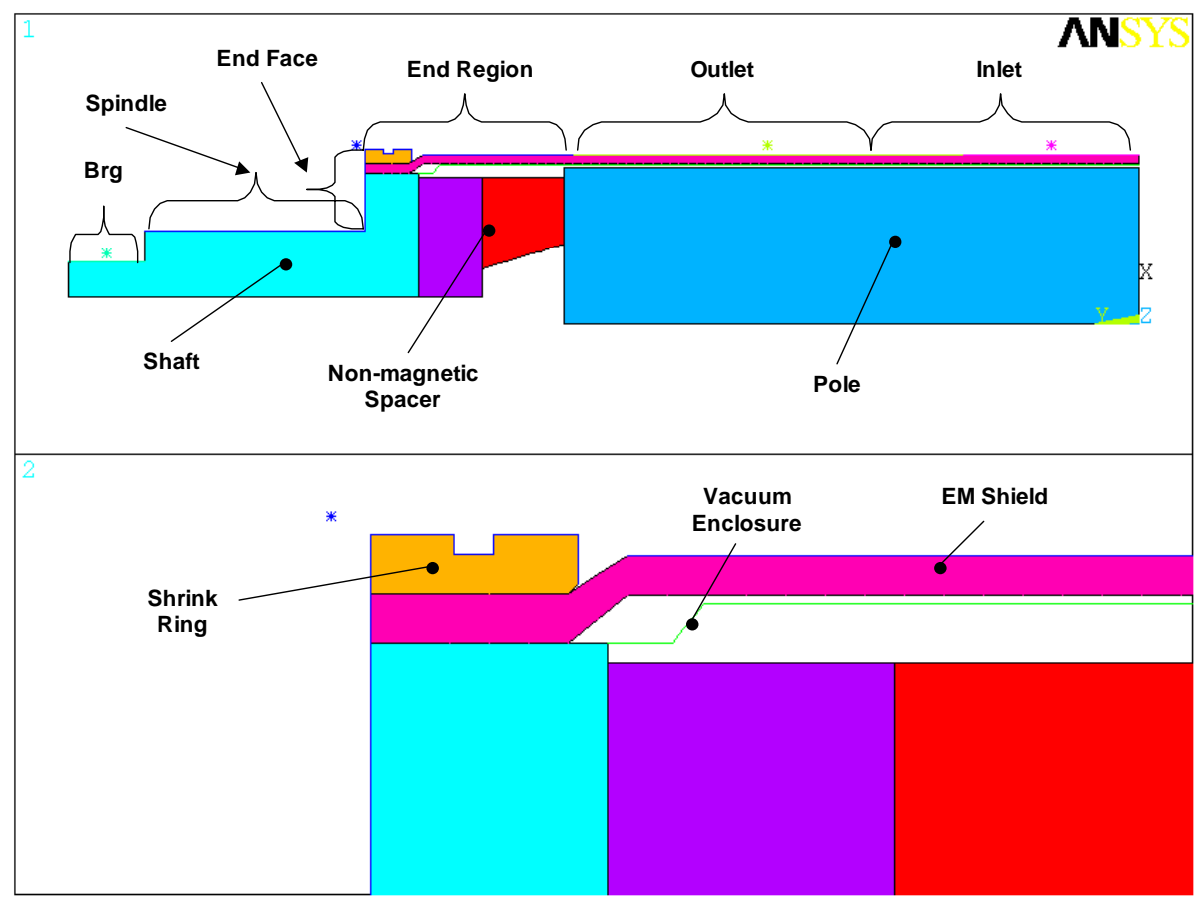

Figure 5-39 - Rotor Cross-Section Showing EM Shield

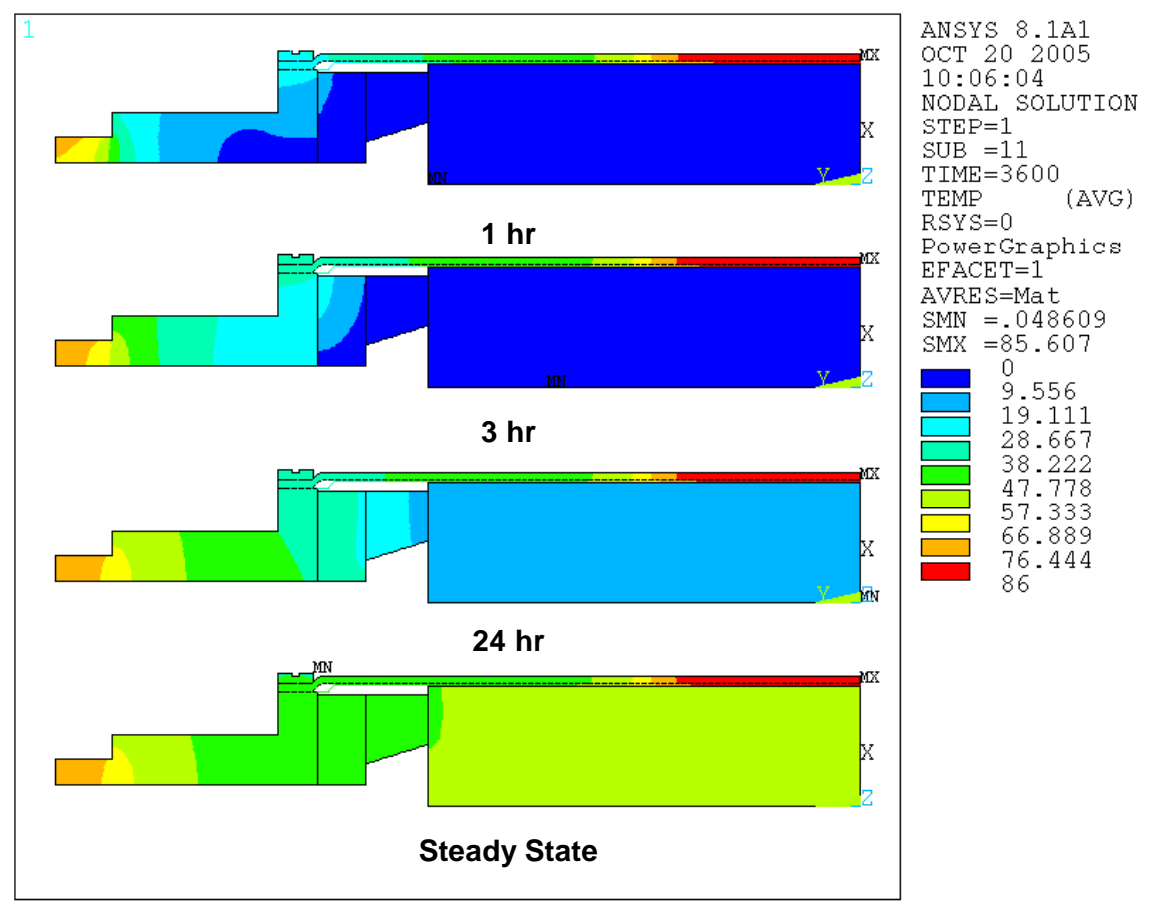

Figure 5-40 - EM Shield and Rotor Temperatures Rise Above 25 Deg C 


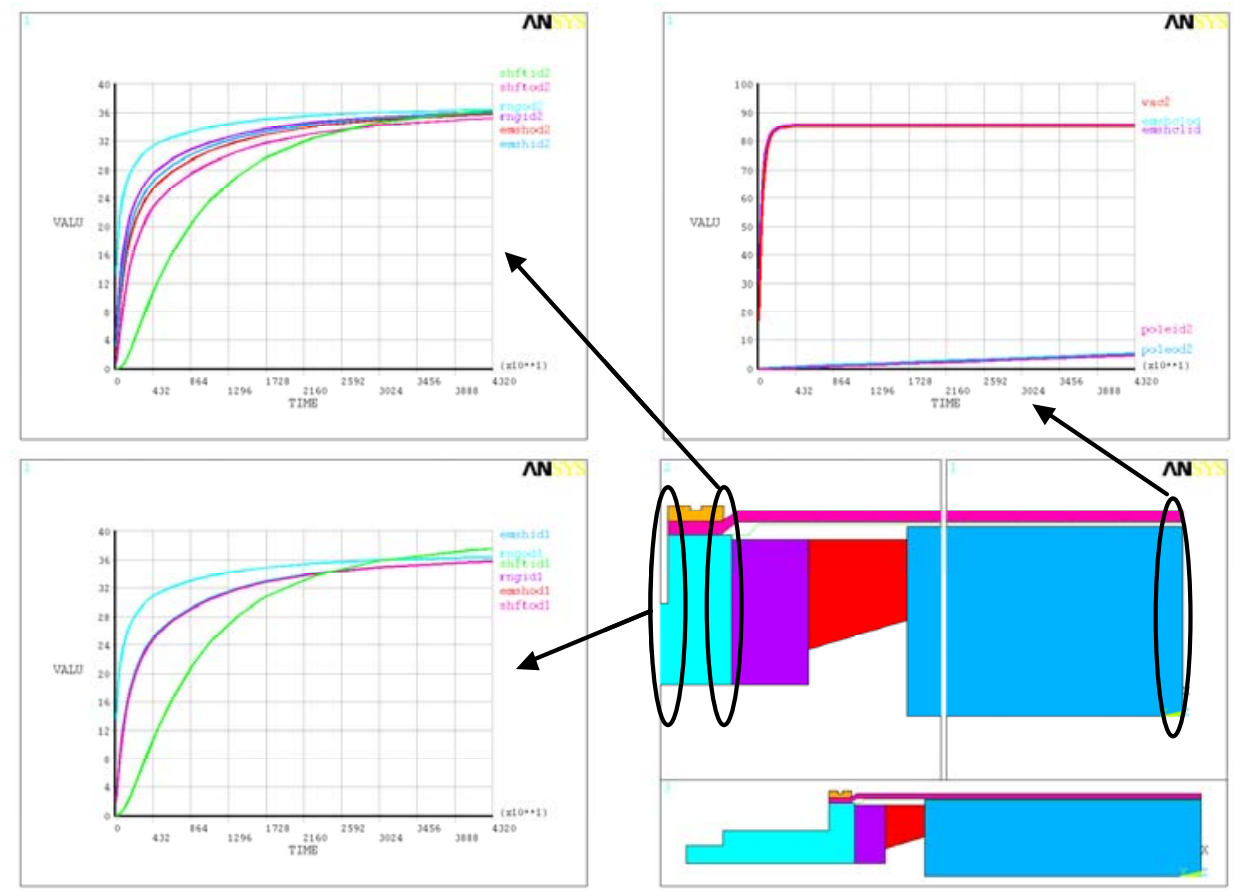

Figure 5-41 - Temperature Rise Versus Time at EM Shield Shrink Locations

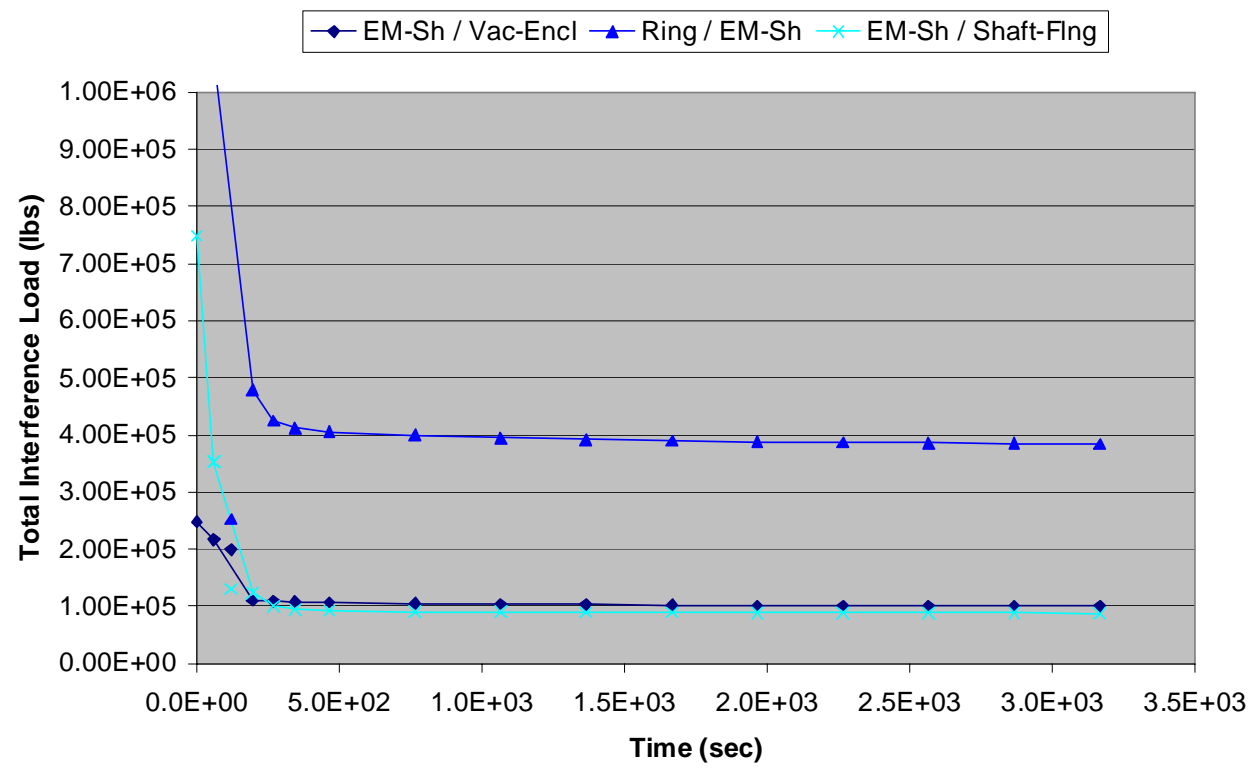

Figure 5-42 - Interference Fit vs. Time for Thermal Transient 


\subsection{Bore Components}

The HTS rotor bore components are the interface between the HTS coil and the external environment. This arrangement requires that the bore components not only transfer current into the coil (typical of bore copper in a standard generator design) but also limit the amount of heat that enters the system, provide a seal between the bore (vacuum) and ambient, transfer the coolant to and from the coil and, in the case of multiple parallel HTS coils, ensure that the incoming current is evenly distributed between the coils.

The bore components consist of the collector ring terminal studs, the bore component support system, vacuum seal and insulation system, refrigeration feed and return tubes, heat station and current leads.

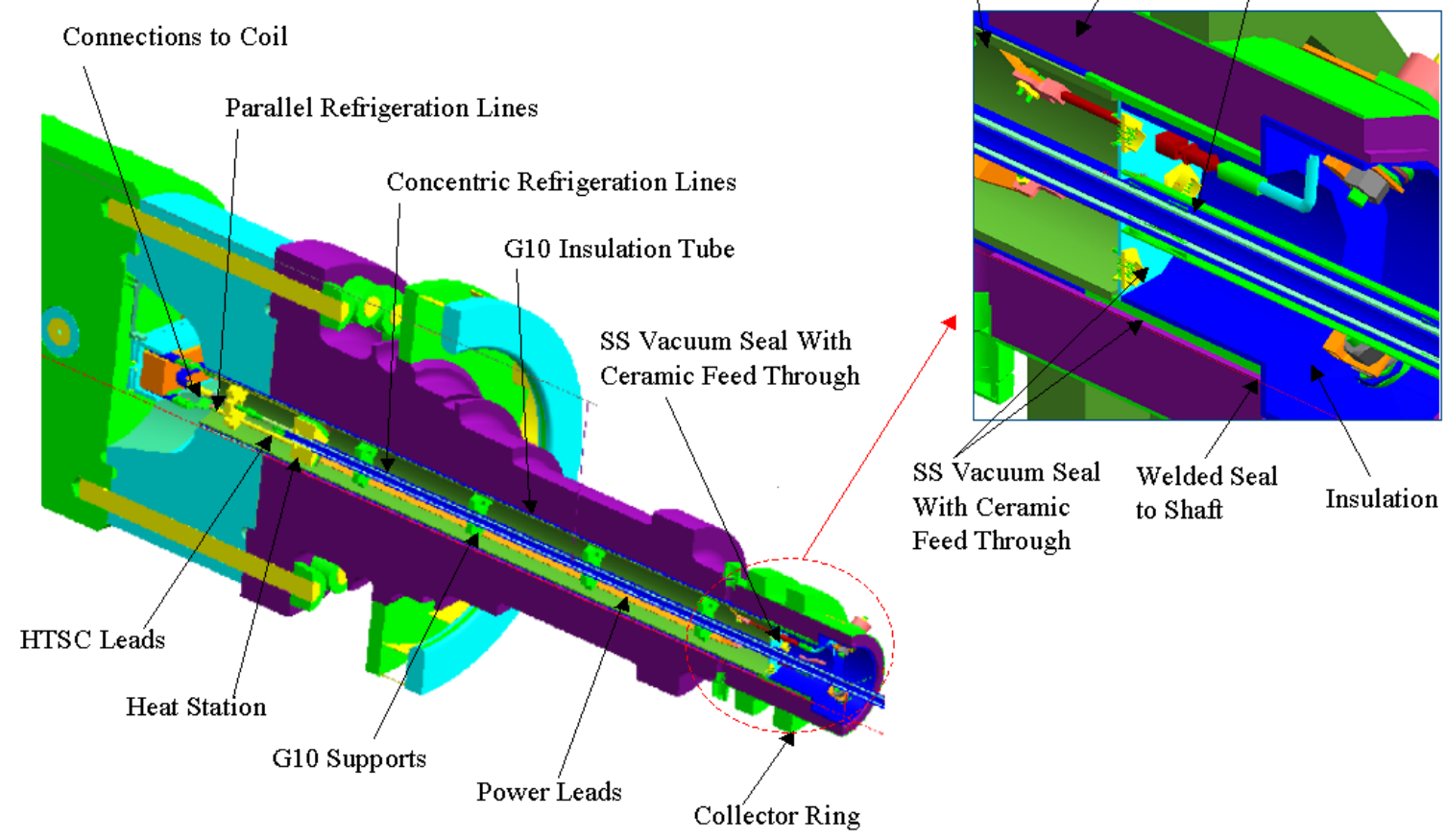

Figure 5-43 - Bore Component Configuration

\subsubsection{Support System, Vacuum Seal and Insulation System}

All bore components will be housed in a G10 tube that is doweled to a 304SS end cap for ease of assembly, protection and electrical insulation. Inside the G10 tube are G10 supports that will support the main leads, instrumentation wire and refrigeration tubes. These supports are held in place with four dowels that extend through the insulating tube and into the G10 support. In addition to supporting the internal spacers these dowels extend out past the OD of the G10 tube and act as spacers to hold the G10 tube away from the bore to create a vacuum space. These supports contain through holes so that a vacuum may easily be pulled. The edges of these supports are rounded to minimize 
contact area with the G10 tube and refrigeration tubes. This is required to minimize vacuum virtual leaks and heat transfer.

The support system and bore component design philosophy is that the G10 tube and all of the bore components would be pre-fabricated and then inserted into the bore as an assembly. At that point all of the coil connections would be made and the 304SS end cap would be welded to the bore to seal the vacuum space.

The end cap will contain eight ceramic feed-throughs. Four of these feed-throughs will be of the single conductor type. These will be sized and utilized to transfer the field current to and from the coil. Four of the feed-throughs will be multi-conductor type (19 pin type) to transmit instrumentation wiring from the vacuum side to ambient. Refrigeration tubes will pass through the center of the end cap. The external most refrigeration tube shall be welded to the end cap.

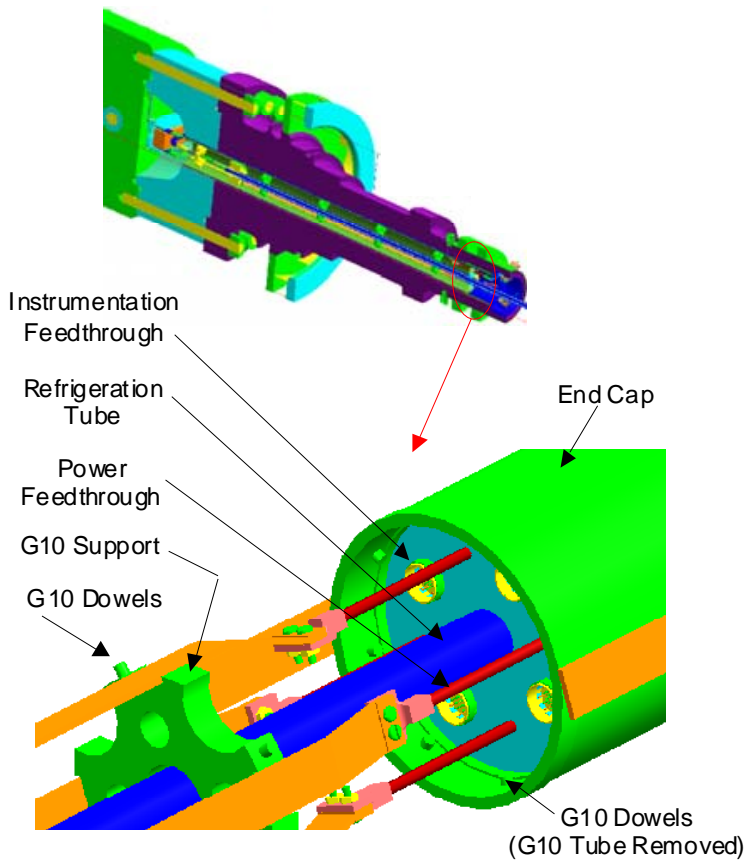

Figure 5-44 - Bore Component Support Assembly

\subsubsection{Refrigeration Tubes}

Four concentric tubes will carry the refrigeration gas between the coils and transfer coupling. These tubes will be separated by "twist ties". These "twist ties" are simple twisted stainless steel strips. By twisting the strip it will minimize the contact surface between tubes and provide some pliability for installation. The outermost tube will terminate at the end cap. The second and third tubes will terminate at the heat transfer station while the inner tube will terminate just after it passes through the center of the heat station. 


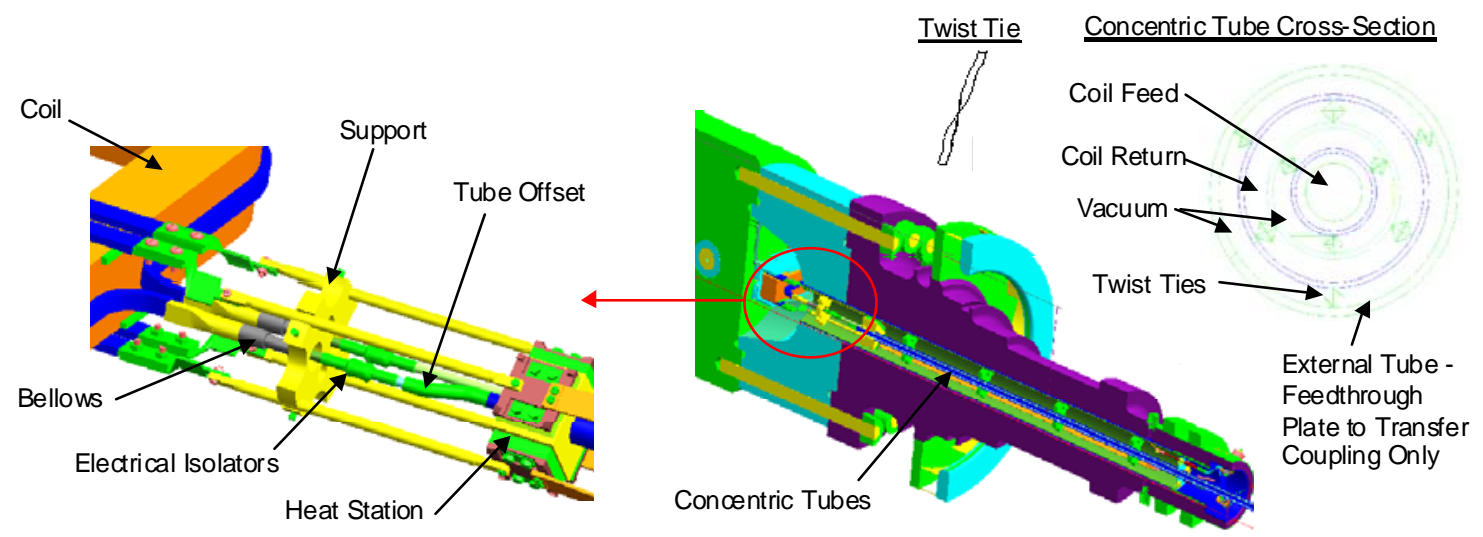

Figure 5-45 - Refrigeration Tube Configuration

\subsubsection{Heat Station}

The heat station performs two functions. First, it separates the refrigeration feed and return lines. Beyond this point the lines will no longer be concentric. Second, it removes any heat that is being conducted down the main leads before they reach the coil. The heat station consists of a copper block that is machined such that when the refrigeration tubes are attached a plenum area is created. The return-cooling medium from the coil will flow through this plenum and be used to cool the heat station. The heat station has been designed to maintain the temperature of the block approximately $10 \mathrm{~K}$ higher than that of the cooling medium while only raising the cooling medium approximately $0.5 \mathrm{~K}$.

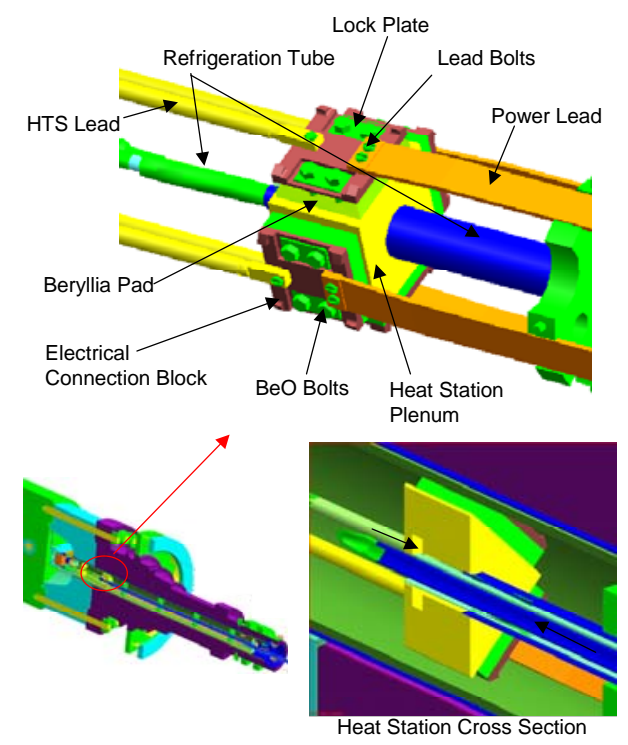

Figure 5-46 - Heat Transfer Station 
The electrical lead will be tied to the cool heat station through beryllia $(\mathrm{BeO})$ pads, which are electrically insulating yet thermally conducting. The beryllia pads will be soldered and bolted in place with non-electrically conducting bolts between the copper plenum block and copper electrical connection block. The main electrical leads will be bolted and soldered to the copper electrical connection block.

\subsubsection{Current Leads}

A braided copper lead will extend from the end cap ceramic feed through to the heat station. This lead must be sized to limit conduction from the external environment (small cross-section) and resistance heat generation (large cross-section). This lead will be supported within the bore with G10 supports. After the heat station HTS leads will be used to further limit heat transfer into the HTS coils, a final section of flex lead will be used between the HTS lead and coil to allow for coil movement and misalignment. A G10 support will be used to support the end of the HTS leads. The second flex lead sections will extend past the end of the G10 bore tube so that they can be easily attached to the coil.

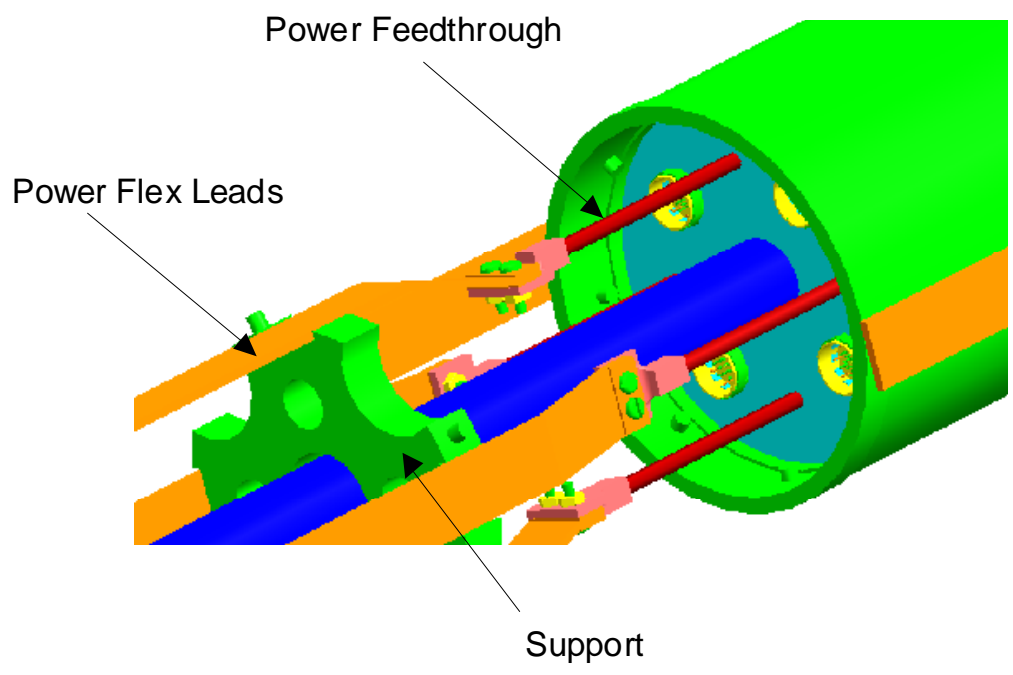

Figure 5-47 - Power Leads

\subsection{Collector}

The collector design for the 100 MVA generator is based on the existing 7E collector design. The plan for the 100 MVA HTS project was to test the rotor in an existing 7E stator so the majority of work focused on modifying an existing 7E collector. The collector changes required are minimal: reduction of the number of brushes due to the decreased field current, removal of the exhaust ventilation air duct because an exhaust fan is not required and the addition of a shaft seal. 


\subsection{Vacuum Environment}

The internal cavity of the 100 MVA generator rotor must be evacuated in order to limit residual gas conduction and convection to the cryogenic system. There are a number of requirements that define the acceptable vacuum level and the durations associated with maintaining it.

- The vacuum system of the 100 MVA generator must be maintained at pressures lower than $10^{-5}$ Torr.

- The time to achieve that vacuum shall not exceed 72 hours.

- Vacuum Service Interval: Target 5 years, LSL of 3 years.

- The time to recharge the getters, not including the subsequent vacuum pumpdown cycle, shall not exceed 24 hours.

- A means to safely release the vacuum within the rotor shall be provided. The time needed to vent the rotor shall not exceed two (2) hours.

To determine the time to achieve an acceptable level of vacuum, the vacuum circuit of the rotor was mapped out in terms of a series of pumping restrictions (molecular and viscous conductance) from the pump-out ports, which are located on the collector end, to the getter assembly that terminates the vacuum cavity on the turbine end. The viscous regime conductance was determined by finding the hydraulic diameter of various internal cross-sections from the pump to the turbine end of the rotor. The effective pumping rate in the 760 to $7.6\left(10^{-2}\right)$ Torr range with a $3.5 \mathrm{cfm}$ rated pump is $1.6 \mathrm{l} / \mathrm{s}$. The time required to obtain a vacuum of $7.6\left(10^{-2}\right)$ Torr is approximately 35 minutes. The molecular conductance of the individual sections, such as the annulus between the refrigeration lines, was determined using standard vacuum tables and equations based on different cross-sectional geometries. The overall circuit resistance (conductance) from the pump to the turbine end, shown in the figure below, was determined by adding parallel resistance and taking the inverse of the sum of the inverses of the series resistances. The effective pumping speed in the molecular flow regime was determined to be 9.6 Torr-1/s with a 3001/s turbo pump. The total time required to go from 760 Torr to $10^{-6}$ Torr was determined to be approximately 42 minutes. This leaves ample time to bake the system and to activate the getters.

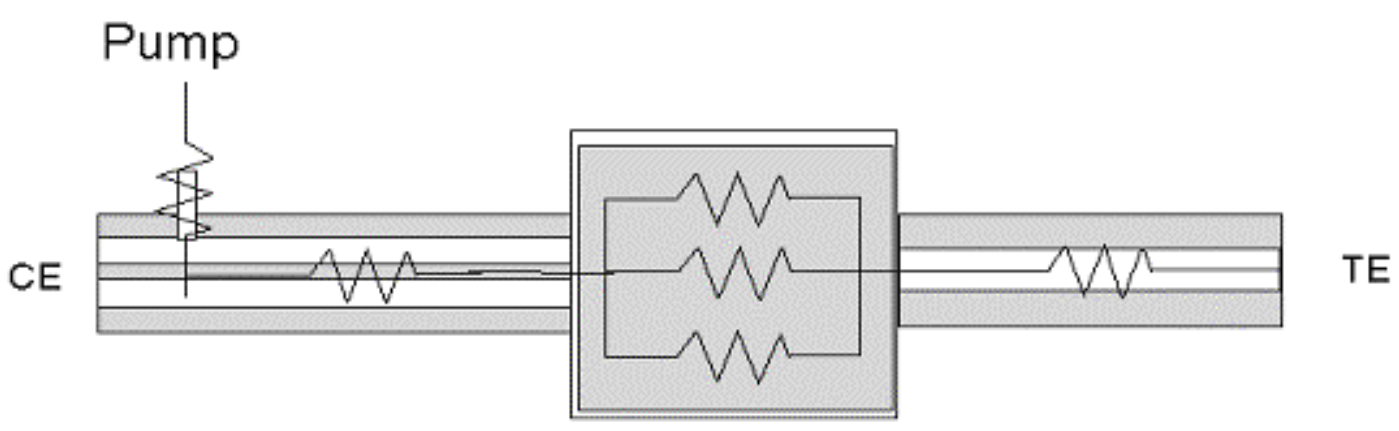

Figure 5-48 - Conductance Circuit 
Getters are required to maintain the vacuum level under $10^{-5}$ Torr. The same SAES zirconium-based getters that were used on the Demonstrator will be used on the 100 MVA generator. Hydrogen is the main contributor to elevating pressure, since it is not cryo-pumped at 20-30 K. A vacuum model was created to determine the number of getters required for this system by calculating the total amount of hydrogen that is outgassed by components in the evacuated area of the rotor. LANL provided outgassing rates for materials that are inside the vacuum cavity. Over five years, 2456 Torr-l of hydrogen would be released from components inside the rotor. Each individual getter has a hydrogen sorption capacity of 125 Torr-l. A minimum of 20 SAES ST 172/HI/20-10 getters would be required to adsorb that quantity of hydrogen.

The individual getters would be placed in stainless steel channels in a fashion similar to the Demonstrator. The getter assembly would be welded in the bore of the turbine end spindle, far away from the refrigeration and superconducting leads. This assembly also serves as the termination point of the vacuum at the turbine end.

Table 5-13 - Performance of Getter System

\begin{tabular}{lcc}
\hline \multicolumn{1}{c}{ SAES ST 172/HI/20-10 } & Units & Value \\
\hline Nominal Active Getter (per unit) & g & 12.5 \\
Getter Material Hydrogen Sorption & Torr-l/g & 10 \\
Hydrogen Sorption & Torr-l/unit & 125 \\
Total Hydrogen Outgassed (over 5 years) & Torr-1 & 2426 \\
Getters Required & --- & 20 \\
\hline
\end{tabular}

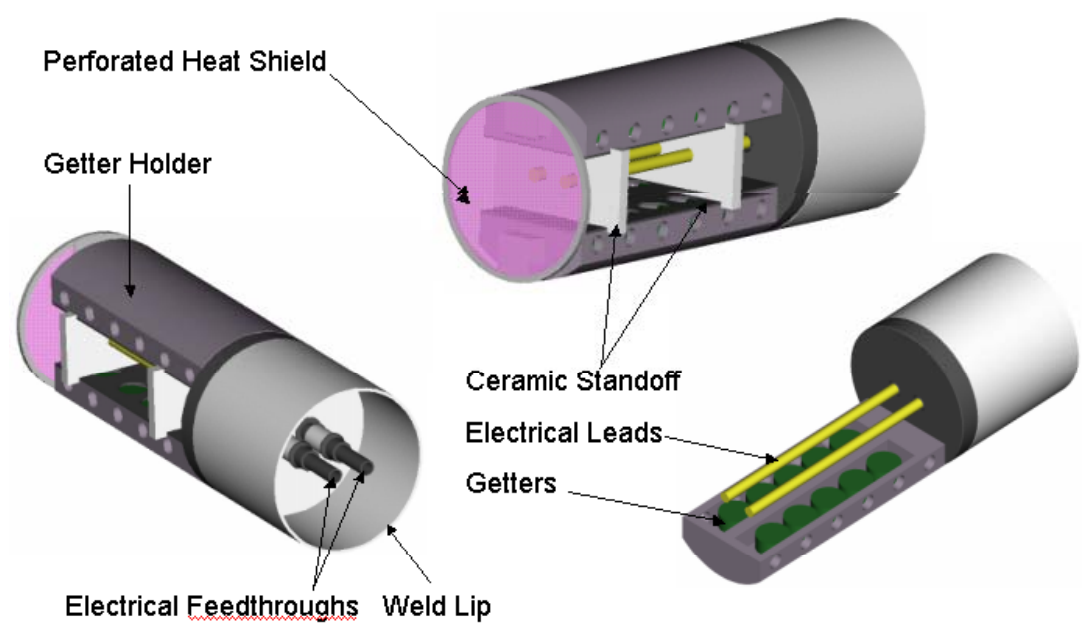

Figure 5-49 - Getter Assembly 


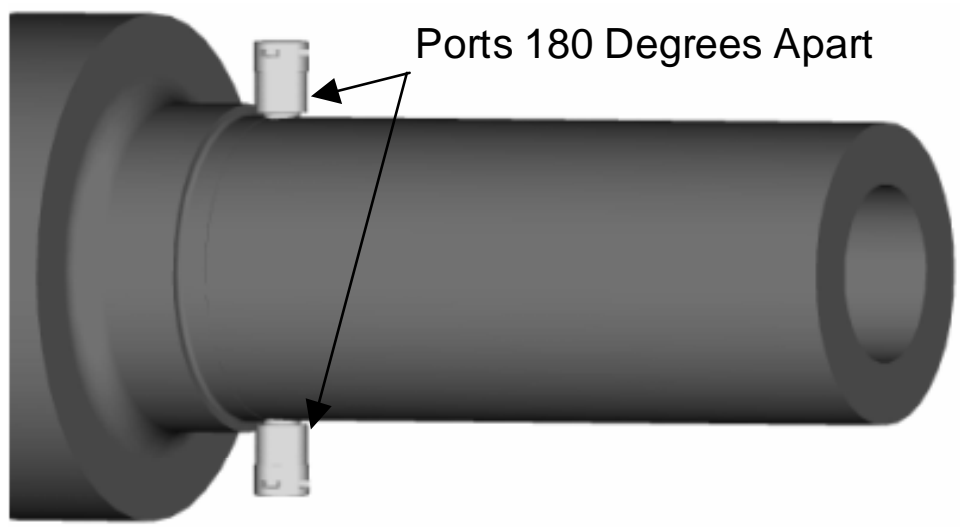

Figure 5-50 - Pump-out Port Location

\subsection{Emissivity Controls}

Emissivity controls are required in the HTS rotor to minimize heat transfer to the rotor cryogenic system and should be applied on warm and cold surfaces. Silver tank plating and aluminized Mylar were implemented as controls for the Demonstrator. Because of the size of the 100 MVA rotor components, silver brush plating methods were also evaluated so that large plating vessels would not be required.

Testing was performed to determine the emissivity of silver-plating by tank and brush plating processes under different substrate conditions such as surface roughness and plating thickness. Additional testing was performed to determine the effect of contaminants, degradation, and methods used to protect control surfaces. The testing led to the following conclusions.

- Fingerprints had little immediate effect but a larger effect over time.

- There was little difference between 25-150 microinch finish of the steel substrate. However, Scotchbrite had a negative effect with finishes above 200 microinch.

- Both silver-plating methods produced emissivities between 0.02 and 0.04 .

- The substrate material does not matter. The 0.0002 ” film is optically thick

Long-term exposure to atmospheric pollutants and oxidization has the largest effect on silver-plated surfaces according to the reactions:

$$
\begin{gathered}
2 \mathrm{Ag}+\mathrm{SO}_{2} \rightarrow \mathrm{Ag}_{2} \mathrm{~S}+\mathrm{O}_{2} \\
2 \mathrm{Ag}+\mathrm{O}_{2} \rightarrow \quad 2 \mathrm{Ag}_{2} \mathrm{O}
\end{gathered}
$$




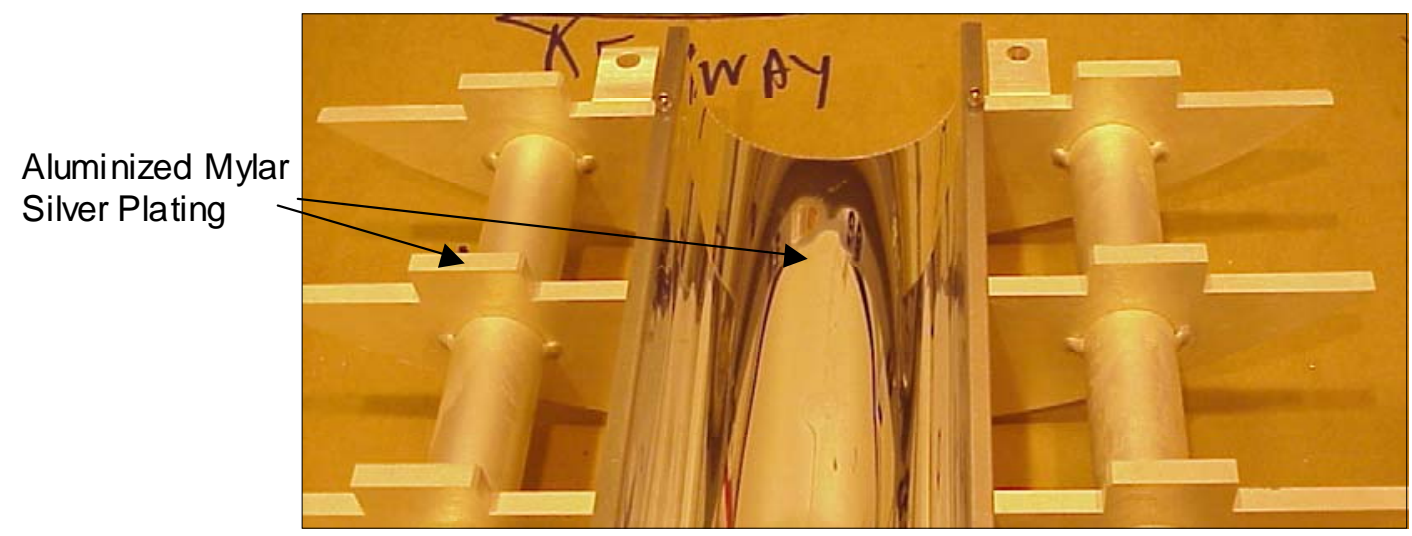

Figure 5-51 - Demonstrator Emissivity Components

Figure 5-52 shows the effect of exposing silver-plated samples to different environments for extended durations. The results show that silver-plated parts should be bagged and wrapped with Silver Saver paper or its equivalent. Alternatively, large parts can be wrapped with Silver Saver paper and plastic and fed with a slow, dry nitrogen purge. Silver surfaces should be cleaned with alcohol before insertion into the system and provisions should be made to protect components that are assembled but not under vacuum by bagging the assemblies and purging with nitrogen. Separate testing showed that tarnish remover also helped reduce emissivity after exposure. Because of the difficulties associated with protecting silver-plated parts, a single layer of aluminized Mylar $(\varepsilon=0.04)$ on simple radially inward facing surfaces should be used where applicable.

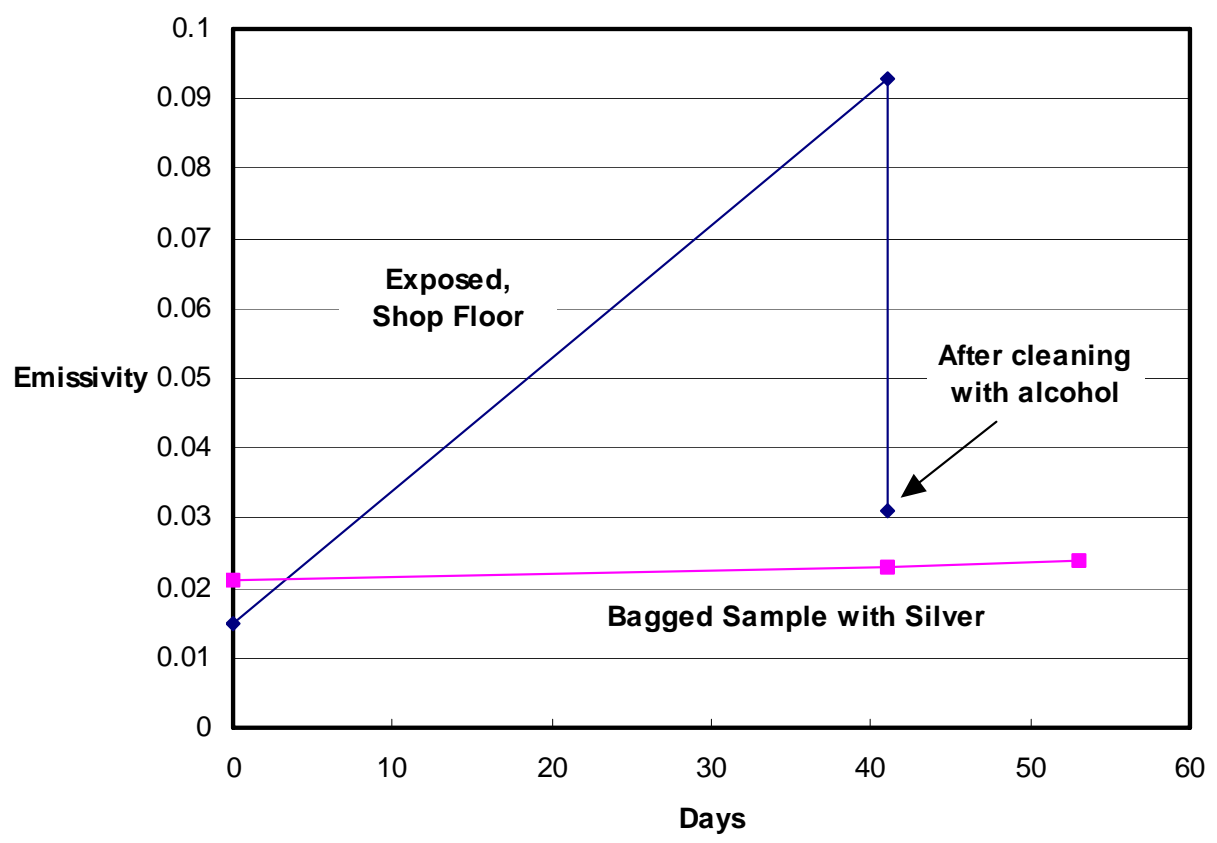

Figure 5-52 - Emissivity Degradation Study 


\subsection{Transfer Coupling}

The transfer coupling is a key subsystem in the cryogenic system for the HTS generator. It transfers cryogenic cooling fluid to and from the rotor to cool the rotor winding. The Demonstrator transfer coupling was designed to accommodate the cryogenic flow rate for the 100 MVA generator, so the lessons learned from testing and manufacturing the Demonstrator transfer coupling led to a reliability model and minor improvements.

One of the goals of the 100 MVA generator program was to provide an HTS generator for which the reliability, availability, and maintainability (RAM) of the HTS generator was equal to or superior to a conventional generator. Reliability models were developed and evaluated for the transfer coupling. Figure 5-53 and Figure 5-54 show a schematic diagram and reliability model for the transfer coupling. The analysis identified several areas that need further analysis and development in order to meet the reliability targets including bearing lubrication and sealing technology.
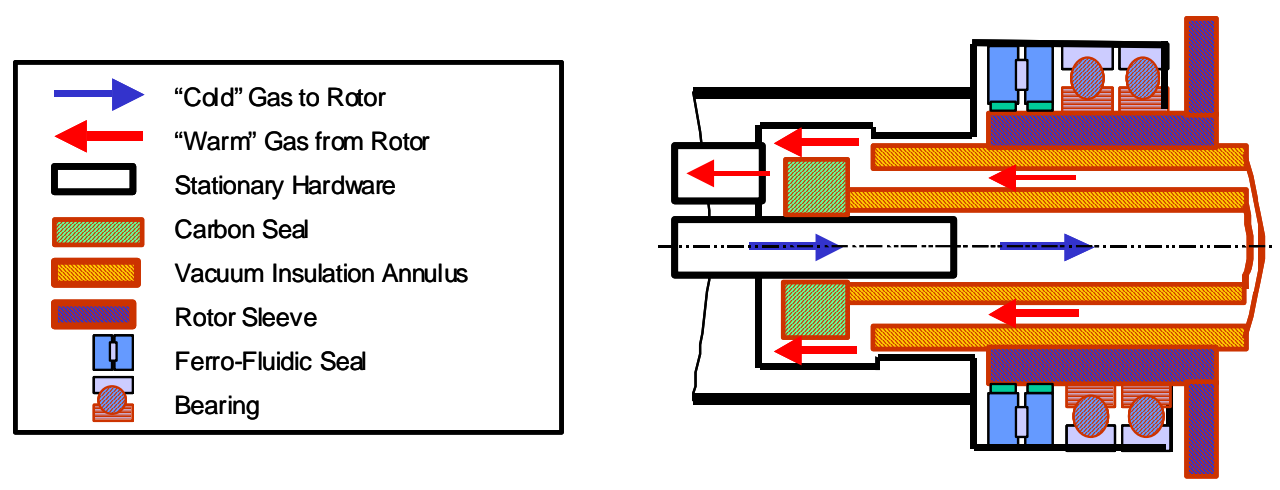

Figure 5-53 - Schematic of Transfer Coupling

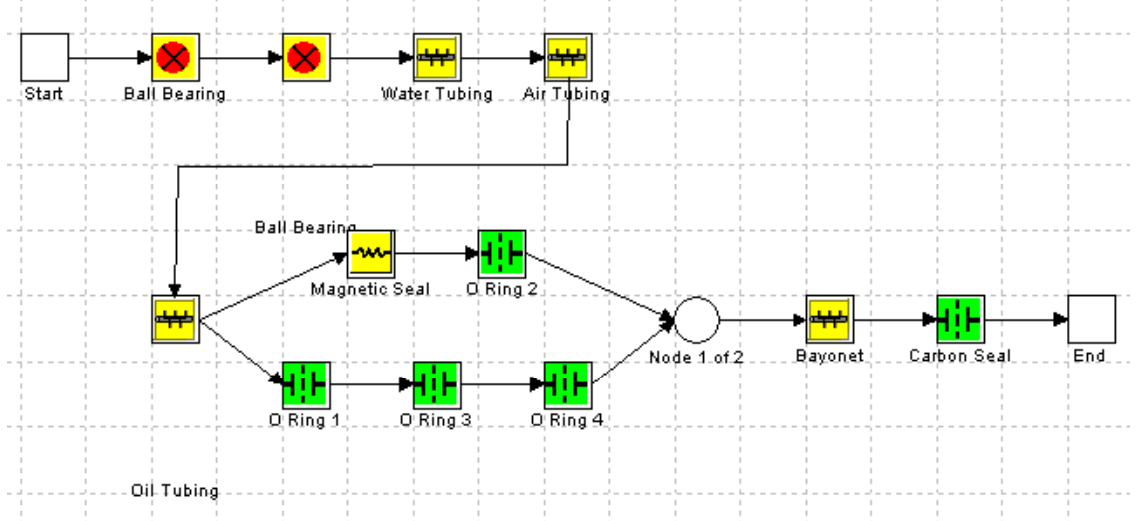

Figure 5-54 - Reliability Model for Transfer Coupling 


\section{Economic Evaluation}

Task 1 included a subtask to develop an economic model that covered the costs and benefits of operating the HTS generator. The economic judgments associated with any technology program are always done in the context of the organization making the judgment. That context includes:

- A view of the external market (in this case, the power generation market)

- Estimates about the progress on technology

- Financial considerations (cost of money, etc.)

As such, different organizations may arrive at different conclusions for a given technology opportunity. That is likely to be the case for HTS generators.

GE's economic evaluation of the HTS generator is based on proprietary information that cannot be disclosed. However, general comments and high-level considerations of benefits vs. cost can illustrate how the evaluation was made.

\subsection{Possible HTS Generator Benefits}

The benefits of any HTS generator in a power generation application may include

- The value of avoided losses.

- Any possible reduction in the capital cost of the generator because of the HTS rotor.

- Potential revenue because of enhanced reactive power capacity (VARS)

- Incremental improvements in generator reliability

- Improved power plant stability

Avoided losses can represent either fuel not burned or incremental sales of electricity and that choice is at the discretion of the power plant operator. The value will depend greatly on the cost of fuel, the number of operating hours per year, and the market price for electricity.

Studies done within this program and elsewhere confirm that reductions in the overall generator cost are possible if a generator were initially designed with an HTS rotor. Most of those savings are related to an improved use of ventilation that allows for an overall higher power density.

The opportunity for revenue from enhanced reactive capability appears to be highly situational. In some instances, reactive power capacity may have a well-defined value. However, there is no generally accepted means to establish that value for the general case, nor a means to compensate a power plant owner for any additional reactive power capacity in the HTS generator. 
It is quite possible the HTS rotor will offer reliability benefits to the generator owner simply because the rotor would experience far fewer thermal excursions over its lifetime. That lessened thermal duty may translate into a delayed rotor rewind after $20-25$ years. However, that improved reliability must be considered in the context of a more complex generator. The transfer coupling and the cryocooler are additional components in the power train that represent instances of single point failures. Redundant cryocoolers could be included but at an additional cost. Nonetheless, the transfer of coolant onto the rotor would remain a weak point.

Improvements in power plant stability have been cited as driving forces for superconducting generators in some countries. However, as with the reactive power capacity, this benefit is certainly situational and cannot support a general business case for this technology.

\subsection{Costs of the HTS Generator}

The additional costs of the HTS generator in a utility application include

- A possible higher capital cost

- An increase in maintenance costs

GE's investigation into the cost structure for the HTS generator shows that the higher cost for the generator is driven by three majors factors:

- The cost of the HTS wire,

- The cost to support the HTS coil during operation, and

- The cost of the cryocooler.

Table 6-1 shows the comparative cost of the 100 MVA HTS generator as a percentage of the cost of the conventional generator assuming an HTS wire cost of $\$ 25 / \mathrm{kA}-\mathrm{m}$. The HTS coil, the refrigeration, and the mechanical support represent an extra $70 \%$ cost beyond the same functional components in the conventional generator. These estimates are based on GE’s judgment of “mature” product costs given the present technology.

Regardless of the cost of the generator, the HTS generator in the power plant represents an on-going cost to the plant operator. Maintenance personnel will have to be assigned (part-time) to monitor the equipment and perform periodic maintenance of the refrigeration system. This cost will be assumed to be $\$ 20,000 /$ year. 
Table 6-1 - Cost of 100 MVA HTS Generator Compared to Conventional Generator

\begin{tabular}{lcc}
\hline & Base Generator Cost & HTS Generator Cost \\
\cline { 2 - 3 } Field Coil $\left.{ }^{*}\right)$ & $11 \%$ & $34 \%$ \\
Refrigeration & --- & 21 \\
Rotor Forging \& Coil Support & 9 & 35 \\
Other Rotor & 12 & 19 \\
Stator \& Final Assembly & 59 & 58 \\
Exciter & 9 & 9 \\
Total Generator Cost & $100 \%$ & $176 \%$ \\
\hline
\end{tabular}

* For \$25/kA-m HTS wire

\subsection{Economic Assessment}

Given the potential benefits of higher efficiency and the prospect of significantly greater generator costs, one can bound the overall economic viability of the HTS generator.

Table 6-2 shows a simple model of the value of the avoided losses. It assumes the improved losses shown in Table 5-2 (265 kW) and considers both a base-loaded generator operating 8000 hours per year and a unit operated only 3000 hours per year (quite typical of smaller air-cooled generators). Furthermore, the table considers the cost of HTS wire over a range from $\$ 150 / \mathrm{kA}-\mathrm{m}$ to $\$ 5 / \mathrm{kA}-\mathrm{m}$. The present value of the losses is based on incremental electricity sales at $\$ 35 / \mathrm{MW}$-hr over a 15 year period at $15 \%$ cost of money.

Table 6-3 addresses the benefits for a 575 MVA hydrogen-cooled generator.

One simple question: "Does the more efficient HTS generator return enough capital to pay for its HTS wire?" Table 6-2 shows that, for the most part, the 100 MVA generator does not. The only exceptions are for a cyclic-loaded unit with very inexpensive wire $(\$ 5 / \mathrm{kA}-\mathrm{m})$ or a base-loaded unit with wire at $\$ 25 / \mathrm{kA}-\mathrm{m}$ or less. In contrast, Table $6-3$ shows that the efficiency benefit of the larger generator is sufficient to cover the wire cost in most cases.

This assessment shows that high operating hours and inexpensive HTS wire are necessary for the HTS generator to be economically viable. However, they are not sufficient. As Table 6-1 showed, the cost of the refrigeration and coil support remain expensive components in the rotor assembly. Improvements in refrigeration and wire characteristics (higher operating temperatures and strain capacity) are needed. 
Table 6-2 - Benefits of Efficiency Savings on a 100 MVA Generator

\begin{tabular}{|c|c|c|c|c|c|c|c|}
\hline & & \multicolumn{3}{|c|}{ Base Load } & \multicolumn{3}{|c|}{ Cyclic Operation } \\
\hline Loss Savings & $\mathrm{kW}$ & \multicolumn{3}{|c|}{265} & \multicolumn{3}{|c|}{265} \\
\hline Operating Hours & $\mathrm{hrs} / \mathrm{yr}$ & \multicolumn{3}{|c|}{8000} & \multicolumn{3}{|c|}{3000} \\
\hline Incremental Electricity Sales & $\$ 1,000 / \mathrm{yr}$ & \multicolumn{3}{|c|}{74} & \multicolumn{3}{|c|}{28} \\
\hline Annual Maintenance & $\$ 1,000 / y r$ & \multicolumn{3}{|c|}{20} & \multicolumn{3}{|c|}{20} \\
\hline Net Benefit & $\$ 1,000 / \mathrm{yr}$ & \multicolumn{3}{|c|}{54} & \multicolumn{3}{|c|}{8} \\
\hline Present Value of Benefit & $\$ 1,000$ & \multicolumn{3}{|c|}{317} & \multicolumn{3}{|c|}{46} \\
\hline HTS Wire Price & $\$ / \mathrm{kA}-\mathrm{m}$ & 150 & 25 & 5 & 150 & 25 & 5 \\
\hline Covers the HTS Wire Cost? & & NO & YES & YES & NO & NO & YES \\
\hline
\end{tabular}

Table 6-3 - Benefits of Efficiency Savings on a 575 MVA Generator

\begin{tabular}{|c|c|c|c|c|c|c|c|}
\hline & & \multicolumn{3}{|c|}{ Base Load } & \multicolumn{3}{|c|}{ Cyclic Operation } \\
\hline Loss Savings & $\mathrm{kW}$ & \multicolumn{3}{|c|}{2000} & \multicolumn{3}{|c|}{2000} \\
\hline Operating Hours & hrs/yr & \multicolumn{3}{|c|}{8000} & \multicolumn{3}{|c|}{3000} \\
\hline Incremental Electricity Sales & $\$ 1,000 / y \mathrm{r}$ & \multicolumn{3}{|c|}{560} & \multicolumn{3}{|c|}{210} \\
\hline Annual Maintenance & $\$ 1,000 / y \mathrm{r}$ & \multicolumn{3}{|c|}{20} & \multicolumn{3}{|c|}{20} \\
\hline Net Benefit & $\$ 1,000 / y r$ & \multicolumn{3}{|c|}{540} & \multicolumn{3}{|c|}{190} \\
\hline Present Value of Benefit & $\$ 1,000$ & \multicolumn{3}{|c|}{3158} & \multicolumn{3}{|c|}{1111} \\
\hline HTS Wire Price & $\$ / \mathrm{kA}-\mathrm{m}$ & 150 & 25 & 5 & 150 & 25 & 5 \\
\hline Covers the HTS Wire Cost? & & YES & YES & YES & NO & YES & YES \\
\hline
\end{tabular}

\subsection{Conclusions}

GE has concluded that given the current HTS technology and the cost of the HTS wire, the cost disadvantage of a 100 MVA HTS generator, combined with its relatively infrequent operation, more than offsets any efficiency benefits.

Larger generators with ratings greater than 500 MW may be suitable candidates for the HTS technology. They offer greater efficiency benefits and are more likely to be operated as base-loaded units. Furthermore, some cost trends scale more slowly than the rating, so factors that are significant for small generators may be less significant in larger generators. 


\section{Plant Integration}

\subsection{Equipment Packaging}

The generator model selected for the prototype unit was a Model 7A6 for the GE Frame $7 \mathrm{E}$ gas turbine. This generator model has a walk-in compartment on the collector end that is approximately six feet long and ten feet wide.

It is very important to get the refrigeration system as close to the transfer coupling as possible since the cold helium lines, even with vacuum insulation, will absorb approximately one watt for each foot of length. The original concept for packaging the refrigeration system was to place it in the walk-in compartment. Since this compartment is mechanically connected to the generator and is subject to vibration from the generator, the original refrigeration specification included a requirement for the level of external vibration that the refrigerator could withstand. Some thought was also given to mounting the refrigerator on vibration isolation pads to protect it from the generator vibration, but before that concept was developed the refrigerator outgrew the compartment.

As the needed cooling capacity and size of the refrigeration system grew, the packaging concept evolved.

\subsubsection{Refrigeration System}

The refrigeration systems would be relocated to an external enclosure that could be used for both shipping and on-site protection. Normal metal shipping containers are approximately eight feet wide by twenty or forty feet long. The twenty-foot version was expected to be adequate for this refrigerator. Air Liquide provided a layout showing how their refrigeration system would fit within such a container. Since the scope of this project was to get through prototype factory testing, the detailed design of the enclosure would be considered in a follow-on program wherein the generator would be tested in a power station.

Placing this enclosure near the generator should not be a problem for an outdoor installation, but is likely to be very difficult for an existing, indoor generator, based on visits to plants at Dayton Power \& Light and Mass Power that have 7A6 generators.

\subsubsection{Helium Transfer Coupling}

The helium transfer coupling is the interface between rotating and stationary helium cooling lines. For the Demonstrator, the transfer coupling was connected to a two-foot long bellows that could absorb the lateral rotor vibration. The bellows was rigid in the axial direction. In a turbine-generator, the interface between this bellows and the helium supply lines must be able to absorb the axial movement of the generator rotor caused by 
the turbine expansion and contraction during startup and shutdown. This interface must also be insulated to avoid an electrical path from the collector end of the rotor to ground.

\subsubsection{Chiller}

A chiller is required to provide cooling to the refrigeration system and transfer coupling. A number of chiller configurations and vendors were considered and a trade-off study was performed to evaluate all options. A reliability study was also performed for each configuration to determine if it met the RAM requirements in the ordering drawing. The required MTBF is driven by the overall refrigeration unit's MTBF and the MTBF values that were obtainable for the cryocooler. There are two configurations that would meet the RAM requirements: a unit with multiple circuits or a unit with a bypass that uses city water as a backup. The trade-off study showed that a low cost multiple circuit unit is the best option, which in this case was achieved by putting two identical units side-by-side and adding controls to allow the system to automatically switch to the secondary unit in case of a failure of the primary unit or a need to perform maintenance. Unlike the multiple circuit unit, the city water backup configuration requires additional plumbing and may leak glycol into the plant water system.

\subsection{Operation and Maintenance}

The task of assessing operation and maintenance aspects of an HTS generator at the power plant level was carried out jointly with AEP. Some highlights from that assessment are:

A gas turbine unit is an ideal application for the initial installation of the prototype rotor since the HTS rotor and auxiliaries can be installed and operated during the off-peak season when power generation is not mandatory. The HTS coil, refrigeration system, and helium transfer coupling can also be evaluated for both on-line and longer-term off-line operation. However, it seems unlikely that a 100 MW to $200 \mathrm{MW}$ combustion gas peaking power plant is the ideal, economical, commercial application for an HTS rotor unless the initial cost and maintenance costs can be significantly decreased. The added auxiliaries and required refrigeration system maintenance are unfavorable to an unattended station. Because many of these plants do not see base load operation, the small increase in rotor efficiency may not overcome the initial cost and added maintenance. To take advantage of the efficiency improvement, the HTS rotor should be used at a base loaded power plant on a much larger unit.

An HTS rotor could be a consideration for a replacement rotor if a utility finds itself in need of a new replacement rotor at a base-loaded plant. The HTS rotor would offer a reduction in life-cycle maintenance costs, an increase in unit efficiency, and additional reactive capability. Each situation and plant will have to 
be evaluated individually. For larger units the reduced wear and the increased efficiency become major advantages.

Perhaps the most noteworthy life-cycle maintenance benefit of the HTS rotor over the conventional rotor is the reduced mechanical wear and tear on the rotor insulation system. The centrifugal forces caused by start/stop speed changes are enormous. For a conventional rotor the winding coils have to be somewhat loose within the slots and the end turn blocking has to accommodate the movement caused by thermal expansion and contraction. The copper winding itself is prone to distortion from the routine centrifugal forces of start/stop cycling. The mechanical forces caused by thermal expansion and contraction from low load to full load operation are also damaging. As the coils slide across each other, the turn-to-turn insulation is abraded and over time turn-to-turn shorts develop, usually in the outer most coils. The forces are particularly deleterious on combustion gas turbine-generators, which are used for peaking duty. Industry experience has shown that the conventional combustion gas turbine-generator used for peaking duty may require that the rotor winding be re-insulated or completely replaced after 10 to 15 years of service due to these routine operating forces. However, the start/stop duty is much less on the base-loaded units; these rotors may require rewinds after 20 to 25 years of service. Because of being reinsulated, many rotors require a full speed balance resulting in shipping the rotor to a facility with a balance pit.

The consolidated construction of the HTS coil produces a robust winding; centrifugal forces should not be damaging. Since the HTS coil is super-cooled prior to start up, it does not experience a temperature change from out-of-service to full-load service. Therefore, there are no thermally induced forces to abrade turn-to-turn insulation. The HTS coil may never requiring re-insulation.

The HTS coil is enclosed in a vacuum inside a sealed cylinder; this eliminates the possibility for rotor contamination. An air-cooled rotor is very prone to contamination affecting the electrical integrity. Even hydrogen-cooled rotors are subject to contamination from seal oil and lubricating oil. In addition, a highly stressed retaining ring is not required on the HTS rotor. 


\section{Power System Integration}

\subsection{GE Assessment}

The technical issues for a 100 MVA HTS generator operating on a power system were assessed using standard techniques. A significant portion of that work examined operational characteristics. A second portion examined protective relaying systems (field ground, differential protection, etc.).

\subsubsection{Grid Interaction Studies}

Power system interface studies for the HTS generator were conducted to assess performance of the generator in order that such generators may be successfully integrated with electric power grids. As the program progressed, three designs were considered, with Design \#3 being most like the anticipated 100 MVA prototype design.

The characteristics of superconducting generators affecting system performance may be quite different from those of conventional generators. In this study the performance of the HTS generator (HTSG) was compared to that of a conventional generator that is normally employed in this 105.7 MVA Frame 7 gas turbine application. A comparison of approximate reactance, time constant, and inertia data is shown in Table 8-1 for all three designs.

It is also observed from inspection of Table 8-1 that the open circuit time constants are all larger for the superconducting machine. Consequently, the short circuit time constants are also expected to be larger. Especially noteworthy is the field open circuit time constant for the superconducting generator: 2273 seconds or 0.63 hours for Design \#3, as compared to about 11 seconds for the conventional generator. This time constant is a measure of how quickly generator field current changes in response to field driving (exciter output) voltage. This long field time constant for the superconducting generator is an expected result due to the combination of high field inductance and low field resistance.

Finally, it is observed that the gas turbine-generator combined inertia is lower for the superconducting generator. The generator inertia alone, not shown in the table, is about $32 \%$ lower than that of the conventional generator. When combined with the gas turbine prime mover, the overall inertia is only $10 \%$ less with the superconducting generator. 
Table 8-1 - Comparison of Generator Parameters

\begin{tabular}{|c|c|c|c|c|}
\hline Parameter & 7A6 & $\begin{array}{c}\text { HTSG } \\
\text { Design \#1 }\end{array}$ & $\begin{array}{c}\text { HTSG } \\
\text { Design \#2 }\end{array}$ & $\begin{array}{c}\text { HTSG } \\
\text { Design \#3 }\end{array}$ \\
\hline MVA & 105.8 & 105.8 & 105.8 & 105.8 \\
\hline SCR & 0.48 & 0.82 & 0.72 & 0.8 \\
\hline $\mathrm{H}^{*}$ & $5.92 / 5.92$ & $5.12 / 5.48$ & $5.48 / 5.48$ & $5.12 / 5.62$ \\
\hline$X^{\prime \prime}{ }_{d v}$ & 0.138 & 0.140 & & \\
\hline$X^{\prime \prime}{ }_{d v}$ & 0.205 & 0.262 & 0.144 & 0.144 \\
\hline$X_{d v}^{\prime}$ & 0.216 & 0.311 & 0.330 & 0.336 \\
\hline$X_{d}$ & 2.053 & 1.216 & 1.371 & 1.378 \\
\hline $\mathrm{T}_{\text {do }}^{\prime}$ & 11.22 & 70809 & 9545 & 2273 \\
\hline $\mathrm{T}_{\text {do }}$ & 0.232 & 0.424 & 0.285 & 0.285 \\
\hline T"'do & 0.0026 & 0.173 & & \\
\hline $\mathrm{T}_{\mathrm{a} 3}(\mathrm{est})$ & 0.293 & 0.336 & 0.412 & 0.412 \\
\hline$X^{\prime \prime \prime}$ & 0.138 & 0.140 & & \\
\hline $\mathrm{X}_{\mathrm{qv}}^{\prime \prime}$ & 0.198 & 0.206 & 0.145 & 0.145 \\
\hline$X_{\mathrm{qv}}^{\prime}$ & 0.616 & 0.850 & 0.814 & 0.863 \\
\hline $\mathrm{X}_{\mathrm{q}}$ & 2.003 & 0.853 & 0.839 & 0.865 \\
\hline $\mathrm{T}_{\mathrm{qo}}^{\prime}$ & 5.93 & 28354 & 33.685 & 32.45 \\
\hline $\mathrm{T}_{\text {qo }}$ & 0.252 & 0.123 & 0.817 & 0.817 \\
\hline $\mathrm{T}^{\prime \prime \prime}$ qo & 0.003 & 0.129 & & \\
\hline $\begin{array}{c}\text { Field } \\
\text { Inductance }\end{array}$ & $1.72 \mathrm{H}$ & $115.9 \mathrm{H}$ & $284 \mathrm{H}$ & $62.1 \mathrm{H}$ \\
\hline Field Resistance & $0.241 \Omega$ & $0.005 \Omega$ & $0.03 \Omega$ & $0.025 \Omega$ \\
\hline
\end{tabular}

* Total H used for stability studies/Total $\mathrm{H}$ of torsional model. 


\subsubsection{Study Approach}

These grid and prime mover interface studies were undertaken to evaluate the interface implications of the superconducting generator in light of its different characteristics. The desire and ultimate design goal is a superconducting generator that meets all present and anticipated future requirements.

The following broad study categories were undertaken to evaluate unit performance and interface with the grid, as well as prime mover:

- Load rejection studies relative to both unit speed and voltage response.

- Voltage regulation/response studies for load and reactive switching.

- Stability studies, including dynamic (small signal), and transient stability.

- Fault current studies, to determine generator-source fault current duties on equipment.

- Fault and switching studies to determine unit shaft torsional stress.

- Pole slip studies to determine induced field voltage due to pole slip.

The approach to these grid/prime mover interface studies was to evaluate performance by dynamic and transient simulation studies, supplemented with classical calculation procedures where appropriate, tailored to the specific performance aspect being investigated. The generator and bus-fed excitation system were modeled in detail in the simulation studies. Basic gas turbine/governor and power system models were incorporated in the study models.

The generator model was developed based on a finite element model of the generator. From this model, resistance and reactance as functions of frequency were found. The resulting computer model for this representation had seven electrical plus two mechanical state variables. It should be noted that there were states included which corresponded to an additional amortisseur circuit in each axis plus a mutual leakage term in the d-axis circuit.

The data for this model was initially specified in terms of breakpoints rather than as individual resistance and inductance terms. Conversion between the breakpoint data and resistance and inductance values that are required were obtained by a curve fitting procedure. This procedure was used for both generators being modeled: (1) a conventional GE 7A6C generator and (2) the generator with a superconducting rotor (three different designs).

Performance was determined, where practical and meaningful, for both the superconducting and conventional generators; aspects of performance were compared and judgments relative to adequacy of performance or suggestions for improvement were made. 


\subsubsection{Summary and Conclusions}

The following observations and conclusions regarding interface of the HTS generator, are drawn from the results of these studies.

\section{Voltage Regulation and Response}

Very high transient gain for the voltage regulator, along with high ceiling voltage (750 volts for Design \#3) of the superconducting generator is required due to the long field time constant for the machine. A high transient gain (13,980 for Design \#3) appears to be desirable for voltage regulation and response.

For all generator designs, the magnitude of terminal voltage disturbances during for load switching near the generator are somewhat larger with the superconducting generator as compared to the conventional generator, but well within the bounds of acceptable operation, especially for interconnected system operation. Voltage recovery with the superconducting generator for load switching is better than that of the conventional generator/exciter studied. See Figure 8-1.

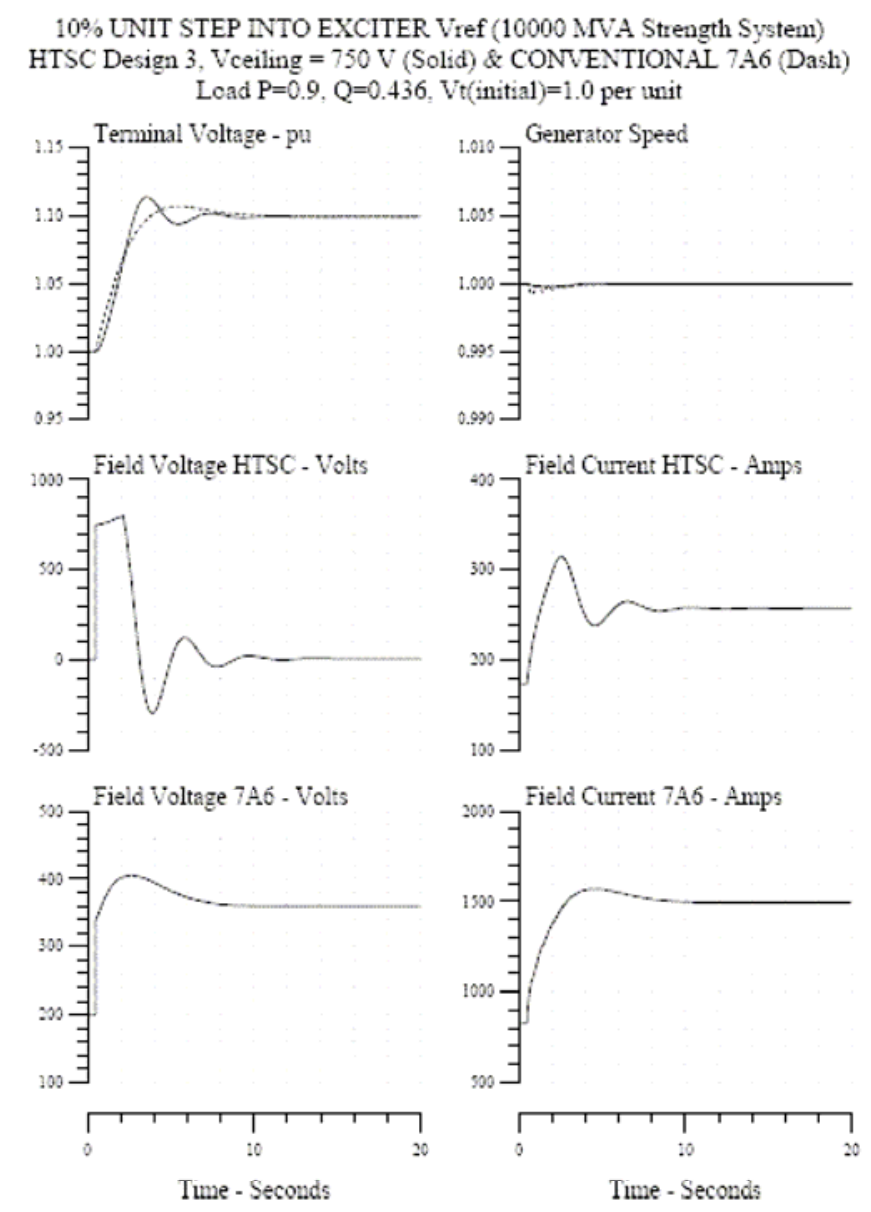

Figure 8-1 - Voltage Step Simulation Comparing HTS To Conventional Generator 


\section{Load Rejection Response}

The peak overspeed following load rejection for the HTS generator is slightly higher compared to the conventional generator as a result of the lower inertia of the HTS generator. The peak overspeed increase is expected to be more pronounced in steam turbine applications because the total turbine-generator inertia will be reduced by a larger percentage, and turbine output power reduction is generally slower.

The peak overvoltage following load rejection is higher, and overvoltage is of longer duration, for the HTS generator compared to the conventional generator, as shown in Figure 8-2. It is unlikely this will affect station design (i.e., surge arrester ratings) since similar overvoltage vs. time profiles are experienced for load rejection with other conventional generator applications with rotating exciters.

Voltage response and overspeed response differ little between faulted and non-faulted conditions prior to the load rejection event. The peak over voltage is slightly higher for fault initiated load rejection.

The overall performance for load rejection conditions for the HTS generator application studies is judged acceptable.

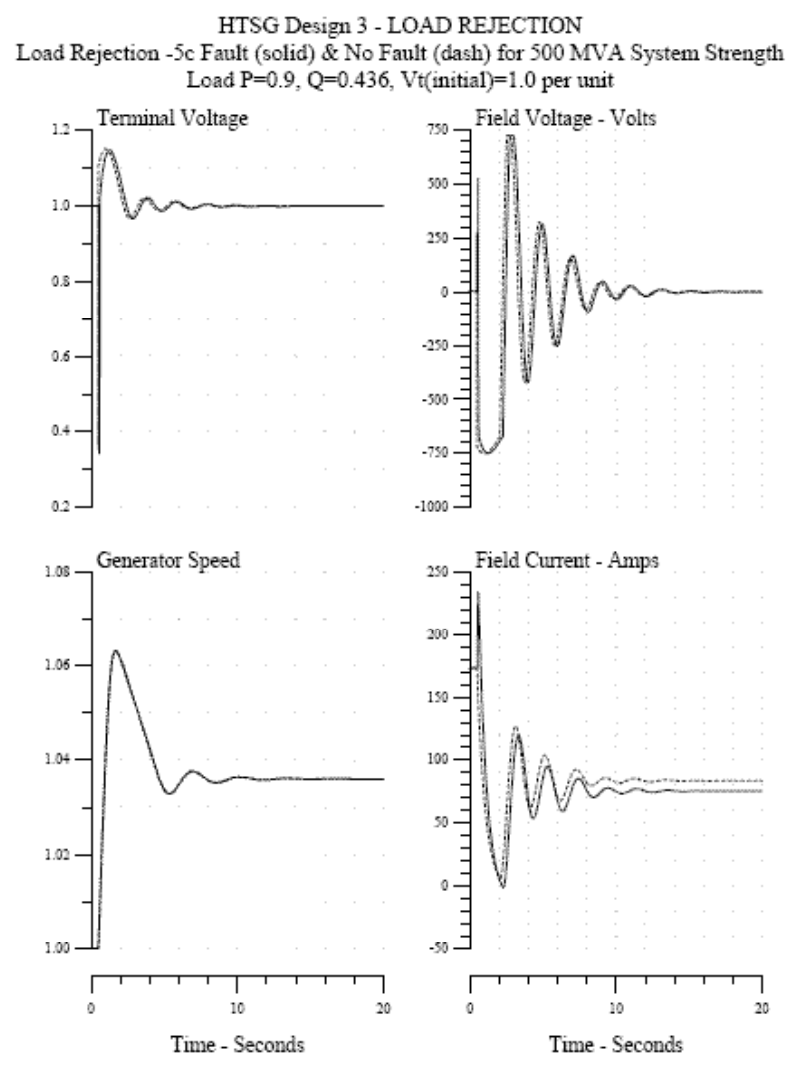

Figure 8-2 - Load Rejection Simulation On HTS Generator Design 3 


\subsubsection{Steady-State Stability}

Steady-state stability is small signal stability, i.e. the dynamic response to small gradual changes such as load changes, where the stability limit is established by insufficient synchronizing torque. Steady-state instability is generally characterized by a monotonic "pulling out" of machine rotor angle relative to the system. Historically, steady-state stability is considered without continuously acting generator controls, i.e. speed governor and automatic voltage regulator. Steady-state stability limits for the superconducting generator are expected to be greater than those for the conventional generator. This may be of importance for certain generator contingencies (manual voltage control).

\subsubsection{Dynamic Stability}

Dynamic stability is defined here as the small signal stability with all controls active and modeled where damping is the primary concern. Dynamic instability is characterized by sustained or growing oscillations of machine rotor angle relative to the system. Dynamic, or "oscillatory", stability was evaluated using small signal frequency domain analysis tools, together with GESTAB, to determine the small signal response of the system as a function of system parameters.

State-space techniques were used to perform the analysis of the dynamic stability of the turbine-generator connected to the power system. A useful way of presenting the dynamic stability analysis results is the root locus diagram. These diagrams show the movement (loci) of the eigenvalues (roots of the characteristic equation) in the complex as some parameter of the system is varied. The greater the real part of the eigenvalue, for a given imaginary part, the greater the damping (exponential decay rate) of that mode will be, presuming the eigenvalue lies in the left hand part of the complex plane. In these studies, root loci were developed on system short circuit strength, with and without turbine-generator controls, and with and without a Power System Stabilizer (PSS).

The addition of turbine-governor and generator-excitation controls, with nominal settings, modestly reduces local mode damping for both the HTS and conventional generators. The resulting damping is similar but the local mode damping for the superconducting generator is better than the conventional generator for strong systems.

A PSS can be applied to the superconducting generator exciter to further enhance damping. In the case of the superconducting generator, the PSS will be somewhat more complex, requiring higher order lead-lag filters and a torsional interaction filter. Design \#3 requires a six lead-lag filter. Attention will need to be given to the noise performance implications of the high gain PSS for the superconducting generator.

Figure 8-3 shows the root loci for the turbine-generator as a function of system strength for the superconducting generator Design \#3. These loci are for the condition of manual control of turbine speed (no governor) and manual generator voltage control and 
therefore illustrate the natural modes of the turbine-generator as a function of power system strength. Only one oscillatory mode exists, the "local mode", corresponding to the machine swinging against the system. Natural damping is about the same for this local mode across the range of system strengths compared to the conventional machine. The superconducting generator has a higher frequency of oscillation, in part due to its lower inertia. The impact of the controls with nominal settings on local mode damping is almost negligible.

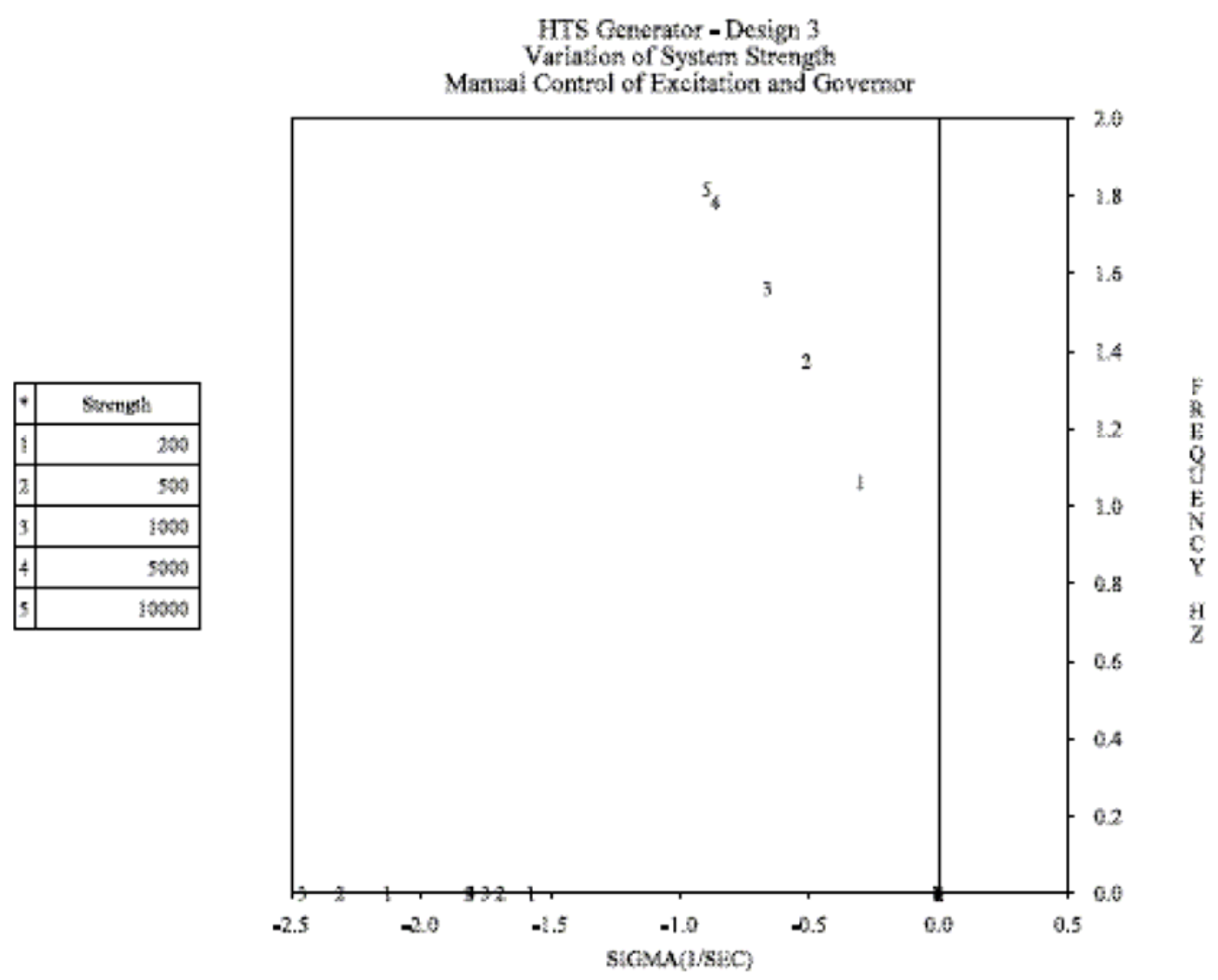

\section{Figure 8-3 - Root Loci Versus System Strength - HTS Generator Design 3 In Manual Control}

The time response for high-side faults is shown for the Design \#3 superconducting generator in Figure 8-4. Results are shown with and without a PSS with six lead lags. The system strength was $500 \mathrm{MVA}$ and the stimulus was a 6-cycle (0.1 second) three-phase fault near the GSU transformer high side. It is instructive to correlate small signal frequency response to time domain response. The local mode frequencies are evident in the generator power and speed responses. The frequency of local mode oscillations is about 1.2-1.3 Hz. That corresponds to the root loci results in Figure 8-3. 


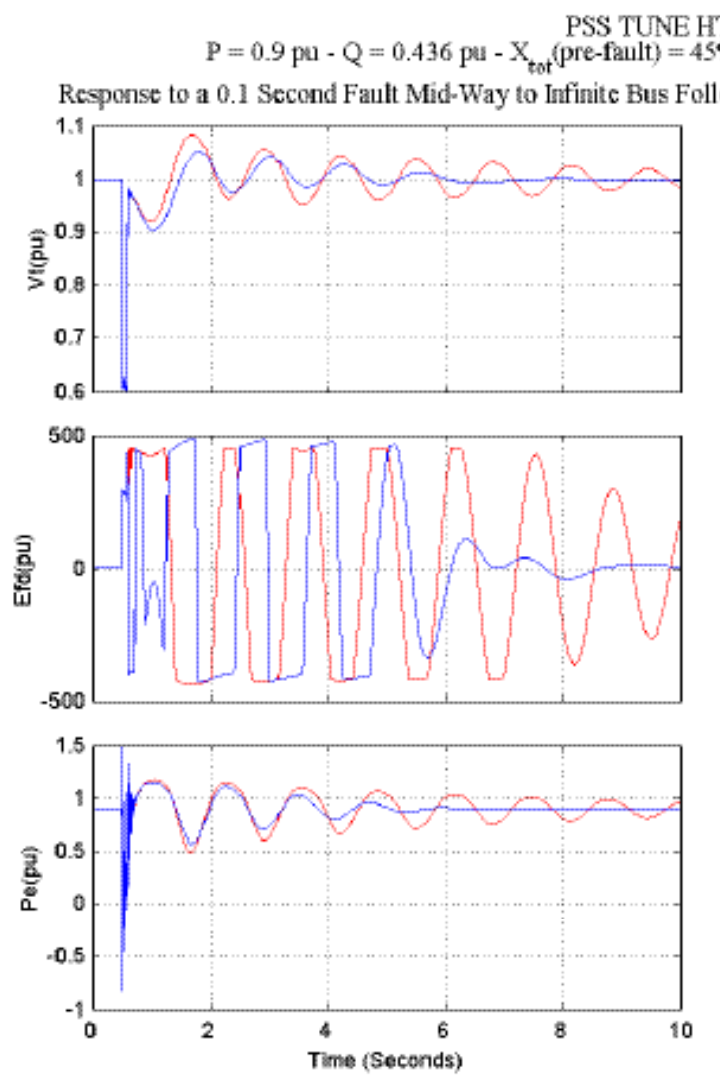

PSS TUNE HTSC Design 3

$P=0.9 \mathrm{pu}-\mathrm{Q}=0.436 \mathrm{pu}-\mathrm{X}_{\text {tot }}\left(\right.$ (pre-fault) $=45 \%-\mathrm{X}_{\text {tot }}($ post-fault $)=67.5 \%-$ PSS Lead Lag :

ed by the Loss of Lines - Bluc: PSS ON - Red : PSS OFF
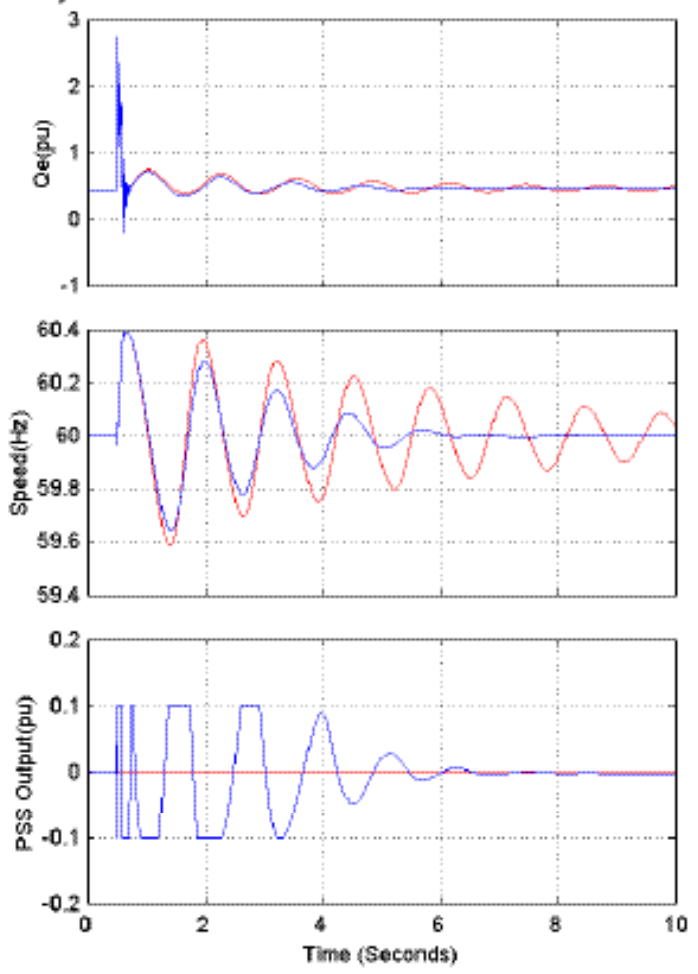

Figure 8-4 - Time Response For Fault With And Without PSS - HTS Generator Design \#3 - 6 Lead/Lag Parameters

\subsubsection{Transient Stability}

Transient stability involves large disturbances such as balanced and unbalanced faults on the power system. Transient instability is characterized by pullout of the machine rotor angle during or immediately following the disturbance, i.e. on the "first swing". In reality, the system, or generating unit and the system, must be stable in both the dynamic and transient sense, following a system disturbance and reconfiguration, for stability to exist.

Transient stability, as measured by fault critical clearing times at rated generator output, is similar for the superconducting and conventional generators, with perhaps a slight advantage to the conventional generator for overexcited operation, and a slight advantage to the superconducting generator for under-excited operation.

Inspection of Figure 8-5 shows the expected result: the critical fault clearing time increases (is more stable) as the system strength increases. In addition, stability increases with more over-excited operation. That is, the critical fault clearing times are longer at 0.90 power factor lagging operation than for unity power factor operation. Stability margins would be even less at leading power factor operation. It appears that the transient 
stability advantage of lower initial rotor angle for the superconducting generator is largely offset by its higher transient reactance and lower inertia, compared to the conventional generator. Generator field current is also shown in the figures and tables. The longer the duration of fault, the higher is the resulting peak field current. Highest field current therefore occurs for critical fault clearing time.

Figure 8-6 shows samples of the time response from the many simulation cases with the machine near its transient stability limit, i.e., at the critical fault clearing time, for a 5000 MVA strength system for the superconducting rotor generator. This case also represents the highest superconducting rotor field current (520 amps peak) case for stable fault conditions.

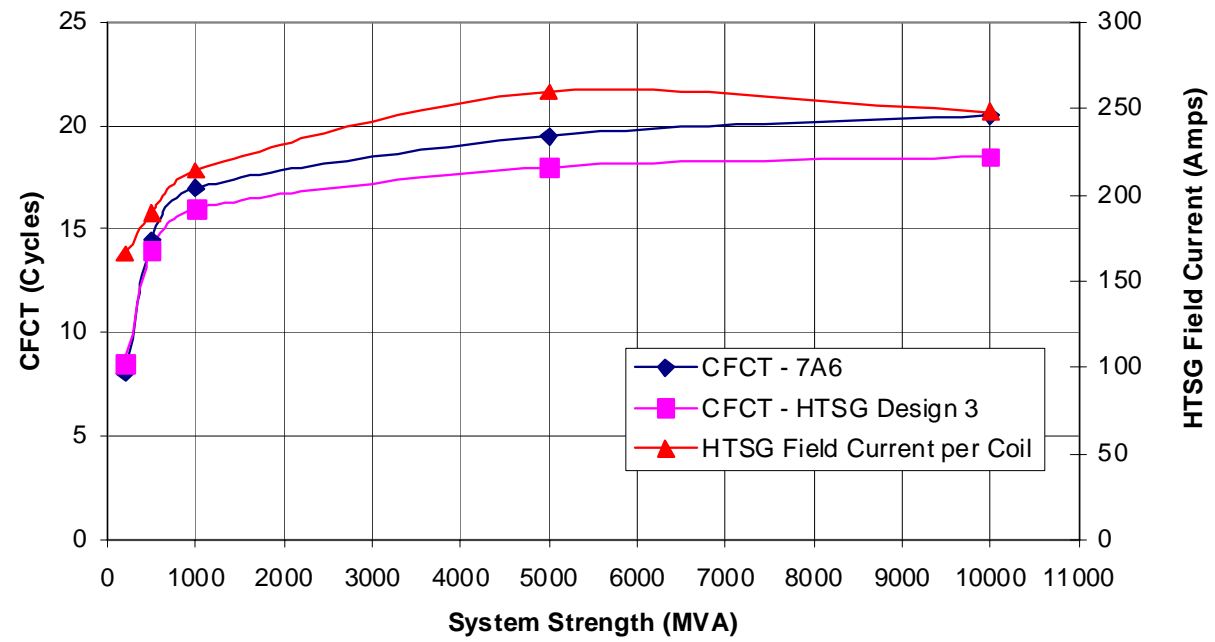

Figure 8-5 - Critical Fault Clearing Time (Cycles) \& HTSG Design 3 Field Current (Amps). Load P = 0.9, $Q=0.436, \mathrm{Vt}($ Initial $)=1.0 \mathrm{pu}$

\subsubsection{Short-Circuit Considerations}

It can be expected that the generator-source fault currents for HTS generators will differ from those for conventional generators as a result of their different reactance and time constant characteristics. For instance, the superconducting generator that is the subject of this study has a low sub-subtransient reactance and significantly longer time constants than its conventional counterpart. Accordingly, it is expected that higher, slower decaying fault currents may result for faults in the vicinity of the machine.

Simulations were used to establish implications on equipment fault current duties on circuit breakers, transformers, and bus work. Comparisons are made to the duties for conventional generators, as determined by simulation. 

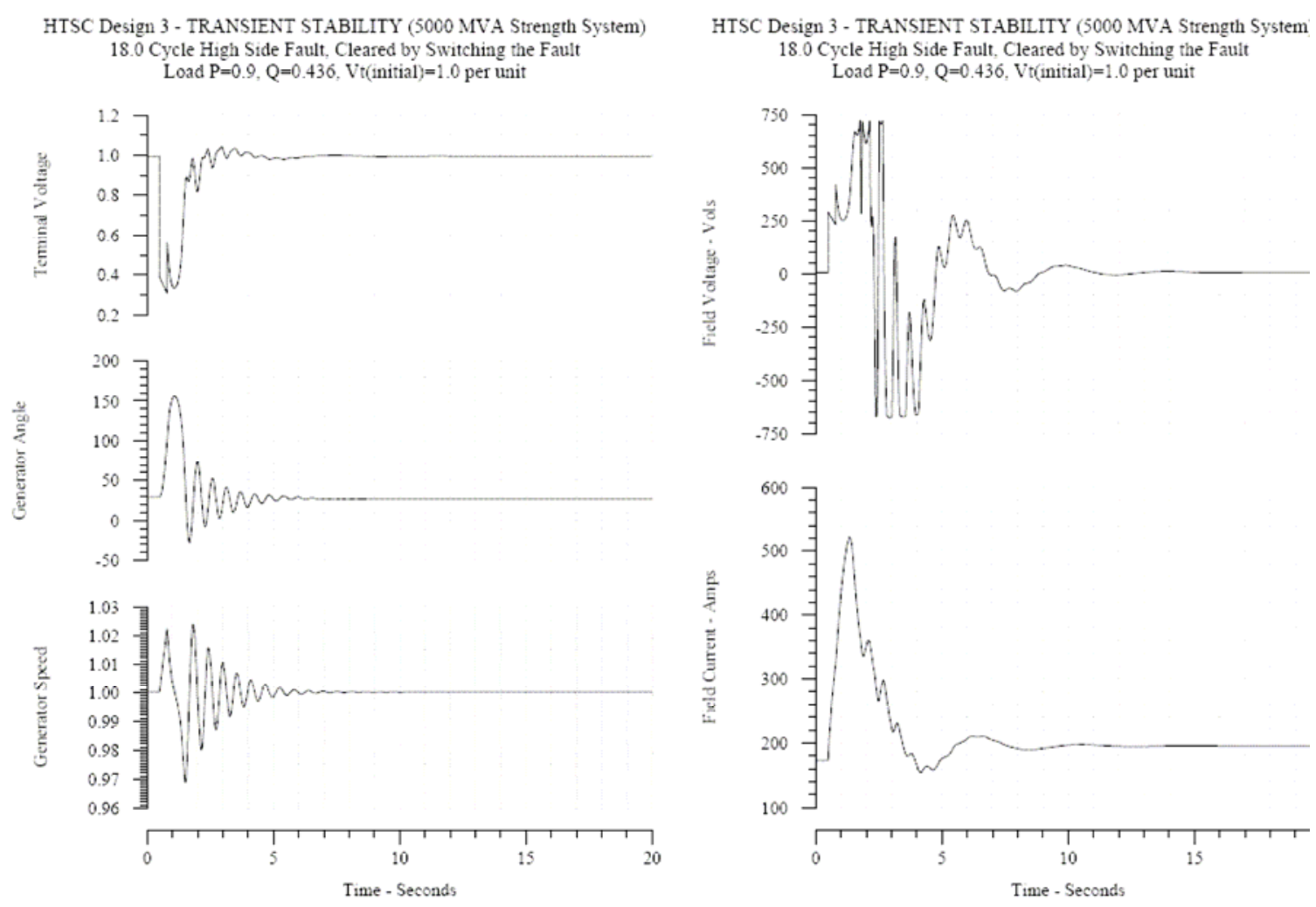

Figure 8-6 - 18 Cycle Three-Phase Fault On High Side

The following classes of simulations were run as part of this study:

- High side faults, both balanced (three-phase) and unbalanced (line-line, line-line to ground, line-ground), cleared by a generator high-side circuit breaker.

- Low side faults outside generator protection zone (low side breaker), both balanced and unbalanced.

- Generator zone three-phase faults (low-side and high-side) cleared by deexcitation of the generator.

Generator-source short-circuit currents are higher for the superconducting generator than for the conventional generator designs studied. The higher fault currents are not limiting, however, for the specific application and machine designs studied. The generator-source short circuit current for a low-voltage generator circuit breaker was well within the minimum circuit breaker rating of $40 \mathrm{KA}$ symmetrical. Furthermore, the system-source short circuit current will often dictate the generator circuit breaker short circuit rating. In this application, the system will dictate the low voltage breaker rating if it is above 2500 MVA short circuit capacity, and the high voltage breaker rating if it is above about 350 MVA short circuit capacity. Correspondingly, the system will dictate limiting transformer maximum short circuit currents if it is above approximately 1800 MVA short circuit capacity. 
Figure 8-7 and Figure 8-8 and compare superconducting and conventional generator response to a low side, double line to ground fault. One interesting aspect is the amount of 60 and $120 \mathrm{~Hz}$ content in the conventional field current. The superconducting field current is relatively harmonic-free, indicating that the EM shield is successfully blocking these frequencies. A plot of the amortisseur currents, Figure 8-9, shows the 60 and 120 $\mathrm{Hz}$ component there instead.

Design \#3 will be require a relatively large generator field discharge resistor, on the order of $2.20 \mathrm{ohms}, 900 \mathrm{~kJ}$. This large value is the result of the long field time constants for the superconducting generator, and is required to provide adequate de-excitation response for generator zone faults. This resistor may drive generator field insulation requirements.

Figure 8-10, Figure 8-11, and Figure 8-12 show the case when the generator field was shorted through a $2.20 \Omega$ resistor. This results in a field voltage of about 750 volts, roughly equal to the ceiling voltage of the exciter, in order not to impose unusual insulation requirements on the field. The simulation indicated current would decay to rated current in about 10 seconds, and the incremental $\mathrm{I}^{2} \mathrm{t}$ to that time is about 26 per unit squared-seconds in the various phases; this is below the limit of 41.4. The resistor energy consumption is $900 \mathrm{~kJ}$ for this event.

COMPARISON SUPERCONDUCTNG vs. 7A6 GENERATOR

6 Cycle Generator Zone, Double Line to Ground Fault, System Strength=1050 MVA

$\mathrm{P}=0.9, \mathrm{Q}=0.436$, Vt(initial) $=1.0$ per unit, Solid=HTSG Design 3, Dotted $=7 \mathrm{~A} 6 \mathrm{Gen}$
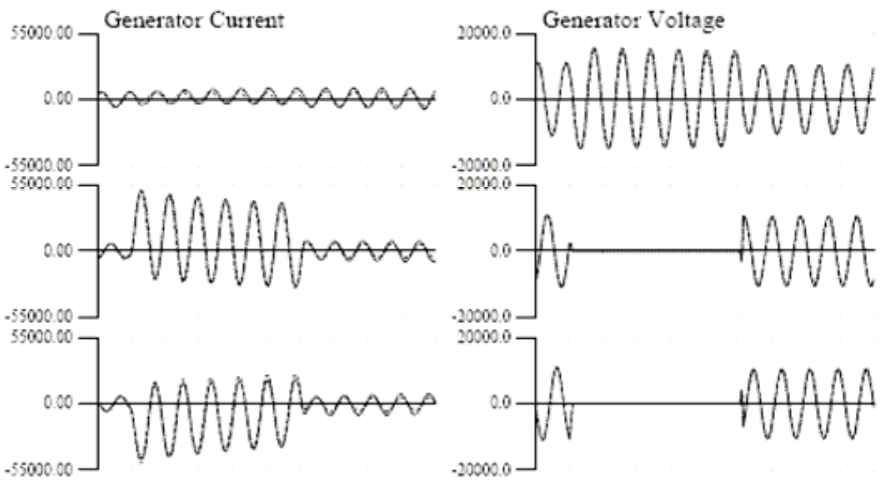

$-200000$

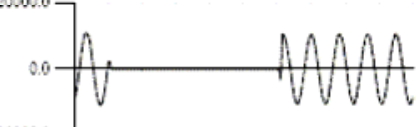

500000
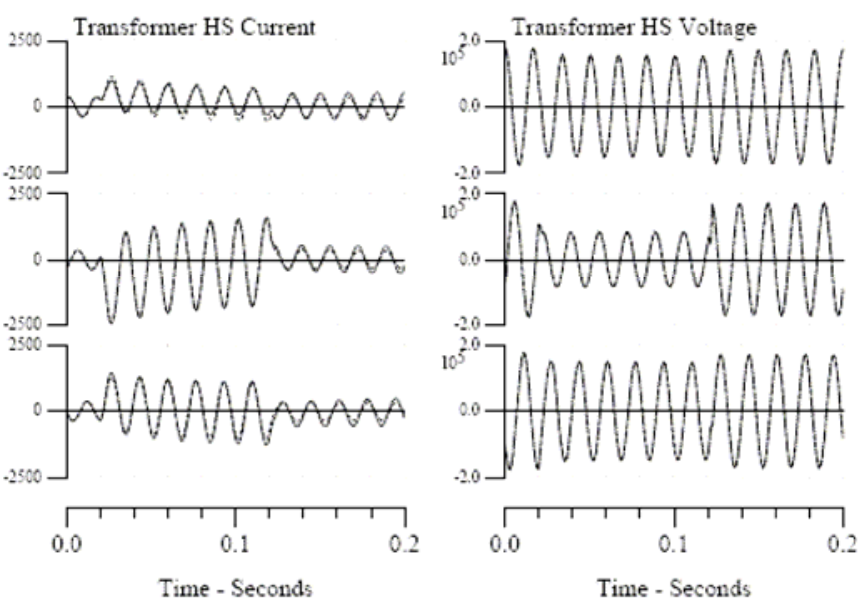

Figure 8-7 - Normally Cleared Low Side Double Line-To-Ground Fault 
COMPARISON SUPERCONDUCTING vs. 7A6 GENERATOR 6 Cycle Generator Zone, Double Line to Ground Fault, System Strength $=1050$ MVA $\mathrm{P}=0.9 . \mathrm{Q}=0.436 . \mathrm{Vt}($ initial $)=1.0$ per unit, Solid=HTSG Design 3, Dotted $=7 \mathrm{~A} 6 \mathrm{Gen}$
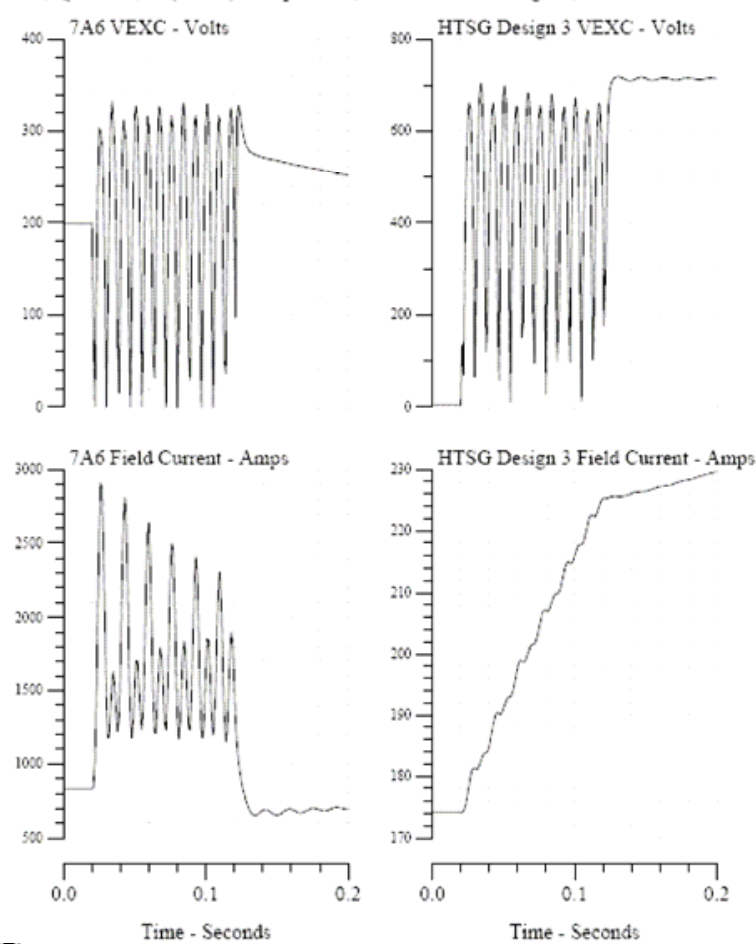

Figure 8-8 - Normally Cleared Low Side Double Line-To-Ground Fault

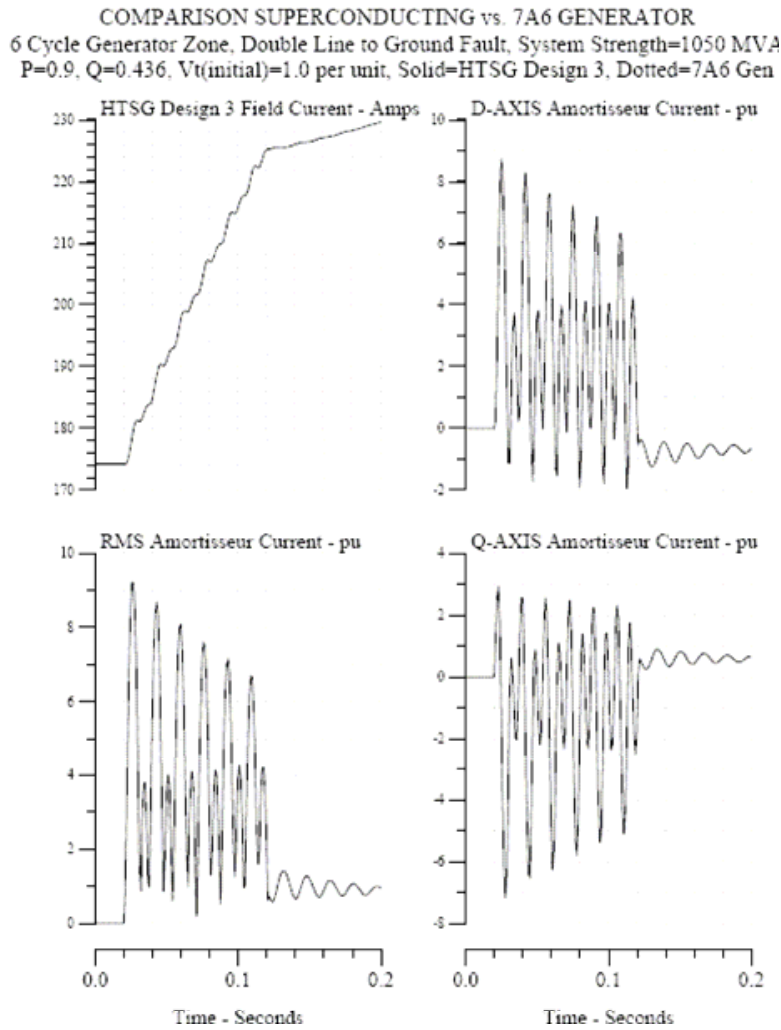

Figure 8-9 - Normally Cleared Low Side Double Line-To-Ground Fault 


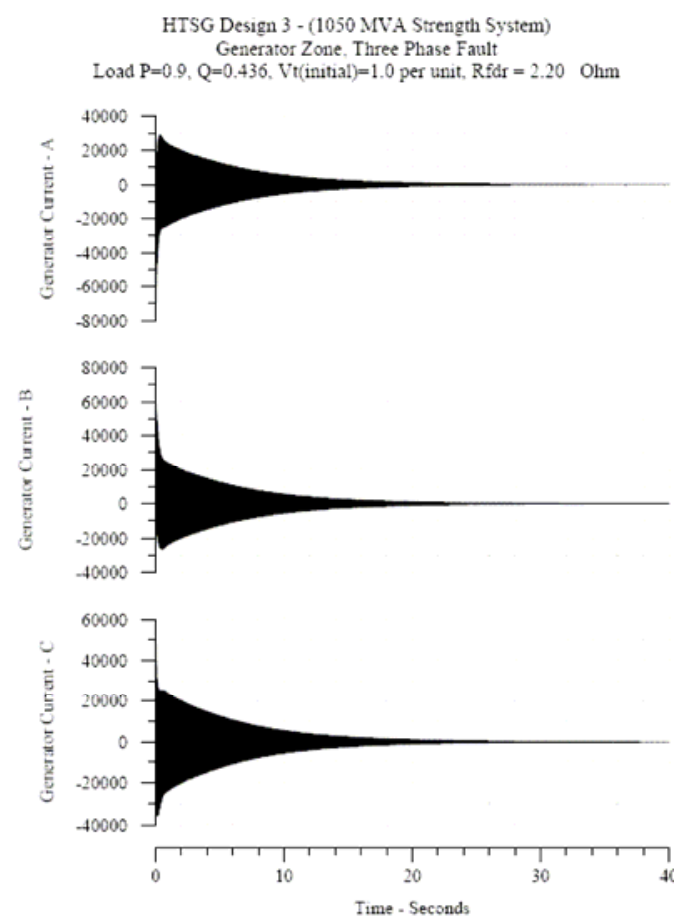

Figure 8-10 - Low Voltage Generator Zone Three-Phase Fault - HTS Design 3 Generator (2.20 $\Omega$ Field Discharge Resistor)

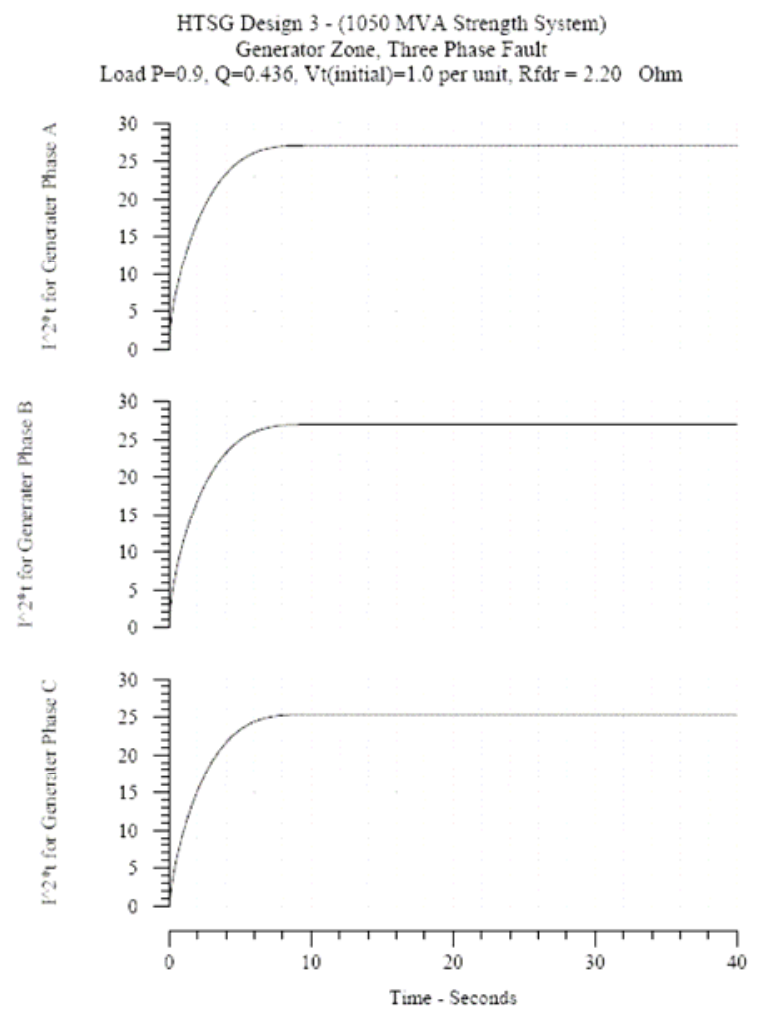

Figure 8-11 - Low Voltage Generator Zone Three Phase Fault - HTS Design 3 Generator (2.20 $\Omega$ Field Discharge Resistor) 


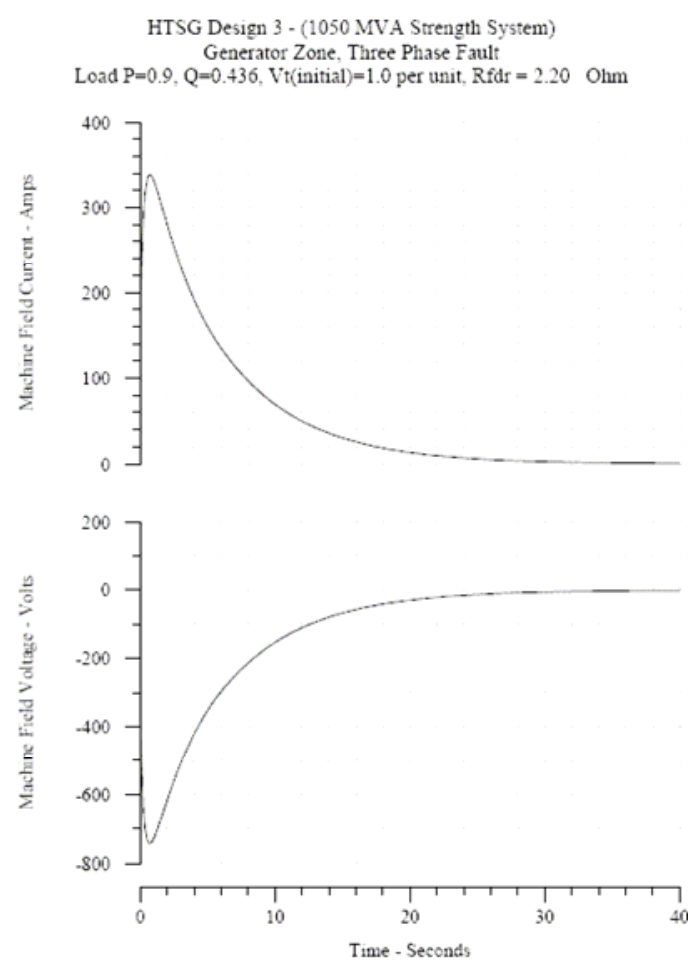

\section{Figure 8-12 - Low Voltage Generator Zone Three Phase Fault - HTS Design 3 Generator (2.20 $\Omega$ Field Discharge Resistor)}

\subsubsection{Torsional Duty}

Turbine-generator rotor and shaft systems, including couplings, must be designed to withstand, as well as provide normal life expectancy for, system disturbances to which it may be subjected. Three extreme events, from a torsional duty and resulting rotor system design point of view include:

- Bolted three-phase fault (uncleared) at the generator terminals,

- Synchronizing the generator 180 degrees out-of-phase with an "infinite" system, i.e. a system with infinite or very large short circuit capacity relative to unit rating.

- Synchronizing the generator 120 degrees (leading) out-of-phase with an infinite system.

These cases were simulated to determine the shaft-system torsional response for the superconducting generator as well as for the conventional generator. The torsional duties are qualitatively evaluated by comparison of torsional response levels between the superconducting and conventional machines. Figure 8-13 shows torque results of one simulation. 
Transient shaft torques for disturbances such as terminal faults and synchronizing out of phase are not significantly higher for superconducting rotor generator than for conventional generators. Rotating Grid torque results for similar disturbances are available in Section 5.2.7. The Rotating Grid model represents the generator with less approximation than the terminal reactance model, and internal component torques are also available.

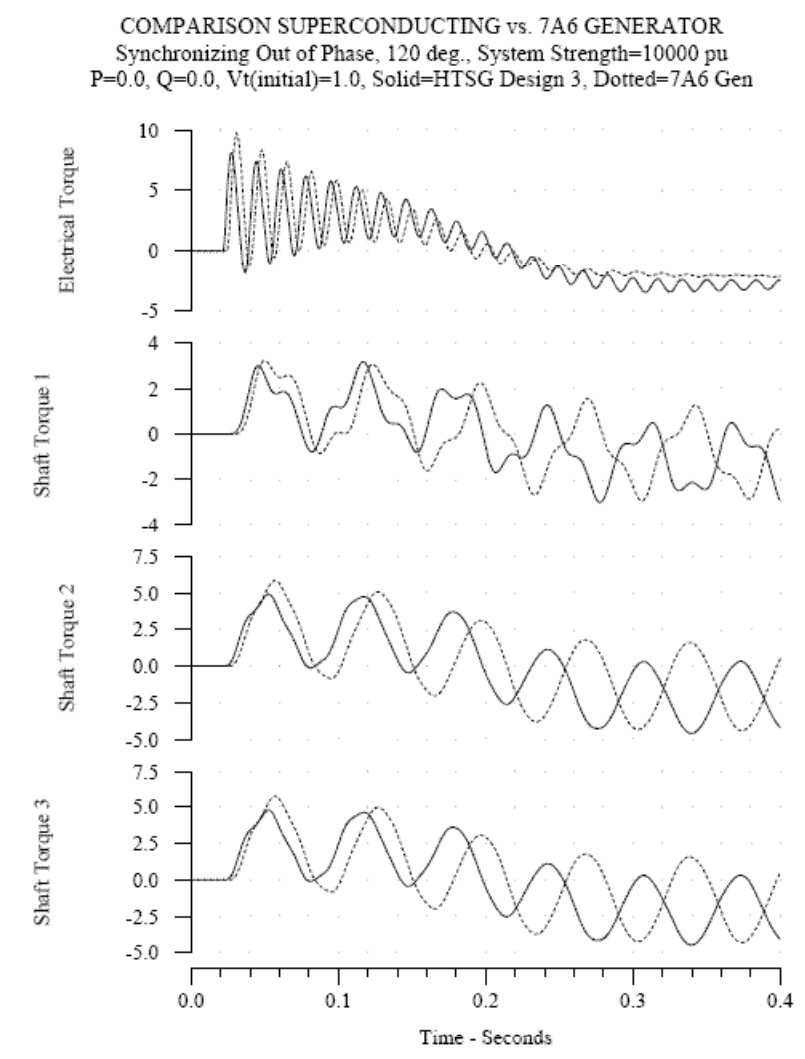

Figure 8-13 - Torques For 120 Degree Synchronization Out Of Phase

\subsubsection{Field Induced Voltage Due to Pole Slip}

During some system transients, the field current of a generator may try to go negative. However with most thyristor or diode excitation systems, the bridge will block negative field currents giving rise to an induced field voltage that will appear at the field terminals. This can result in a peak inverse voltage that the excitation system thyristors or diodes must withstand. The normal procedure for calculating induced field voltage is to simulate the machine in normal full load operation and then set the field voltage to zero. A conventional 7E generator will normally start slipping poles in about 10 seconds and have a peak induced field voltage of about 1800 volts.

The results for excitation removal on the HTS generator Design \#3 are shown in Figure 8-14. In this case, the HTS generator started slipping poles at 1760 seconds or just less than 30 minutes. The peak induced field voltage was 1200 volts. The terminal voltage 
slowly dropped to about $0.77 \mathrm{pu}$ during that period. The generator would also be absorbing significant reactive power and would have probably have tripped on underexcited operation or under-voltage long before slipping poles. It is clear that there is plenty of time for an operator to take action before protective devices trip the unit

A simulation was run for pole slipping due to loss of synchronism, i.e. the fault clearing time in excess of CFCT. In this case, it was a 19.0 cycle three-phase fault on the high side of the GSU transformer for 10,000 MVA system strength. The generator field current does not try to go negative, so the situation for excessive induced field voltage is not present.

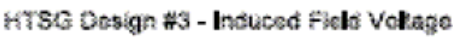
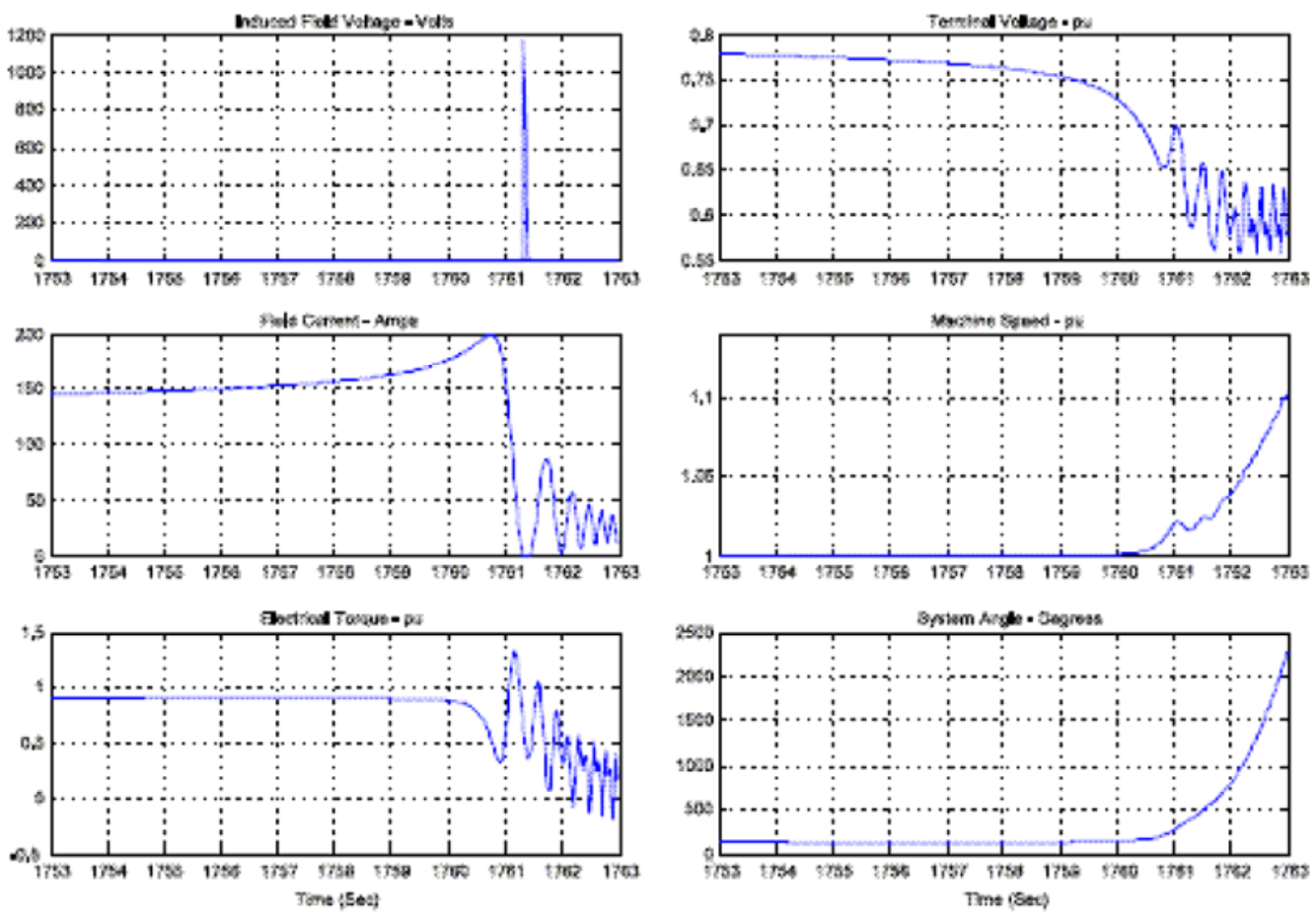

Figure 8-14 - Induced Field Voltage From Pole Slipping - HTS Generator Design 3

\subsubsection{Preliminary Protection Assessment}

An assessment of protection requirements for an HTS generator was performed to determine whether typical generator protection applications that would be applied to a conventional 7A6C generator could also be applied to the HTS Design 3 generator. In addition, the GE model G60, generator management protective relay is assumed in the applications.

Generator protection applied to GE manufactured generators should follow IEEE standard C37.102, IEEE guide for AC Generator Protection and GE technical publication GEK 75512K, Generator Protection. These provide generally accepted industry forms of 
protection for generator stator phase and ground faults, abnormal operating conditions, and generator field faults.

\subsection{American Electric Power Studies}

\subsubsection{Commercial Value of Reactive Power}

While it is important to quantify the enhanced reactive power capability of HTS generators, it will be ultimately the commercial market value of reactive power that determines if this HTS-enabled capability is a marketable product advantage.

The commercial evaluation will have to quantify two areas:

- The cost of equipment

- The market value of reactive power delivered to the grid in terms of $\$ / k V A R-h r s$.

Preliminary discussions with various utility personnel, including AEP and PG\&E, have provided estimates for the lowest-cost solution to provide VARs: depending on transmission line voltage levels into which the capacitor bank is connected and other site specifics, the capital cost of switched capacitor banks is approximately in the range of 20 - \$50/kVAR. Preliminary estimates indicate that the incremental cost of producing more VARs with an HTS generator compared to a conventional generator will be lower.

Even though utilities and grid operators recognize the essential need for VARs, to date it has not been a commodity that power generators are paid for, and remains difficult to quantify. There is a general trend in grid interconnection standards to specify a power factor of 0.85 at the high side of the step up transformer, rather than at the generator terminals. This indicates the growing need for VARs on the grid, without assigning a clear economic value. The current understanding is that a generator with an improved power factor capability represents a differentiating factor between two different merchant power plants that bid for power delivery contracts.

Based on the current understanding, Table 8-2 provides a qualitative comparison of the different competing VAR solutions.

\subsubsection{HTS Generator Reactive Capability \& Voltage Control Performance Study}

American Electric Power (AEP) Transmission Planning group conducted a simulation study to assess the reactive capability and transmission system voltage control performance of the proposed HTS generator. This is an extension of the "Value of VARS" discussion in Section 8.2.1. It found a very limited number of cases where this capability would be helpful when the generator is installed on a retrofit basis, partly because of site limitations such as the step-up transformer. 
Table 8-2 - Qualitative Comparison of Alternative VAR Solutions

\begin{tabular}{lcccc}
\hline & $\begin{array}{c}\text { Switched } \\
\text { Capacitor }\end{array}$ & $\begin{array}{c}\text { Static VAR } \\
\text { Source }\end{array}$ & $\begin{array}{c}\text { Rotating } \\
\text { Machine }\end{array}$ & $\begin{array}{c}\text { HTS } \\
\text { Generator }\end{array}$ \\
\cline { 2 - 5 } $\begin{array}{l}\text { Response to Voltage } \\
\text { Decrease }\end{array}$ & $\begin{array}{c}\text { Increase } \\
\text { VARS (-) }\end{array}$ & $\begin{array}{c}\text { Increase } \\
\text { VARS (+) }\end{array}$ & $\begin{array}{c}\text { Increase } \\
\text { VARS (+) }\end{array}$ & VARS (+) \\
Speed of Response & $\begin{array}{c}\text { Fast (sags } \\
\text { w/voltage) }\end{array}$ & $\begin{array}{c}\text { Fast } \\
\text { (thyristor } \\
\text { controlled) }\end{array}$ & Fast & Fast \\
Relative Cost & $\$-\$ \$$ & $\$ \$ \$$ & $\$ \$-\$ \$$ & $\$ \$$ \\
\hline
\end{tabular}

The proposed HTS generator includes a superconducting rotor combined with a conventional stator. In this configuration, the field winding reactive capability limit is eliminated, leaving only the stator to limit the generator's overexcited reactive output. Therefore, the goal of the study was to identify potential applications on the transmission system that could benefit from the different reactive capability characteristics of the proposed HTS generator design.

Because the overexcited reactive capability of the proposed HTS generator design is represented by the A"-B arc in Figure 8-15, at full generator MW output the overexcited reactive capability is essentially the same as a conventional generator. Therefore, the proposed HTS generator's utility as an improved voltage support device on the transmission grid is restricted to situations in which it has been dispatched to a reduced MW level.

In most cases on the transmission grid, increased voltage support is typically required during times of increased system stress. This usually includes high system loads and large inter-area power transfers. During these periods of high system stress, most of the generators connected to the system are typically dispatched at full MW output. In particular, most of the new gas turbines would be dispatched at full MW output since they operate most efficiently at maximum MW output. Therefore, an HTS generator would not be able to contribute extra voltage support in these situations, since it also would likely be dispatched at full MW output to supply the increased system load and maximize generator MW sales. 


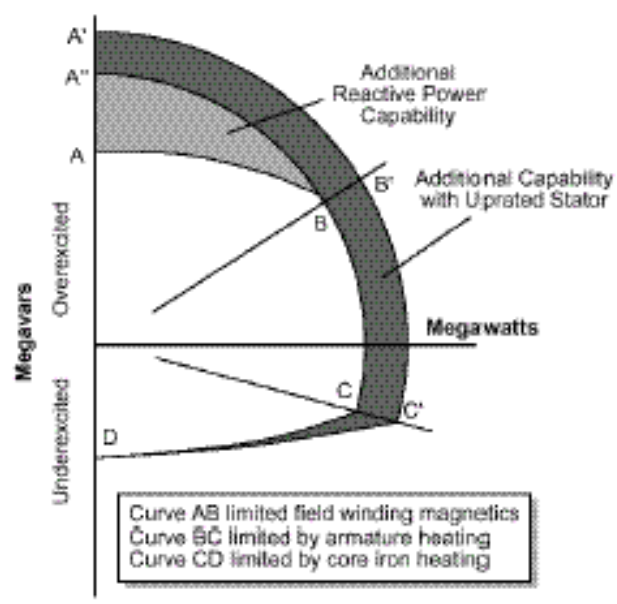

Figure 8-15 - Reactive Capability Curve for Generator

AEP also considered a specific instance in December 2003 where general customer loads were low, yet there was a large transmission of energy going to a pumped storage plant in Ludington, Michigan. At the same time, three $345 \mathrm{kV}$ transmission lines were out of service, causing a large amount of power to flow through AEP's Donald C. Cook plant. The voltage at this point was forced down from the $103 \%$ dispatch point to $100.2 \%$ as calculated by a baseline simulation. This depressed voltage reduces the megawatt transmission capability and is a measure of how well the system is holding up.

AEP then replaced the large nuclear generator at the Cook plant with 20 HTS generators with increased reactive capability. They tried the simulation with the existing step-up transformer and with an uprated transformer that would have lower reactance and voltage drop.

The simulation showed that with the uprated, low-reactance transformer, the HTS generator would be able to support the system voltage at the original dispatch level of $103 \%$ with plenty of capacity to spare. When the existing transformer is used the generator would hit its maximum voltage limit before running out of reactive capability, and this would limit the generator's ability to produce VARs. In this second simulation the HTS generator could push the voltage up to only $101.6 \%$, reducing the usefulness of the extra VAR capacity.

The following conclusions can be drawn:

- The proposed HTS generator design can be useful for providing improved system voltage support as compared to conventional generator designs, but only in special system operating situations where the generator is likely to be dispatched at reduced MW levels.

- The GSU transformer associated with a new HTS generator installation will need to be designed with an impedance that allows the generator to access the full increased reactive capability without encountering generator terminal voltage restrictions. It is important to note that such a transformer will have a low 
impedance that would tend to increase the fault currents, forces, and torques on the equipment.

- Retrofitting an HTS rotor into an existing generator may not fully optimize the generator's available gross reactive capability for voltage control because of generator terminal voltage restrictions due to the existing GSU transformer.

\subsubsection{HTS Generator System Stability Performance Study}

The second study compared the HTS generator behavior to conventional generator behavior at several stability-limited sites on the AEP power system. The HTS generator was found to have stability that is as good as or better than the conventional generator.

A system dynamics study was conducted for generation connected at three AEP transmission stations: Rockport $765 \mathrm{kV}$, Conesville $345 \mathrm{kV}$ and Picway $138 \mathrm{kV}$. These locations were selected because they represent a reasonable spectrum of stability performance issues faced by AEP.

For each station, time-domain stability simulations were carried out for a variety of operating scenarios representing normal (i.e. no prior outage) and prior outage scenarios. The existing AEP generating units were replaced with HTS generators and with conventional gas-fired 7E generators. For each operating scenario, the generation level was selected to be close to, or beyond, the stability limit, in order to facilitate a comparison of stability performance of the HTS generator versus conventional gas-fired generator.

The Rockport generating plant has $2600 \mathrm{MW}$ generation and only two $765 \mathrm{kV}$ outlets. Because of the large generation level compared to the available transmission capacity at the station, Rockport is a stability-limited plant.

The observations below illustrate that in many cases a PSS will be required to provide acceptable stability performance. The PSS required for the HTS generator has six leadlag networks whereas existing PSS units have two or three. The additional networks can be accomplished in the software of existing PSS units. Figure 8-16 and Figure 8-17 show one simulation where stability was unacceptable without the PSS but quite acceptable with the PSS.

\subsubsection{Observations Without Power System Stabilizer}

\section{Rockport}

The (monotonic and oscillatory) stability performance of the HTS generator is slightly worse than that of the conventional generator for all four operating scenarios studied. For all four operating scenarios, the stability performance of both generators is unacceptable. 


\section{Conesville}

The oscillatory stability performance of the HTS generator is slightly better than that of the conventional generator for the "no prior outage" operating scenario. The oscillatory stability performance of the HTS generator is slightly worse than that of the conventional generator for the "prior outage" operating scenario. The stability performance of the HTS generator for the "prior outage" scenario is unacceptable.

\section{Picway}

The oscillatory stability performance of the HTS generator is better than that of the conventional generator for both operating scenarios studied. For both scenarios, the performance of both generators is acceptable.

\subsubsection{Observations with PSS}

\section{Rockport}

The oscillatory stability performance of the HTS generator is slightly better than that of the conventional generator for all four operating scenarios studied. The stability performance of both generators is acceptable for all four scenarios.

\section{Conesville}

The oscillatory stability performance of the HTS generator is better than that of the conventional generator for both operating scenarios studied. The stability performance of both generators is acceptable for both scenarios.

\section{Picway}

The oscillatory stability performance of the HTS generator is better than that of the conventional generator for both operating scenarios studied. The stability performance of both generators is acceptable for both scenarios.

Overall, the stability performance of the HTS generator is comparable to that of the conventional generator. The stability performance of the HTS generator could be either better or worse than that of conventional gas-fired generator, depending upon the amount of generation and strength of transmission system at the location. 
Application of power system stabilizers on the HTS generator is expected to provide marked improvement in oscillatory stability performance. Excitation system/PSS parameters will have to be tuned for the specific location, which is the industry practice.

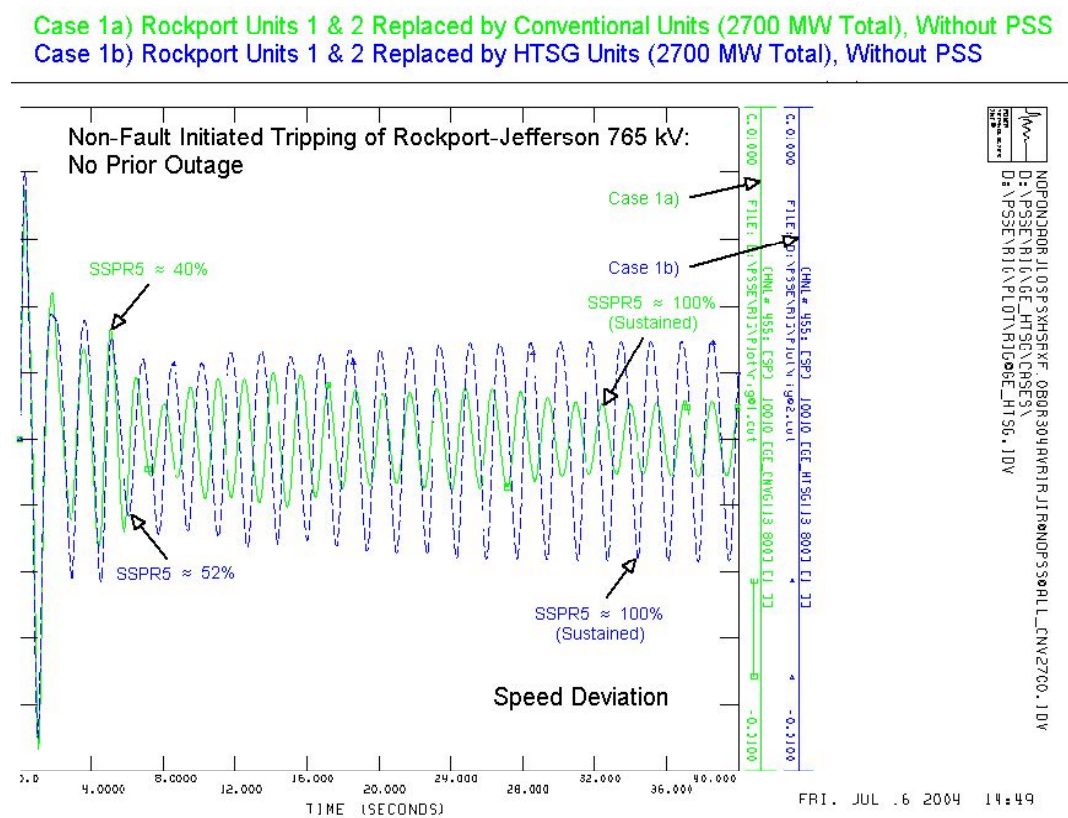

\section{Figure 8-16 - Rockport Simulation Showing Unacceptable Stability Performance Without PSS}

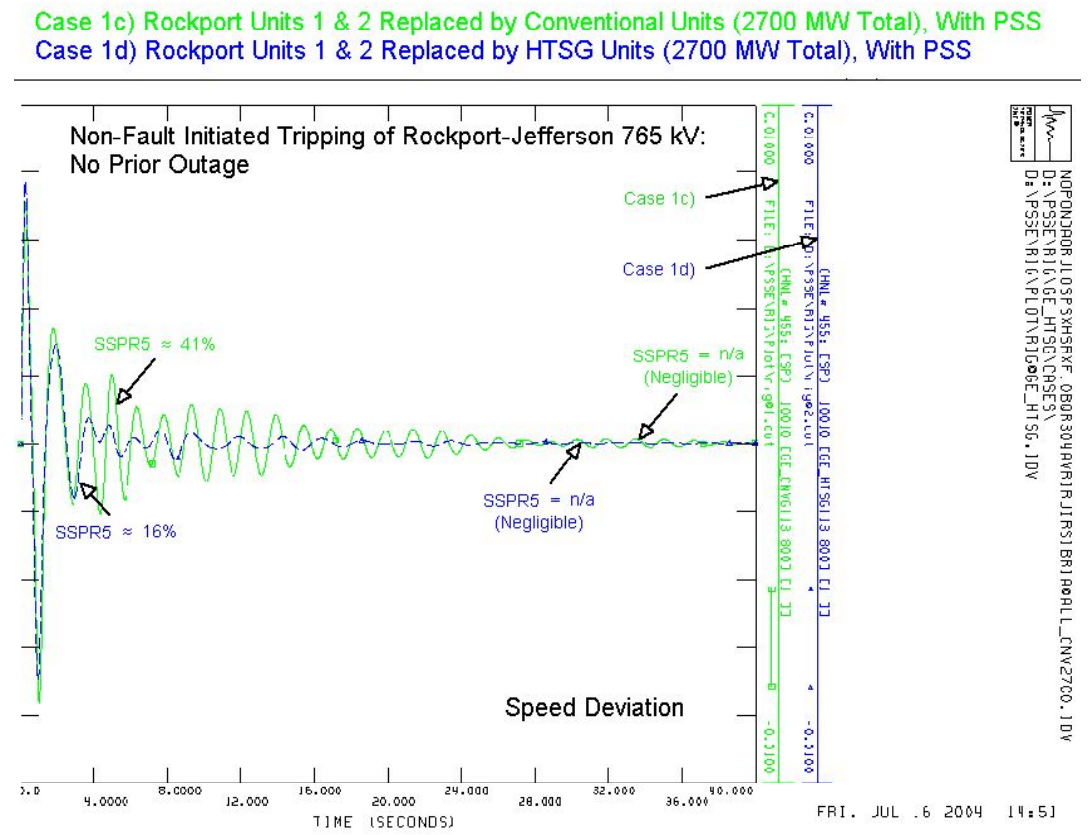

Figure 8-17 - Rockport Simulation Showing Acceptable Stability Performance with PSS 


\section{Appendices}

\subsection{Selected References}

1 B. ten Haken, R.B. Wilson, H.H.J. ten Kate and J. Tenbrink, "Critical Current Reduction Due to Strain in Bi-2212 Wires”, in "Applied Superconductivity”, ed. H.C. Freyhardt, DGM Informationsgellschaft mbH, Germany, 1993, p. B235.

2 B. ten Haken, H.H.ten Kate, and J. Tenbrink, “ Compressive and Tensile Axial Strain Reduced Critical Currents in Bi-2212 Conductors" IEEE Transactions on Applied Superconductivity, 5, no.2, pp. 1298-1301 (1995)

3 J. W. Ekin, D. K. Finnemore, Q. Li, J. Tenbrink, and W. Carter, "Effect of axial strain on the critical current of Ag-sheathed Bi-based superconductors in magnetic fields up to 25 t” Appl. Phys. Lett., 61, pp. 858-860 (1992)

4 H. S. Shin and K. Katagiri, "Influence of external reinforcement on stress/strain characteristics of critical current in Ag/BSCCO superconducting tapes” in pro. Int. Workshop Mechano-Electromagnetic Property of Composite Superconductor, Knob, 2001, pp. 31-34

5 J. J. Rabbers et al., "An engineering formula to describe the AC loss of BSCCO/Ag tape”, IEEE Transactions on Applied Superconductivity. 11, pp. 2623 -2626 (2001)

6 S. P. Ashworth and M. Suenaga, "Measurement of AC losses in superconductors due to ac transport currents in applied AC magnetic fields" Physica C 313, pp. 175-187 (1999)

7 S. P. Ashworth and M. Suenaga, "Experimental determination of the losses produced by the interaction of AC magnetic fields and transport currents in HTS tapes", Physica C 329, p. 149-159 (2000)

8 Fogarty, JM, "Development of a 100 MVA high temperature superconducting generator”, 2004 IEEE Power Engineering Society general meeting (Denver CO, 610 June 2004) 2, pp. 2065 - 2067 (2004)

9 Sivasubramaniam, K et. al., "Performance of an HTS generator field coil under system fault conditions." IEEE Transactions on Applied Superconductivity, 16, No. 4, pp.1971 - 1975 (2006)

10 Sivasubramaniam, K, "AC losses in a high temperature superconducting generator", IEEE Transactions on Applied Superconductivity, 15, pp. 2162 - 2165. (2005)

11 Ryan, D.T, et. al. "Critical current degradation in HTS wires due to cyclic mechanical strain” IEEE Transactions on Applied Superconductivity, 15, pp. 3684 - 3687 (2005) 
12 Wensen W, et. al. "Over-current simulation test for high temperature superconducting generator” Record of the 2006 IEEE Industry Applications Conference Forty-First IAS Annual Meeting, Conference, 5, pp. 2390 - 2394 (2006)

13 Kalsi, SS, et. al. "Development status of rotating machines employing superconducting field windings" Proceedings of the IEEE. 92, pp. 1688 - 1704 (2004)

14 Grabovickic, R., et. al. "Measurements of temperature dependence of partial discharge in air gaps between insulated Bi-Sr-Ca-Cu-O tapes" IEEE Transactions on Applied Superconductivity, 15, pp. 3668 - 3671. (2005)

15 Grabovickic, R., et. al. "Partial discharge and accelerated pulsed aging of insulation between parallel plane-plane stainless steel electrodes and between $\mathrm{Bi}-\mathrm{Sr}-\mathrm{Ca}-\mathrm{Cu}-\mathrm{O}$ Tapes at Room Temperature" Conference on Electrical Insulation and Dielectric Phenomena, 2004 Annual Report. CEIDP '04. 2004 pp. 286 - 289 (2004)

16 Urbahn, JA, et. al., "The thermal performance of a 1.5 MVA HTS generator" Advances in Cryogenic Engineering: Transactions of the Cryogenic Engineering Conference - CEC. AIP Conference Proceedings, 710, pp. 849-858 (2004).

17 Amm, K, “100 MVA HTS generator development update” DOE HTS Wire Workshop, January 19, 2005.

18 General Electric, GEK-75512K, “Generator protection”, (2006) 


\subsection{Nomenclature \& Abbreviations}

AEP

AMSC

ANSYS

CDR

CFCT

Demonstrator

EM

FE

Flux2D

GM

GSU

HTS

HTSG

LANL

LSL

MTBF

MVA

ORNL

PDR

PSS

RAM

Rotating Grid

SHI

SSFR

USL

XLTRC
- American Electric Power Co.

- American Superconductor Corporation

- Commercial FE modelling code

- Conceptual Design Review

- Critical fault clearing time

1.5 MW HTS generator designed, built and tested at GE's Global Research facility in Niskayuna, NY

- Electromagnetic

- Finite element

- Commercial 2D electromagnetic finite element code

- Gifford-McMahon cryocooler

- Generator step-up transformer

- High temperature superconducting

- High temperature superconducting generator

- Los Alamos National Laboratory

- Lower specification limit

- Mean time between failures

- Generator apparent output power - megavolt-amperes

- Oak Ridge National Laboratory

- Preliminary Design Review

- Power system stabilizer

- Reliability, availability, and maintenance

Proprietary GE code for 2D time stepping electromagnetics problems

- Sumitomo Heavy Industries

- Standstill Frequency Response

- Upper specification limit

- Rotor dynamic analysis tool 